\title{
Earth Resistivity Structures and their Effects on Geomagnetic Induction in Pipelines
}

By

\author{
Peter Axel Fernberg
}

A thesis submitted to the Faculty of Graduate and Postdoctoral Affairs

In partial fulfillment of the requirements for the degree of

Doctor of Philosophy

in

Department of Earth Sciences

Carleton University

Ottawa, Ontario

(C) 2011, Peter Axel Fernberg 
Library and Archives

Canada

Published Heritage Branch

395 Wellington Street Ottawa ON K1A ON4

Canada
Bibliotheque et

Archives Canada

Direction du

Patrimoine de l'édition

395 , rue Wellington

Ottawa ON K1A ON4

Canada
Your file Votre référence

ISBN: 978-0-494-81571-7

Our file Notre référence

ISBN: 978-0-494-81571-7
NOTICE:

The author has granted a nonexclusive license allowing Library and Archives Canada to reproduce, publish, archive, preserve, conserve, communicate to the public by telecommunication or on the Internet, loan, distribute and sell theses worldwide, for commercial or noncommercial purposes, in microform, paper, electronic and/or any other formats.

The author retains copyright ownership and moral rights in this thesis. Neither the thesis nor substantial extracts from it may be printed or otherwise reproduced without the author's permission.
AVIS:

L'auteur a accordé une licence non exclusive permettant à la Bibliothèque et Archives Canada de reproduire, publier, archiver, sauvegarder, conserver, transmettre au public par télécommunication ou par l'Internet, prêter, distribuer et vendre des thèses partout dans le monde, à des fins commerciales ou autres, sur support microforme, papier, électronique et/ou autres formats.

L'auteur conserve la propriété du droit d'auteur et des droits moraux qui protège cette thèse. $\mathrm{Ni}$ la thèse ni des extraits substantiels de celle-ci ne doivent être imprimés ou autrement reproduits sans son autorisation.
In compliance with the Canadian Privacy Act some supporting forms may have been removed from this thesis.

While these forms may be included in the document page count, their removal does not represent any loss of content from the thesis.
Conformément à la loi canadienne sur la protection de la vie privée, quelques formulaires secondaires ont été enlevés de cette thèse.

Bien que ces formulaires aient inclus dans la pagination, il n'y aura aucun contenu manquant.

\section{Canadä}




\section{STATEMENT of ORIGINAL CONTRIBUTION}

This research was focused on the development of Earth resistivity models, derived from both literature sources and geophysical survey data, specifically the magnetotelluric (MT) method, and an assessment of the worth of these Earth resistivity models as inputs into subsequent modelling Preparation of geomagnetic climatology, modelling of geoelectric field and modelling of the pipe-to-soil potential (PSP) was undertaken by personnel (acknowledged in the individual chapters) at the Ottawa Geomagnetic Laboratory using the information supplied by this author. Some of the results of the geoelectric field and PSP modelling were supplied to this author who then used the results to assess the quality of the Earth resistivity models and to undertake geological interpretation of the causes of enhanced geoelectric field and PSP variations.

Research by this author involved a comprehensive compilation of geological literature, leading to 13 new one-dimensional (1D) layered Earth resistivity models covering parts of Alaska, Yukon, northeastern British Columbia, and western Northwest Territories (Chapters 3 and 4); areas for which such models were lacking. Related fieldwork involved a reconnaissance MT survey undertaken by this author in summer 2006, which included deployment by the author at all seven sounding sites. MT data processing was completed by Dr. C. Samson and this author. Preparation of 1D inversion models, for each MT site, was done by this author with technical assistance from Gary McNeice (Geosystem srl) and Jessica Spratt (Geological Survey of Canada) who are MT specialists. Comparison and analysis of the Earth resistivity models with respect to geoelectric and PSP models was completed wholly by this author. 
For the Ottawa Valley study area (Chapter 5), this author was involved with the first MT survey in 2003, and then personally completed (along with field assistants) two detailed MT surveys in 2005 and 2006, and a small follow-up MT survey in 2009. This is an area of eastern Ontario for which there was no previous MT transect. MT data processing was completed by Dr. C. Samson and this author. Preparation of 2D inversion models was done with the technical assistance of G. McNeice, with the geological interpretation being done by this author. Raw PSP data from the 2003, 2005 and 2006 surveys and some of the PSP modelling results were supplied to this author, respectively by Dr. L. Trichtchenko and Dr. D. H. Boteler at the Ottawa Geomagnetic Laboratory. PSP data for the 2009 survey were collected by this author. Analysis of PSP data was completed by this author with guidance and participation of Dr. Trichtchenko. Comparison of the PSP modelling against the 2D inversion was completed by this author. Most of the material presented in Chapter 5 is based on Fernberg et al. (2007).

From the data produced by this research, this author has established that the use of literature- and MT-derived 1D Earth resistivity models are a viable input for the modelling of PSP variations, on a regional scale of a pipeline route (Chapters 3 and 4), and that the underlying Earth resistivity structure has an significant influence on the observable PSP variations. This research has established for the first time (Chapter 5) the simultaneous nature of geoelectric field fluctuations and PSP variations, and has shown the important role of lateral discontinuities of geological features in the enhancement of PSP variations. Overall, the research undertaken for this thesis has proven that the use of Earth resistivity models are a valuable tool for predicting PSP variations along a proposed 
or existing pipeline, which can be used for design of corrosion protection systems and / or mitigation of corrosion on pipelines worldwide. 


\section{ABSTRACT}

Geomagnetically induced (telluric) currents flowing in pipelines can interfere with their cathodic corrosion protection systems. Intensity of geomagnetic activity and pipeline structure influences the magnitude of telluric currents, a problem particularly acute in northern regions where geomagnetic disturbances are stronger and more frequent. Furthermore, lateral variations of subsurface resistivity are suspected to be a contributing cause of large pipe-to-soil potentials (PSP) observed locally on some pipelines worldwide. However, the extent to which the geological conditions beneath a pipeline influences telluric currents and PSP has not been fully investigated. Therefore, this study tested the hypothesis that large PSP amplitudes are, in part, a consequence of differing Earth resistivity structure, both vertically and laterally, along a pipeline route. As well, statistics regarding exceedance of telluric activity and PSP over the operational lifetime of a northern pipeline are provided.

A combination of geological literature compilation, magnetotelluric (MT) and PSP surveys, and numerical analysis was applied to test the hypothesis. A progressive approach was undertaken, examining three separate pipeline routes, two of which are proposed and one existing. The work resulted in the first regional MT soundings along the length of the Mackenzie River valley, and detailed combined MT and PSP surveys along part of the Ottawa Valley.

This study demonstrated that literature-derived 1D Earth resistivity models can be used to predict PSP variations over a broad scale (Alaska, Mackenzie Valley study areas), and are reasonably accurate in comparison to a model obtained from 1D inversion of MT 
data (Mackenzie Valley sudy area). In addition, it was shown that PSP can be modelled (Ottawa Valley study area) using a spatially-variant surface geoelectric field. This new approach effectively accommodates a geological complex area where rapid lateral changes of subsurface resistivity occur along a pipeline route. Future work would include spectral analysis to better isolate and identify the Earth response causing large amplitude geoelectric field and PSP observed near Pakenham along the Ottawa Valley pipeline, and forward modelling to identify the kind of geological feature responsible. 


\section{ACKNOWLEDGEMENTS}

I would like to extend my thanks and appreciation to my thesis co-supervisor Prof. Claire Samson and the Dept. of Earth Sciences at Carleton for giving me the opportunity and funding to undertake this unique project involving a combination of geology and geophysics with a practical engineering application. I also want to thank Dr. Larisa Trichtchenko, thesis co-supervisor, and Dr. David Boteler, an "unofficial" cosupervisor, for their kind assistance and allowing me the chance to work at the Geomagnetic Laboratory. A thank you also goes to Dr. Donald Danskin at the Geomag Lab for various assistance, especially with IDL routines to extract MT data, to Myles Harrison for geomagnetic data compilation and plots, and thank you to all the others at the lab from whom I sought assistance. In addition I would like to thank Garry McNeice, Jim Craven, Jessica Spratt, Gerry Graham, Martyn Unsworth, Ian Ferguson, Barry Narod, and Wolfgang Soyer for introducing me to the magnetotelluric geophysical method, its techniques and analysis. A thank you goes out Diane Regimbald, Calvin Andrews, Mike Pearson, Michelle Folta, Sasha Blinova, Tomas Pacha, Adam Jones and Alex Trichtchenko for all their assistance in the field during the various MT and PSP surveys. Another thank you is to Patricia Larocca for her participation on the 2003 ORV survey. I also gratefully appreciate the financial support received from pipeline companies, through Carleton University and the Geomagnetic Laboratory, which in part funded this study. And, I must send my thanks to the pipeline company for allowing me to install data loggers on their system, and to the various landowners for access onto their properties to allow placement of MT instruments. 


\section{TABLE OF CONTENTS}

STATEMENT of ORIGINAL CONTRIBUTION ................................................... ii

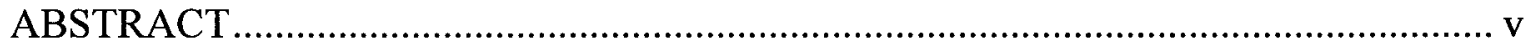

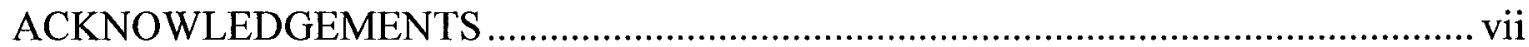

TABLE OF CONTENTS .......................................................................... viii

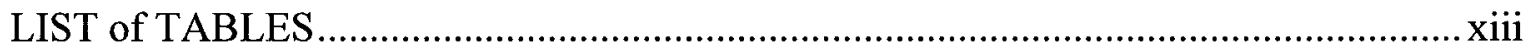

LIST of FIGURES ........................................................................................ xiii

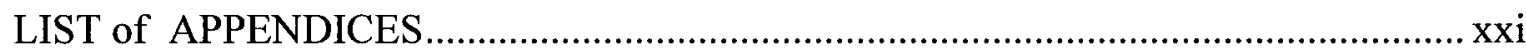

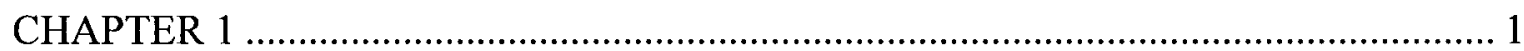

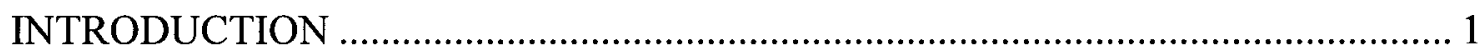

1.1 Effects of Telluric Currents on Pipelines................................................ 1

1.1.1 Sources of Telluric Currents in Pipelines ......................................... 1

1.1.2 Pipeline Corrosion and Cathodic Protection Systems .......................... 2

1.1.3 Past Investigations of the Impact of Telluric Currents on Pipelines...... 5

1.1.4 Modelling of Geoelectric Field and PSP in Pipelines......................... 6

1.2 Objective, Scope and Study Areas for Research................................... 8

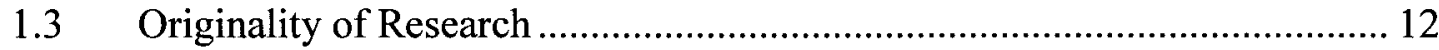

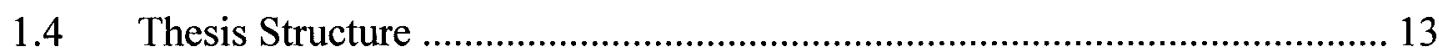

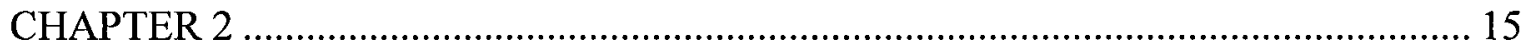

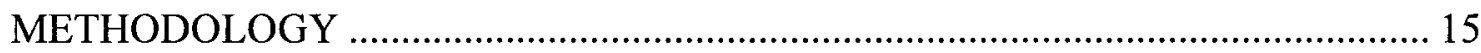

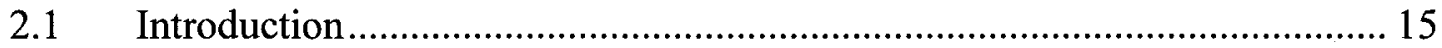

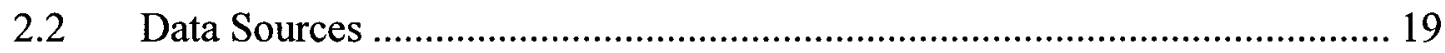

2.2.1 Literature Compilation................................................................. 19 


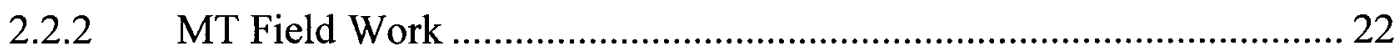

2.2.3 Permanent Geomagnetic Observatories ............................................ 26

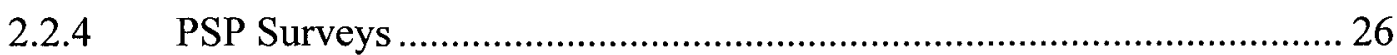

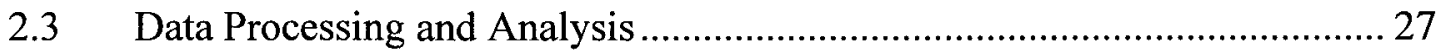

2.3.1 MT Processing and Inversion (1D, 2D) ……………….................. 29

2.3.2 Geoelectric Field Data and PSP Data Processing ….............................. 30

2.3.3 Statistical Analysis ................................................................ 31

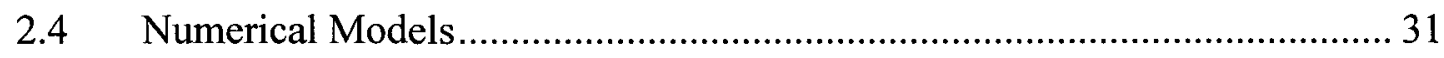

2.4.1 Theoretical 1D Layered Earth Resistivity Models................................ 32

2.4.2 Geoelectric Field Modelling ……………........................................... 33

2.4.3 Surface Impedance Modelling ……………….................................. 35

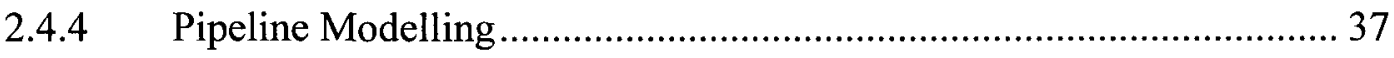

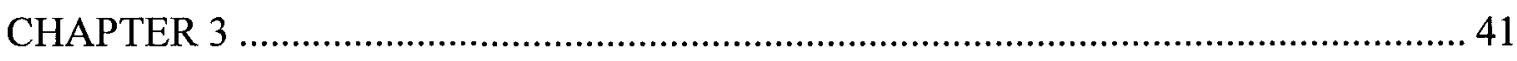

ALASKA HIGHWAY CORRIDOR .......................................................................... 41

$3.1 \quad$ Overview and Objectives ...................................................................... 41

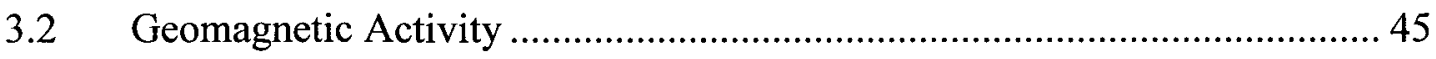

3.2.1. Local Geomagnetic Activity Levels ....................................................... 45

3.2.2. Geomagnetic Climatology ......................................................................... 47

3.3 Geological Setting along Pipeline Route ……………………................... 48

3.3.1 Tectonic Framework, Bedrock Geology and Major Faults .................. 48

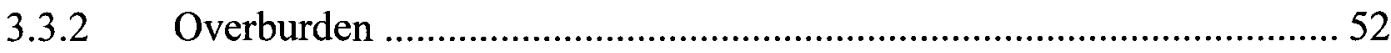

3.3.3 Permafrost Distribution and Depth .................................................... 53

3.3.4 Previous Geophysical Surveys along the Alaska Pipeline Corridor ..... 54 
3.4 1D Modelling of Earth Electrical Resistivity............................................... 57

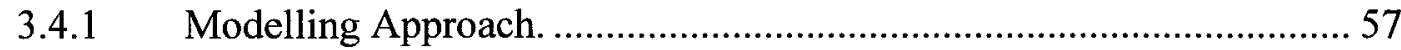

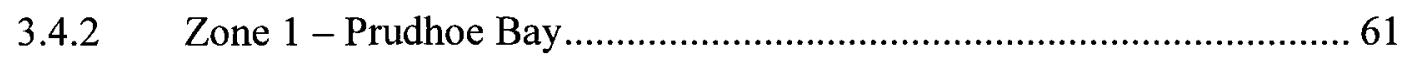

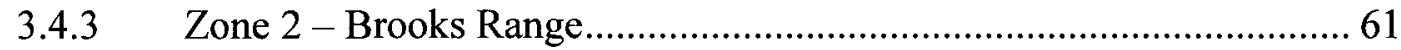

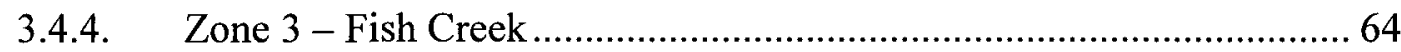

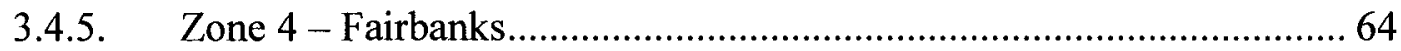

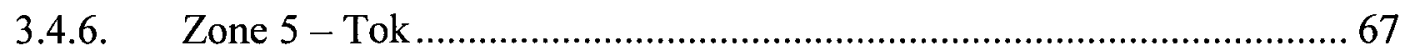

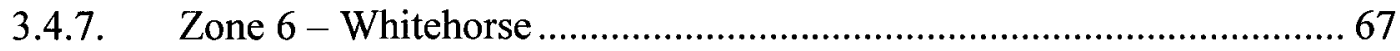

3.4.8. Zone 7 - Northeastern BC .............................................................. 70

3.4.9. Zone 8 - Boundary Lake................................................................ 70

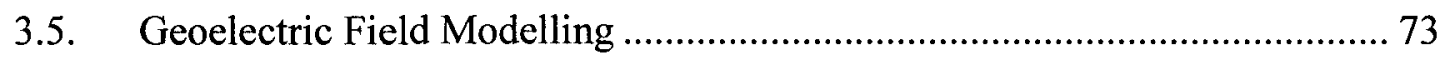

3.5.1 Surface Impedances Determination .................................................. 73

3.5.2 Effects of Layered Earth Models on the Geoelectric Field................... 74

3.5.3 Statistical Evaluation of Telluric Activity ............................................ 80

3.6 Modelled PSP using 1D Earth Resistivity Models ..................................... 83

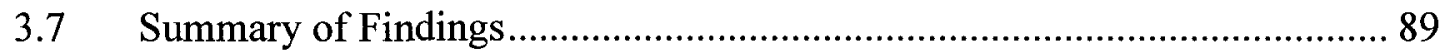

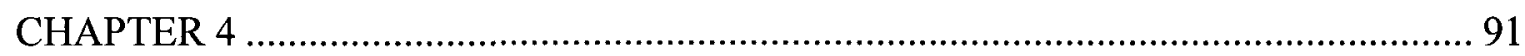

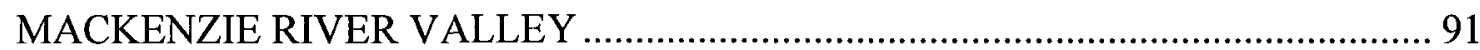

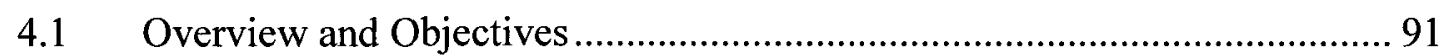

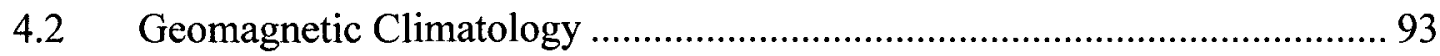

4.3 Geological Setting along Pipeline Route …….......................................... 95

4.3.1 Tectonic Framework, Bedrock Geology and Major Faults ................... 95

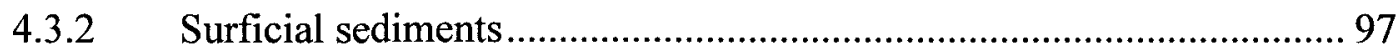


4.3.3 Permafrost Distribution and Depth ................................................... 98

4.4 Geophysical Surveys in the Mackenzie River Valley................................... 98

4.4.1 Previous Surveys ........................................................................ 98

4.4.2 MRV Magnetotelluric Survey, 2006................................................... 99

4.5 Modelling of Earth's Electrical Resistivity ................................................ 104

4.5.1 Literature-Derived 1D Earth Resistivity Model.................................... 104

4.5.2 MT Survey-Derived Earth Resistivity Model ..................................... 109

4.6. Geoelectric Field Modelling …………………................................... 120

4.6.1 Literature-Based Surface Impedances Determination ......................... 120

4.6.2 MT-Based Surface Impedances Determination .................................. 122

4.6.3 Comparison of Surface Impedance Determinations .......................... 124

4.6.4 Types of Geoelectric Field Variations .............................................. 135

4.6.5. Statistical Estimations of Telluric Activity ........................................... 137

$4.7 \quad$ Applications to PSP Modelling .............................................................. 140

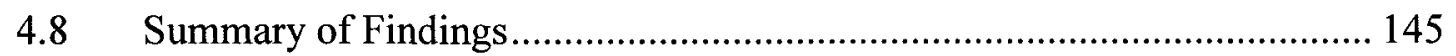

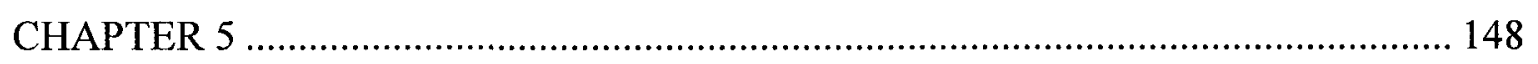

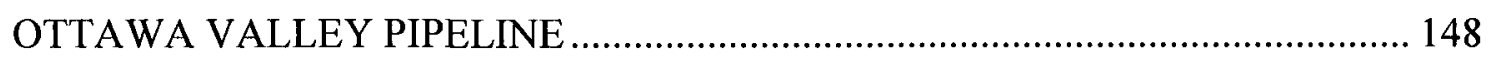

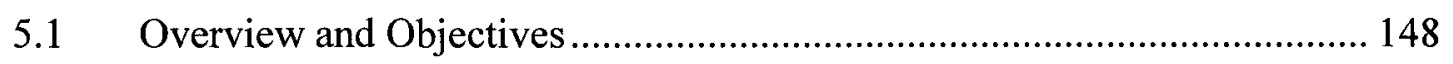

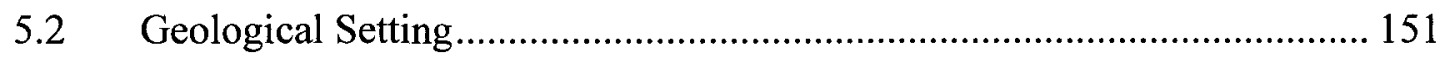

5.3 Geophysical Surveys in the Ottawa Valley Study Area ………................. 156

5.3.1 Previous Electromagnetic and Seismic Surveys ................................. 156

5.3.2 Simultaneous Magnetotelluric and PSP Surveys 2003-2009.............. 157

5.4 Geoelectric Field and PSP Time Series Recordings .................................. 163 
5.4.1 Data Quality Assessment .................................................. 163

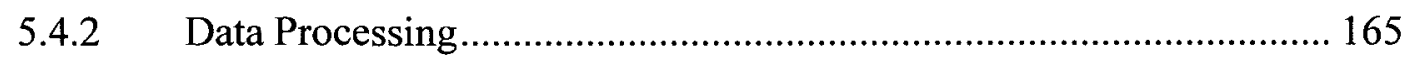

5.5 Analysis of Geoelectric Field and PSP Data...................................... 170

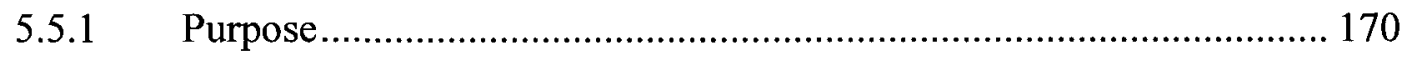

5.5.2 Comparison of Concurrent Geoelectric Field and PSP Time Series .. 170

5.5.3 PSP Amplitude Variations along Pipeline, Time Series Ratio .......... 173

5.6 Processing, Inversion and Analysis of MT Data................................... 178

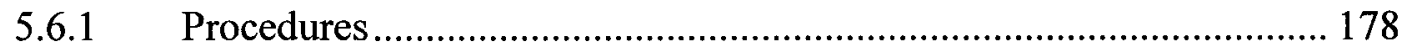

5.6.2 Geological Interpretation ...................................................... 181

5.6.3 Surface Impedances and Modelled Geoelectric Field...................... 183

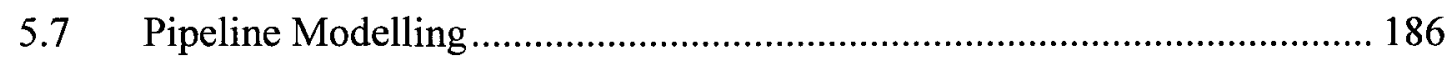

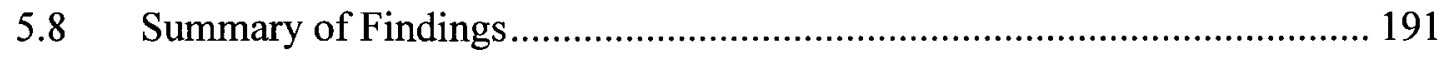

CHAPTER 6 CONCLUSIONS, RECOMMENDATIONS \& FUTURE WORK........ 194

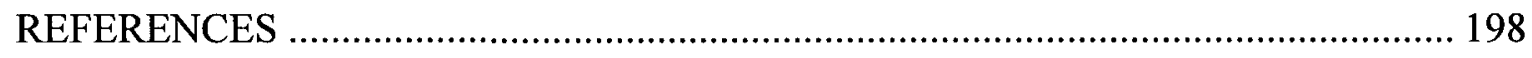

xii 


\section{LIST of TABLES}

Table 2.1. Information sources and models used for the study areas .............................. 20

Table 3.1. Geomagnetic data sources for geoelectric field calculation ........................... 78

Table 4.1. Data acquisition summary for the MRV 2006 magnetotelluric survey ........ 103

Table 4.2. Summary of processing for MRV 2006 magnetotelluric survey ................... 111

Table 5.1. Survey statistics and instrument specifications......................................... 159

\section{LIST of FIGURES}

Figure 1.1. General map showing location of the three study areas, the geomagnetic zones and selected geomagnetic observatories.

Figure 2.1. Flowchart showing the various data sources, analyses and models presented in this thesis

Figure 2.2. Schematic showing the field layout for a combined AMT and MT recording

Figure 2.3. Photographs showing components of the Phoenix Geophysics MTU-5A magnetotelluric instrument.

Figure 2.4. Photographs showing Tinker-Rasor DL-1 digital data logger (right) and a $\mathrm{Cu} / \mathrm{CuSO}_{4}$ electrode (left); and, pipeline test post, with data logger attached to backside of post.

Figure 2.5. Calculation of the geoelectric field from the geomagnetic field and a layered

1D Earth resistivity model. 36 
Figure 2.6. Schematic of the DSTL model of pipeline including distributed voltage sources representing the induced geoelectric field.

Figure 3.1. Annual geomagnetic activity indices from year 2004 at the Yellowknife Geomagnetic Observatory in the auroral zone and in Ottawa Geomagnetic Observatory at a lower latitude, in the sub-auroral zone.

Figure 3.2. Route of the proposed Alaska Highway Corridor natural gas pipeline in relation to the three major zones of geomagnetic activity.

Figure 3.3. Activity indices derived from $95 \%$ occurrence levels of HRX, at six different geomagnetic observatories. 46

Figure 3.4. Percentage hours of exceedance for the three geomagnetic activity indices at five different geomagnetic observatories along the pipeline route. 49

Figure 3.5. Terranes of the Canadian - Alaskan Cordillera. 50

Figure 3.6. Location of MT surveys along or crossing the proposed pipeline corridor... 55

Figure 3.7. Maps of the averaged resistivity at various crustal and mantle depths as determined by MT transects along highways in part of northwestern Canada......... 56

Figure 3.8. Earth resistivity in Alaska as 2- and 3- layer models........................58

Figure 3.9. Zones along the pipeline route used to construct 1D Earth resistivity models. 60

Figure 3.10. 1D Earth resistivity model for Zone 1 - Prudhoe Bay..................................62

Figure 3.11. 1D Earth resistivity model for Zone 2 - Brooks Range.............................. 63

Figure 3.12. 1D Earth resistivity model for Zone 3 - Fish Creek. ................................... 65

Figure 3.13. 1D Earth resistivity model for Zone 4 - Fairbanks....................................66

Figure 3.14. 1D Earth resistivity model for Zone 5 - Tok..........................................68 
Figure 3.15. 1D Earth resistivity model for Zone 6 - Whitehorse.

Figure 3.16. 1D Earth resistivity model for Zone 7 - Northeastern BC........................ 71

Figure 3.17. 1D Earth resistivity model for Zone 8 - Boundary Lake. ........................... 72

Figure 3.18. Surface impedances for the eight 1D layered Earth resistivity models determined for the Alaska Highway Corridor. 75

Figure 3.19. Calculated geoelectric field $\left(E_{\mathrm{x}}\right)$ for different layered Earth models (Zones $1-8$ ), using the 17 January 2004 geomagnetic data recorded at Ottawa Geomagnetic Observatory. 77

Figure 3.20. Geoelectric field variations in the Ex (northward) and Ey (eastward) directions for a geomagnetically quiet (Nov. 6, 2004) and stormy day (Nov. 8, 2004) experienced along the eight resistivity zones along the AHC pipeline route. 79

Figure 3.21. Telluric Activity Indices derived from the $95 \%$ occurrence levels for the east-west component of the geoelectric field, $E_{y}$, in 2004. 81

Figure 3.22. Percentage of hours exceeding the HMA telluric activity index - in an eastwest direction - for each resistivity zone for the entire 32 year time period between 1975 and 2007. 82

Figure 3.23. Modelled PSP, on the Alaska Highway Corridor pipeline, produced by a 1 $\mathrm{mV} / \mathrm{km}$ geoelectric field flowing (top) geographic north-south; and, (bottom) geographic east-west. 85

Figure 3.24. PSP variations that would be experienced in different resistivity zones, i.e. Earth models, along the Alaska Highway Corridor pipeline during a transition from geomagnetically quiet to storm conditions. 86 
Figure 3.25. Statistical exceedance of PSP hourly maximum amplitude, based on a 32 year period from 1975 to 2007 , for four resistivity zones.

88

Figure 4.1. Percentage of exceedance of HRX in Yellowknife for three geomagnetic activity levels

Figure 4.2. Major geological framework within the western portion of the Northwest Territories.

Figure 4.3. Location of selected geophysical surveys completed proximal to the regional to the Mackenzie River valley pipeline route. 100

Figure 4.4. Views of sounding sites and instruments for the MT survey undertaken in the Mackenzie River valley, summer 2006 102

Figure 4.5. Compilation of the five 1D Earth resistivity models along the proposed Mackenzie River valley pipeline route. 107

Figure 4.6. Apparent resistivity and phase response curves (unrotated) for six MT sounding sites along the Mackenzie Valley proposed pipeline route

Figure 4.7. Comparison of the smooth (Occam) 1D inversion models (only invariant mode shown) obtained from MT surveying (purple lines) versus the literaturederived 1D Earth resistivity models (black lines).

Figure 4.8. Comparison of the 4-layered 1D inversion models (modes XY (red lines), YX (blue lines) and invariant (green lines)) obtained from MT surveying versus the literature-derived 1D Earth resistivity models (black lines). 116

Figure 4.9. Surface impedances for the five resistivity zones along the Mackenzie Valley proposed pipeline, calculated from literature-derived 1D Earth resistivity models 121 
Figure 4.10. Surface impedances for the Zone 5 Earth resistivity model, without an active layer and with a thawed and frozen $2 \mathrm{~m}$ thick active layer.

Figure 4.11. Comparison of all calculated surface impedances obtained from 1D inversion of MT measurements

Figure 4.12. Comparison of (top) apparent resistivity response curves from MT sounding site MRV005 Taglu and (bottom) surface impedances calculated from literature for Zone 1 (purple solid line) and calculated from a 1D inversion of MRV005 sounding data (dashed black line). 126

Figure 4.13. Comparison of (top) apparent resistivity response curves from MT sounding site MRV010 Inuvik and (bottom) surface impedances calculated from literature for Zone 2 (orange solid line) and calculated from an inversion of MRV010 sounding data (dashed black line).

Figure 4.14. Comparison of (top) apparent resistivity response curves from MT sounding site MRV020 Mountain River and (bottom) surface impedances calculated from literature for Zone 3 (green solid line) and calculated from an inversion of MRV020 MT sounding data (dashed black line). 128

Figure 4.15. Comparison of (top) apparent resistivity response curves from MT sounding site MRV025 Norman Wells and (bottom) surface impedances calculated from literature for Zones 3 (green solid line) and 4 (magenta solid line) and calculated from an inversion of MRV025 sounding data (dashed black line). 129

Figure 4.16. Comparison of (top) apparent resistivity response curves from MT sounding site MRV030 Peatland and (bottom) surface impedances calculated from literature 
for Zones 4 (magenta solid line) and 5 (dark yellow solid line) and calculated from an inversion of MRV030 sounding data (dashed black line). 130

Figure 4.17. Comparison of (top) apparent resistivity response curves from MT sounding site MRV035 Fort Simpson and (bottom) surface impedances calculated from literature for Zone 5 (dark yellow solid line) and calculated from an inversion of MRV035 sounding data (dashed black line).

Figure 4.18. Geoelectric field variations in the $E_{x}$ (northward) and $E_{y}$ (eastward) directions for a geomagnetically quiet and stormy day experienced along the five resistivity zones within the Mackenzie River Valley study area.

Figure 4.19. Statistical exceedance of the Hourly Maximum Activity (HMA) telluric activity indices, in $E_{x}$ direction, for all five resistivity zones in the Mackenzie River Valley study area for year 2004.

Figure 4.20. Calculated geoelectric field along the pipeline during moderately disturbed geomagnetic conditions, 17 January 2004, using the different layered Earth models (Zones $1-5)$ and geomagnetic data from Yellowknife Geomagnetic Observatory..

Figure 4.21. Model of PSP, on the proposed Mackenzie River valley pipeline, produced during a moderately disturbed geomagnetic conditions (unsettled day) with an HRX $=300 \mathrm{nT}$, for 17 January 2004.

Figure 4.22. PSP variations that would be produced at the north (Zone 1; Taglu) and south (Zone 5; KP1221) ends of the proposed Mackenzie River valley pipeline on 17 January 2004, during moderately disturbed geomagnetic conditions typical of an unsettled day. 
Figure 5.1. Top panel is a map of part of the TransCanada natural gas pipeline showing locations of the 1997 PSP recording sites. Bottom panel shows the simultaneous pipe-to-soil (PSP) recordings at nine sites along the pipeline..

Figure 5.2. Bedrock geology map of the Ottawa Valley, including major divisions and lithotectonic elements, and natural gas pipeline route.

Figure 5.3. Location of MT sounding sites for multiple surveys in the Ottawa Valley study area.

Figure 5.4. Views of MT instruments and sounding sites, Ottawa Valley. 160

Figure 5.5. Views of TransCanada mainline right-of-way, Ottawa Valley study area.. 161

Figure 5.6. An example of simultaneous variation of geomagnetic field rate of change (top two), geoelectric field (middle) and PSP (bottom) measurements obtained on October 8, 2003. 167

Figure 5.7. An example of simultaneous recorded geoelectric field and PSP data, before and after filtering, obtained from the 2005 ORF survey 168

Figure 5.8. Comparison of the time series from simultaneously recorded geoelectric field and PSP along the central portion of the pipeline route, using $1 \mathrm{~Hz}$ data (resampled from original time series). Recorded May 16, 2006.

Figure 5.9. Comparison of the time series from simultaneously recorded geoelectric field and PSP along the northern half of the pipeline route, using $1 \mathrm{~Hz}$ data (resampled from original time series). . Recorded May 19, 2006.

Figure 5.10. Simultaneous PSP recordings at multiple test posts on two different days, June 2, 2005 (left panel) and June 7, 2005 (right panel) 
Figure 5.11. Amplitude ratio of observed PSP along the pipeline as determined from the (a) 1997 ITS investigation, (b) 2003 ORV survey, and (c) 2005 ORF survey....... 176

Figure 5.12. Coherency between 14 individual MT sounding sites and its reference sites, from the $2005 \mathrm{ORF}$ survey, as a function of frequency for the horizontal geomagnetic field components $H_{x}$ and $H_{y}$ 180

Figure 5.13. (a) 2D inversion model (TM component) beneath pipeline. (b) Measured $Z_{y x}(45)$ surface impedance (dashed line) at $0.01 \mathrm{~Hz}$ used as input to pipeline modelling and modelled response $\boldsymbol{Z}_{\boldsymbol{y} x}$ impedance (solid lines) - at eight different frequencies - obtained from $2 \mathrm{D}$ inversion model..

Figure 5.14. Calculated geoelectric field and modelled PSP variations versus distance along pipeline (modified from Fernberg et al., 2007, Fig. 9). Case 1: uniform geoelectric field of $2 \mathrm{mV} / \mathrm{km}$. Case 2: geoelectric field derived from measured $Z_{y x}(45)$ impedances, at $0.01 \mathrm{~Hz}$ 188

Figure 5.15. Comparison of (a) ratio of observed PSP amplitude, in time domain, and (b) the Case 2 modelled PSP amplitude ratio variations along the pipeline. Pipeline schematic at top of figure. Schematic representation of bedrock geology and tectonic terrane along the pipeline route are shown at bottom of figure. 190 


\section{LIST of APPENDICES}

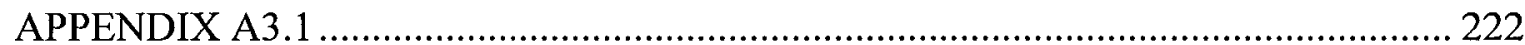

1D EARTH RESISTIVITY MODELS for ALASKA HIGHWAY CORRIDOR

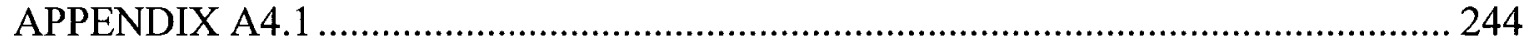

1D EARTH-RESISTIVITY MODELS for MACKENZIE RIVER VALLEY STUDY

AREA

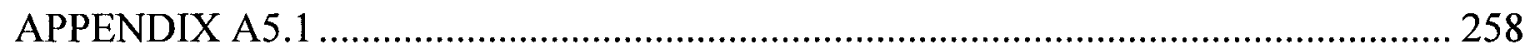

COORDINATES OF PSP DATA LOGGER \& MT SOUNDING SITE LOCATIONS 


\section{CHAPTER 1 \\ INTRODUCTION}

\subsection{Effects of Telluric Currents on Pipelines}

\subsubsection{Sources of Telluric Currents in Pipelines}

Variations of the Earth's magnetic field induce a geoelectric field at the Earth's surface and interior. This alternating geoelectric field, in turn, drives geomagnetically induced currents (GIC) along electrically conductive technological networks, such as pipelines, power transmission lines and railways (Lanzerotti and Gregori, 1986), and may cause serious harm to the infrastructure. In keeping with terminology used in the pipeline industry, GIC will here forth be referred to as "telluric current". Pinholes and breaks in the pipe coating (known as "holidays"), caused by damage during pipe burial or debonding from the pipe steel because of manufacturing or installation errors, allow telluric currents to enter and exit the highly conductive pipeline steel creating conditions where accelerated corrosion may occur (Gummow et al., 2001). Furthermore, telluric current in pipelines interfere with corrosion protection systems by creating continuously changing variations in the pipe-to-soil potential (PSP) that disrupt pipeline surveys (Place and Sneath, 2001).

The sun is the origin of the geomagnetic field variations which produce telluric currents. Solar disturbances, in the form of solar flare eruptions and coronal mass ejections, propagate through interplanetary space eventually impacting the magnetosphere surrounding Earth and creating intense fluctuations of Earth's geomagnetic field (Campbell, 2003; Prölss, 2004). At high geomagnetic latitudes (60$70^{\circ}$ ) through a complex interaction and favourable coupling between the solar wind and 
Earth's natural magnetic field, an intense electrical current system, known as the auroral electrojet, is generated in the conductive ionospheric zone, $100 \mathrm{~km}$ above Earth's surface. The auroral electrojet forms an oval-shaped ring - the auroral zone - around the Earth's geomagnetic poles. The auroral electrojet is responsible for the greater intensity and frequency of geomagnetic disturbances in the auroral zone. It is these fluctuating geomagnetic fields that induce strong telluric currents to flow in the Earth and along conductive pipelines, thereby creating a hazard for pipelines constructed in the auroral zone.

\subsubsection{Pipeline Corrosion and Cathodic Protection Systems}

Corrosion is an oxidation-reduction reaction and is of special concern for pipelines because of the danger of significantly reducing its operational lifetime. Peabody (2001, chapters there within) describes the corrosion process as the removal of electrons (oxidation) from the pipe metal and the consumption of these electrons by either an oxygen or water reduction reaction. The oxidation reaction is commonly called the anodic reaction and the reduction reaction is the cathodic reaction. For corrosion to occur both of these electrochemical reactions are necessary and charge neutrality is maintained. The site where the pipe metal is being lost by oxidation is referred to as the anode. At the anode, direct electric current (defined as a flow of positive charge, i.e. ionic current) flows from the metal surface into the surrounding moist soil (the electrolyte) as metal ions leave the pipe surface. The current flows through the soil to a site (the cathode) on the pipeline surface where the reduction reaction occurs, forming hydrogen and hydroxyl ions. To complete the oxidation-reduction process, the pipeline itself provides a metallic path to electrically connect the anode (i.e. the pipeline) and cathode. It is the potential 
difference between the anode and cathode which causes current to flow, with the anode being more negative than the cathode potential.

To reduce the corrosion rate of a metal surface, a technique known as cathodic protection (CP) is used. The movement of direct current is forced from the surrounding soil (electrolyte) onto all surfaces of the pipeline thereby shifting the potential of the steel to be more negative, making the entire pipeline surface a cathode and resulting in a reduction of the corrosion rate of the metal.

For buried pipelines (typically within $2 \mathrm{~m}$ of ground surface), the primary means to prevent corrosion is the use of a high-resistive coating (a paint and / or wrap). It is at these coating holidays where ionic current exits and corrosion is possible. For a pipeline without a CP system, continuously varying telluric currents (caused by the ever fluctuating geomagnetic field) will also flow from the pipe's metal surface exposed at the holiday and into the surrounding moist soil, so the charges transferring through the oxidation reaction result in the loss of pipe metal (Gummow, 2002). As an additional means to protect pipelines from corrosion at holidays, CP systems are required by law in most countries as a condition for a pipeline operating licence. $\mathrm{CP}$ protection is accomplished by either passive sacrificial systems or as active impressed current systems. Sacrificial CP provides an alternative location for corrosion by connecting the pipeline steel to a sacrificial anode, usually made of zinc, which corrodes first allowing the pipe steel to survive a longer time. Impressed $\mathrm{CP}$ is a more advanced system that is designed to keep the pipeline at a certain negative voltage with respect to the surrounding soil to counteract the oxidation reaction, by means of an electrical direct current impressed into the pipe steel (Beavers, 2001). 
The potential difference between the pipe and the surrounding soil is measured as the pipe-to-soil potential (PSP) and should be maintained at a level of about $-850 \mathrm{mV}$ to $1100 \mathrm{mV}$ (Beavers and Garrity, 2001) with respect to a $\mathrm{Cu}-\mathrm{CuSO}_{4}$ reference electrode. . When PSP is above $-850 \mathrm{mV}$ corrosion occurs. When it is below $-1100 \mathrm{mV}$ (overprotected) the current flow encourages water and ion migration through the coating, causing the coating to disbond from the steel, and production of hydrogen that can ingress into surrounding steel leading to brittle failure (Beavers, 2001b).

It is common practice to survey pipelines once a year to measure PSP variations to check that the CP system is providing the proper PSP level. Because fluctuating telluric currents are always flowing along the pipeline and are superimposed on the impressed steady-state CP current, the final combined PSP will never be at a constant level. However, if such surveys are undertaken during geomagnetic disturbances, the resulting telluric currents will cause observation of extreme and erratic PSP values (Bianchetti, 2001) which will either mask or generate PSP deviations that indicate faults in the pipeline coating. According to standards for CP systems, fluctuations of about 300 $\mathrm{mV}$ would largely be mitigated by a CP system (Gummow, 2002). Larger fluctuations, however, are of concern since the CP system would not be able to maintain the prescribed PSP levels. For that reason, it becomes important to know where PSP varies along a pipeline and the frequency of PSP exceedance. Several factors that can influence PSP variations are:

- The geomagnetic activity (both magnitude and frequency of the magnetic variations);

- The Earth resistivity profile beneath the pipeline; and, 
- The pipeline structure (presence of bends, flanges and termination, splitting or merging of one or two pipes, coating) and orientation.

During geomagnetic disturbances, telluric currents may be sufficiently strong to cause the PSP to exceed the prescribed safe levels for considerable time during which the pipeline is not being adequately protected. Gummow (2002) points out that with increasing levels of geomagnetic activity the rate of corrosion increases. Therefore, the design of a CP system for pipelines located in auroral zones should consider how the efficiency of the $\mathrm{CP}$ system might be reduced by the cumulative effect of telluric current variations over the 30 to 50 year operational life-span of the pipeline.

\subsubsection{Past Investigations of the Impact of Telluric Currents on Pipelines}

A considerable body of work has been undertaken on the study of telluric currents flowing along pipelines, including the analysis of their impact and mitigation. Investigations have evolved as follows:

- The problem of telluric interference on pipeline CP systems was first noted in the early 1950s during surveys to measure PSP (Allison and Huddleston, 1952; Russell and Nelson, 1954).

- Later, extensive investigations were made on pipelines in the mid-west of the United States by Gideon et al. $(1968,1970)$ and Gideon (1971)

- Development of the TransAlaska pipeline in the late 1970s located just beneath the auroral electrojet initiated more studies led by Campbell $(1978,1980,1986)$, Merritt (1978), Smart (1982) and Wallace $(1978,1980)$. This led to the realization that telluric currents are more significant at higher latitudes as result of 
greater geomagnetic activity and frequency, and are strongest where a pipeline runs parallel to the east - west trending auroral electrojet.

- The impact of telluric currents on pipelines has been investigated in other Nordic countries located beneath the auroral zone (Henriksen et al., 1978; Peabody, 1979; Pirjola and Lehtinen, 1985; Camitz et al., 1997; Boteler and Trichtchenko, 2000; Edwall and Boteler, 2001).

- Telluric current interference on CP systems has been reported from lower latitudes, including the Mombasa to Nairobi multi-product pipeline in Kenya (Barker and Skinner, 1980), the Dampier to Perth natural gas line in Australia (McCoy, 1989), pipeline crossing the Andes Mountains in Argentina (pers. comm., 2008), and four different pipelines in Australia (Marshall et al., 2010).

- From 1997 to 1999 , an international study of telluric current effects was completed on several Canadian and Scandinavian pipelines (Boteler and Trichtchenko, 2000). The study identified high PSP variations in areas of geological boundaries.

\subsubsection{Modelling of Geoelectric Field and PSP in Pipelines}

In addition to observations of PSP, numerical analysis and modelling can be undertaken to identify locations where on the pipeline PSP will be exceeded and to what degree and frequency. This can be done for either existing or proposed pipeline routes.

Numerical modelling for pipelines has typically been divided into two components; geophysical and technological (Viljanen, 1989). First, the geophysical component deals with the calculation of a geoelectric field at various pipeline locations. Second, the technological component utilizes the geoelectric field as an input into a 
pipeline model which is used to compute the PSP at numerous points along the pipeline route.

The need for the geophysical component in the modelling process is due to the lack of regular recordings of the geoelectric field, either at geomagnetic observatories or along pipeline routes. Hence, a geoelectric field has to be calculated, usually based on recordings of the geomagnetic field obtained from the closest geomagnetic observatory and application of the "plane wave" approach (Pulkkinen et al., 2001; Trichtchenko and Boteler, 2002). In this approach, the geomagnetic variations are regarded as a plane wave propagating downward into an Earth comprised of horizontal layers of differing resistivity and thickness. Such a representation of Earth is referred to a one-dimensional (1D) layered Earth resistivity model

Using a 1D Earth resistivity model is limited in that lateral variation of the Earth resistivity structure is not recognized. Furthermore, a 2D Earth resistivity model better reflects the reality of the subsurface. Lateral variations of Earth resistivity have not been well investigated although several papers have presented models for different 1D layered Earth structures (Viljanen, 1989; Osella and Favetto, 2000). An initial attempt to address how lateral variations affect the PSP was made by Boteler et al. (2003)

For the technological component of the modelling process, two pipeline models can be used to calculate the PSP. The first one approximates the pipeline as an infinitely long cylinder (ICL) and is based on the theory developed for long cylindrical ore bodies (Kauffmann and Keller, 1981). This approach was adapted to pipeline studies by Ogunade (1986), Viljanen (1989), Osella et al. (1999) and Trichtchenko and Boteler (2002). In parallel to the ICL pipeline model, distributed-source transmission line 
(DSTL) theory first described by Schelkunoff (1943) was applied to modelling telluric currents on a New Zealand pipeline (Boteler and Cookson, 1986). The DSTL pipeline model was used to predict that largest PSP variations would occur at discontinuities in the pipe, or where the geoelectric fields vary over a short distance as occurs near a coastline due to the resistivity contrast between conductive seawater and resistive land. The DSTL approach has proven to be valid (Boteler and Seager, 1998) and flexible enough to incorporate real features of pipeline networks, such as bends, corrosion protection devices, flanges, branch lines and pipeline termination, and has been used subsequently in many studies (Pulkkinen et al., 2001; Trichtchenko and Boteler, 2002; Boteler et al. $(2005,2009)$, including the work presented in this thesis.

\subsection{Objective, Scope and Study Areas for Research}

The overall objective of this thesis was to test the hypothesis that differences of Earth resistivity structure along a pipeline route can be a contributing cause of large PSP variations on the pipeline. Two major questions are addressed in this thesis:

1) Do Earth resistivity structures produce telluric activity differences and, hence, differences in PSP variations, along separate sections of the pipeline each with its own unique 1D layered Earth model? Are these differences statistically valid over the decades long duration of a pipeline's operation?

Previous studies (Osella and Favetto, 2000; Trichtchenko and Boteler, 2002; Pulkkinen et al., 2007) have shown that differences in the underlying Earth resistivity structure can be the cause of differences in PSP variations and telluric currents. In spite of this finding, no statistical study has been done. Because corrosion is a cumulative process and pipeline life is $30-50$ years long, a statistical study is important to estimate 
the telluric-associated reduction of the pipeline life, especially in the auroral zone. Recordings of PSP variations are normally taken only for several hours or days during annual pipeline surveys. This limited amount of data does not allow for an appreciation of daily, monthly and yearly variations of the PSP and the ability to estimate the cumulative duration of PSP exceedances in order to assess the impact of telluric activity on the entire pipeline. This thesis shows how the use of the long-term statistics of the geomagnetic field in conjunction with Earth resistivity models lead to the development of statistically meaningful telluric activity indices and PSP amplitude variations, useful for design consideration on planned and existing pipelines (Chapters 3 and 4).

2) Do resistivity boundaries in the Earth's subsurface, possibly at intrusive bodies and regional faults, or from changes of crustal thickness and mineralogy, produce significant lateral variations of PSP amplitude?

To investigate this idea, a pipeline crossing a resistivity boundary must be chosen and closely-spaced geophysical measurements must be made because the effect of a lateral resistivity variation cannot be accounted for by simple interpolation of two adjacent but different layered Earth models (Boteler et al., 2003). Because natural variations of the geomagnetic field are of low frequency and penetrative deep into Earth's interior, the magnetotelluric (MT) geophysical method is the most suitable means to measure the Earth resistivity structure at great depths and is therefore used as an investigative tool for this thesis. To accomplish the investigation, simultaneous MT and PSP recordings were made in an area where the pipeline crosses a major geological boundary coincident with a large lateral change of PSP amplitude (Chapter 5). 
The scope of work included MT and PSP surveys undertaken by the author, data analysis, and numerical modelling of the Earth's subsurface in order to predict PSP changes along a pipeline. Three separate locations in Canada (Figure 1.1) formed the study areas for this thesis, as follows:

- Proposed Alaska Highway pipeline, a natural gas line extending southward from Prudhoe Bay, Alaska, crossing into the Yukon Territory and northeastern British Columbia in Canada and then terminating at Boundary Lake on the BC / Alberta provincial border. Part of the route will run parallel to the existing Trans-Alaska crude oil pipeline.

- Proposed Mackenzie River valley pipeline which will run south from the Mackenzie Delta to join the existing pipeline network at Zuma, Alberta. The southern half of the route will run parallel to the existing Norman Wells to Zuma crude oil pipeline operated by Enbridge.

- Part of the Ottawa Valley portion of the TransCanada Pipeline (TCPL), a continental-long natural gas mainline that extends from the Alberta/Saskatchewan border east to the Québec/Vermont border.

The approach chosen was to proceed from the larger to smaller scale, with increased application of MT data. To investigate if the Earth resistivity structure statistically and significantly affects the amplitude of the geoelectric field (and hence the PSP), the Alaska Highway pipeline was chosen because the underlying geological structure is better known, based on crustal-scale geophysical data. To validate the hypothesis on the statistical importance of geological effects on pipelines and the soundness of modelling geoelectric fields using literature-derived Earth resistivity values, 


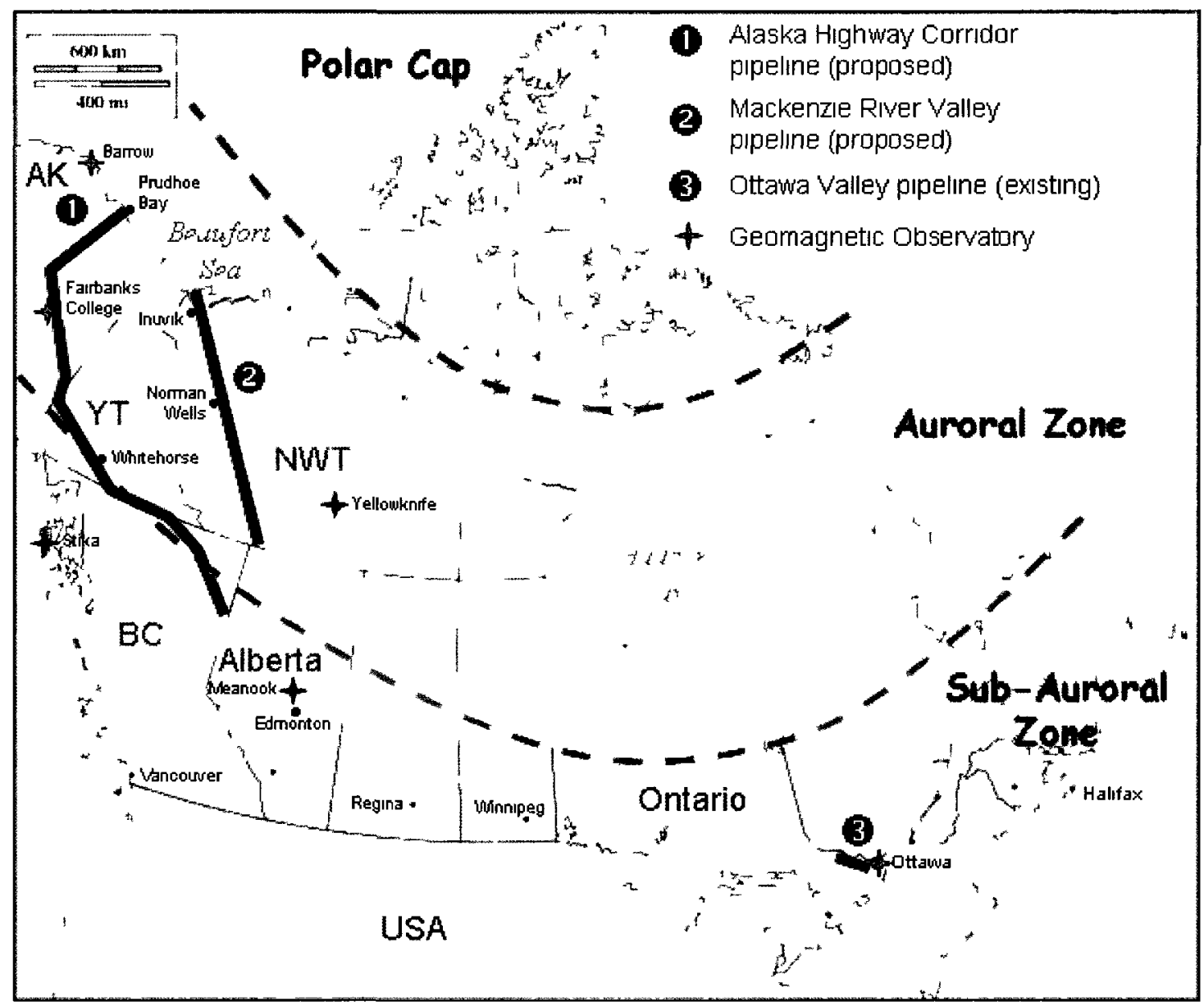

Figure 1.1. General map showing location of the three study areas, the geomagnetic zones and selected geomagnetic observatories (modified from d-map com, 2010) Abbreviations: AK, Alaska, BC, Britısh Columbia, NWT, Northwest Territories; YT, Yukon Territory. 
the proposed Mackenzie Valley pipeline route was selected as a test area. Statistical information from a previous study (Boteler et al., 2005) of the proposed Mackenzie Valley pipeline was incorporated into the assessment. A comparison was made of literature-derived and measured resistivity (the latter using select MT survey measurements gathered for this thesis) to determine whether there was any significant difference between modelled and measured geoelectric results. Finally, detailed joint MT and PSP surveys were completed along the TCPL mainline in the Ottawa Valley. The combined surveys had multiple purposes; (i) to confirm that lateral telluric and PSP variations are the result of the same physical phenomena, (ii) that PSP could be accurately modelled using MT survey data thereby predicting where significant lateral PSP variations would occur along the pipeline route, and, (iii) to identify a geologically probable cause for such PSP variations.

\subsection{Originality of Research}

The research work presented in this thesis was conducted during the course of the author's contract employment from 2005 to 2009 in Ottawa with the Geomagnetic Laboratory, Geological Survey of Canada, and included the following original concepts and/or surveys, and related work.

- Construction of numerous 1D layered Earth resistivity models for pipeline routes in auroral zones, such as in Alaska and along the Mackenzie Valley to assess the statistical effect of telluric activity on the pipeline system. These layered Earth models also serve as the initial input into the geoelectric field model, which, in turn, provides the input into the DSTL pipeline model used to produce a PSP value. 
- A wide-spaced MT survey from Fort Simpson to the Mackenzie Delta, being the first to cover the length of the Mackenzie River valley, to record the geoelectric structure for preparation of 1D inversion Earth models.

- Evaluation on the suitability of using literature-derived 1D Earth resistivity models by comparing them to models obtained through 1D inversion of MT data

- Multiple closely-spaced combined MT and PSP surveys, being the first such field experiments reported in the literature (Fernberg et al., 2007), along the TCPL mainline in the Ottawa Valley that provided new insight on the crustal structure of the Grenville geological province. Results of these surveys were used; (i) for comparison and assessment of simultaneously recorded geoelectric field and PSP variations, and (ii) to provide the input into the DSTL pipeline model applied for a specific length of the pipeline.

\subsection{Thesis Structure}

The thesis is structured in the following manner. Chapter 1 states the problem. In addition, background information about geomagnetic induction and the effects on pipeline corrosion protection is given. Thesis objectives are also presented, as well as the scope of original work. Chapter 2 describes the methodology, geophysical instrumentation and data sources that were utilized. Subsequent Chapters 3 to 5 individually present results, in order of increasing complexity. Chapter 3, covering the Alaska Highway pipeline, presents results based on regional 1D Earth resistivity models compiled from literature. Chapter 4, covering the Mackenzie River valley pipeline route, presents 1D regional models developed from literature data, as well as 1D Earth resistivity profiles measured experimentally at several locations along the proposed 
pipeline route. Finally, Chapter 5, covering the Ottawa Valley pipeline, contains the most experimental work as it features $2 \mathrm{D}$ subsurface resistivity effects on PSP. The concluding Chapter 6 summarizes the work undertaken for this thesis, its value to the pipeline industry and proposes future research directions. 


\section{CHAPTER 2 METHODOLOGY}

\subsection{Introduction}

To demonstrate how electrical properties (i.e. resistivity, and its inverse, conductivity) of the Earth's subsurface can affect pipeline operations, a multi-step investigative process was undertaken, which shows how there is a connecting chain of physical phenomena starting from Earth's internal structure leading to the PSP variations observed on the pipeline.

Knowing there is a direct connection between Earth resistivity and the geoelectric field at the Earth's surface (Cagniard, 1953; Tikhonov, 1950; Kaufmann and Keller, 1981), the initial step was to examine the effect of Earth resistivity on the geoelectric field variations. For in turn, the geoelectric field serves as an input into a pipeline model which is used to calculate PSP variations, thereby showing how different Earth resistivity structures affect PSP variations through the geoelectric field.

The first and most important task is to build the Earth resistivity model that corresponds to the true resistivity of the geological setting of the pipeline route, for its accuracy is critical in achieving a modelled PSP that represents realistic effects. Because the frequencies of natural geomagnetic variations are very low, ranging from millihertz to several $\mathrm{Hz}$ (Kaufmann and Keller, 1981), the penetration depth into Earth's interior is very high (up to several $100 \mathrm{~s} \mathrm{~km} \mathrm{depth),} \mathrm{thus} \mathrm{deep} \mathrm{geological} \mathrm{conditions} \mathrm{in} \mathrm{the} \mathrm{crust} \mathrm{and}$ mantle will affect the measurable surface geoelectric field. 
The best way to obtain this information is through the results of magnetotelluric (MT) surveys. MT is a passive electromagnetic (EM) geophysical method that records the natural geoelectric and geomagnetic fields covering a frequency range between 0.0001 to $10,000 \mathrm{~Hz}$, which equates to a signal penetration from shallow crust to upper mantle depths. Comprehensive descriptions of the physical basis behind the MT method can be found in Vozoff (1991) and Simpson and Bahr (2005).

The MT method was chosen as a tool in this study of PSP variations because the natural sources signal (geomagnetic variations), which manifests itself as a geoelectric field and is measurable by MT instruments, is the natural phenomena at the origin of PSP variations.

In this thesis, the results of MT surveys conducted by the author as well as publications from previous MT surveys were utilized, along with additional sources of information about resistivity and depth of geological structures. The data were used to construct the Earth resistivity models that are the prelude to modelling the geoelectric field and PSP along a pipeline route. For the Alaska Highway (Chapter 3) and Mackenzie River Valley (Chapter 4) study areas, change of resistivity and its effect on geoelectric field and PSP variations, were only examined in a vertical direction (1D approximation) using a set of layered Earth models derived from a literature compilation and, for the Mackenzie River Valley, also from a limited MT survey. In the case of the Ottawa Valley (Chapter 5), the availability of detailed MT survey results permitted use of a $2 \mathrm{D}$ approximation to test the hypothesis that lateral and vertical changes of subsurface resistivity also affect PSP variations. 
To obtain geoelectric field values, the measurements collected during MT surveys can also be used. However, the recording duration at an MT sounding site is typically less than 48 hours and, for the MT surveys completed by the author, it was less than one full day. The concern is that "short" duration MT measurements are not representative of the cumulative duration of the geoelectric field variations that could occur over the decades-long operational life of a pipeline. Thus, in order to account for the cumulative multi-year effect on a pipeline corrosion protection system, it becomes necessary to examine how Earth resistivity structures affect telluric activity on a time scale of decades. Since there are no measurements of the geoelectric field on this time scale, such an assessment requires a statistical study using available geomagnetic data from permanent geomagnetic observatories in conjunction with Earth resistivity models to numerically simulate the desired long duration record of the geoelectric field (Chapter 3 and 4).

For two of the study areas, Alaska Highway and Mackenzie River Valley, where pipelines are proposed, the examination of how resistivity of geological structure affects PSP variation requires that pipeline modelling be undertaken (Chapters 3 and 4). Only in the Ottawa Valley study area, on the existing TCPL mainline, could PSP be measured by the author to confirm the validity of the pipeline model (Chapter 5).

This chapter describes the data sources, analyses and models employed to investigate how resistivity of geological structures affects the PSP variations. Figure 2.1 is a flowchart showing the various data sources used for inputs into the four models, and how results from one model cascade as an input into the next model. Also provided is a description of the data sources and geophysical instrumentation (Section 


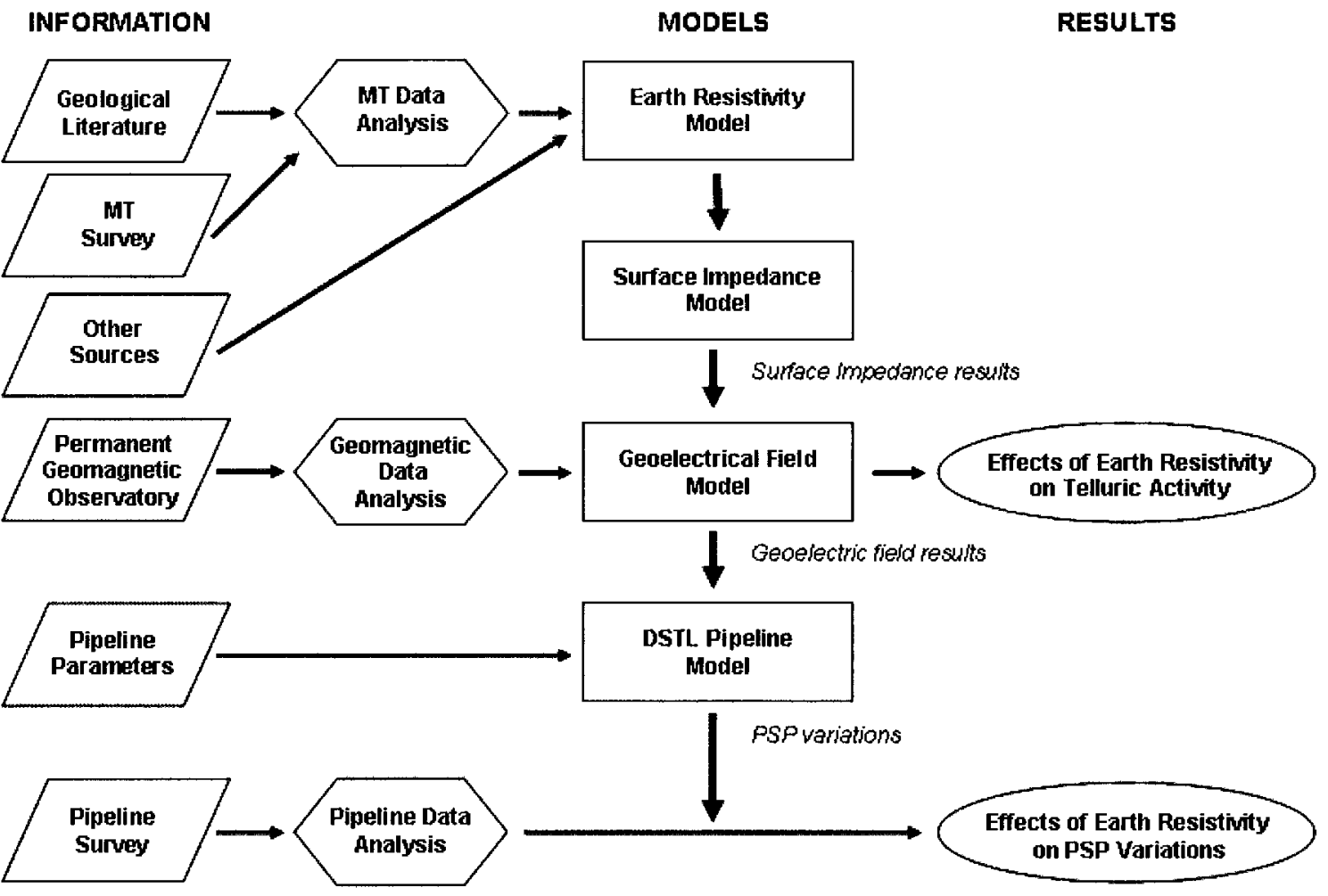

Figure 2.1. Flowchart showing the various data sources, analyses and models presented in this thesis. 
2.2), particular methods applied to different types of data (Section 2.3) and the numerical models used for analysis (Section 2.4). Table 2.1 is a summary of information sources and models that were applied to each study area.

\subsection{Data Sources}

Both published geological literature and geophysical data that were acquired for the thesis are described below.

\subsubsection{Literature Compilation}

A review of publicly-available information was undertaken by the author, and included government geological reports and maps including on-line resources, soilengineering studies of the areas near pipeline routes, and scientific journals. The purpose was to gather resistivity values and depths to the various layers of crust and mantle in order to construct Earth resistivity models specific to the pipeline routes. An emphasis was placed on using apparent electrical resistivity values obtained from MT surveys conducted as part of crustal investigations since such a value would represent the resistivity of the Earth material over a large area. However, it should be recognized that crustal transects tend to be focused on areas of geological interest such as regional faults, where conceivably the resistivity of the surrounding upper crust could be greatly modified by the presence of the fault itself. Where available and appropriate, induction logs from hydrocarbon exploration wells were also examined to obtain near-surface electrical resistivity values. The approach used was to be consistent in applying the same resistivity value for the same material (type of overburden, sedimentary basin, intrusives or lithotectonic assemblage) or mantle divisions. 
Table 2. 1. Information sources and models used for the study areas

\begin{tabular}{|c|c|c|c|c|}
\hline & \multirow{2}{*}{\multicolumn{3}{|c|}{ STUDY AREA }} \\
\hline & & & & \\
\hline & & $\begin{array}{c}\text { Alaska } \\
\text { Highway } \\
\text { Corridor }\end{array}$ & $\begin{array}{c}\text { Mackenzie } \\
\text { River } \\
\text { Valley } \\
\end{array}$ & $\begin{array}{l}\text { Ottawa } \\
\text { Valley }\end{array}$ \\
\hline \multirow{4}{*}{ 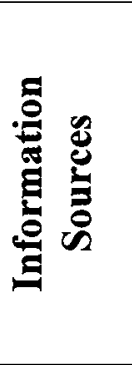 } & $\begin{array}{l}\text { Geological } \\
\text { Literature }\end{array}$ & $\mathrm{X}$ & $\mathrm{X}$ & $\mathrm{X}$ \\
\hline & MT Survey & --- & $\mathrm{X}$ & $\mathrm{X}$ \\
\hline & $\begin{array}{l}\text { Geomagnetic } \\
\text { Observatory }\end{array}$ & $\mathrm{X}$ & $\mathrm{X}$ & $\mathrm{X}$ \\
\hline & PSP Survey & --- & --- & $\mathrm{X}$ \\
\hline \multirow{8}{*}{ 悉 } & $\begin{array}{l}\text { 1D Earth Resistivity, } \\
\text { literature derived }\end{array}$ & $\mathrm{X}$ & $\mathrm{X}$ & -- \\
\hline & $\begin{array}{l}\text { 1D Earth Resistivity, } \\
\text { MT survey derived }\end{array}$ & --- & $\mathrm{x}$ & $\mathrm{X}$ \\
\hline & $\begin{array}{l}\text { 2D Earth Resistivity, } \\
\text { MT survey derived }\end{array}$ & --- & --- & $\mathrm{X}$ \\
\hline & Surface Impedance & $\mathrm{X}$ & $\mathrm{X}$ & $\mathrm{X}$ \\
\hline & Geoelectric Field & $\mathrm{X}$ & $\mathrm{X}$ & $\mathrm{X}$ \\
\hline & DSTL Pipeline & $\mathrm{X}$ & $\mathrm{X}$ & $\mathrm{X}$ \\
\hline & 1D MT Inversion & --- & $\mathrm{X}$ & -- \\
\hline & 2D MT Inversion & -- & --- & $\mathrm{X}$ \\
\hline \multirow{3}{*}{ 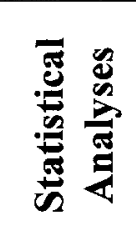 } & $\begin{array}{l}\text { Geomagnetic } \\
\text { Climatology }\end{array}$ & $\mathrm{X}$ & $x$ & --- \\
\hline & Telluric Activity & $\mathrm{X}$ & $\mathrm{X}$ & --- \\
\hline & PSP Accidences & $\mathrm{X}$ & --- & --- \\
\hline
\end{tabular}


Most published MT survey results were found in descriptions of crustal transects completed along part of the Alaska Highway Corridor and the southernmost portion of the Mackenzie Valley Corridor study areas. Although seismic transects have been completed in eastern Ontario, there have been no prior MT transects in the Ottawa Valley study area.

Selection of a resistivity value for the upper crust layer has proven to be most problematic since overall resistivity is dependent on the most common rock types present, degree of metamorphism and structural complexity, and availability of interpreted MT data. Lower layers of an Earth resistivity model, comprising the mantle, tend to be more homogenous over a broader scale. Also, because the resolution of MT data decreases with depth the changes of resistivity between adjacent Earth resistivity models along a pipeline route is greater for the upper layers than for deeper layers. The end result is greater non-uniformity of resistivity in the upper crust layer along the pipeline route.

For the mid-to-lower crust and mantle the assumption was made that the resistivity does not vary much, and therefore resistivity values obtained from a crustal transect can be extended to areas on the pipeline route distant from the actual transect location where the MT sounding was made. Hence, mid-to-lower crust and mantle sensitivities for the 1D Earth resistivity models prepared for the Alaska Highway Corridor and Mackenzie Valley Corridor were extrapolated from regional MT surveys often quite distant to the location of a particular 1D Earth resistivity model.

Layer depths for overburden, including permafrost, were obtained from surgical geology maps that provide general estimates of deposit thickness. Permafrost depths were also presented on some stratigraphic compilation maps of the Alaska North Slope, 
the extensive coastal plains and low rolling hills stretching from the Brooks Mountain Range northward to the Arctic Ocean. The North Slope hosts considerable petroleum reserves and production areas. Sedimentary basin depths were obtained from stratigraphic cross-sections (compiled from well logs) and general basin thickness maps. These cross-sections and maps provided the thicknesses of the sedimentary formations and depth to the crystalline basement rocks. Published crustal cross-sections were used to determine the Moho (crust / mantle boundary) depth, and are based on extensive seismic surveying and interpretation. The 100,400 and $600 \mathrm{~km}$ depths of each mantle division are the generally accepted depths in the geological literature. Detailed descriptions and particular references are given in the following chapters for each of the three study areas.

\subsubsection{MT Field Work}

As part of this research project, MT soundings were undertaken by this author and field assistants in two of the study areas. The purpose was to map the underlying electrical resistivity and obtain measurements of the surface geoelectric field. A MT transect, completed in 2006 on the proposed Mackenzie Valley pipeline route, consisted of six widely-spaced stations, extending from the Mackenzie Delta coastline southward to Fort Simpson. Multiple MT surveys, in conjunction with PSP surveys, were completed in the Ottawa Valley pipeline study area over a six year period from 2003 to 2009, encompassing 39 MT stations in total.

A commercially available 5-component MT central processing unit (Phoenix Geophysics MTU-5A system) was used to measure simultaneously the surface geoelectric field in two orthogonal directions $\left(E_{x}, E_{y}\right)$ as well as the horizontal $\left(H_{x}, H_{y}\right)$ 
and vertical $\left(H_{z}\right)$ components of the magnetic field. The surface geoelectric field was measured using electrodes at the ends of $100 \mathrm{~m}$ long wire dipoles forming a cross pattern. The three orthogonal components of the geomagnetic field were measured by induction coils. Two frequency ranges were recorded. For the MT frequency band $(0.001-400 \mathrm{~Hz})$, the sampling frequencies are: continuously at $15 \mathrm{~Hz}$, and periodically at 150 and 2400 Hertz, in snapshots of $16 \mathrm{~s}$ and $2 \mathrm{~s}$ duration, respectively. For the AMT frequency band $\left(10-10^{4} \mathrm{~Hz}\right)$, the instrument samples the five components at three different sampling frequencies: continuously at $150 \mathrm{~Hz}$, and periodically at 2400 and $24000 \mathrm{Hertz}$ in snapshots of $2 \mathrm{~s}$ and $0.1 \mathrm{~s}$ duration, respectively. Unless specifically mentioned in the text from here on, the term MT refers to both AMT and MT frequency ranges.

At each sounding site, both the AMT and MT variations of the geoelectric and geomagnetic field were recorded. One central processing unit was fitted with three long MTC-50 coils to record the three components of the magnetic field at MT frequencies. A second central processing unit was fitted with two shorter MTC-30 coils to measure the two horizontal components of the magnetic field at AMT frequencies. The central processing units shared a single-set of orthogonal electric lines used to measure the geoelectric field, with the electrical signal being relayed between the two units using jumper cables. Figure 2.2 illustrates the layout of the MT instruments for a combined AMT and MT sounding, and Figure 2.3 provides photographs of instrument components.

For MT surveying undertaken in both the Mackenzie River and Ottawa Valley study areas, recordings were done simultaneously at two widely-spaced sounding sites (25 to $100 \mathrm{~km}$ for Mackenzie; 5 to $75 \mathrm{~km}$ for Ottawa) to enable use of the remotereference noise reduction technique (Gamble et al., 1979) which is used to attenuate 


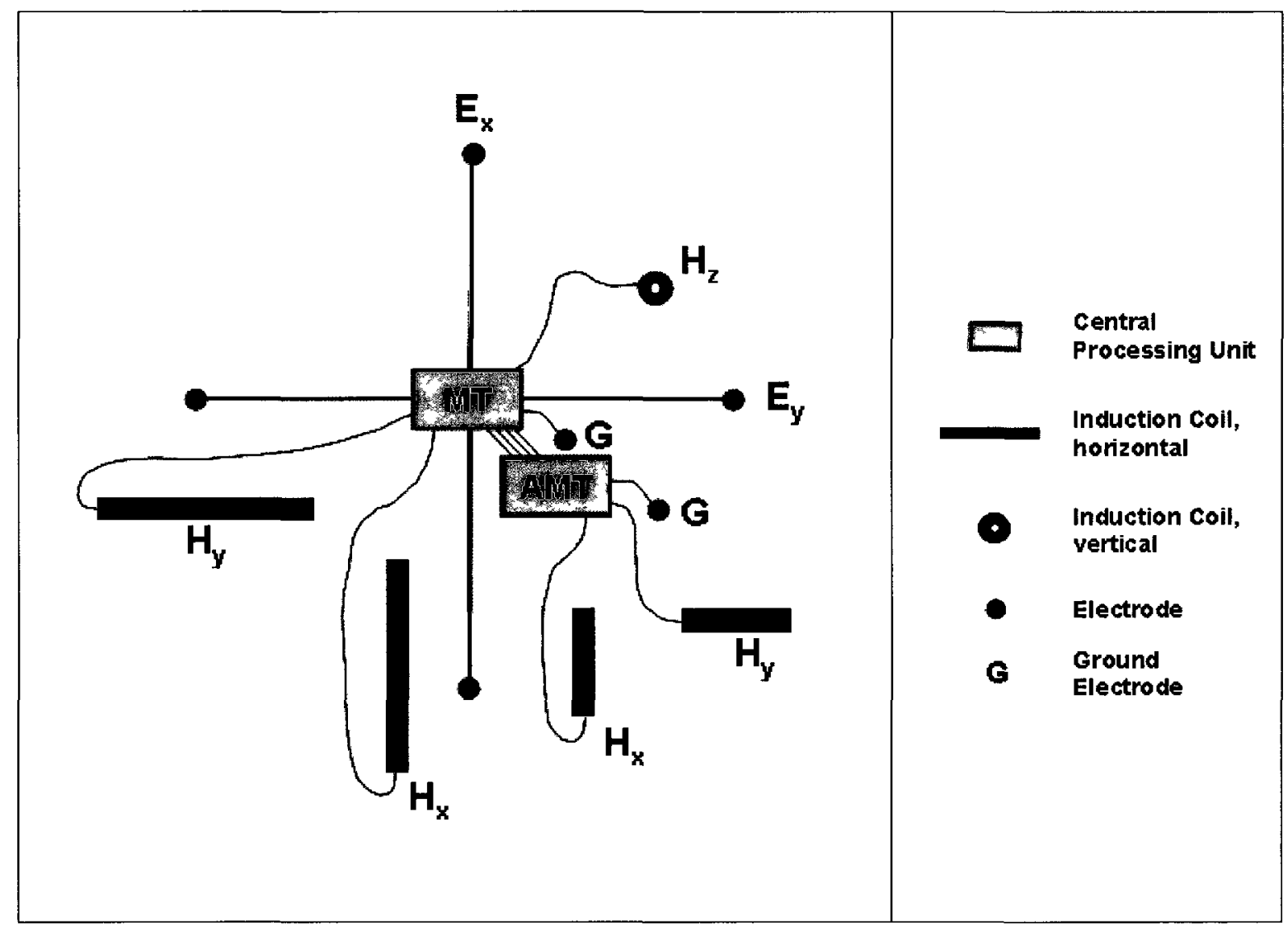

Figure 2.2. Schematic showing the field layout for a combined AMT and MT recording (after Fernberg et al, 2006). Not to scale. 

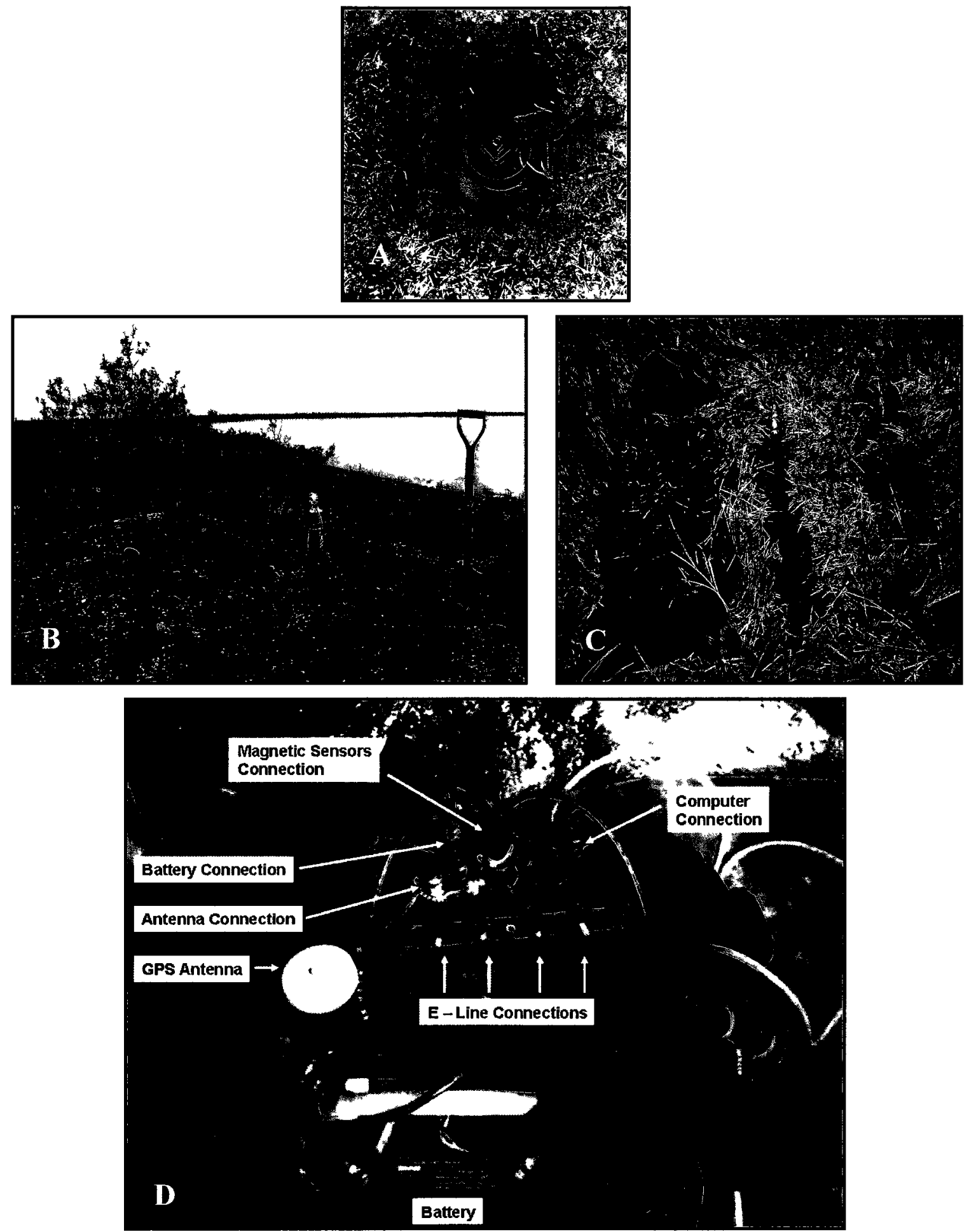

Figure 2.3. Photographs showing components of the Phoenix Geophysics MTU-5A magnetotelluric instrument: A, buried electrode in wetted soil; B. buried, vertical induction coil; $\mathrm{C}$, buried, horizontal induction coil; and, D, central processing unit with battery and GPS receiver (Folta, 2004, Fig. 2.3). 
cultural EM interference (e.g. electrical fences, power lines) that can contaminate the recorded natural signals. EM noise sources were more of an issue in populated eastern Ontario than in northern Canada. Recordings were also done overnight when geomagnetic activity is strongest (Beamish et al., 2002; Milan, 2007) and were typically of 11 to 18 hours duration.

\subsubsection{Permanent Geomagnetic Observatories}

Geomagnetic data, covering the period 1975 to 2007, were obtained from Natural Resources Canada, Geomagnetic Laboratory, located in Ottawa. The data were recorded at American and Canadian geomagnetic observatories closest to the three study areas (Figure 1.1). Recordings consist of three components of the magnetic field, $\mathrm{X}$ (northward), Y (eastward) and Z (vertically down).

Canadian and American observatories sample the magnetic field components at 8 $\mathrm{Hz}$ using a Narod Geophysics ring-core fluxgate magnetometer (Intermagnet, 2010). A 9-point boxcar filter is applied to the $8 \mathrm{~Hz}$ data to produce a $1 \mathrm{~Hz}$ data set. Then, the 1 $\mathrm{Hz}$ data are further filtered using a 49 point Gaussian filter, and resampled at intervals of 5 seconds. The 5 -second data streams are then filtered using a 19 point Gaussian filter and resampled at 1 minute intervals (Geol. Surv. of Cdn, 2010). The 1-minute data set is the standard for digitally filtered samples issued by the INTERMAGNET worldwide consortium of geomagnetic observatories. Both 1-second and 1-minute geomagnetic data were utilized as input into the geoelectric field model.

\subsubsection{PSP Surveys}

PSP data were recorded only in the Ottawa Valley Pipeline study area, concurrently with the MT soundings in 2003, 2005, 2006 and 2009. The purpose was to 
determine if PSP and MT recordings were capturing the same geoelectric field variations, and to confirm the location along the pipeline where anomalously large PSP had previously been identified.

PSP measurements, for survey years 2003, 2005 and 2006 were collected by field assistants on behalf of the author. PSP data were measured using commerciallyavailable, small portable data loggers (Tinker-Rasor DL-1) connected to pre-existing test posts along the pipeline, as shown in Figure 2.4. PSP measurement over the entire length of the study pipeline, at 1 to $2 \mathrm{~km}$ spacing, in one day would have required a large number of data loggers. Instead, each day's PSP recordings - made at mobile PSP sites were compared to a reference PSP site.

The direct-current (DC) voltage difference between the steel pipeline and a reference $\mathrm{Cu} / \mathrm{CuSO}_{4}$ electrode placed in surrounding soil was recorded at a pre-selected sampling rate of $5 \mathrm{~Hz}$. Recording duration coincided with the geoelectric field measurements obtained by MT instruments. Timing of each sample was achieved by an internal clock, which sometimes was not perfectly synchronized with the GPS time stamps used by the MT instruments. This resulted in a time lag between the PSP and MT recordings.

\subsection{Data Processing and Analysis}

Processing and analysis of MT, geoelectric field and PSP data were undertaken by the author, with results of the statistical analysis performed by the Ottawa Geomagnetic Laboratory being supplied to the author. Detailed statistical analysis of geomagnetic conditions and telluric activity for the Alaska Highway Corridor study area can be found in Assessment of Telluric Current Effects on Proposed Alaska Highway Pipeline, by 

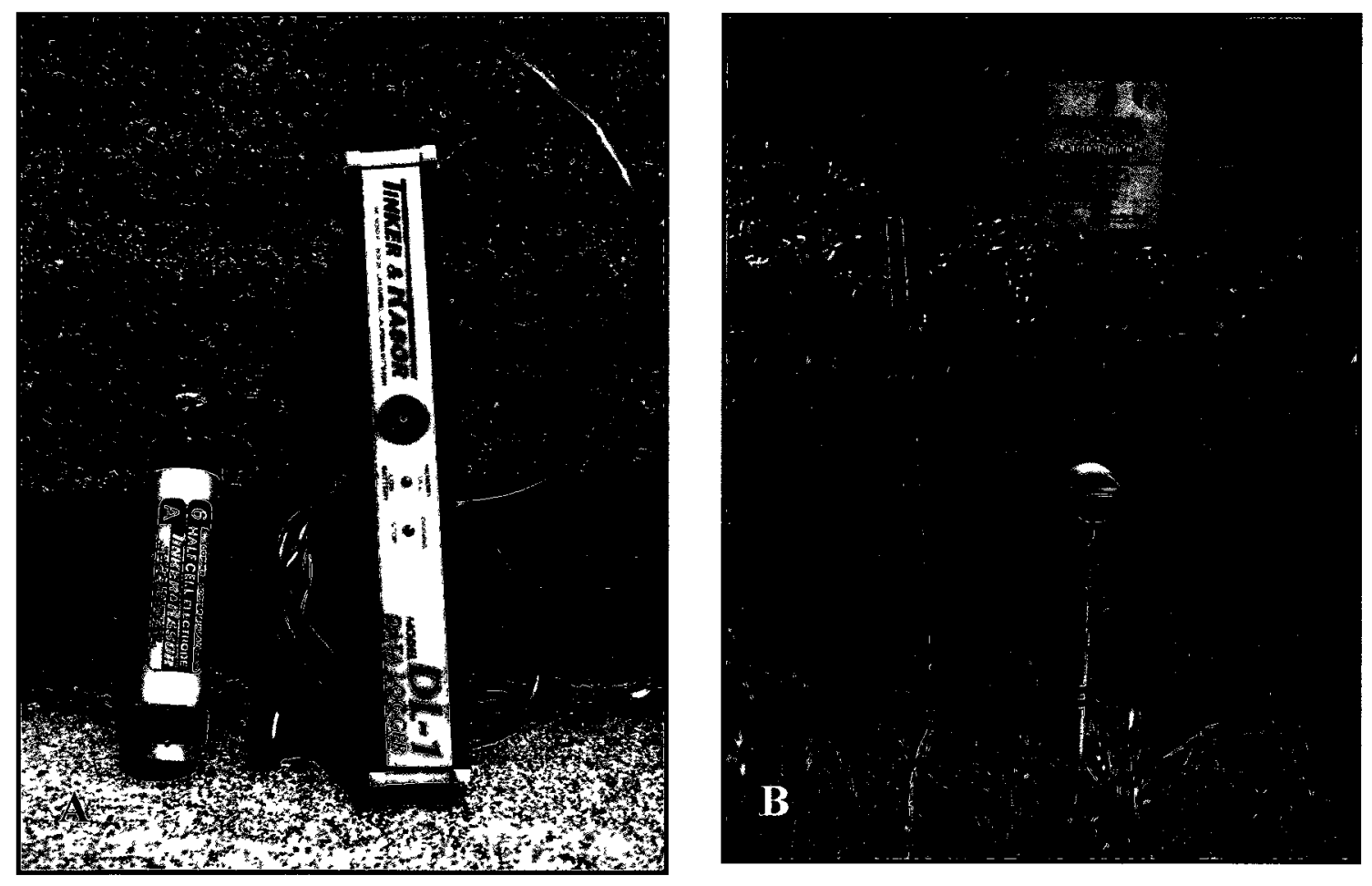

Figure 2.4. Photographs showing: A, Tinker-Rasor DL-1 digital data logger (right) and a $\mathrm{Cu} / \mathrm{CuSO}_{4}$ electrode (left); and, $\mathrm{B}$, pipeline test post, with data logger attached to backside of post. 
Boteler, D.H., Trichtchenko, L., Fernberg, P., and Harrison, M., 2009; and, for the Mackenzie River Valley study area in Study of Telluric Current Impacts on the Mackenzie Gas Project Pipeline, by Boteler, D.H., Trichtchenko, L., and Fernberg, P., 2005. Data processing and analysis for the Ottawa Valley study area were initially presented in Quantitative Analysis of the Earth Conductivity Structures and their Effects on Pipe-to-Soil Potentials along the TransCanada Mainline at Arnprior, Ontario, by Samson, C., Fernberg, P., Trichtchenko, L., and Boteler, D.H., 2006, and in Fernberg et al. (2007).

\subsubsection{MT Processing and Inversion (1D, 2D)}

The raw time series MT data underwent multiple processing steps to remove errors and extraneous EM noise interference to obtain reliable apparent resistivity and phase information. This was then used as an input to obtain an inversion model that depicts change of resistivity with depth, either vertically only (the $1 \mathrm{D}$ model) or both vertically and laterally in one specified direction (the $2 \mathrm{D}$ model). $1 \mathrm{D}$ inversions were prepared for the Mackenzie Valley study area, whereas 2D inversion of MT survey data was only completed for the Ottawa Valley study area because a sufficient coverage of soundings sites was available. Commercial software was used to perform all stages of data processing and inversion.

The SSMT2000 ${ }^{\circledR}$ software from Phoenix Geophysics was used to Fourier transform the raw time series data (at several sampling rates) into the frequency domain and to compute impedances. The software allows for a variety of robust processing routines to reduce the effect of noise in the data. Then the Phoenix Geophysics MTEdit ${ }^{\circledR}$ software was used to edit out poor quality data, display the impedance as apparent 
resistivity and phase response curves and other computed parameters, and prepare electronic data files for export to geophysical interpretation software. Sounding sites where the data quality was poor or incomplete were excluded from further analysis and inversion.

To produce layered Earth resistivity models, the WinGLink ${ }^{\circledR}$ software from Geosystem srl, Milan, was used to compute 1D and 2D MT inversions. WinGLink calculates both 1D layered inversion and smooth Occam 1D inversion models (developed by Constable et al., 1987) using the apparent resistivity and phase curves. The inversions were run using the software's defaults settings until pre-set conditions minimizing the differences between model and actual data are achieved. For a 2D inversion, WinGLink incorporates the algorithm developed by Rodi and Mackie (2001). It is an iterative process that finds regularized solutions for impedance data using the method of nonlinear conjugate gradients (Geosystem, 2003). Further description of data processing, issues and results can be found in Chapters 4 and 5 .

\subsubsection{Geoelectric Field Data and PSP Data Processing}

A computer program, prepared by the Ottawa Geomagnetic Laboratory, was used to convert the MT geoelectric and geomagnetic field data (15 Hz sampling) from the instrument's internal binary format. Then the $15 \mathrm{~Hz}$ data was downsampled using a cosine bell filter to reduce the sampling down to a 1-second data set compatible with the 1-second geomagnetic observatory data. Recorded 5-second PSP data was also filtered in the same manner and downsampled to frequency of $1 \mathrm{~Hz}$ to be compatible with the results of numerical modelling. 


\subsubsection{Statistical Analysis}

Archival records of geomagnetic data, in combination with layered Earth resistivity models supplied by the author, underwent a statistical analysis by the Ottawa Geomagnetic Laboratory. Geomagnetic 1-minute data were first converted to an hourly range index, the difference between the maximum and minimum in one hour. Then a statistical distribution of the hourly indices was plotted for one representative year, from which levels corresponding to different probabilities of exceedance were chosen. This was done for geomagnetic observatories located proximal to the Alaska and Mackenzie study areas, as a means to describe the geomagnetic activity over sections of the respective pipeline routes.

To evaluate the telluric activity, the modelled geoelectric field values computed from geomagnetic and surface impedance data (refer to following description of numerical models) were used in a similar way. Indices of telluric activity, such as hourly maximum value and hourly standard deviation were produced and their distributions plotted. Different levels of exceedance were chosen on the basis of the statistical distribution. Chapters 3 and 4 provide detailed examples.

\section{$2.4 \quad$ Numerical Models}

Four different numerical models (Figure 2.1) developed by others were used for this thesis. A brief description of the physical principles and main governing equations are presented below. Use of the numerical models followed a sequential approach. First was the construction of Earth resistivity models for various zones along the pipeline routes, either based on a literature compilation or from MT survey results. Then the surface impedance was computed, using as an input these theoretical Earth resistivity 
models derived from geological literature and/or geophysical data sources, followed by computation of the geoelectric field model and finally application of the pipeline model to produce the PSP variations.

To test the pipeline model, PSP variations calculated using the numerical pipeline model, were compared with observed PSP data from a PSP survey. This was only done for the Ottawa Valley study area where a pipeline exists.

\subsubsection{Theoretical 1D Layered Earth Resistivity Models}

Based on the literature review, the pipeline routes in the Alaska Highway and Mackenzie Valley study areas were divided into a series of zones that reflect significantly different geological realms which in turn would manifest themselves as zones of differing resistivity. The identification of a zone was based on the concept of geological terranes where a terrane represents a region of the Earth's crust characterized by a distinctive assemblage of rock that is different from its neighbours. Terranes are typically fault bounded. For each zone, an Earth resistivity model was produced. Thus, lateral resistivity changes are taken into account by the changes in the resistivity models from zone to zone. Each 1D model is comprised of a series of layers, showing the thickness and resistivity, extending from Earth's surface through the crust and into the mantle.

The $1 \mathrm{D}$ model approach is the simplest means to broadly assign resistivity values to any particular layer. Such an approach avoids geological complexity which commonly varies in rock type and thickness both vertically and laterally. Although a $1 \mathrm{D}$ model is unlikely to represent the true complex $3 \mathrm{D}$ resistivity of the underlying Earth, it can be used to determine the extent to which telluric currents can be modified by gross changes of resistivities within the Earth. 


\subsubsection{Geoelectric Field Modelling}

Geoelectric field data is one of the inputs (other inputs being the pipeline's physical characteristics) required to model PSP variations. In areas where MT data are not available, the geoelectric field can be modelled. To compute the modelled geoelectric field, there are two information requirements: the Earth's surface impedance and geomagnetic data for the geographic location of interest.

At the frequencies of geomagnetic field variations $\left(10^{-5}\right.$ to $\left.1 \mathrm{~Hz}\right)$, the penetration depth of an electromagnetic signal within the Earth extends to hundreds of kilometers, through the entire crust and into the mantle. Hence, the resulting surface geoelectric field is influenced by the combined response of all above mentioned layers. Therefore the resistivity of the Earth down to these depths has to be taken into account in calculating the relation between the geoelectric and geomagnetic fields at the surface.

One-dimensional variation of resistivity with depth within the Earth can be modelled using multiple horizontal layers with different uniform conductivities (inverse of resistivity) with the last layer as a uniform half-space. Simulation of the geoelectric field is based on the approach of using a simple plane wave (uniform in both the $x$ and $y$ directions) propagating down into the Earth through layers with different resistivities (presented in the following equations as the inverse parameter, conductivity). These descriptions that can be found in many fundamental reference books on geomagnetism and magnetotelluric methods (Schelkunoff, 1943; Wait, 1982).

In the following equations, a coordinate system with $x$ axis pointing north, the $y$ axis pointing east, and the $z$ axis pointing vertically downwards has been used. Changes 
of the electric $(E)$ and magnetic $(H)$ fields in the frequency domain with the depth $(z)$ can be given by diffusion equations:

$$
\begin{aligned}
& \frac{d^{2} E}{d z^{2}}=i \omega \mu \sigma E \\
& \frac{d^{2} H}{d z^{2}}=i \omega \mu \sigma H
\end{aligned}
$$

where $E$ and $H$ is the electric and magnetic field in each layer, $\mu$ is the permeability of the layered Earth, $\sigma$ is the conductivity of each layer, and $\omega$ is the wave frequency.

When propagating downward through a layered Earth with different resistivities for each layer $n$, the electromagnetic wave partially continues its propagation and partially is reflected; thus the solution for each layer $n$ can be presented as the sum of propagating and reflected waves, as follows (Kaufman and Keller, 1981, p.44):

$$
\begin{aligned}
& E_{n}(z, \omega)=A_{n}(z, \omega)\left(e^{-k_{n} z}+r_{n}(z, \omega) e^{k_{n} z}\right) \\
& H_{n}(z, \omega)=A_{n}(z, \omega)\left(\frac{e^{-k_{n} z}}{Z_{n}(z, \omega)}-r_{n}(z, \omega) \frac{e^{k_{n} z}}{Z_{n}(z, \omega)}\right) ; n=1, N
\end{aligned}
$$

where $A_{n}(z, \omega)$ is the wave amplitude in layer $n$ and $r_{n}(z, \omega)$ is the reflection coefficient at layer interface $n$, and $k_{n}=\sqrt{i \omega \mu \sigma_{n}}$ is the propagation constant, and $Z_{n}(z, \omega)$ is the impedance (ratio of the electric and magnetic fields) for layer $n$. This is described further in section 2.4.3.

For each of the study areas, the geomagnetic field at the surface of the Earth, i.e. layer $1, H_{I}(\omega)$ is known from magnetic observations, and the geoelectric field at the surface $E_{l}(\omega)$ can be obtained as:

$$
E_{1}(\omega)=Z_{1}(\omega) H_{1}(\omega)
$$


if the surface impedance $Z_{I}(\omega)$ (ratio of the geomagnetic and geoelectric field) is known from other relationships.

Figure 2.5 shows the sequence of operations to compute the geoelectric field at Earth's surface:

i) Conversion of the geomagnetic data from time into frequency domain using a Fast Fourier Transformation (FFT).

ii) Multiplication by the surface impedance (in frequency domain), obtained from a 1D Earth resistivity profile of particular area.

iii) Inverse Fourier transform $\left(\mathrm{FFT}^{-1}\right)$ of geoelectric data expressed in frequency domain into time domain.

Therefore, the amplitude of the geoelectric field produced during a geomagnetic disturbance is dependent on the magnitude and frequency of the geomagnetic field variations $H$ and the Earth's surface impedance $Z$, which is itself frequency dependent.

\subsubsection{Surface Impedance Modelling}

Surface impedance $Z_{I}$ represents the transfer function between geomagnetic variations and geoelectric field at the Earth's surface. It can either be calculated or directly obtained from MT data. Impedance $Z_{n}$ at any layer $n$ can be found from a layered Earth resistivity model by applying the recursion relation for the impedance of a $N$-layered half-space (Weaver, 1994):

$$
Z_{n}=i \omega \mu\left(\frac{1-r_{n} e^{-2 k_{n} l_{n}}}{k n\left(1+r_{n} e^{-2 k_{n} l_{n}}\right)}\right), n=1, N
$$




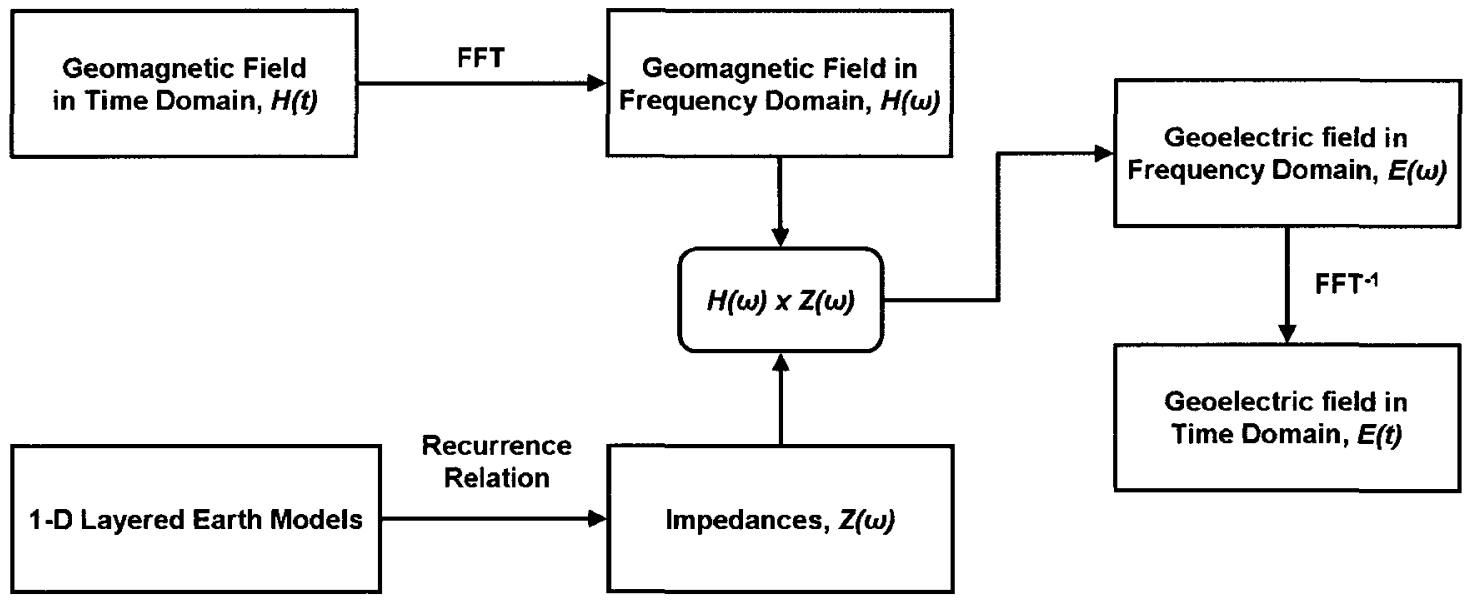

Figure 2.5. Calculation of the geoelectric field from the geomagnetic field and a layered 1D Earth resistivity model (Boteler et al., 2009, Fig. 4.1). 
where $l_{n}$ is the thicknesses of the layer $n, k_{n}$ is the propagation constant of layer $n$ and reflection coefficient $r_{n}$ is defined as:

$$
r_{n}=\frac{1-k_{n} \frac{Z_{n-1}}{i \omega \mu}}{1+k_{n} \frac{Z_{n-1}}{i \omega \mu}}
$$

Assuming the bottom layer $N$ is a uniform half-space layer, there is no reflection, therefore impedance for the bottom most layer can be found explicitly as:

$$
Z_{N}=\frac{i \omega \mu}{k_{N}}
$$

\subsubsection{Pipeline Modelling}

The effect of telluric currents on a real pipeline or a pipeline network can be modelled by the distributed-source transmission line (DSTL) theory first described by Schelkunoff (1939). DSTL theory has been used to study alternating-current (AC) induction in pipelines (Taflove and Dabkowski, 1979) and was adapted by Boteler and Cookson (1986) to investigate geomagnetic induction in pipelines. Further testing of the DSTL pipeline model involving pipelines in Nordic countries was completed by Boteler and Trichtchenko (2000). In the DSTL approach, the pipeline is represented as a set of small electrical circuits with specific series impedances (the steel of the pipe) and admittances (coating on the pipe), and an electrical power source which corresponds to the natural geoelectric field (Figure 2.6). The geoelectric field is represented as voltage sources distributed along the transmission line.

The basic equations (Trichtchenko and Boteler, 2002) describing the voltage $\left(V_{p}\right)$ 

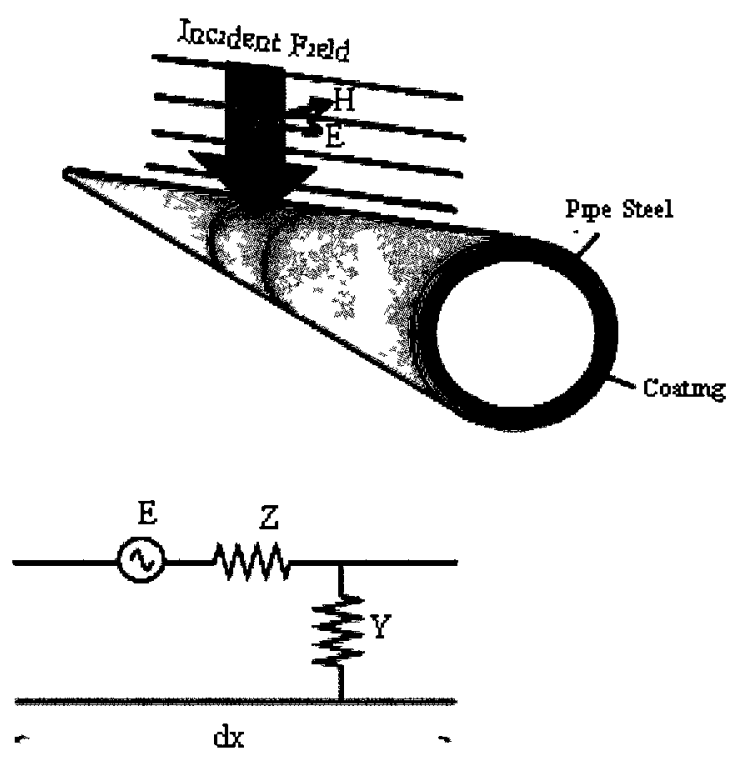

Figure 2.6. Schematic of the DSTL model of pipeline including distributed voltage sources representing the induced geoelectric field (Trichtchenko and Boteler, 2002, Fig.6). Abbreviations: $\mathrm{H}$, geomagnetic field; $\mathrm{E}$, geoelectric field; $\mathrm{Y}$, parallel admittance; and $Z$, series impedance. 
and current $\left(I_{p}\right)$ produced in any small section of the pipeline $\left(d_{x}\right)$ by a geoelectric field $E_{p}$ are following from Kirchoff's rules as:

$$
\begin{aligned}
& \frac{d^{2} V_{p}}{d x^{2}}-\gamma^{2} V_{p}=\frac{d E_{p}}{d x} \\
& \frac{d^{2} I_{p}}{d x^{2}}-\gamma^{2} I_{p}=-Y E_{p}
\end{aligned}
$$

where $\gamma$ is the propagation constant along the pipeline, defined as $\gamma=\sqrt{Z Y}, \mathrm{Y}$ is the parallel admittance (conductance to ground of the pipeline coating), and $Z$ is series impedance (resistance of the pipeline steel) per unit length.

For each point with coordinate $x$ along the pipe, the solutions of equations (2.9) and (2.10) for the section of the pipeline with uniform geoelectric field are:

$$
\begin{aligned}
& V_{p}=\frac{E_{p}}{\gamma}\left(A_{p} e^{-\gamma\left(x-x_{1}\right)}-B_{p} e^{-\gamma\left(x_{2}-x\right)}\right) \\
& I_{p}=\frac{E_{p}}{\gamma Z_{c}}\left(1+A_{p} e^{-\gamma\left(x-x_{1}\right)}+B_{p} e^{-\gamma\left(x_{2}-x\right)}\right)
\end{aligned}
$$

where $x_{1}$ and $x_{2}$ are the positions of the ends of the pipeline, $A_{p}$ and $B_{p}$ are constants dependent on the boundary conditions at the ends of the pipeline, $Z_{c}=\sqrt{Z / Y}$ is the characteristic impedance of the pipeline, typically $1-2$ ohms (Trichtchenko and Boteler, 2002). Hence, the derived $V_{p}$ represents the PSP variations and $I_{p}$ represents the amount of current along the pipeline. 
The termination at the end of any pipeline section may be other sections of pipe, perhaps with different electrical properties, and each experiencing the induced geoelectric field. Calculations start from the last section of pipeline using the known resistance to ground and geoelectric field in it; see Boteler (1997), Boteler and Seager (1998) and Boteler (2000) for details.

Telluric currents can enter and leave the highly conductive pipeline at any ground (soil) connection (such as holidays or grounding wires), at the ends of the pipeline or through coating admittance. A PSP exists and varies wherever the current flows on and off the pipeline. According to DSTL theory and observations (Boteler and Seager, 1998; Gummow et al., 2001) the largest PSP variations occur at the ends of the pipeline, and exhibit opposite sign at each end. At the pipe end where PSP is negative with respect to surrounding ground the telluric current flows onto the pipe, and flows off the pipe at the other end where the PSP is positive. Depending on the local ground resistance at pipe ends, the PSP can conceivably exceed the desired range of cathodic protection (Boteler et al., 2009). A change of pipeline orientation, with respect to the driving geoelectric field, results in a difference of geoelectric field on either side of the bend with extra current flowing to ground thus creating additional voltage (i.e. PSP) at the bend that which falls off exponentially with distance away from the bend (Gummow et al., 2001).

Because the geoelectric field input into the DSTL pipeline model is dependent on the Earth resistivity values (obtained from models or physical measurements) for any existing or proposed pipeline, then a theoretical PSP can be calculated for any specific location along the pipeline network. Changes of underlying Earth will be reflected as changes to the calculated PSP as a function of distance along the pipeline. 


\section{CHAPTER 3}

\section{ALASKA HIGHWAY CORRIDOR}

\subsection{Overview and Objectives}

An obvious area to study telluric current effects on pipelines is in the auroral zone, encompassing northern Canada and Alaska, where telluric currents are significant due to the considerably larger variations of the natural geomagnetic field. Figure 3.1 illustrates the difference of geomagnetic activity between the auroral zone (representative conditions measured at the Yellowknife Geomagnetic Observatory) and a low-latitude location in the sub-auroral zone (Ottawa Geomagnetic Observatory), for year 2004, an example of a typical year punctuated by several significant magnetic storms. It is in the sub-auroral zone where much of Canada's pipeline network is situated.

The first investigations (Campbell, 1978, 1980) of the effects of telluric currents on pipelines located in northern regions were made in Alaska, and the concern that strong induced currents generated during large, and common, geomagnetic disturbances can strongly interfere with corrosion protection of pipe steel still remains today. This is especially true in view of the proposed Alaska Highway Corridor (AHC) pipeline which would transport natural gas from the North Slope of Alaska to major markets in southern North America via a $2800 \mathrm{~km}$ long buried pipeline (TransCanada, 2010). Starting at Prudhoe Bay, the pipeline route extends about $1200 \mathrm{~km}$ through the State of Alaska and then continues another $1600 \mathrm{~km}$ in Canada, through Yukon Territory and part of northern British Columbia, terminating at Boundary Lake, Alberta, where the pipeline joins an existing continental pipeline distribution network (Figure 3.2). Between Prudhoe Bay and Big Delta, Alaska, the gas pipeline will follow the existing crude oil Trans-Alaska 

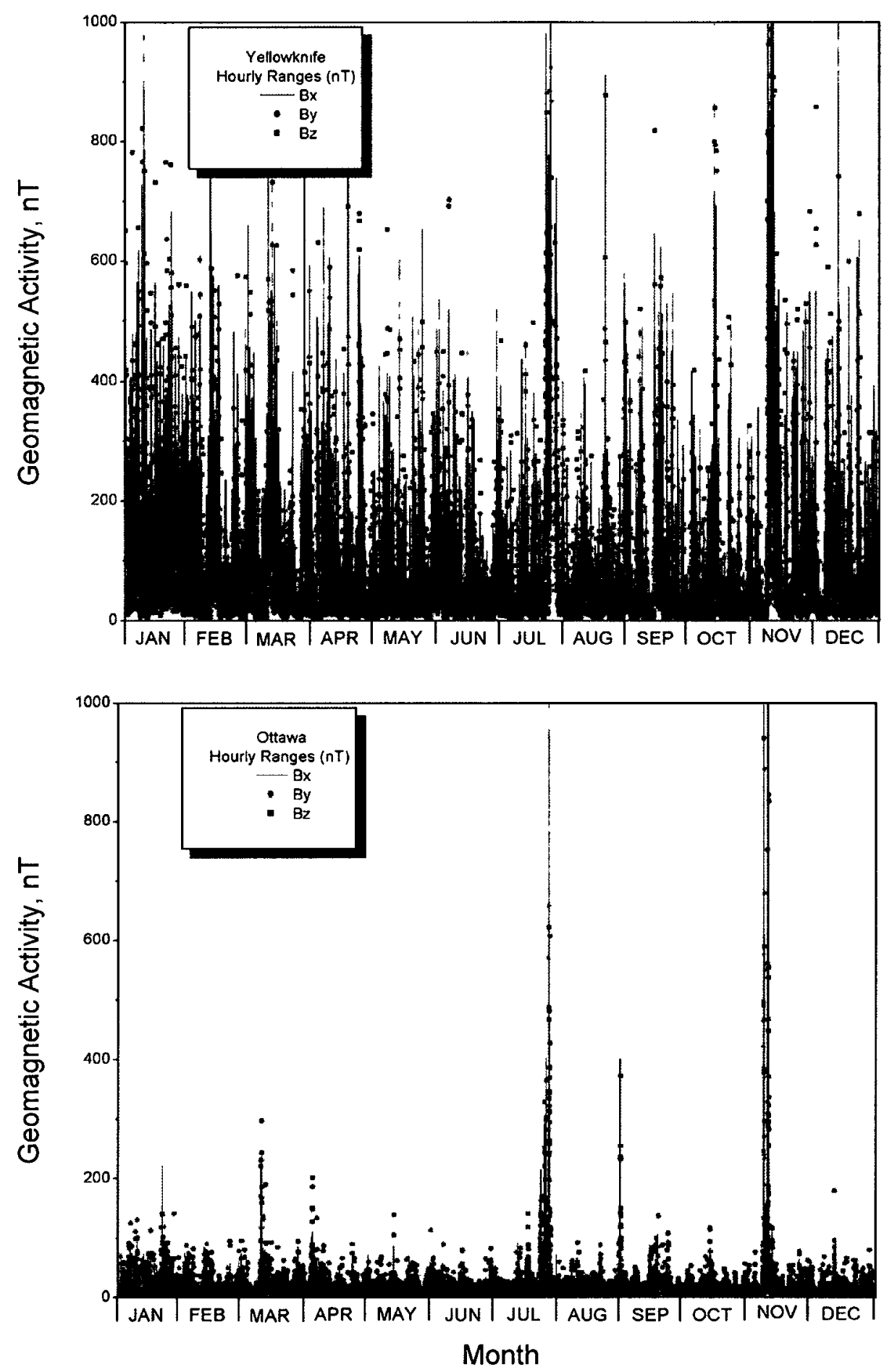

Figure 3.1. Annual geomagnetic activity indices from year 2004 at the (top) Yellowknife Geomagnetic Observatory $\left(62.480^{\circ} \mathrm{N}\right.$, $114.482^{\circ} \mathrm{W}$ ) in the auroral zone and in (bottom) Ottawa Geomagnetic Observatory $\left(45.403^{\circ} \mathrm{N}, 75.552^{\circ} \mathrm{W}\right)$ at a lower latitude, in the subauroral zone (Boteler et al., 2005, Figs. $2.2 \& 2.3$ ). 


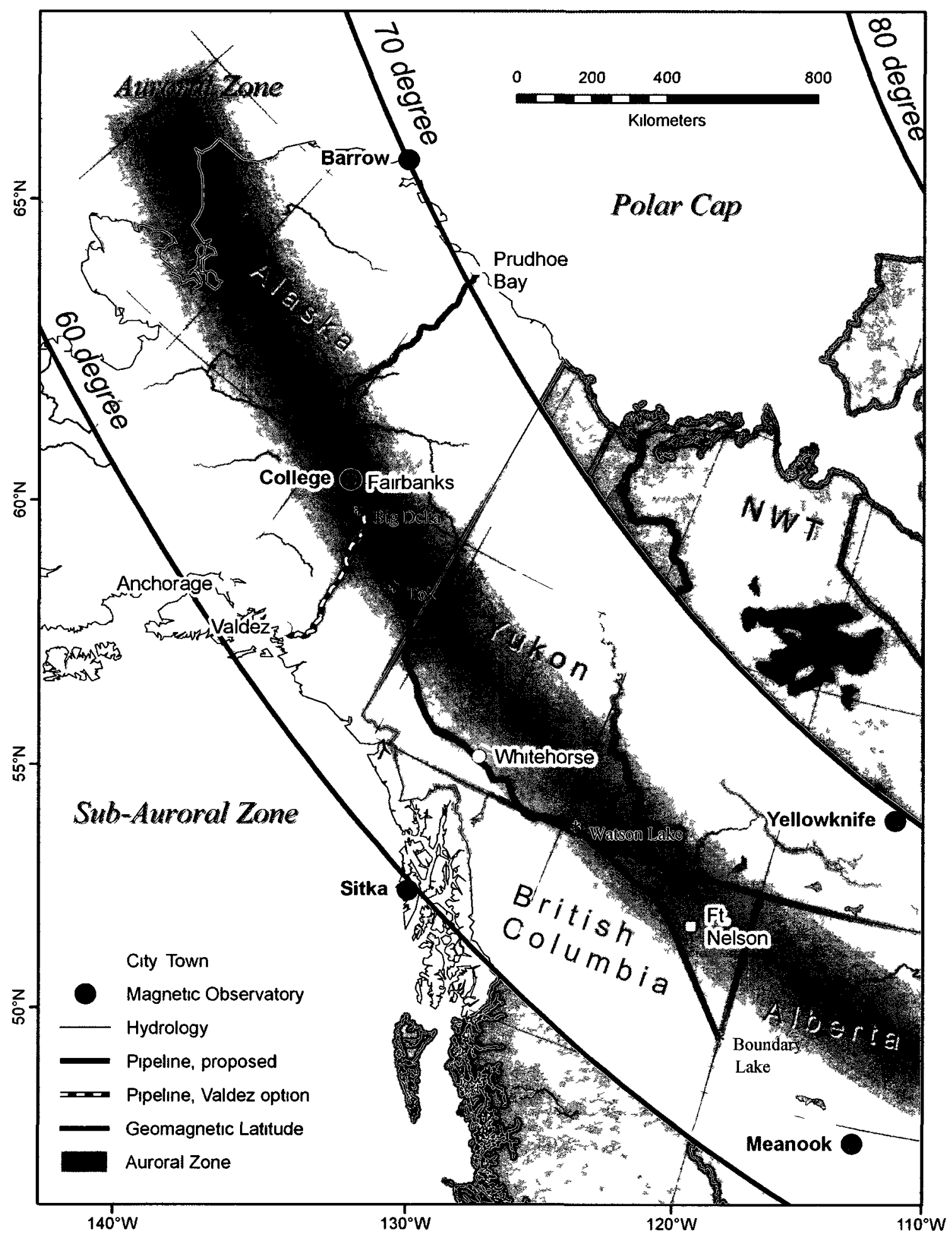

Figure 3.2. Route of the proposed Alaska Highway Corridor natural gas pipeline in relation to the three major zones of geomagnetic activity. 
pipeline right-of-way. The entire proposed route for the pipeline takes it through much of the geomagnetically active auroral zone where the geomagnetic field is more intense than in the polar cap and sub-auroral zones. As a consequence, the larger telluric currents induced in the pipeline should result in significantly high amplitude pipe-to-soil potential (PSP) variations (Campbell, 1980; Shapka, 1992; Camitz et al., 1997; Pirjola et al., 2000). In order to assess the scale and location of PSP variations along the proposed AHC route, and the connection between PSP and the underlying Earth resistivity structure, a study was initiated and which is described in this chapter.

This chapter is partly based on a report completed by the Geomagnetic Laboratory, Ottawa, (Assessment of Telluric Current Effects on Proposed Alaska Highway Pipeline, by Boteler, D.H., Trichtchenko, L., Fernberg, P., and Harrison, M., 2009). The author of this thesis was responsible for all matters related to the geological considerations and determination of the resistivity structure along the pipeline route, on which all subsequent aspects of the Ottawa Geomagnetic Laboratory's report depended.

First, in this chapter, a brief analysis of the geomagnetic activity in the pipeline area is provided. A main portion of the chapter is devoted to a detailed description on how geological and geophysical information was used to prepare one-dimensional (1D) models of the Earth resistivity, which are used as an input into the modelling of the geoelectric field and PSP. A review of publicly-available information was undertaken, and included government geological reports and maps including on-line resources, soilengineering studies of the Trans-Alaska Pipeline, and scientific journals. The focus was on identifying previous geophysical surveys, undertaken as part of crustal investigations, which provide measurements of subsurface electrical resistivity, and to obtain 
information on the thickness of the crust. Other data, such as geomagnetic variations recorded at government observatories within the region, exist and are available on-line from the Geological Survey of Canada (GSC, 2010) and United States Geological Survey (USGS, 2010).

Based on the results of the literature review, the pipeline route was divided into a series of zones that reflect significantly different geological realms which in turn would manifest themselves as zones of differing resistivity. For each zone, a 1D Earth resistivity model was constructed in which the resistivity changed as a function of depth, extending from Earth's surface through the crust and into the mantle. Lateral variations of resistivity are taken into account only by the changes between different Earth resistivity models from zone to zone. A review of past geophysical surveys used in constructing the 1D Earth resistivity models is presented. A description of each model constructed for the eight different resistivity zones identified along the pipeline route are presented. An appendix provides tables detailing the information sources and justifications for resistivity values and layer thicknesses chosen for each of the models. Finally, the results of modelling the geoelectric field, based on the developed Earth resistivity models, and effects of telluric activity on pipeline are presented and discussed.

\subsection{Geomagnetic Activity}

\subsubsection{Local Geomagnetic Activity Levels}

Statistical analysis of the geomagnetic activity covering the pipeline route has been done (Boteler et al., 2009) using data from five American and Canadian geomagnetic observatories (Figure 3.3), namely Barrow, College, Yellowknife, Meanook 


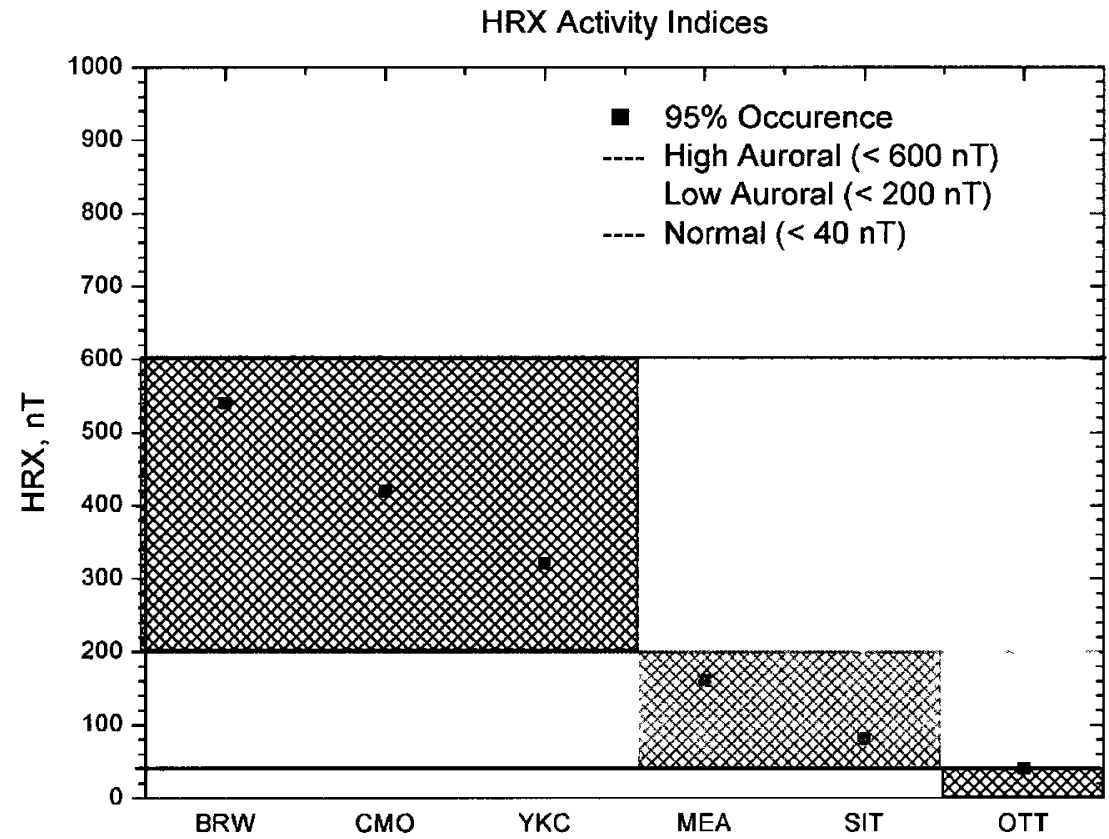

Figure 3.3. Activity indices derived from $95 \%$ occurrence levels of HRX, at six different geomagnetic observatories (after Boteler et al., 2009, Fig. 2.6). Abbreviations: Barrow (BRW), College (CMO), Yellowknife (YKC), Meanook (MEA), Sitka (SIT), and Ottawa (OTT). 
and Sitka, all within the auroral zone. Data from the geomagnetic observatory in Ottawa provides an additional comparison with sub-auroral geomagnetic activity. To describe the geomagnetic variations, one-minute geomagnetic data were used to calculate an hourly range index in the north-south component of the geomagnetic field (HRX), defined as the difference between maximum and minimum values in the same hour.

To establish the activity levels, the year 2004 was selected as being representative of typical geomagnetic activity. The HRX direction was chosen because it creates a geoelectric field in the east-west direction which coincides with alignment of the pipeline route, resulting in most of the electrical current being driven in the same direction as the pipeline.

To determine what is a common quiet level of geomagnetic activity, an examination of the annual dataset of HRX values for Ottawa revealed that for $95 \%$ of the year the maximum hourly range is less than 40 nanotesla (nT). In comparison to Ottawa, it is apparent that the pipeline is planned to be located in a zone of significantly elevated geomagnetic activity as shown in Figure 3.3. Further, to simplify the study, only two subdivisions were done, i.e. high auroral and low auroral zones (Figure 3.3). The "high auroral zone" is represented by observatories Barrow, College and Yellowknife with 95\% occurrence lower than 600 nT but above 200 nT. The "low auroral zone" is represented by Meanook and Sitka with $95 \%$ occurrence below 200 nT but above the sub-auroral threshold of $40 \mathrm{nT}$.

\subsubsection{Geomagnetic Climatology}

Because pipelines have a 30 to 50 year operational life span, it is necessary to examine how geomagnetic activity changes through a similar period of time. Therefore, 
geomagnetic data covering the period from 1975-2007 underwent a statistical analysis to determine the cumulative time when a specific activity index would be exceeded at each of the observatories listed above. Figure 3.4 illustrates quantitative differences between the geomagnetic activity levels within the study area over a 32 year period from 1975 to 2007 , and in comparison with the sub-auroral activity levels at Ottawa. Shown is the percentage of hours for which HRX exceeds the three different activity levels of 40, 200 and $600 \mathrm{nT}$ at each observatory. Since exceedances shown in Figure 3.4 are based on 32 years of data, the percentages shown for Ottawa do differ slightly for equivalent exceedance values determined using only the 2004 year data. For the $40 \mathrm{nT}$ level, there is an exceedance of approximately $15 \%$ at Sitka, 30\% at Meanook, $50 \%$ at College, $60 \%$ at Yellowknife and $80 \%$ at Barrow. Extreme geomagnetic activity above the level of 600 $\mathrm{nT}$ was exceeded approximately $0.3 \%$ of the time ( $\sim$ day per year) at Sitka to up to $3 \%$ of the time ( $\sim 11$ days per year) in Barrow. Thus, different parts of the proposed pipeline will be subject to different levels of the geomagnetic variations during pipeline lifetime.

\subsection{Geological Setting along Pipeline Route}

\subsubsection{Tectonic Framework, Bedrock Geology and Major Faults}

Much of the pipeline route crosses the geologically complex, mountainous Cordilleran region of Alaska and northwestern Canada where numerous terranes have collided up against the ancestral North American tectonic plate (Figure 3.5). Some terranes have since been displaced along large-scale strike-slip faults. In the Canadian portion of the route, the pipeline crosses two geological provinces, the Cordilleran Orogen and the Interior Platform. 


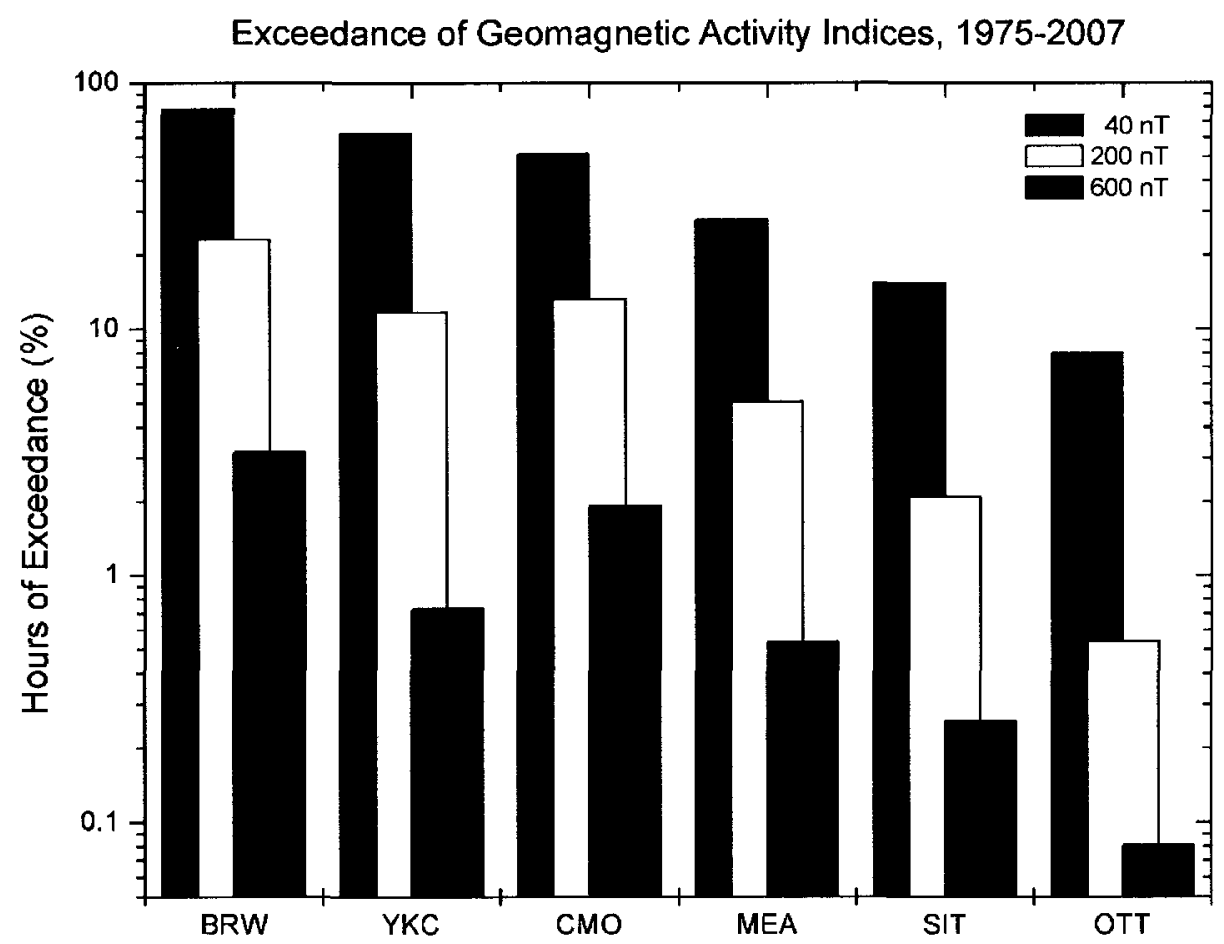

Figure 3.4. Percentage hours of exceedance for the three geomagnetic activity indices at five different geomagnetic observatories along the pipeline route (Boteler et al., 2009, Fig. 2.7). Statistics at OTT is given for comparison. Statistics were based on a $20 \mathrm{nT}$ bin size, with the possible error estimated as being one-half bin (i.e. $10 \mathrm{nT}$ ). Abbreviations: Barrow (BRW), College (CMO), Yellowknife (YKC), Meanook (MEA), Sitka (SIT), and Ottawa (OTT). 


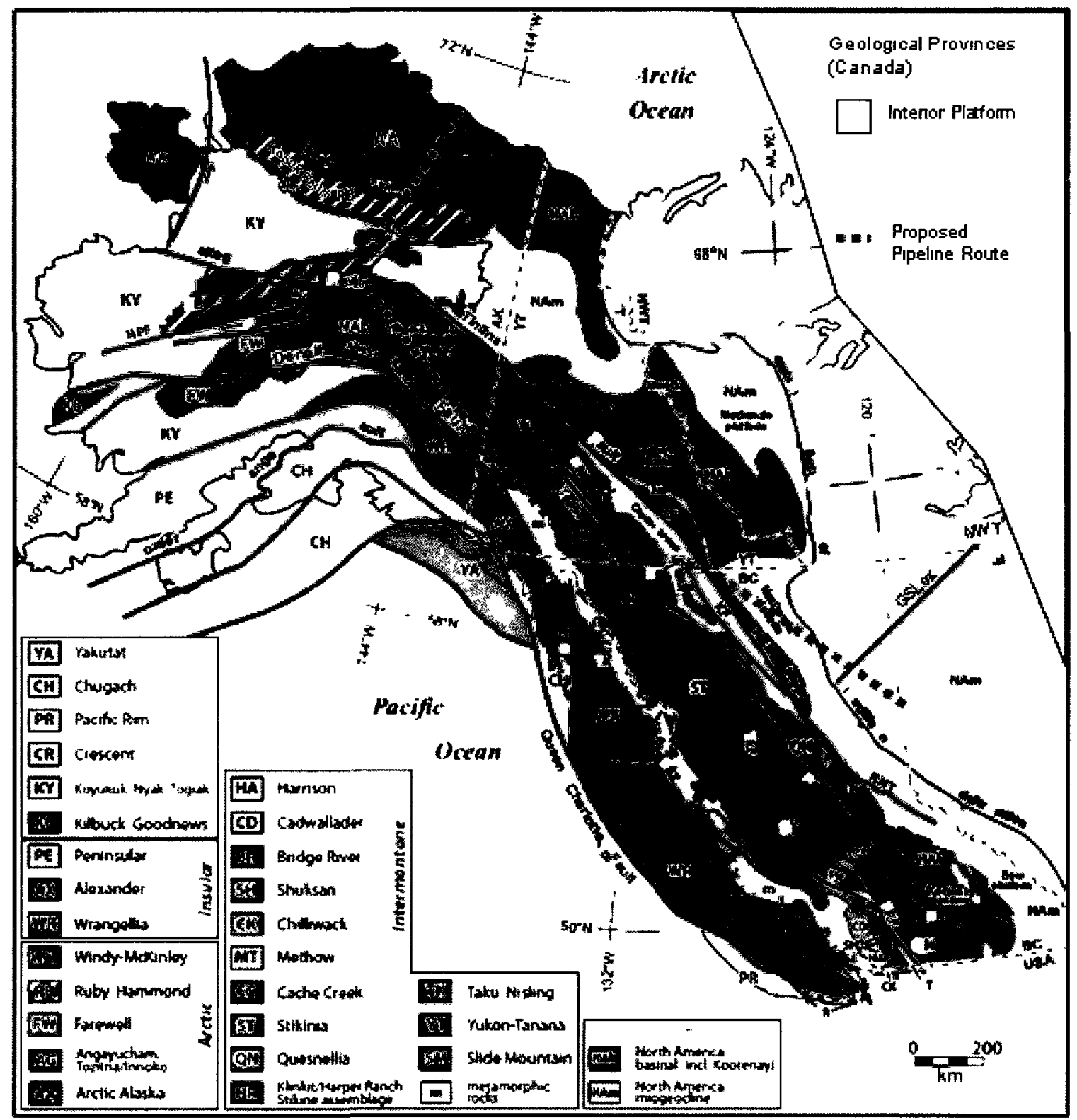

Figure 3.5. Terranes of the Canadian - Alaskan Cordillera (after Nelson and Colpron, 2007, Fig. 1). Intermontane, Arctic and Insular are major terranes. General route of proposed pipeline marked by dashed line. Abbreviations of interest: AB-Alberta, AKAlaska, BC-British Columbia, GSLsz-Great Slave Lake shear zone, NWT-Northwest Territories, RMT-Rocky Mountain Trench, YK-Yukon Territory. 
To identify approximately uniform resistivity zones on the scale of tens to a few hundred kilometres long the concept of terranes was applied, using Nelson and Colpron's (2007) terrane map (Figure 3.5). Terranes are regions of the Earth's crust, often faultbounded, and characterized by a distinctive assemblage of rock that is markedly different from its neighbors. As such their gross geology is reflected in their distinctive overall electrical resistivity, which is most likely different from that of other terranes. Clowes and Hammer (2002) point out that, while regional MT data in western Canada and Alaska exhibit many similarities, there are differences in the electrical resistivity due to variations within terranes and between different terranes.

Sedimentary bedrock underlies much of the pipeline route in Alaska. The foothills and coastal plain of the North Slope are underlain by a laterally extensive and thick succession of marine and non-marine sedimentary rocks that form the Colville sedimentary basin, which reaches a depth of $9 \mathrm{~km}$ in front of the Brooks Range mountains. Beneath the Colville Basin is the Arctic Alaska Terrane, a mix of metamorphosed sedimentary, volcanic and intrusive rocks more deformed closer into the Brooks Range. Collision of the North Slope tectonic microplate into Alaska split apart the pre-existing North American plate crust, causing uplift and deformation to form the Brooks mountain range and to depress the mantle to create a $50 \mathrm{~km}$ thick crust (Fuis et al., 1997, 2008). Resultant thrust faulting has produced a series of steeply dipping slices of sedimentary rock that make up the Brooks Range, including metamorphosed sedimentary and volcanic rocks in the central part of the range.

The pipeline also passes over clusters of intrusive igneous rocks that are widespread in central and southeastern Alaska (including the eastern Yukon-Tanana 
Lowland). Extensive exposures of younger volcanic rocks occur in the Porcupine Plateau and westernmost Yukon-Tanana Upland. Metamorphosed rocks are common beneath the route in southeastern Alaska.

Several major faults cross the pipeline route (Figure 3.5). From north to south they are as follows: Kobuk, Tintina, Teslin and Great Slave Lake Shear Zone. The Denali fault runs parallel along part of the pipeline corridor.

In Canada, folded and faulted sedimentary bedrock also underlies much of the pipeline route. Substantial exposure of intrusive igneous rock and undivided metamorphic rock occur west and northwest of Whitehorse. Up to $4 \mathrm{~km}$ thick flat-lying sedimentary bedrock of the Interior Platform underlies the southeastern end of the route in northeastern British Columbia. Buried beneath the Interior Platform are ancient basement crystalline rocks, part of ancestral North America, which have been-subdivided into numerous domains that reflect origin and dominant rock type. Of particular interest to the determination of a resistivity profile are the Ksituan, Kiskatinaw, Nova and Fort Simpson domains comprised of metamorphosed granitic rocks and gneisses exhibiting linear zones of low-resistivity (Ross and Eaton, 2002; Turkoglu et al., 2009), which occurs at the southern-most end of the AHC route.

\subsubsection{Overburden}

Overburden of differing kinds is present along the pipeline route at varying depths. The pipeline route normally follows rivers and mountain passes, and hence surficial deposits are typically a combination of fluvial-deposited gravels and sands in a river valley bottom flanked by terrace gravels. Glacially deposited moraine-till underlies the valleys cutting though the Brooks Range. Colluvium is common along the higher 
mountain slopes. From the south side of Brooks Range to Fairbanks, the route crosses an expanse of alluvium, eolian deposits and colluvium. Along the Tanana River valley from Fairbanks to the Alaska-Yukon boundary, the route is underlain by a rapidly varying mix of surficial material, including river flood-plain alluvium, valley-bottom eolian deposits of silt and sand, glacio-fluvial outwash gravels, glacial till moraine, and alluvial fan deposits of sand and gravel. Within the Canadian portion, there is an extensive cover of glacial moraine deposits forming a till blanket and/or till veneer, although the route tends to follow valleys where glaciofluvial sands and gravels, and glaciolucustrine silts and clays are predominant.

\subsubsection{Permafrost Distribution and Depth}

Permafrost of varying continuity underlies about three-quarters of the pipeline route, being thicker and of greater lateral extent in the north and diminishing evermore southward. At Prudhoe Bay, permafrost extends to depths of about $600 \mathrm{~m}$, but shallows toward the Brooks Range where it varies in depth from about 25 to $110 \mathrm{~m}$. From Fairbanks southeastward to Tok and the international border, much of the pipeline route follows a river valley where permafrost is sporadic (10-50\% frozen) to isolated $(>0$ $10 \%$ ), with permafrost depths varying irregularly between 10 and about $100 \mathrm{~m}$.

Much of the Canadian portion of the pipeline route, from the Alaska border to Fort Nelson, lies within a sporadic discontinuous (10-50\%) permafrost zone with a depth of less than $10 \mathrm{~m}$. Southeast of Fort Nelson, permafrost only occurs as isolated patches and then ceases to exist halfway to Boundary Lake, the end of the route. 


\subsubsection{Previous Geophysical Surveys along the Alaska Pipeline Corridor}

In Alaska, a program of MT soundings was undertaken by the U.S Geological Survey during 1985-1992 for the Trans-Alaska Crustal Transect (TACT). As shown in Figure 3.6, the TACT-MT survey covered the entire Alaska portion of the proposed pipeline route. About half of these MT soundings underwent a preliminary 1D inversion by Campbell et al., (2001), producing for each sounding site a tabulation of the layer thickness and corresponding resistivity down to response depth of $20 \mathrm{~km}$. No inversions were presented for the portion of pipeline north of Brooks Range across the North Slope, although MT data were acquired.

In the mid-1980s, Stanley et al. (1990) completed transects (Figure 3.6) across the Denali fault and Alaska Range, focusing on the shallow crust. The results were presented using a stitched $1 \mathrm{D}$ model to represent a $2 \mathrm{D}$ cross-section of the subsurface. Later MT surveys completed in 2002 (Fisher et al., 2004) did identify low-resistivity structures immediately below and adjacent to the Denali Fault, however, this particular survey stopped $30 \mathrm{~km}$ short of the proposed pipeline corridor.

During the 1990s and early 2000s, the Geological Survey of Canada, as part of the Lithoprobe SNORCLE (Slave-Northern Cordillera Lithospheric Evolution) program, completed three regional-scale crustal transects - Corridors 2, 3 and 5-crossing the main geological structures in the Yukon, Northwest Territories and British Columbia (Figure 3.6). The crust was imaged using both seismic and MT methods. Comprehensive 2D interpretations have been published by several authors (e.g. Jones et al., 2005). Figure 3.7 provides maps of average resistivity of the crust and upper mantle at various depths. A recently published geophysical study of the upper mantle structure in northern 


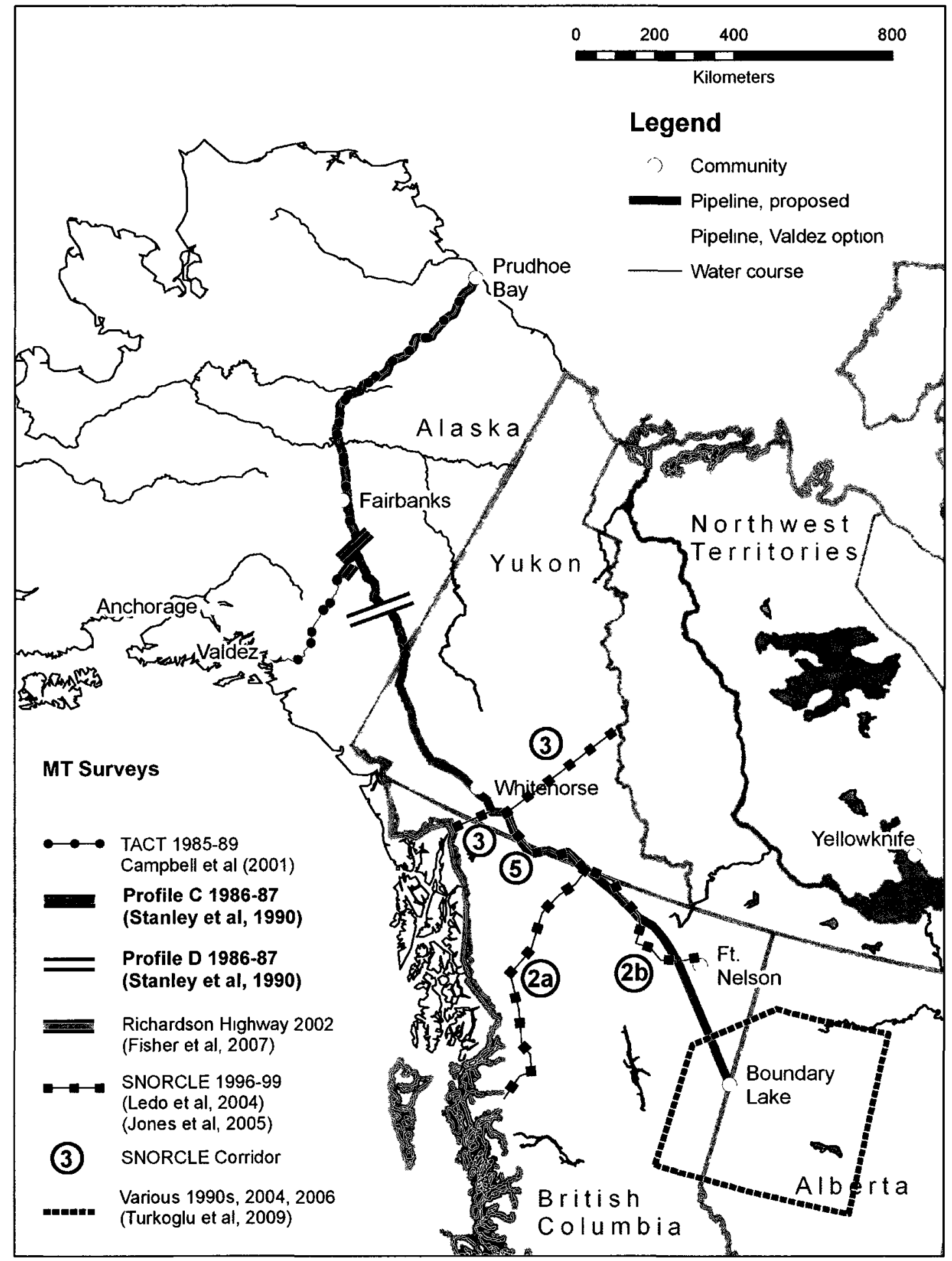

Figure 3.6. Location of MT surveys along or crossing the proposed pipeline corridor. 

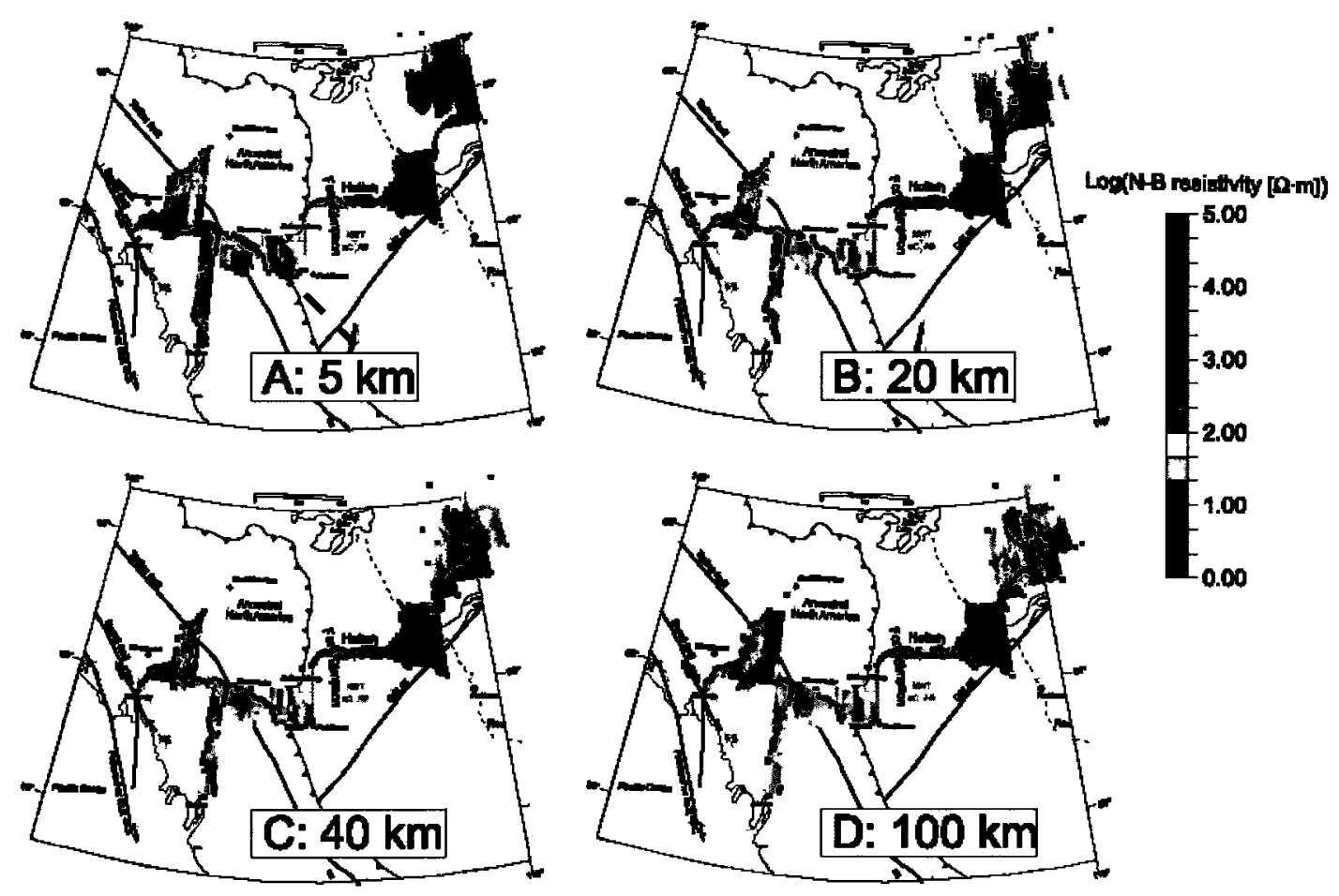

Figure 3.7. Maps of the averaged resistivity at various crustal and mantle depths as determined by MT transects along highways in part of northwestern Canada (after Jones et al., 2005, Fig. 4). Pipeline route is shown as red dashed line on Figure 3.7.A. The overall resistivity of the crust (A-C) is higher than that of the upper mantle (D), a worldwide trend. 
Alberta (Turkoglu et al., 2009) incorporated both new MT (using 3D interpretation) and previous 2D MT surveys.

Where applicable, resistivity and layer thicknesses obtained from previous MT surveys were used in the development of the 1D Earth resistivity models discussed in the next section.

\subsection{D Modelling of Earth Electrical Resistivity}

\subsubsection{Modelling Approach.}

The earliest known 1D Earth resistivity models covering Alaska (Figure 3.8) were 2 and 3 layer models prepared by Campbell (1978) for investigation of telluric current effects on the TransAlaska pipeline. This model was used to calculate the geoelectric field for geomagnetic field variations with periods between 5 minutes and 4 hours, penetrating to crustal and mantle depths down to $1200 \mathrm{~km}$.

In this thesis, a more detailed study has been done. The area adjacent to the pipeline route was divided into eight zones based on a combination of terrane and dominant bedrock geology previously described in section 3.3.1. Specific to the Alaska portion of the pipeline route, results from the TACT-MT survey were used to provide a constraint on the assignment of resistivity values to the upper crust layer for 1D Earth resistivity models. To obtain an initial cross-sectional representation of resistivity changes using TACT-MT data, the preliminary interpreted depth and resistivity of the layers (by Campbell et al., 2001) for a series of selected MT sounding sites were stitched together and then contoured. Induction logs from oil and gas exploration wells were used to assign resistivity values to sedimentary basin rock for the portion of pipeline crossing the Alaska North Slope, because no preliminary 1D interpretations prepared from the 


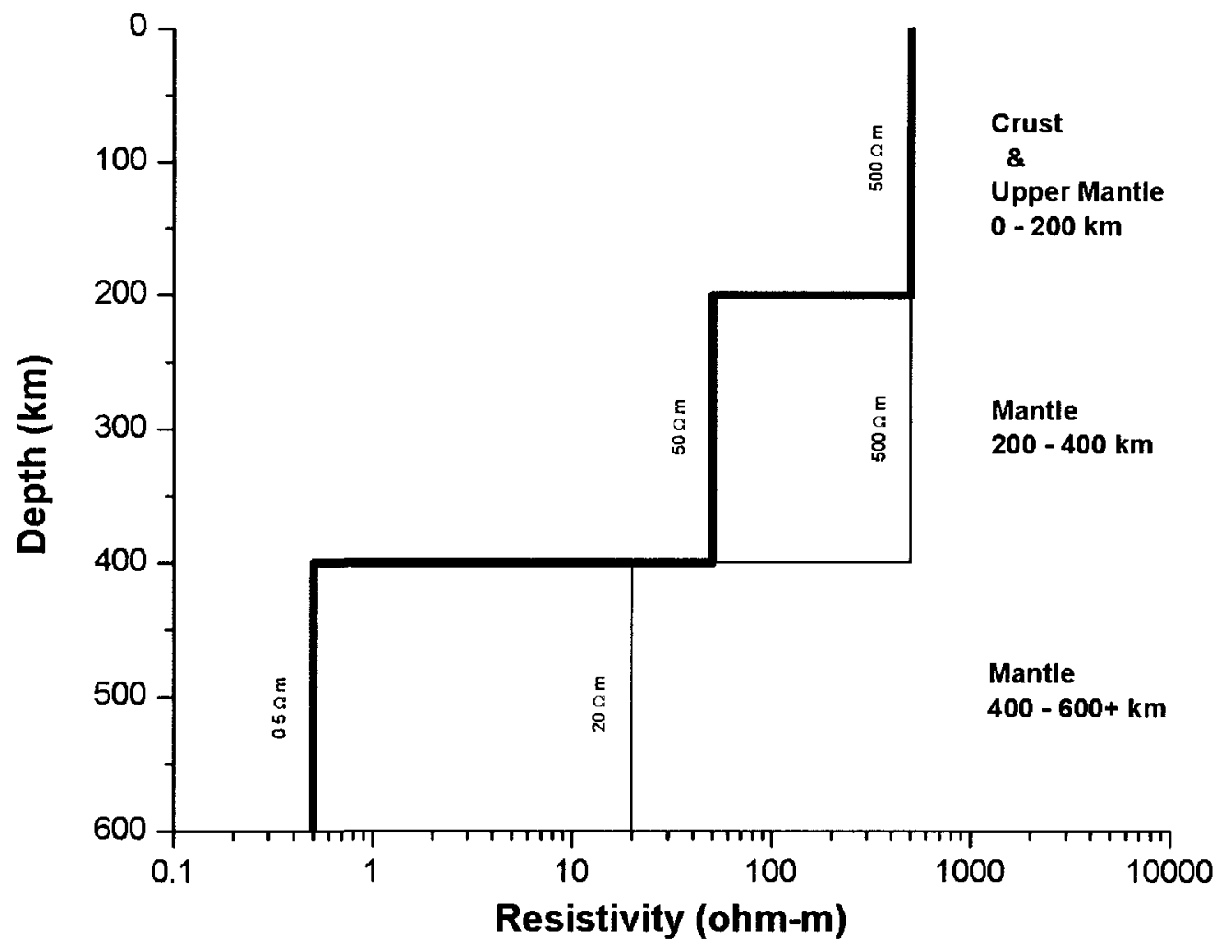

Figure 3.8. Earth resistivity in Alaska as 2- and 3-layer models shown as light and heavy lines, respectively (modified from Campbell, 1978, Fig. 10). 
TACT-MT survey has been published. For some zones, airborne EM surveys were available and provided resistivity values for the overburden.

Those areas of the pipeline underlain by sedimentary basins, which exhibit considerably lower resistivity, were considered as distinct zones although the terrane in which they occur was of longer extent. In addition, areas with extensive amounts of intrusive rocks were considered as distinct zones since such rock is usually more resistive. It is also important to realize that for each zone, the resistivity assigned to the layers has been extrapolated from a MT survey that either follows part of the pipeline route or crosses it at a single location. Locations of each of the eight zones are shown in Figure 3.9.

Zone 1 covers the Alaska North Slope and includes the Colville sedimentary basin underlying Prudhoe Bay to the Brooks Range. Zone 2 crosses the Brooks Range mountains. Zones 3, 4 and 5 cover the central and southeastern region of Alaska, with Zones 3 and 5 containing more resistive rocks. Zone 6 comprises much of southern Yukon. Zone 7 crosses part of northeastern British Columbia. Zone 8 is within part of the Western Canada Sedimentary Basin that covers most of the Canadian prairies. A brief description of each zone, as well as the zone's representative 1D layered Earth resistivity model (Figures 3.10 to 3.17 ), is presented below. Appendix A3.1 contains accompanying tables for each Earth resistivity model (Tables A3.1.1 to A3.1.8) with the background information on the justification and source(s) of the assigned thickness and resistivity. Notes and abbreviations common to these tables are included at the end of Table A3.1.8. 


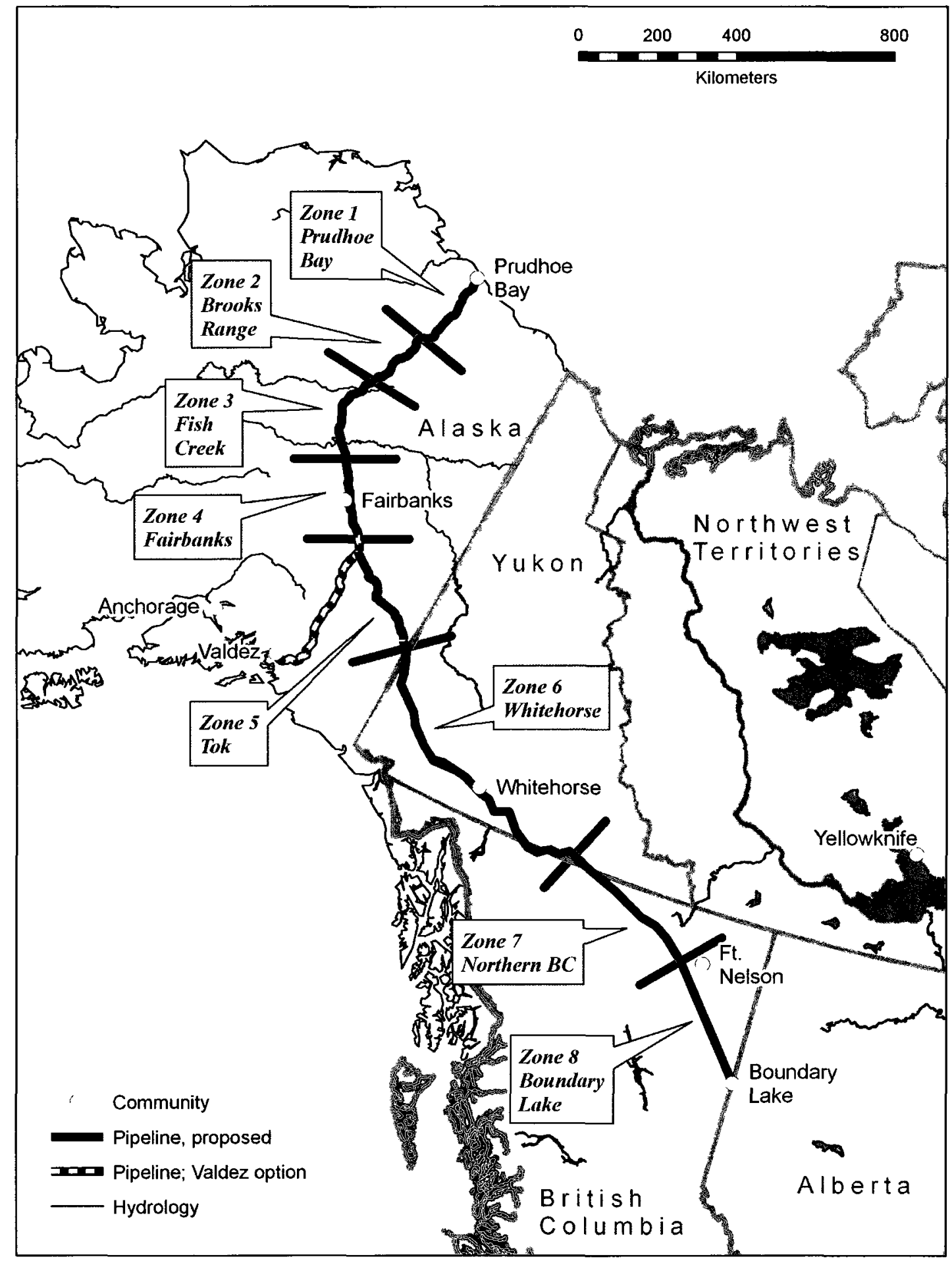

Figure 3.9. Zones along the pipeline route used to construct 1D Earth resistivity models. 


\subsubsection{Zone 1 - Prudhoe Bay}

Zone 1 (Figure 3.10) extends $225 \mathrm{~km}$ from Prudhoe Bay (at mileage point AMP0) to Galbraith Lake (AMP-140) on the north side of the Brooks Range mountains, crossing the Arctic Coastal Plain and Arctic Foothills. Continuous permafrost is about $600 \mathrm{~m}$ thick at the coast, thinning southward to about $240 \mathrm{~m}$. Overburden is predominantly modern flood-plain alluvium along the Sagvanirktok River which parallels the pipeline route. Underlying crustal rocks of the North Slope subterrane (part of the Arctic Alaska Terrane in the Arctic Superterrane) include a $3.6 \mathrm{~km}$ thick sedimentary basin succession of shale, siltstone, sandstone and some limestone over more deformed and metamorphosed sediments. Upper crustal resistivity was obtained by extrapolation from deep-well induction logs completed in the region because interpreted TACT-MT survey data was lacking.

\subsubsection{Zone 2-Brooks Range}

Zone 2 (Figure 3.11) extends $177 \mathrm{~km}$ across the Brooks Range from Galbraith Lake (at AMP-140) on the north flank to Middle Fork-Koyukok River (at AMP-250) on the south flank of the mountains. Continuous permafrost reaches a depth of at least $70 \mathrm{~m}$. Overburden is predominately coarse colluvium and glacial moraine on the slopes with alluvium on the mountain valley floors. Bedrock is an extensive thrust-faulted thick assemblage of sedimentary and metamorphosed sediments; belonging to a variety of subterranes of the Arctic Alaska Terrane. Upper crustal resistivity was obtained from a combination of extrapolation from deep-well logs on the North Slope and values from previous preliminary interpretations of the TACT-MT soundings. 


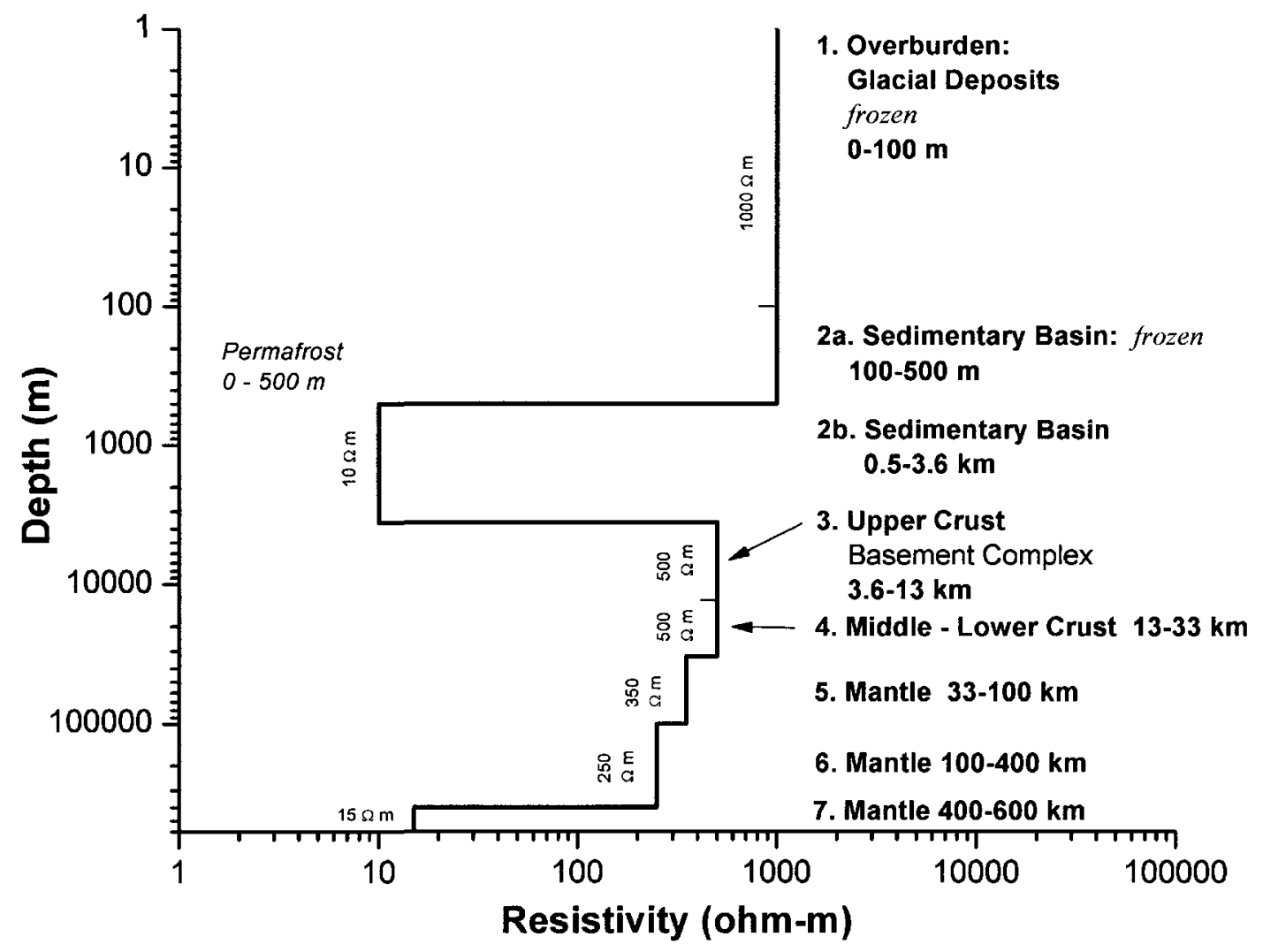

Figure is to be read in conjunction with accompanying table Resistivity values and depths have been interpreted from published geological reports and maps, and may differ from actual conditions measured by a geophysical survey and/or borehole

Figure 3.10. 1D Earth resistivity model for Zone 1 - Prudhoe Bay. Refer to Table A3.1.1 for additional details. 


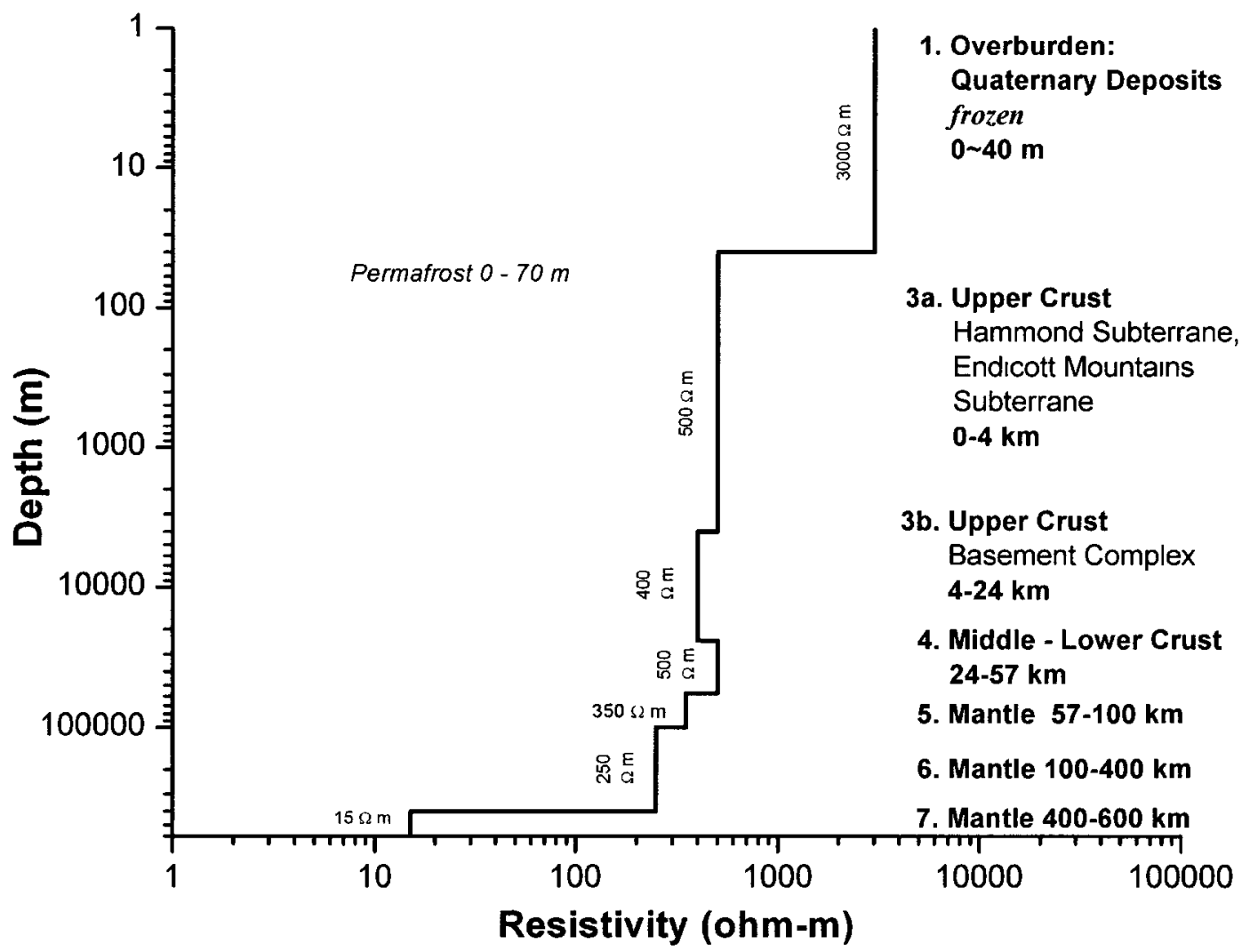

Figure is to be read in conjunction with accompanying table Resistivity values and depths have been interpreted from published geological reports and maps, and may differ from actual conditions measured by a geophysical survey and/or borehole

Figure 3.11. 1D Earth resistivity model for Zone 2 - Brooks Range. Refer to Table A3.1.2 for additional details. 


\subsubsection{Zone 3 - Fish Creek}

Zone 3 (Figure 3.12) extends $210 \mathrm{~km}$ from the south flank of Brooks Range (AMP-250) to the Livengood area (AMP-380), crossing the Porcupine Plateau into the beginning of the Yukon-Tanana Uplands. Permafrost is mostly continuous with depth varying anywhere from less than $25 \mathrm{~m}$ to over $100 \mathrm{~m}$. Overburden is variable, with glacial till in the north, colluvium along hill slopes, and silts in the south. Bedrock is a mix of sedimentary, volcanic and intrusive rocks; belonging to a variety of terranes and subterranes of the Arctic Superterrane. The Kaltag - Tintina fault system marks the southern margin of Zone 3. Crustal resistivity was based on average of TACT-MT preliminary 1D interpretations.

\subsubsection{Zone 4-Fairbanks}

Zone 4 (Figure 3.13) extends $225 \mathrm{~km}$ from the Livengood area (AMP-380) to near Big Delta (AMP-520), across the Yukon-Tanana Uplands. Isolated permafrost (discontinuous elsewhere) occurs along Tanana River valley - which parallels much of the pipeline route and highway - with depths ranging from about 30 to $100 \mathrm{~m}$. Overburden is mainly windblown silt with colluvium on hill slopes. Bedrock is comprised of metasediments, undivided metamorphosed rock and minor metavolcanics; belonging to the ancestral North America tectonic realm. The Kaltag - Tintina fault system marks the north margin of Zone 3, and the Shaw Creek fault its south margin. Crustal resistivity was based on average of TACT-MT preliminary 1D interpretations. 


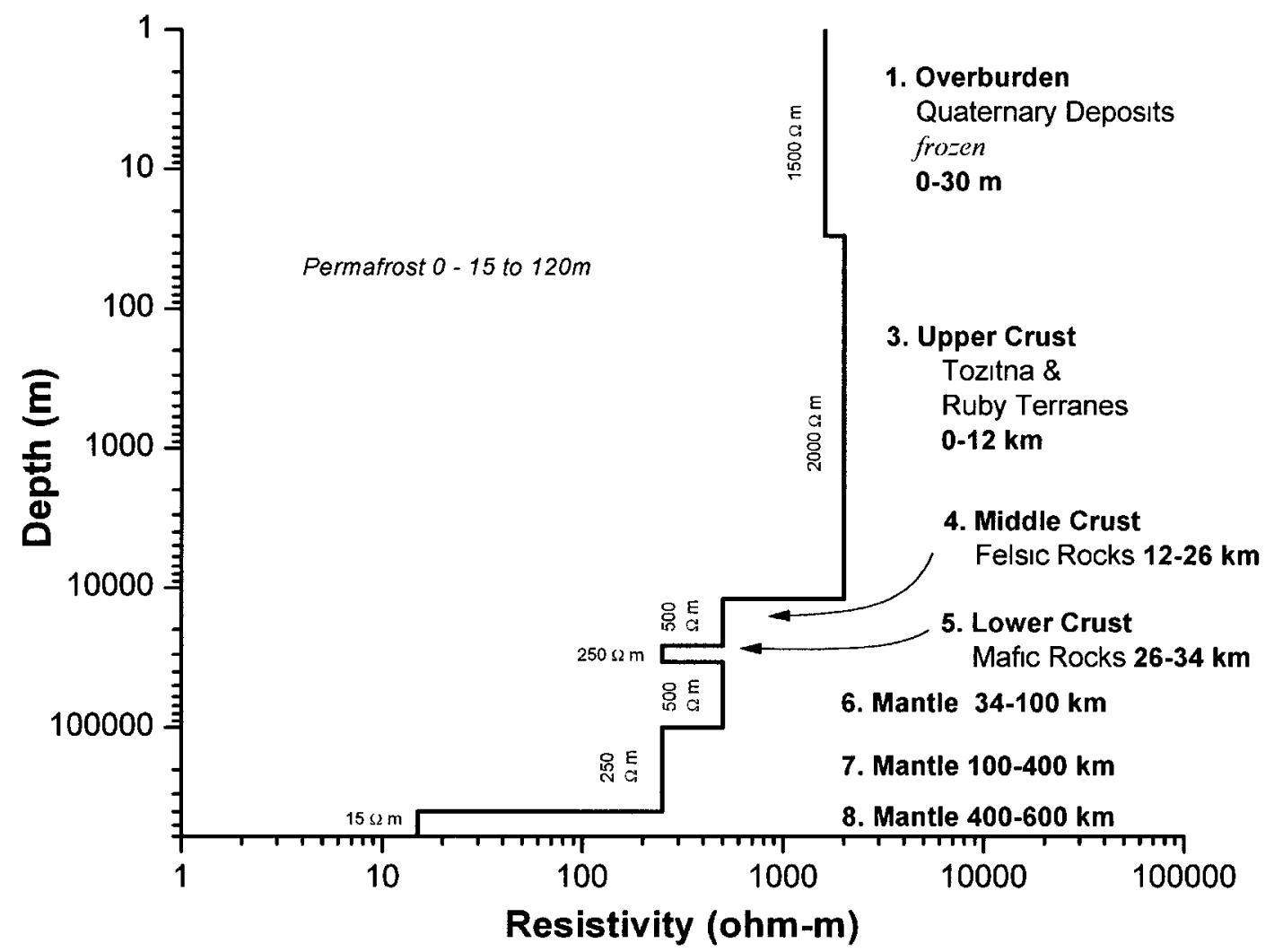

Figure is to be read in conjunction with accompanying table Resistivity values and depths have been interpreted from published geological reports and maps and may differ from actual conditions measured by a geophysical survey and/or borehole

Figure 3.12. 1D Earth resistivity model for Zone 3 - Fish Creek. Refer to Table A3.1.3 for additional details. 


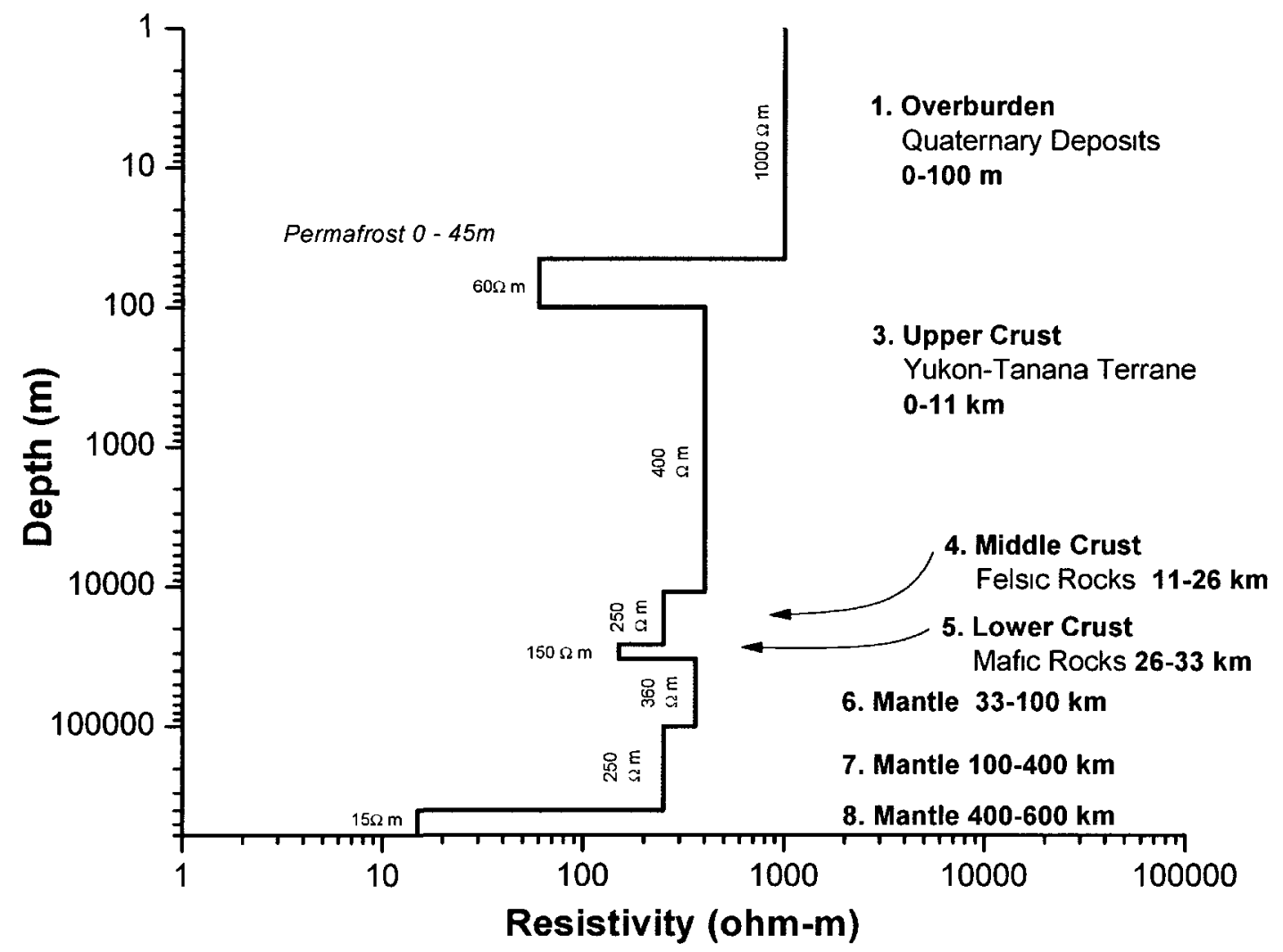

Figure is to be read in conjunction with accompanying table Resistivity values and depths have been interpreted from published geological reports and maps, and may differ from actual conditions measured by a geophysical survey and/or borehole

Figure 3.13. 1D Earth resistivity model for Zone 4 - Fairbanks. Refer to Table A3.1.4 for additional details. 


\subsubsection{Zone $5-$ Tok}

Zone 5 (Figure 3.14) extends $344 \mathrm{~km}$ from near Big Delta (AMP-520) to the Alaska-Yukon border (AMP-734 / YKP-0), across the continuation of the Yukon-Tanana Uplands and in the Tanana river valley. Sporadic and/or isolated permafrost (discontinuous elsewhere), depth ranges from about 10 to $60 \mathrm{~m}$, occurs along the Tanana River valley which parallels much of the pipeline route and highway. Overburden exhibits rapid changes from modern flood-plain alluvium, alluvial fans to glacial outwash and moraines. Bedrock is strongly deformed metasediments with some younger volcanic rock, and extensive masses of intrusive rock; belonging either to ancestral North America or the Yukon-Tanana Terrane. The Shaw Creek fault marks the north margin of Zone 5. Upper crustal resistivity was obtained from examination of a contour plot of stitched TACT-MT preliminary 1D interpretations. High resistivity of upper crust in this zone is attributed to presence of intrusive igneous rock.

\subsubsection{Zone 6 - Whitehorse}

Zone 6 (Figure 3.15) extends $862 \mathrm{~km}$ from the Alaska-Yukon border (YKP-0) to Watson Lake / Lower Post area (BKP-30), across the Yukon Plateau, part of the Cassiar Mountains and into the Laird Plateau. Sporadic-discontinuous permafrost reaches a depth of about $10 \mathrm{~m}$. Overburden is variable. Bedrock consists of assemblages of metasediments, meta-volcanics, with considerable intrusive rock in the Whitehorse area, belonging to various terranes (largest being the Yukon-Tanana Terrane) that make up the Intermontane Superterrane. The Denali fault runs parallel to part of the pipeline 


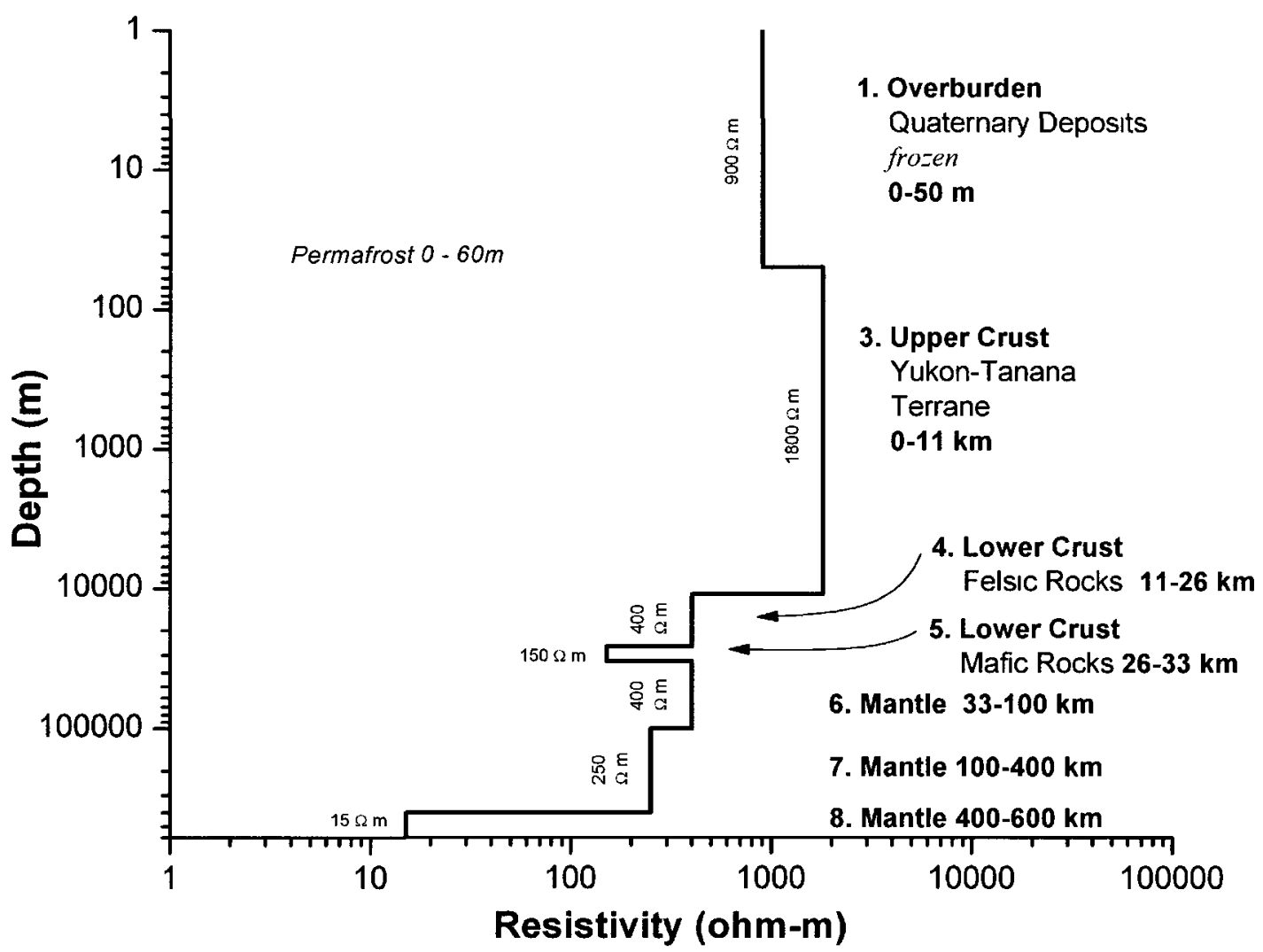

Figure is to be read in conjunction with accompanying table Resistivity values and depths have been interpreted from published geological reports and maps, and may differ from actual conditions measured by a geophysical survey and/or borehole

Figure 3.14. 1D Earth resistivity model for Zone 5 - Tok. Refer to Table A3.1.5 for additional details. 


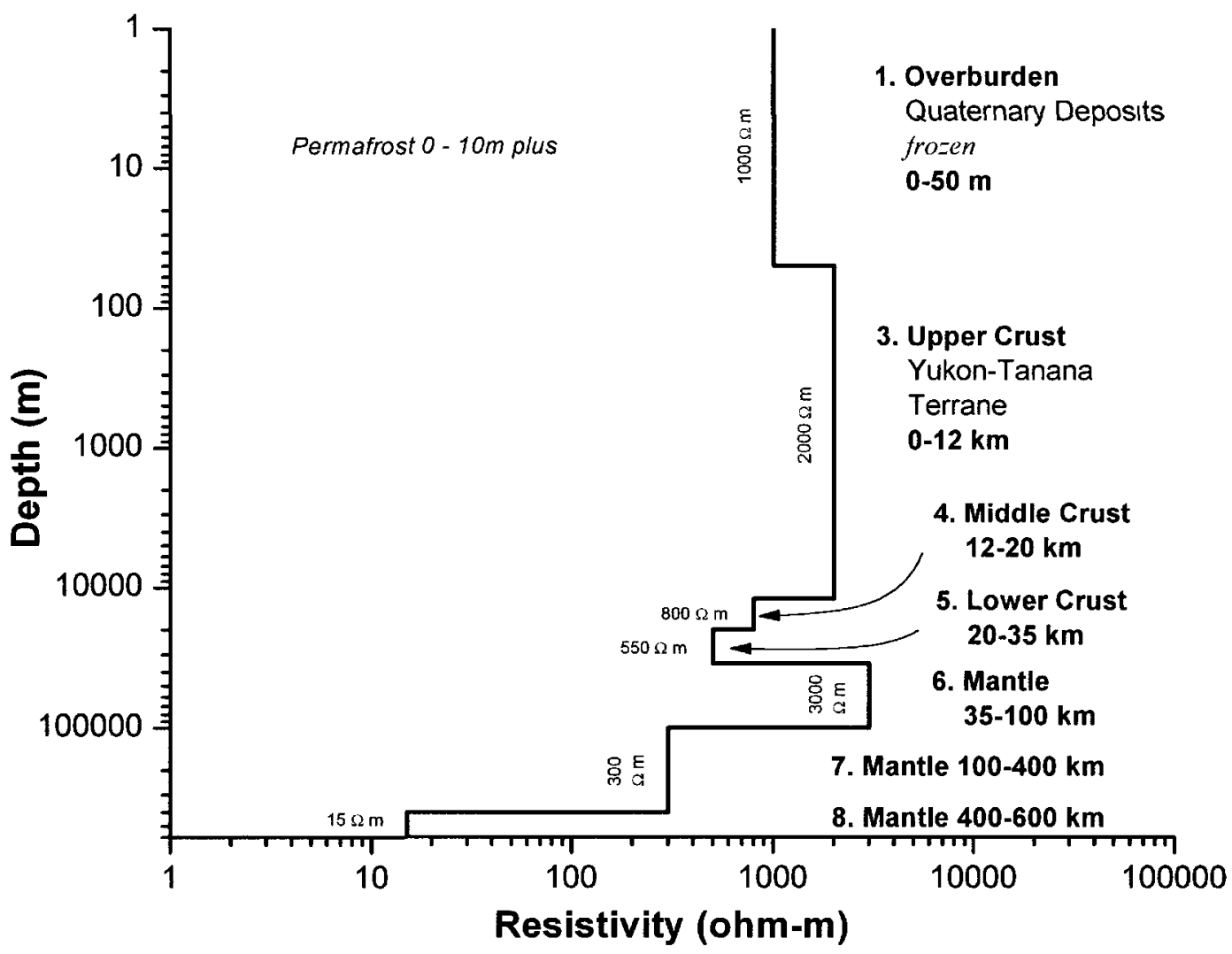

Figure is to be read in conjunction with accompanying table Resistivity values and depths have been interpreted from published geological reports and maps, and may differ from actual conditions measured by a geophysical survey and/or borehole

Figure 3.15. 1D Earth resistivity model for Zone 6 - Whitehorse. Refer to Table A3.1.6 for additional details. 
route, with the Teslin Fault crossing the route, and the Tintina fault being the south margin of Zone 6. Crustal resistivity was obtained from regional combined seismic and MT crustal transects across the centre of the zone. High resistivity of the upper crustal rocks is consistent with presence of mafic/felsic rocks, interlayered with clastic sedimentary and carbonate rocks, and intrusive igneous rock (Wennberg et al., 2002).

\subsubsection{Zone 7 - Northeastern BC}

Zone 7 (Figure 3.16) extends $350 \mathrm{~km}$ from the Watson Lake / Lower Post area (BKP-30) to Steamboat (BKP-380), across the Laird Plain. Sporadic-discontinuous permafrost can exist at depths of less than $10 \mathrm{~m}$. Overburden is predominately till veneer and blanket with glaciolucustrine sand and gravel. Bedrock consists of thrust-faulted weakly metamorphosed sediments; belonging to the ancestral North American tectonic realm. The Tintina fault occurs at the north margin of Zone 7. Upper crustal resistivity was obtained from the regional SNORCLE MT crustal transect along the length of the zone. Diminished resistivity of the upper crustal rocks has been attributed to presence of carbonaceous shales (Ledo et al., 2004). East of the Tintina Fault (Watson Lake) the mantle exhibits low-resistivity (Ledo et al., 2004).

\subsubsection{Zone 8 - Boundary Lake}

Zone 8 (Figure 3.17 ) extends $343 \mathrm{~km}$ across part of the Fort Nelson Lowland and into the Alberta Plateau, from the Steamboat area (BKP-380) to the end of the pipeline route at Boundary Lake (BKP-722) on the Alberta-BC provincial border. Sporadicdiscontinuous to isolated patches of permafrost occurs in the northern half of Zone 8 . Overburden is predominately till veneer and blanket with glaciolucustrine sand 


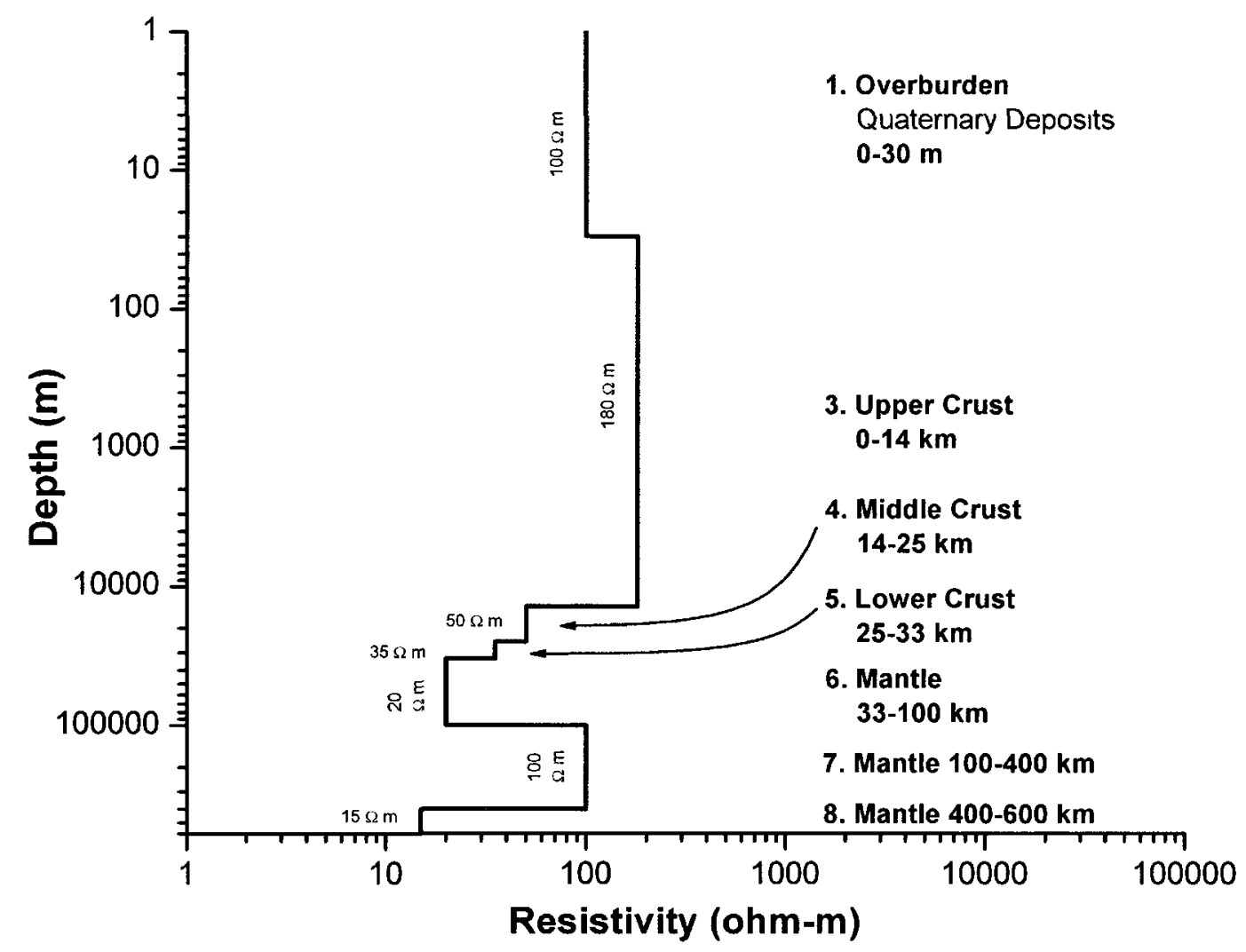

Figure is to be read in conjunction with accompanying table Resistivity values and depths have been interpreted from published geological reports and maps, and may differ from actual conditions measured by a geophysical survey and/or borehole

Figure 3.16. 1D Earth resistivity model for Zone 7 - Northeastern BC. Refer to Table A3.1.7 for additional details. 


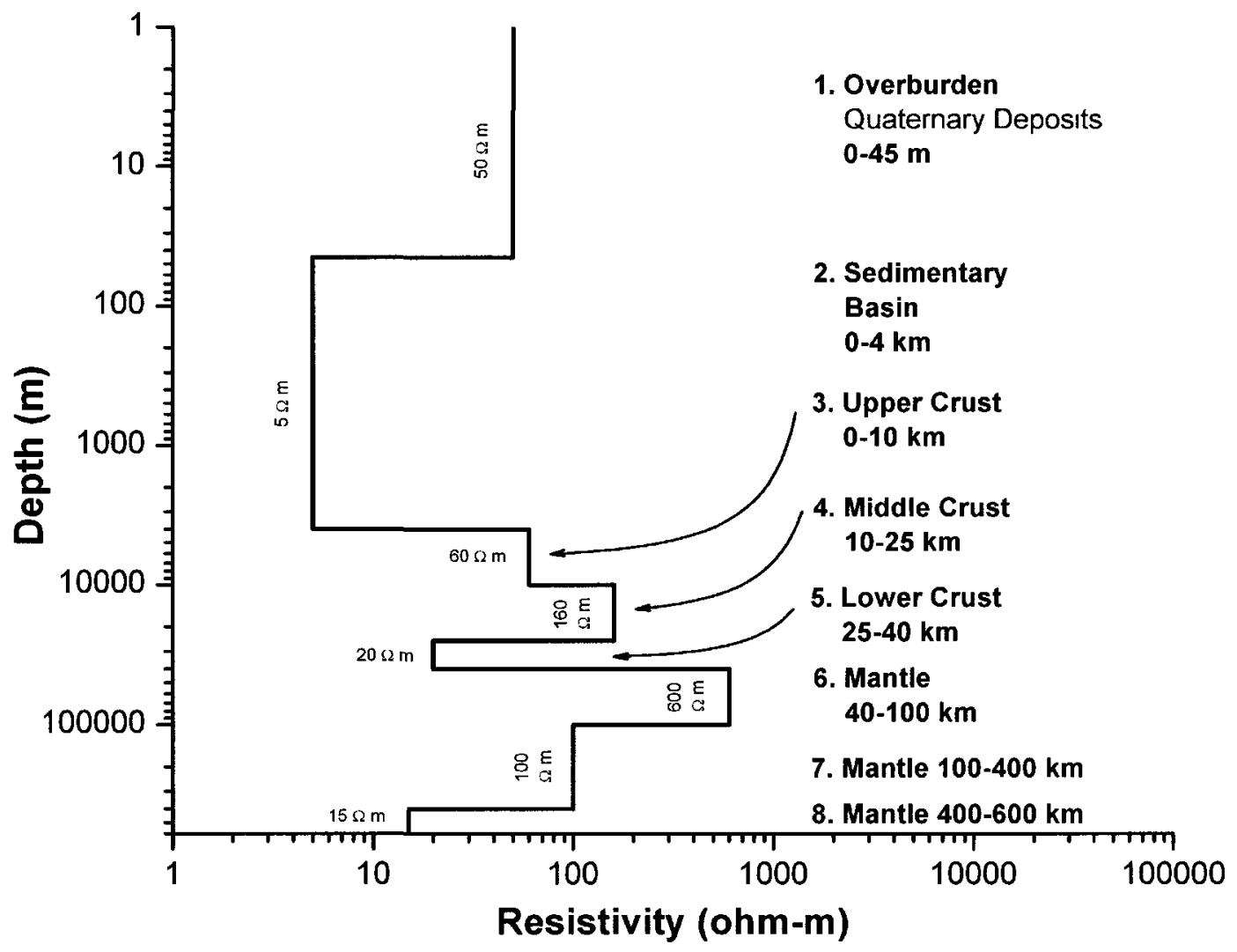

Figure is to be read in conjunction with accompanying table Resistivity values and depths have been interpreted from published geological reports and maps and may differ from actual conditions measured by a geophysical survey and/or borehole

Figure 3.17. 1D Earth resistivity model for Zone 8 - Boundary Lake. Refer to Table A3.1.8 for additional details. 
and gravel in the main river valleys. Bedrock consists of the gently dipping to moderately folded $4 \mathrm{~km}$ thick Western Canada Sedimentary Basin that overlies a complex crystalline Precambrian basement which includes anomalous conductive zones and the Great Slave Lake Shear Zone. Crustal resistivity was obtained from a recent assessment of MT responses in northwestern Alberta (Turkoglu et al., 2009). The exceptionally low resistivity of upper crustal rocks in the Boundary Lake area is likely due to the presence of the $700 \mathrm{~m}$ thick Cretaceous Manville Group, a highly carbonaceous shale which is electrically conductive (Boerner et al., 2000). Low resistivity measured in the lower crust layer could be due to organic material and carbonates transported to depth in an ancient fossil subduction zone and converted to electrically conductive graphite (Turkoglu et al., 2009).

\subsection{Geoelectric Field Modelling}

To numerically model the geoelectric field (see Section 2.4.2) at the Earth's surface requires two inputs: calculated surface impedance and actual geomagnetic recordings. In this section, the determination of the surface impedance and its effects on the resulting geoelectric field are first examined. In order to determine levels of geoelectric activity, a statistical determination of the telluric activity indices was undertaken and results are presented as well.

\subsubsection{Surface Impedances Determination}

Surface impedance is determined over a range of frequencies. Chapter 2 presented the formulae and process of calculating a surface impedance which represents the transfer function between geomagnetic variations and the geoelectric field at the 
Earth's surface, as $E(\omega)=Z(\omega) \times H(\omega)$, where $E$ is the geoelectric field, $Z$ is the surface impedance, and $H$ is the magnetic field at a specific frequency $\omega$.

Using each of the developed 1D Earth resistivity models as an input to the recursion relation (see equation 2.6, Chapter 2) the surface impedance values were calculated for each of the eight resistivity zones along the pipeline route as shown in Figure 3.9. The recursion relation utilizes the layer thickness and its conductivity (inverse of resistivity) as inputs to generate surface impedance as a function of frequency. Surface impedance results were limited to frequencies less than $10^{-2} \mathrm{~Hz}$ (periods less than $\approx 1$ minute) because geomagnetic observatory records (used as the second input for the calculation of surface geoelectric field values) were only available as 1 minute data (frequency $\approx 0.015 \mathrm{~Hz}$ ). Calculations were performed by the Ottawa Geomagnetic Laboratory and results supplied to this author.

Because surface impedance is calculated in the frequency domain, the results are presented as complex numbers which can be decomposed as amplitude and phase values at a specific frequency (Figure 3.18). The largest difference between the surface impedances can be seen in the amplitudes of Northern BC-Zone 7 and Boundary LakeZone 8 compared with the other areas. The amplitude of Prudhoe Bay-Zone 1 also differs from other Alaska Zones 2 to 5 for periods between 1 and 15 minutes.

\subsubsection{Effects of Layered Earth Models on the Geoelectric Field.}

The effect of different surface impedances can best be illustrated by calculating geoelectric field values from a sample of geomagnetic data but with a variety of differing Earth resistivity parameters and comparing the results. Using geomagnetic data for January 17, 2004, from Ottawa Geomagnetic Observatory (representing a baseline 


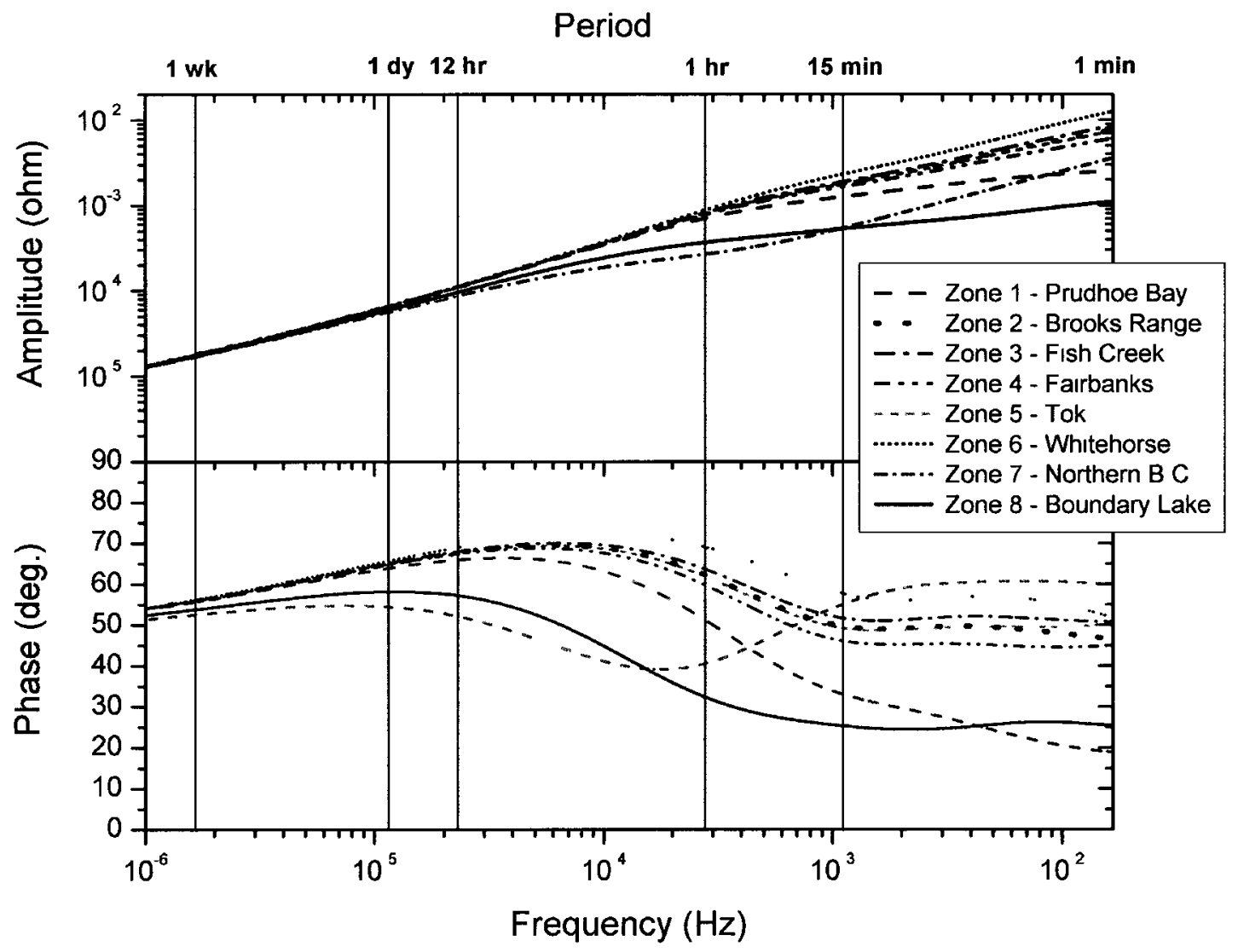

Figure 3.18. Surface impedances for the eight 1D layered Earth resistivity models determined for the Alaska Highway Corridor (after Boteler et al., 2009, Fig. 4.2). 
condition that is less geomagnetically disturbed compared to northern observatories located within the auroral zone) and parameters from each of the eight Earth models, the geoelectric field was calculated as shown in Figure 3.19. The results demonstrate how different geological settings along the pipeline route all under the influence of the same geomagnetic field variations generate different levels of geoelectric field activity. It can be seen that the higher surface impedance for the central Alaskan and Yukon zones (Zones $2-6$ ) results in large geoelectric field values compared with those generated using Zones 7 and 8 which have a smaller geoelectric field due to their smaller surface impedances. The highest geoelectric field is experienced in Zone 6-Whitehorse which, in contrast to the other modelled zones, has an upper mantle that is considerably more resistive. Zone 1-Prudhoe Bay which is underlain by a $3.5 \mathrm{~km}$ thick sedimentary basin layer of very low-resistivity exhibits a geoelectric field amplitude that is slightly attenuated compared to Zones 2 to 6 .

In order to better represent the geoelectric field that would be experienced along the pipeline route, geomagnetic field data from the observatory closest to each resistivity zone were used (see Table 3.1). Combined with surface impedances determined from each of the eight Earth models, the geoelectric field variations in both the north-south $E_{x}$ and east-west $E_{y}$ directions were determined for specific days when quiet time suddenly changed to geomagnetic storm conditions as shown in Figure 3.20. As can be seen, geoelectric field amplitude for a stormy day is $50-150$ times greater compared to a quiet day, both northward and eastward. 


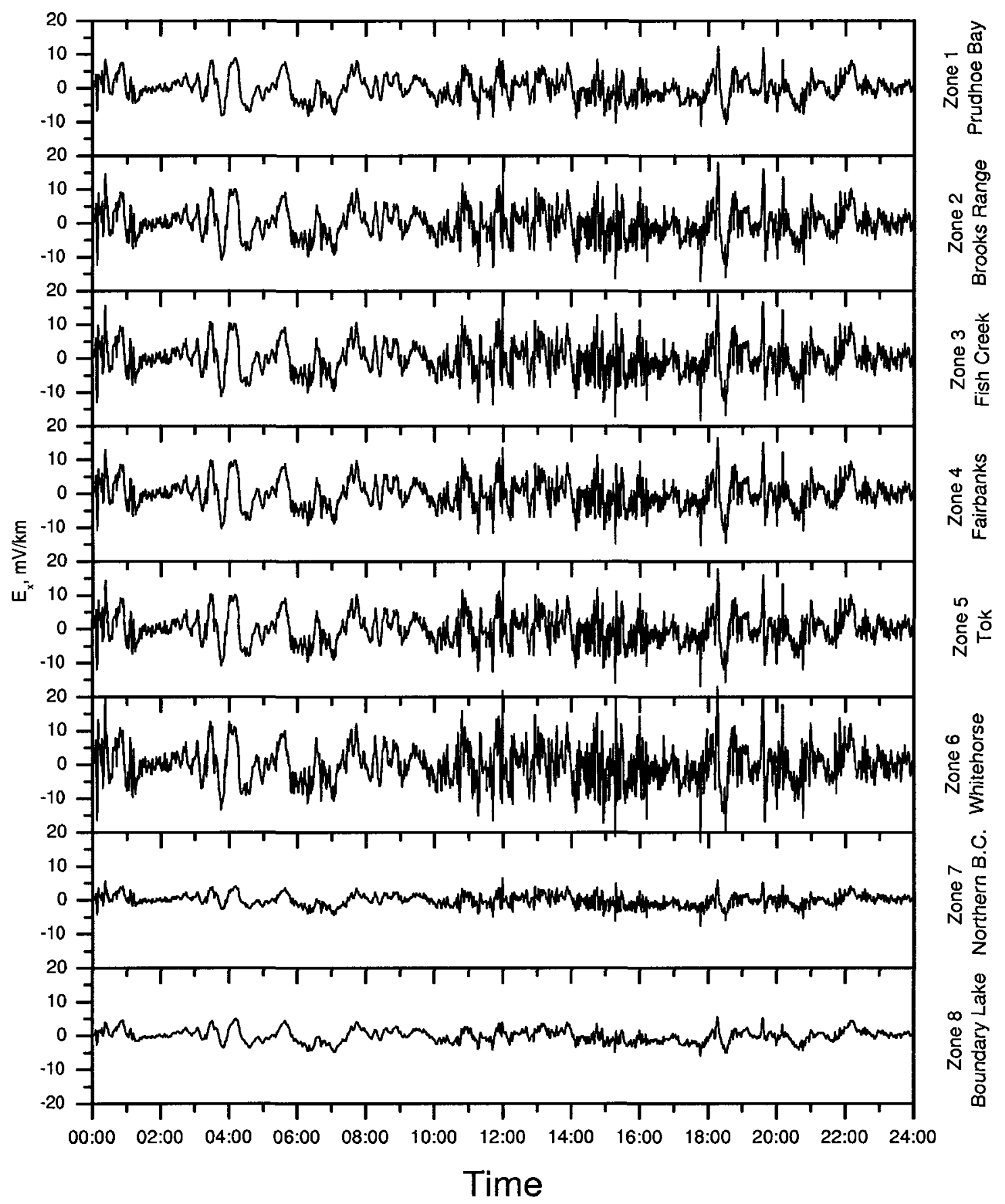

Figure 3.19. Calculated geoelectric field $\left(\mathrm{E}_{\mathrm{x}}\right)$ for different layered Earth models (Zones 1 - 8), using the 17 January 2004 geomagnetic data recorded at Ottawa Geomagnetic Observatory (after Boteler et al., 2009, Fig. 4.3). 
Table 3. 1. Geomagnetic data sources for geoelectric field calculation

\begin{tabular}{lcc}
\hline \multicolumn{1}{c}{$\begin{array}{c}\text { 1D Earth } \\
\text { Resistivity Model }\end{array}$} & $\begin{array}{c}\text { Geomagnetic Observatory } \\
\text { Data Source }\end{array}$ & \multicolumn{1}{c}{$\begin{array}{c}\text { Observatory } \\
\text { Coordinates }\end{array}$} \\
\hline $\begin{array}{l}\text { Baseline } \\
\text { (geomagnetically quiet) }\end{array}$ & Ottawa & $45.403^{\circ} \mathrm{N}, 75.552^{\circ} \mathrm{W}$ \\
Zone 1 - Prudhoe Bay & Barrow & $71.32^{\circ} \mathrm{N}, 156.62^{\circ} \mathrm{W}$ \\
Zone 2 - Brooks Range & College & $64.8741^{\circ} \mathrm{N}, 147.8597^{\circ} \mathrm{W}$ \\
Zone 3 - Fish Creek & College & $64.8741^{\circ} \mathrm{N}, 147.8597^{\circ} \mathrm{W}$ \\
Zone 4 - Fairbanks & College & $64.8741^{\circ} \mathrm{N}, 147.8597^{\circ} \mathrm{W}$ \\
Zone 5 - Tok & College & $64.8741^{\circ} \mathrm{N}, 147.8597^{\circ} \mathrm{W}$ \\
Zone 6 - Whitehorse & College & $64.8741^{\circ} \mathrm{N}, 147.8597^{\circ} \mathrm{W}$ \\
Zone 7 - Northern & & \\
British Columbia & Yellowknife & $62.480^{\circ} \mathrm{N}, 114.482^{\circ} \mathrm{W}$ \\
Zone 8 - Boundary Lake & Meanook & $54.616^{\circ} \mathrm{N}, 113.347^{\circ} \mathrm{W}$ \\
\hline
\end{tabular}



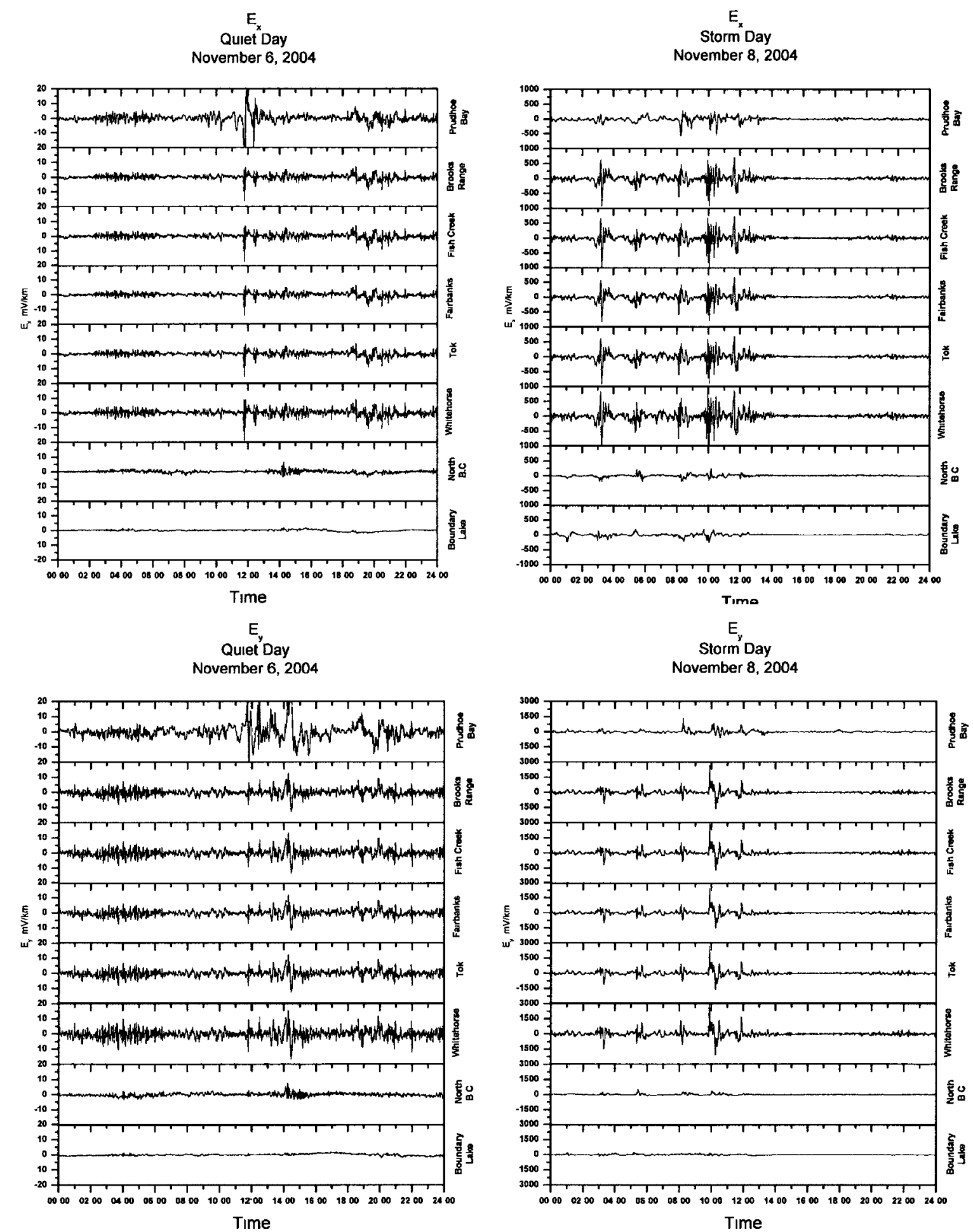

Figure 3.20. Geoelectric field variations in the Ex (northward) and Ey (eastward) directions for a geomagnetically quiet (Nov. 6, 2004) and stormy day (Nov. 8, 2004) experienced along the eight resistivity zones along the AHC pipeline route (after Boteler et al., 2009, Figs. 4.4, 4.5, 4.12 and 4.13). Universal time. Note scale changes of the geoelectric field amplitude. 


\subsubsection{Statistical Evaluation of Telluric Activity}

To statistically delineate levels of telluric activity in the study area, specific activity indices were established in the same manner as for geomagnetic activity levels (see Section 3.2.1). Only one essential telluric activity index, HMA (the hourly maximum amplitude of the geoelectric field), is presented here as an example; details can be found in the report by Boteler, Trichtchenko, Fernberg and Harrison (2009).

Telluric activity levels were established by examining the $95 \%$ occurrence levels at each of zones along the pipeline route, and comparing with $95 \%$ occurrence at Ottawa for sample year 2004. Ottawa represents the normal baseline level of telluric activity encountered in the less disturbed sub-auroral geomagnetic zone. The HMA of the eastwest component of the geoelectric field, $E_{y}$, was chosen as this is produced by the geomagnetic field north-south component used in the geomagnetic index HRX (the geomagnetic and geoelectric fields are orthogonal). The results are illustrated in Figure 3.21. Three levels of telluric activity were determined as follows: $20 \mathrm{mV} / \mathrm{km}$ is a $l o w$ activity level with $95 \%$ occurrence in the sub-auroral zone, such as Ottawa; active level is $160 \mathrm{mV} / \mathrm{km}$ in the low-auroral zone, for example at Meanook; and, highly active level is of $420 \mathrm{mV} / \mathrm{km}$ in the high-auroral zone, found at Barrow, College and Yellowknife observatories.

Applying the derived telluric activity indices to the calculated geoelectric field values over a 32 year time period allows for a statistical examination of the activity levels in each resistivity zone (Figure 3.22 ) defined for the pipeline route. Shown are the numbers of hours during which the HMA $E_{y}$ telluric activity level is exceeded as a percentage of the total number of hours for the entire 32 year time period. 


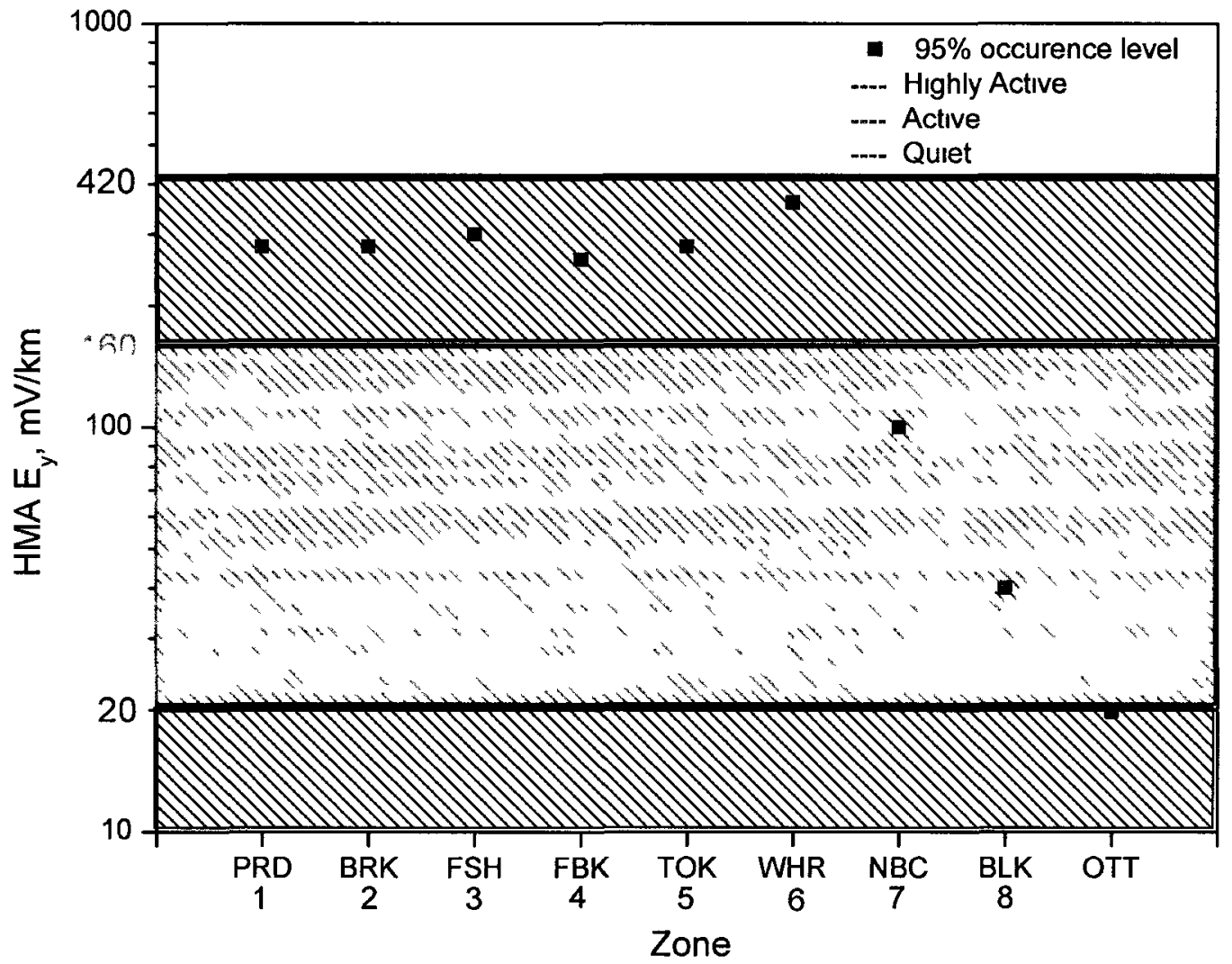

Figure 3.21. Telluric Activity Indices derived from the $95 \%$ occurrence levels for the east-west component of the geoelectric field, $\mathrm{E}_{\mathrm{y}}$, in 2004 (after Boteler et al., 2009, Fig. 4.14). Abbreviations: PRD, Prudhoe Bay; BRK, Brooks Range; FSH, Fish Creek; FBK, Fairbanks; TOK, Tok; WHR, Whitehorse; NBC, Northern B.C; BLK, Boundary Lake; OTT, Ottawa. 


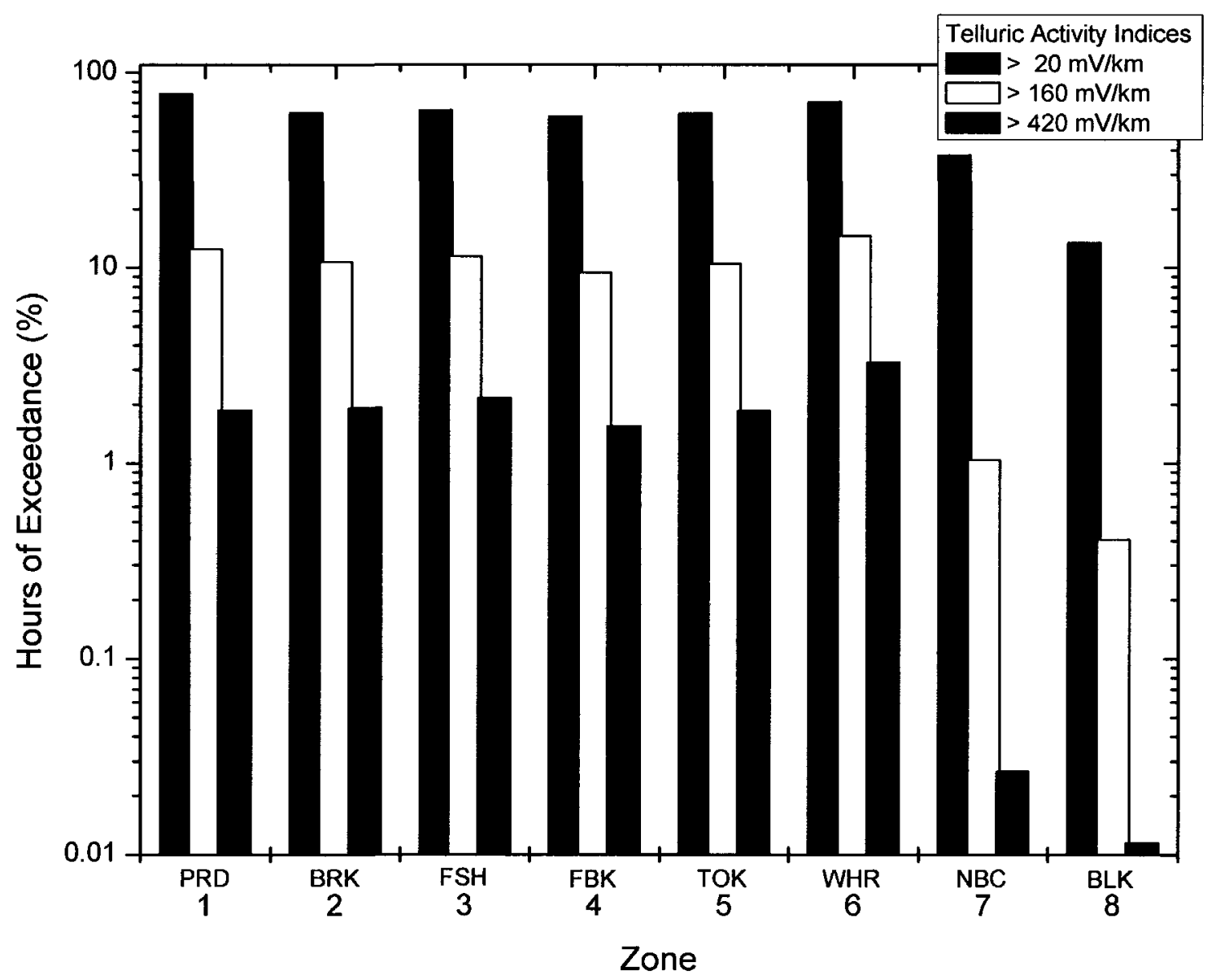

Figure 3.22. Percentage of hours exceeding the HMA telluric activity index - in an eastwest direction - for each resistivity zone for the entire 32 year time period between 1975 and 2007 (Boteler et al., 2009, Fig. 4.15). Abbreviations: PRD, Prudhoe Bay; BRK, Brooks Range; FSH, Fish Creek; FBK, Fairbanks; TOK, Tok; WHR, Whitehorse; NBC, Northern B.C; BLK, Boundary Lake; OTT, Ottawa 
The two southernmost zones, 7-Northern BC and 8-Boundary Lake, are the least active, having the smallest percentages of hours of exceedance for all three levels of activity. Telluric activity in Zone 6-Whitehorse is the most active, exceeding the highest level of $420 \mathrm{mV} / \mathrm{km}$ approximately $3 \%$ of the time, or almost 350 days over a 32 year period. However, for the other resistivity zones the percentage of hours of exceedance for the highest telluric activity level ranges between approximately $1.6-2.2 \%$ or almost 187 to 257 days over 32 years.

\subsection{Modelled PSP using 1D Earth Resistivity Models}

The main purpose of this section is to show the importance of and how an Earth resistivity model is used for pipeline design considerations. The effect of telluric activity on pipeline corrosion protection systems can be modelled using the geoelectric field (either directly measured or calculated using a 1D Earth resistivity model) as an input into a distributed-source transmission line (DSTL) model as has been shown in Chapter 2. DSTL modelling also utilizes the pipeline's physical characteristics as inputs. Due to the proprietary nature of these pipeline parameters (supplied by the pipeline company), only general descriptions can be given with some final results demonstrated.

The following parameters were supplied as inputs: approximate pipeline route with coordinates of each straight segment of the pipeline and its length, as well as physical and electrical characteristics of the proposed pipeline, such as diameter, pipeline steel wall thickness, steel resistivity, and coating conductance.

Calculations of PSP amplitude variations along the entire length of the proposed pipeline route were made by the Ottawa Geomagnetic Laboratory: first with a unit geoelectric field of $1 \mathrm{~V} / \mathrm{km}$ pointing towards geographic north (azimuth angle of $0^{\circ}$ ) and 
then a unit geoelectric field of $1 \mathrm{~V} / \mathrm{km}$ pointing towards geographic east (azimuth angle of $90^{\circ}$ ). A geoelectric field of $1 \mathrm{~V} / \mathrm{km}$ was selected as an estimate of the largest geoelectric field that the pipeline would experience. Resistance to ground, i.e. terminations, at the ends of the pipeline was assigned $15 \mathrm{ohms,}$ a typical value. Results of these model PSP calculations are shown in Figure 3.23.

Next, the PSP variations over a one-day time interval (Figure 3.24), showing the transition from quiet to storm geomagnetic conditions, were calculated for each of the eight resistivity zones along specific locations on the pipeline, as outlined in Boteler et al. (2009), using a continuously varying geoelectric field. These pipeline locations were representative places where the PSP (as determined from Figure 3.23) would exhibit the greatest amplitude, such as at bends (as described in Section 2.4.4). The geoelectric fields for each resistivity zone were calculated using geomagnetic data from the nearest observatory combined with the surface impedance for that zone.

As seen in Figure 3.23 it is the pipeline alignment and structure (Boteler, 2000; Pulkkinen et al., 2001) with respect to the orientation of the geoelectric field that determines the locations along the pipeline where the largest PSP amplitudes will occur. However, the actual value of PSP depends on the regional strength of geoelectric field which itself is dependent on the underlying Earth resistivity structure. For example, with a uniform geoelectric field the greatest change of modelled PSP amplitude occurs in Zone 3-Fish Creek during an east-west geoelectric field direction, and at the ends of the pipeline. But when modelled with a non-uniform geoelectric field, as shown in Figure 3.24, higher PSP amplitude also occurs in Zone 1-Prudhoe Bay and Zone 6-Whitehorse, even though resistivity of the upper crust is considerably less than in Zones 3 and 6 . The 

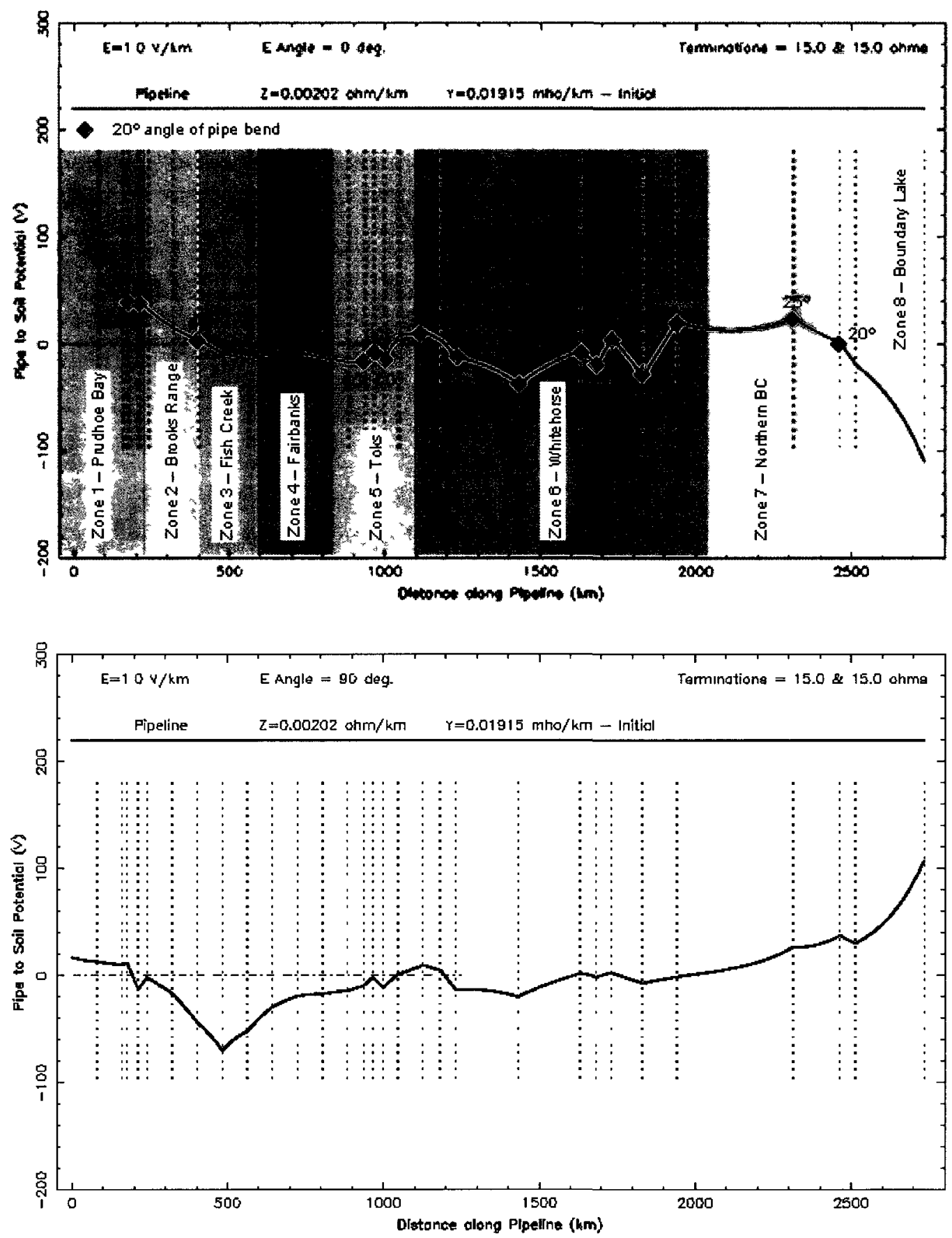

Figure 3.23. Modelled PSP, on the Alaska Highway Corridor pipeline, produced by a $1 \mathrm{mV} / \mathrm{km}$ geoelectric field flowing (top) geographic north-south; and, (bottom) geographic east-west (Boteler et al., 2009, Fig. 5.6 and 5.7). Terminating resistance, to ground, of $15 \mathrm{ohm}$ at ends of pipeline. The extent along the pipeline of each of eight resistivity zones is superimposed on the modelled PSP, in addition to the locations of major bends in the orientation of the pipeline. 


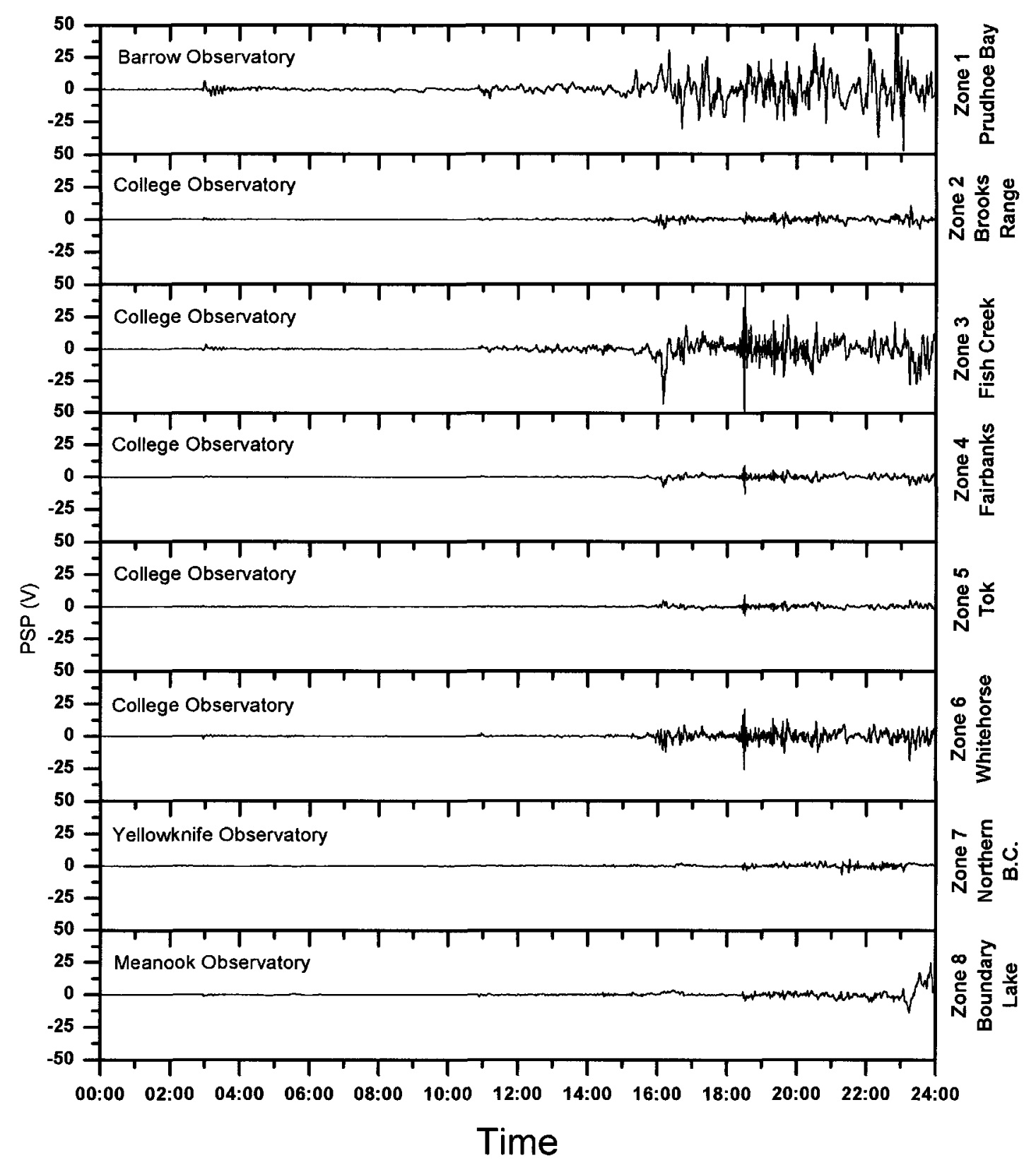

Figure 3.24. PSP variations that would be experienced in different resistivity zones, i.e. Earth models, along the Alaska Highway Corridor pipeline during a transition from geomagnetically quiet to storm conditions (Boteler et al., 2009, Fig. 6.4). PSP calculation based on geoelectric field occurring on November 07, 2004, using data from various geomagnetic observatories (listed for each zone). Ground connections of $15 \mathrm{ohm}$. 
upper crust is considerably less than in Zones 3 and 6 . The increased PSP amplitude seen at Zone 3-Fish Creek (Figure 3.24) could be more influenced by pipeline parameters as it is here that the route sharply changes direction (Figure 3.9). Also, the high PSP amplitude seen at Zone 1-Prudhoe Bay is a combined function of pipeline parameters, termination of pipe, and greater geomagnetic activity because the pipe end is located in the more disturbed high-level region of the auroral zone.

Nevertheless, for pipeline engineers the most important consideration is the overall PSP value at whatever location along a pipeline route, for once identified then mitigation to reduce the PSP amplitude can be initiated. Therefore it is critical that PSP modelling includes all possible causes of PSP variation, plus a statistical appreciation of when PSP variations reach a maximum during a solar cycle for it is when geomagnetic disturbances are greatest that the resulting PSP amplitude is likely to be at its highest value. Boteler et al. (2009) calculated the PSP variations for a 32 year period from 1975 to 2007 to show the statistical occurrences of the maximum PSP value in one hour as illustrated in Figure 3.25. It needs to be noted that the PSP values in Figure 3.25 represent the combined effect from local Earth resistivity, local geomagnetic field conditions (differing magnetic observatories), and pipeline characteristics including orientation of the pipeline with respect to the geomagnetic field. Zone 1-Prudhoe Bay is predicted to experience the highest occurrence of large PSP variations; the PSP hourly maximum amplitude would exceed $10 \mathrm{~V}$ for more than a month each year. Although the lower resistivity of the sedimentary basin beneath Zone 1 would be expected to diminish the size of the geoelectric field and the resulting PSP amplitude, it is the greater level of geomagnetic activity in the area and the situation of being at end of the pipeline that leads 

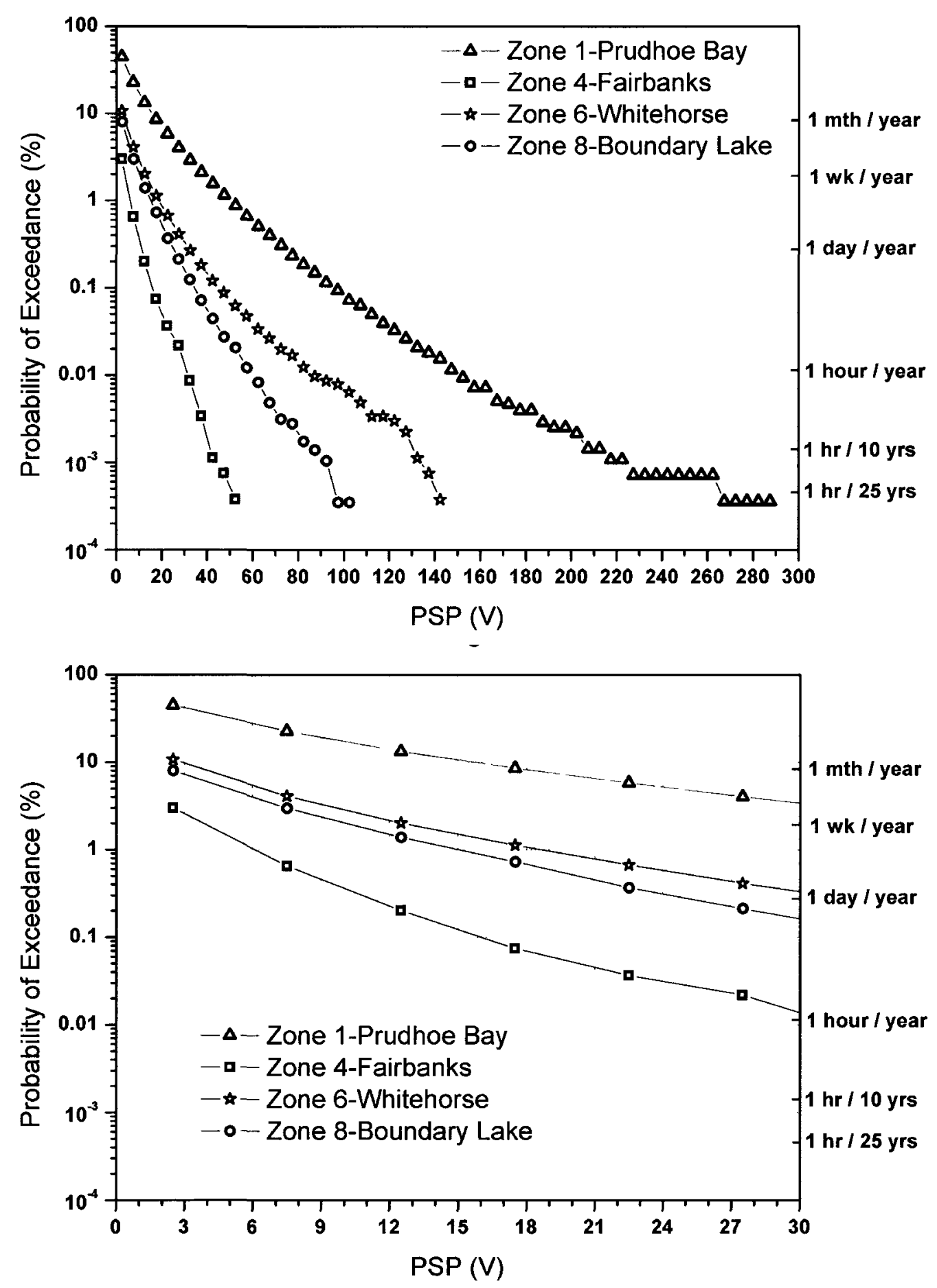

Figure 3.25. Statistical exceedance of PSP hourly maximum amplitude, based on a 32 year period from 1975 to 2007, for four resistivity zones (after Boteler et al., 2009, Fig. 6.11). Bottom panel provides an enlarged view of PSP exceedance from 0 to $30 \mathrm{~V}$. Calculated from a pipeline model with $15 \mathrm{ohm}$ grounding connections. 
to a larger PSP. The second and third highest occurrences are in Zone 6-Whitehorse and Zone 8-Boundary Lake both which are underlain by a resistive upper mantle which gives a higher geoelectric field and PSP, in addition to featuring a pipe bend (Zone 6) and being at end of pipe (Zone 8).

\subsection{Summary of Findings}

As a result of investigations undertaken of the Alaska Highway Corridor study area, the following findings and advancements were made:

a) The higher intensity of geomagnetic activity in the auroral zone leads to a correspondingly higher geoelectric field and PSP compared to geomagnetic activity in sub-auroral latitudes, and as a consequence telluric current interference on pipeline cathodic protection systems can be a significant engineering issue.

b) The regional variability of geomagnetic activity means that the AHC pipeline will be subjected to differing levels of PSP variation.

c) Division of the pipeline route on the basis of lithotectonic terranes is a viable means to broadly identify regions of different resistivity, thereby demonstrating that the Earth resistivity model is an important factor for telluric current assessment.

d) Eight new and original, literature-derived, 1D layered Earth resistivity models (representative of a zone of resistivity along the pipeline route) were developed.

e) Noticeable differences in Earth resistivity, such as in the upper mantle, affect the geoelectric field and consequently the PSP. Statistical evaluation of telluric activity has demonstrated that the southernmost portion of the pipeline route will experience the smallest amount of exceedance of a pre-defined activity level, with 
the highest exceedance centered at Whitehorse where upper mantle resistivity is greatest.

f) Confirmation that PSP results from the combined influence of Earth resistivity, geomagnetic activity and pipeline characteristics, thereby demonstrating that knowledge of all three components is desirable for modelling the PSP variation. 


\section{CHAPTER 4}

\section{MACKENZIE RIVER VALLEY}

\subsection{Overview and Objectives}

A 1,220 km long natural gas pipeline has been proposed for construction in the Northwest Territories of Canada, extending southeasterly from the Mackenzie Delta to the NWT-Alberta provincial boundary where it would join a pre-existing pipeline distribution network (see Figure 1.1). Much of the pipeline route lies within the Mackenzie River valley, and from Norman Wells southward the proposed route runs parallel to the existing Enbridge Inc. crude oil pipeline right-of-way.

Lying beneath the northern geomagnetic zones, a Mackenzie River valley pipeline serves as an important area to investigate the effects of telluric currents and how it influences the design of cathodic protection systems for the proposed pipeline (Fernberg et al, 2007b). A detailed analysis (Study of Telluric Current Impacts on the Mackenzie Gas Project Pipelines, by Boteler, D.H., Trichtchenko, L., and Fernberg, P., 2005) was completed by the Geomagnetic Laboratory, Ottawa, with the author of this thesis being responsible for a significant part of the report, such as the geological and geophysical compilation used to prepare the Earth resistivity models from which telluric effects are modelled. In addition, this author completed a limited magnetotelluric (MT) geophysical survey (Fernberg et al., 2007) along the pipeline route, the first time such a survey has been completed across the length of the Mackenzie River valley. Analysis of the MT survey results were also undertaken by this author and presented here within. 
This chapter summarizes the research undertaken for the telluric currents impact report with the focus being an assessment on the use of Earth resistivity models by comparing models derived either from a literature compilation or results from the MT geophysical survey. As previously done for the Alaska Highway Corridor study area (Chapter 3), zones along the pipeline route were identified which reflect a unique geological similarity and therefore different electrical resistivity values within each zone. One-dimensional (1D) Earth resistivity models were constructed, using two different methods, for each of the five different "resistivity zones" identified along the pipeline route. The first method utilized resistivity and Earth layer depths obtained through a literature compilation, the same approach (see section 3.5) as used to build the 1D Earth resistivity models for the Alaska Highway Corridor study area. An appendix provides tables detailing the information sources and justifications for resistivity values and thickness for layers shown in each of the literature-derived Earth resistivity models. The second method involved an inversion of MT survey data collected during summer 2006. The resulting 1D Earth resistivity models using the two methods were then compared. The purpose was to confirm the validity of using literature-derived resistivity values and depths.

In the same manner as done for the Alaska Highway Corridor, estimates of the geomagnetic activity were first prepared. Results of the estimation confirmed that telluric activity is elevated in the study area. In order to assess what effect elevated telluric activity would have on a pipeline a series of investigative steps were completed. First, using the Earth models, the geoelectric field was calculated for each of the five different resistivity zones along the pipeline route. Second, a statistical evaluation of telluric 
activity covering a 32 year span of time was undertaken using the calculated geoelectric fields. And third, the calculation of pipe-to-soil (PSP) variations was undertaken to demonstrate their usefulness for design considerations.

\subsection{Geomagnetic Climatology}

Analysis of the geomagnetic activity was made using data from the only geomagnetic observatory in the area, Yellowknife (YKC). Geomagnetic data (1-minute sampling) were processed to determine Maximum Hourly Range (in the north-south direction, referred to as HRX) and which serves as an index of geomagnetic activity. For a comparison against a normal sub-auroral level of geomagnetic activity, i.e. baseline condition, data from Ottawa Geomagnetic Observatory were used in the same way as done for the Alaska Highway Corridor. A quiet level of geomagnetic activity of $40 \mathrm{nT}$ was chosen for representative year 2004. In Ottawa, the HRX geomagnetic activity index is lower than $40 \mathrm{nT}$ for $95 \%$ of the year. For the Mackenzie River valley geomagnetic activity indices were determined as follows:

- Quiet Level: $40 \mathrm{nT}$

- Unsettled Level: $300 \mathrm{nT}$

- Active Level: $600 \mathrm{nT}$

Because the operational lifespan of a pipeline ranges from 30 to 50 years, it is imperative that the geomagnetic activity over a similar duration be determined. Thus the Yellowknife geomagnetic data covering the 30 -year period from 1975 to 2004 were analyzed to establish the HRX of geomagnetic activity covering the pipeline route. The percentage of yearly exceedance for each of the geomagnetic activity indices (HRX for 40,300 and $600 \mathrm{nT}$ ) was determined and presented at the Figure 4.1. 


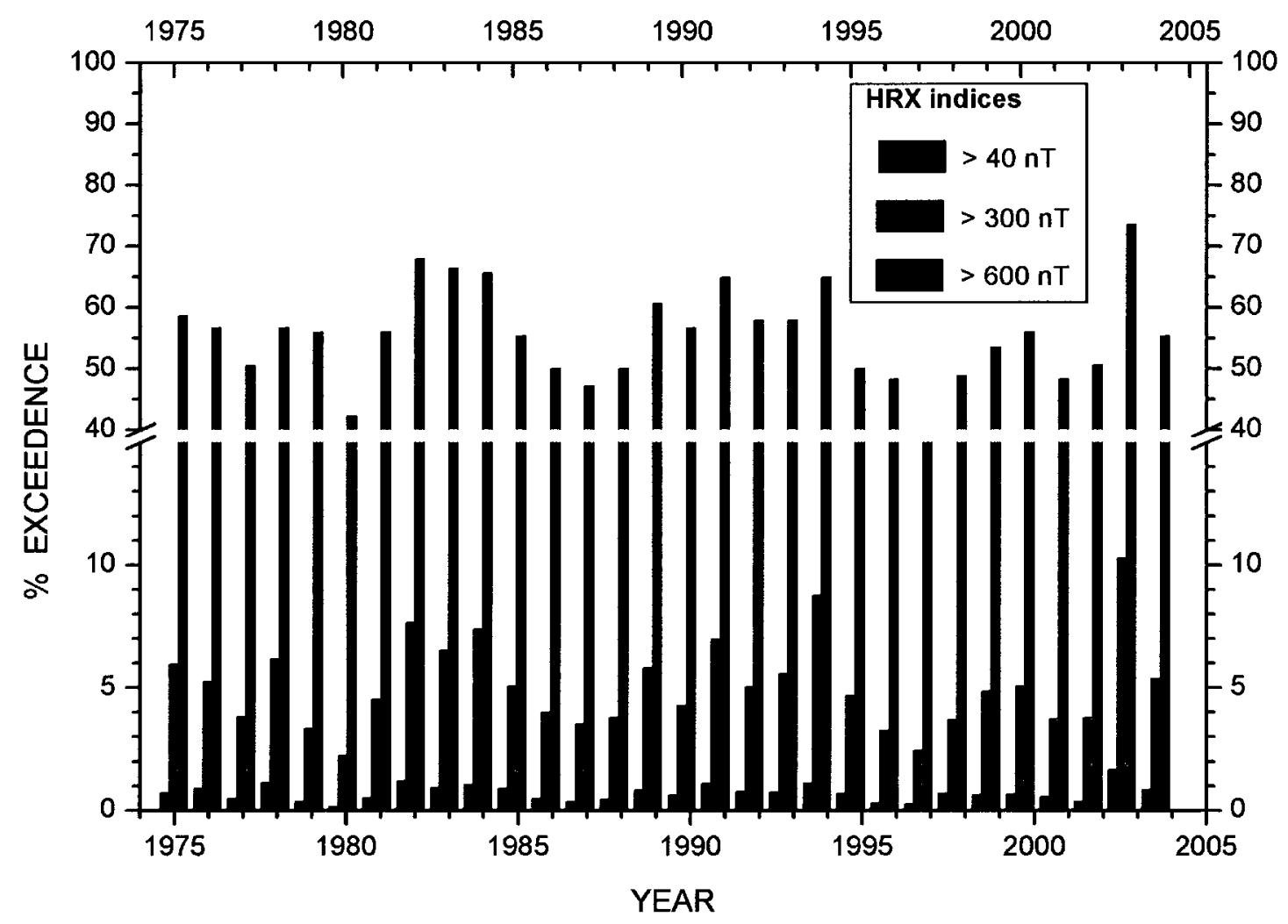

Figure 4.1. Percentage of exceedance of HRX in Yellowknife for three geomagnetic activity levels (modified from Boteler et al., 2005, Fig. 2.8). 


\subsection{Geological Setting along Pipeline Route}

\subsubsection{Tectonic Framework, Bedrock Geology and Major Faults}

The geological framework (Figure 4.2) of the western region of the Northwest Territories (NWT) consists of a thin cover of unconsolidated, glacially derived sediments on top of the nearly horizontal sedimentary bedrock of the Interior Platform geological province, which overlies ancient metasedimentary and crystalline rocks of the Canadian Precambrian Shield. Mountains of the Cordillera bound part of the west margin of the Interior Platform, where between Norman Wells and north of Fort Simpson the pipeline crosses portions of the folded Cordilleran mountain ranges. Forming the northern edge of the NWT is the Arctic Continental Shelf, where along the coastline is the BeaufortMackenzie Basin, a 12 to $14 \mathrm{~km}$ thick offshore package of continental margin sediments (Dixon et al., 1992).

Most of the pipeline route follows the northern continuation of the Interior Platform geological province, an assemblage of strata that forms the Western Canadian Sedimentary Basin; it being an eastward tapering wedge onto the Precambrian shield (Stott and Klassen, 1993). Basin rocks consist of lower and middle Paleozoic clastics (siltstone, sandstones), carbonates (limestone, dolomite) and evaporate (halite, gypsum) beds that are covered by an uppermost veneer of Cretaceous-age clastic rocks. In the Norman Wells area, the sedimentary basin is about $2 \mathrm{~km}$ thick, but in the only about $1 \mathrm{~km}$ in the Fort Simpson area.

Buried beneath the Interior Platform are the older Proterozoic and Archean age rocks of the Canadian Shield that have been-subdivided into numerous domains that reflect origin and dominant rock type. These domains reflect the accretion of early 


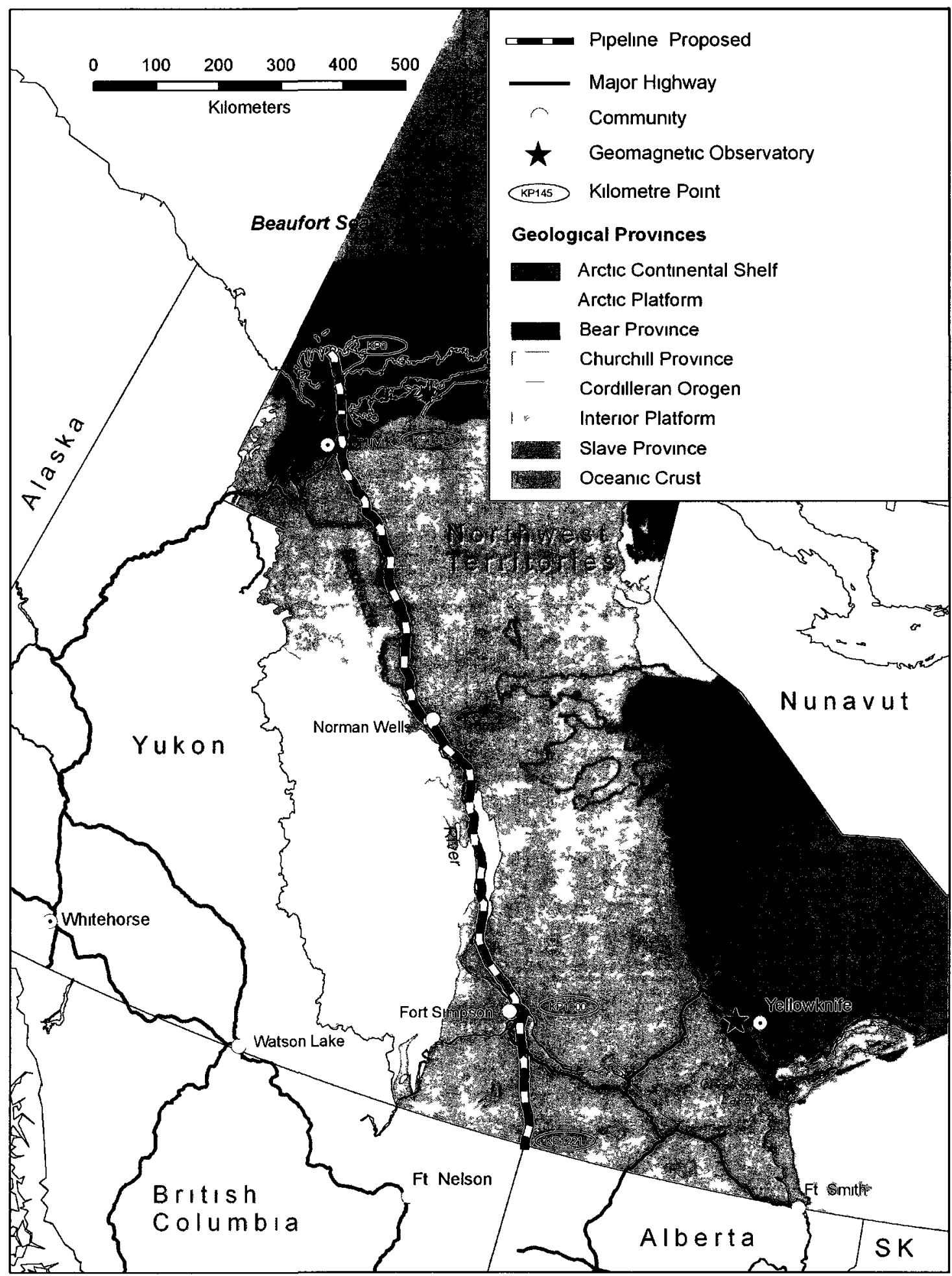

Figure 4.2. Major geological framework within the western portion of the Northwest Territories (modified from Fernberg et al., 2007). 
Precambrian micro-continents onto the pre-existing Slave craton (Villeneuve et al., 1993).

Major faults and other structures crossing the pipeline route include the following:

- Taglu Fault Zone - at about $130 \mathrm{~km}$ north of Inuvik - is a northeast striking fault parallel to the Eskimo Lakes Fault Zone

- Eskimo Lakes Fault Zone - about $60 \mathrm{~km}$ north of Inuvik - is an array of northeast striking en-echelon faults, which define the southeast margin of the Beaufort-Mackenzie Basin

- Cordilleran Deformation Front - swings across the pipeline at about kilometre point (KP) 545-875 - and marks the boundary between the Cordilleran mountain ranges and flat terrain of the Interior Platform.

- Beaver River Structure - at about KP 1010 - is an ancient, possibly Precambrian, cross-strike structural discontinuity.

\subsubsection{Surficial sediments}

Surficial sediments (including overburden soils into which is buried the pipe) at the north and south ends of the pipeline route consist of thin and discontinuous to thick and continuous deposits of glacial till. The Mackenzie Delta itself is characterized by modern alluvial deposition (over an older deltaic complex) onto a broad floodplain with thousands of ponds, and point bars and channel bars of the numerous meandering river channels. Much of the central axis of the Mackenzie Valley (bounding the river) is characterized by thick deposits of glaciolacustrine and lacustrine silt and clay (Aylsworth et al., 2000). Modern alluvial sediments of sand and gravel follow the river channel, but generally do not underlie the pipe route. 


\subsubsection{Permafrost Distribution and Depth}

Permafrost underlies most of the Mackenzie Valley, almost continuous and deep in the north becoming progressively discontinuous and thinner to the south (Terrain Science Division, 2005a). As a result, surficial sediments are usually frozen and often contain ground ice (Aylsworth et al., 2000). Permafrost depth can be variable. In the Mackenzie Delta, it is less than $100 \mathrm{~m}$ but it is over $600 \mathrm{~m}$ in the adjoining coastlands (Taylor et al., 2000). At Inuvik, thicknesses greater than $100 \mathrm{~m}$ are common. In the Norman Wells area, permafrost thickness varies from $35 \mathrm{~m}$ to $143 \mathrm{~m}$.

\subsection{Geophysical Surveys in the Mackenzie River Valley}

\subsubsection{Previous Surveys}

While there have been a considerable number of near-surface geophysical surveys that dealt with mapping of permafrost in various areas of the Mackenzie Valley, there has only been one survey investigating the deep crustal geoelectric structure. Several nearsurface EM geophysical surveys have been completed since the 1970s (Northern Engineering, 1976, 1977; Arcone et al., 1998; Associated Mining, 2004; Brantford et al., 2005; Scott et al., 1990) to measure the electrical resistivity of frozen and unfrozen surface sediments along the Trans-Alaska and Norman Wells pipeline routes, as well as at the Arctic Test Facility at San Sault, NWT (Northern Engineering, 1972) and in the Mackenzie Delta (Redman and Bauman, 2004). The focus was on determining the contrast between frozen and unfrozen ground, and whether geophysical methods could be used to estimate depth of permafrost.

The earliest known MT survey undertaken in the Mackenzie Valley region was in 1974 to test the usefulness of the audiomagnetotellutic method for mapping permafrost 
depth (Koziar and Strangway, 1979). The experiment was done at the Involuted Hill GSC permafrost test site, located in the Tuktoyaktuk peninsula, $100 \mathrm{~km}$ east of the proposed pipeline route.

Between 1996 to 2000, the Geological Survey of Canada (GSC) as part of the Lithoprobe SNORCLE (Slave-Northern Cordillera Lithospheric Evolution) program completed four regional-scale crustal transects (Figure 4.3) crossing the main geological structures in the Yukon, Northwest Territories and British Columbia. Only Corridor 1 extended across the Mackenzie River valley and proposed pipeline route, coming within $25 \mathrm{~km}$ south of Fort Simpson. The crust was imaged using both seismic and MT methods. Comprehensive 1D and 2D interpretations have been published by several authors (Cook et al., 1999; Cook and Erdner, 2005; Jones et al., 2005; Wu et al., 2005).

More recently, the GSC has completed AMT / MT surveys during winters 2007 and 2008 as part of investigations examining the potential for gas hydrate deposits in the Mackenzie Delta (Craven, 2007; Craven et al., 2009). The investigations were done at the Mallik gas hydrate production research well located on Richards Island, about $20 \mathrm{~km}$ east of the proposed pipeline route. However, no inversion models have been published at this time.

\subsubsection{MRV Magnetotelluric Survey, 2006}

As a component of this thesis, a MT test survey was completed by this author and

Dr. C. Samson. The purpose was to measure the Earth resistivity and compare the field data with literature data. A commercially available 5-component MT instrument (Phoenix Geophysics MTU-5A system) was used to measure simultaneously the orthogonal surface geoelectric field, in a north-south $\left(E_{x}\right)$ and east-west $\left(E_{y}\right)$ direction as 


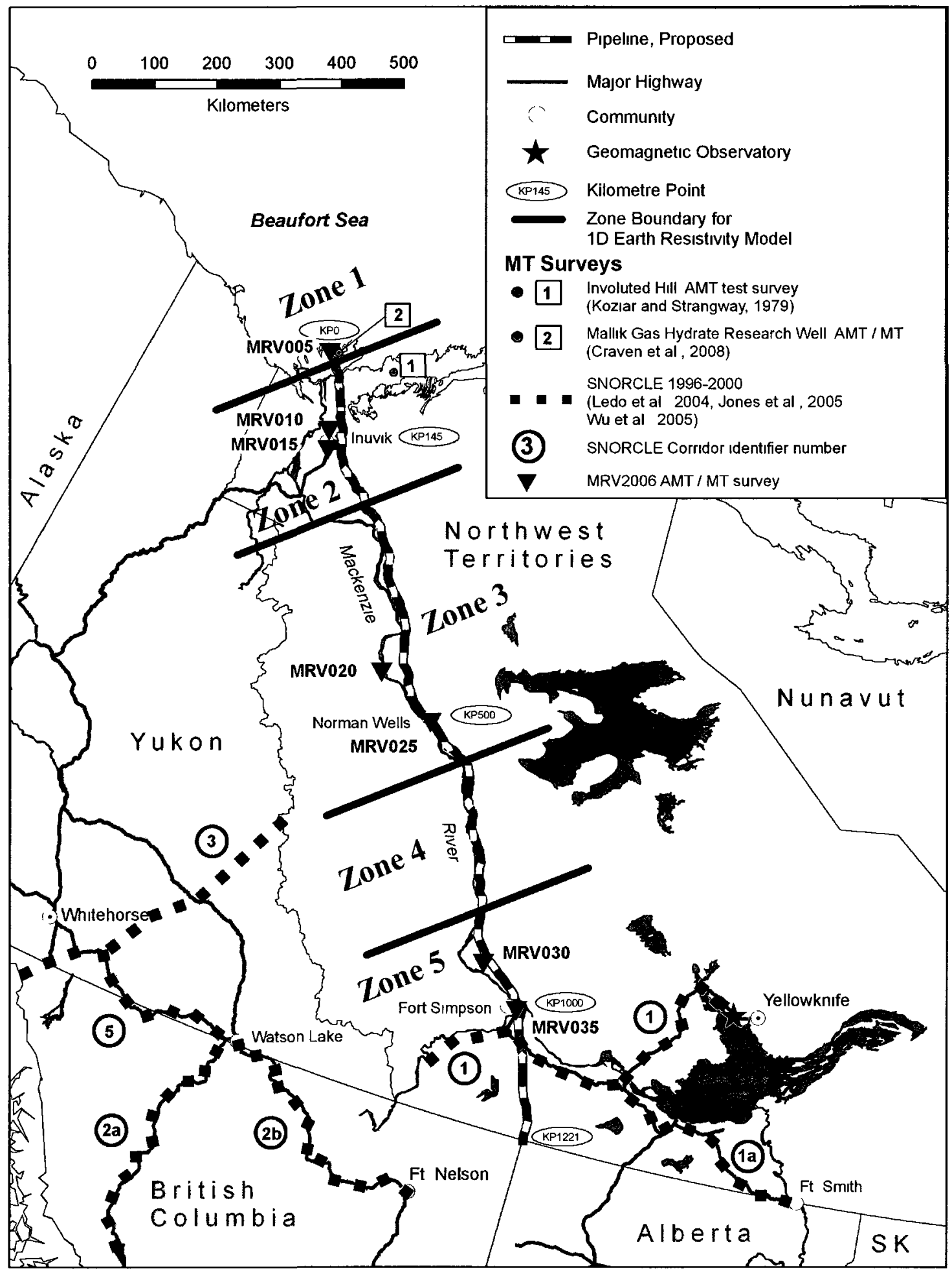

Figure 4.3. Location of selected geophysical surveys completed proximal to the regional to the Mackenzie River valley pipeline route. Zones 1 to 5 refer to regions where the various literature-derived 1D Earth resistivity models apply. 
well as the horizontal $\left(H_{x}, H_{y}\right)$ and vertical $\left(H_{z}\right)$ components of the magnetic field. The two horizontal components of the geoelectric field were measured using electrodes at the ends of $100 \mathrm{~m}$ long wire dipoles. The three components of the geomagnetic field were measured by induction coils oriented magnetic north-south, magnetic east-west and vertically, respectively.

At each MT recording site, both audio-frequency range $(10-10000 \mathrm{~Hz})$ and broadband frequency $(.001-400 \mathrm{~Hz})$ variations of the geoelectric and geomagnetic fields were recorded as time-series data. Data were time stamped using the global positioning system. The MT instrument samples the five components at three different frequencies, continuously at $15 \mathrm{~Hz}$, and intermittently at 150 and $2400 \mathrm{~Hz}$, whereas the AMT instrument samples continuously at $150 \mathrm{~Hz}$ and intermittently at 2400 and $24000 \mathrm{~Hz}$.

The Mackenzie River Valley (MRV) magnetotelluric survey was conducted over a 20-day period in August - September, 2006. MT soundings were undertaken at seven sites (Figures 4.3 and 4.4 and Table 4.1) spaced along the length of the Mackenzie Corridor. Valid data were recorded at all sites except at MRV015 (Inuvik seismograph station) where data were severely disrupted by cultural electromagnetic noise, possibly a consequence of operations at the nearby Inuvik airport.

The survey was designed so that, in most cases, two sites distant from each other were recording simultaneously to allow for both AMT and MT data to be processed using the remote reference noise attenuation method. Instrument problems at site MRV020 Mountain River prevented the recording of AMT data. 


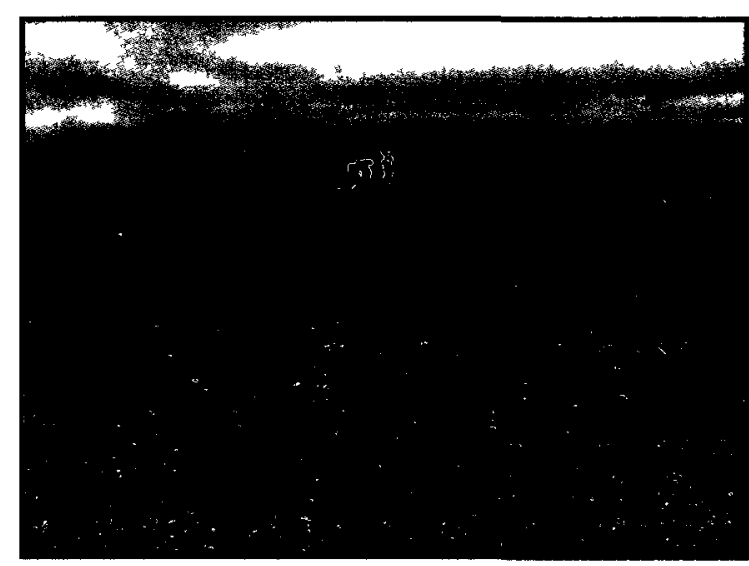

A

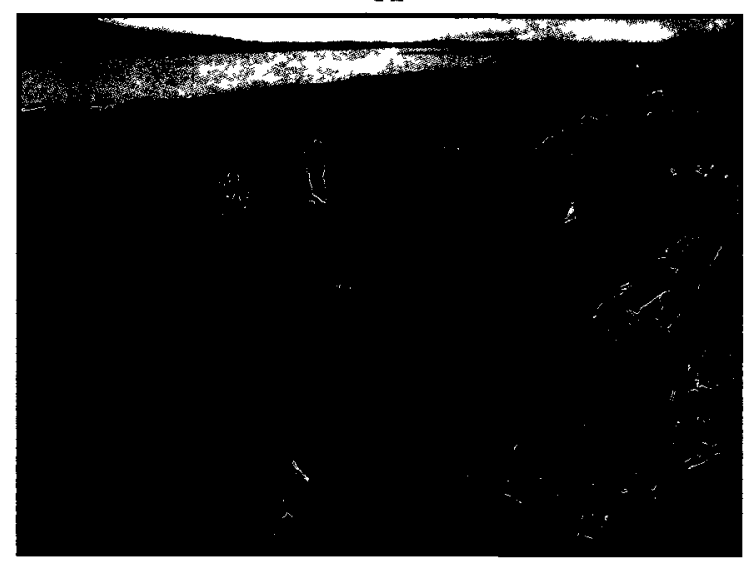

C

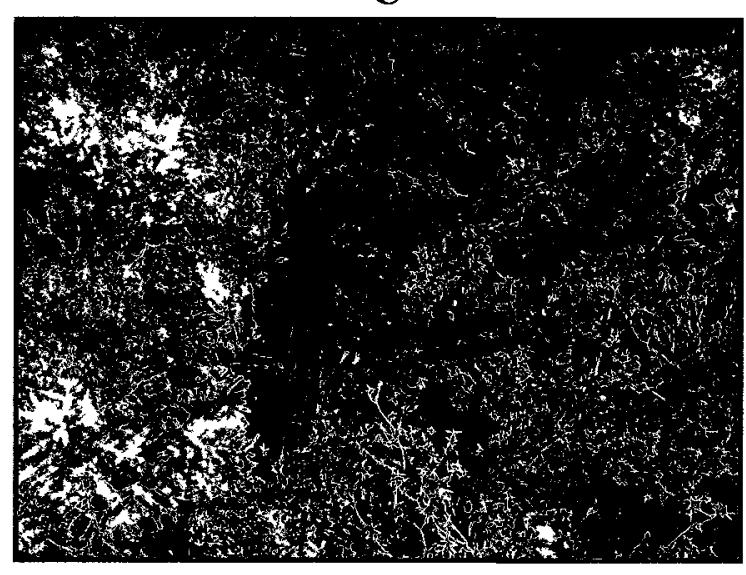

E

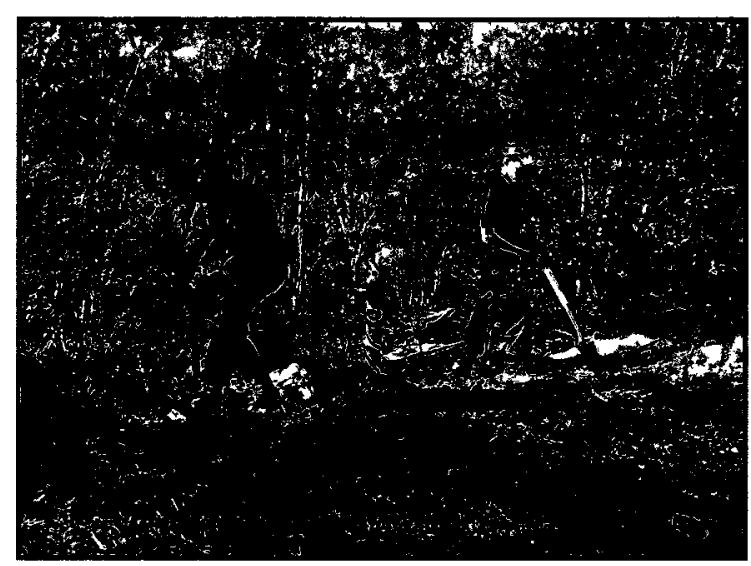

B

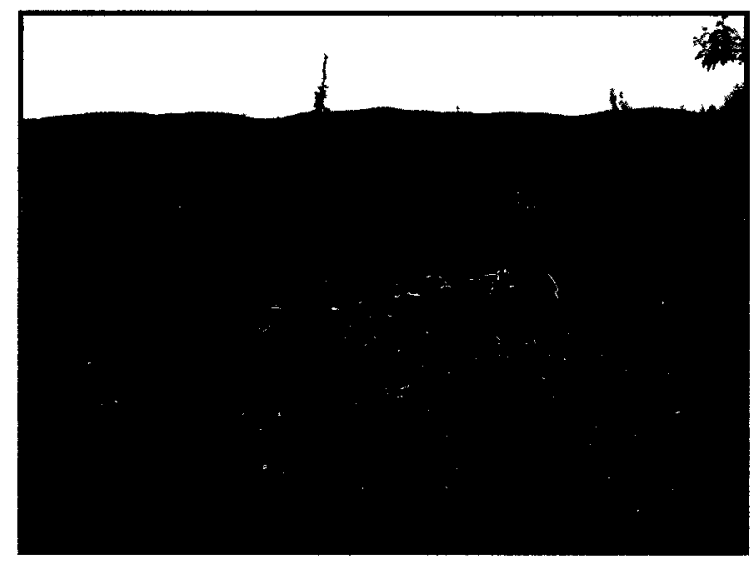

D

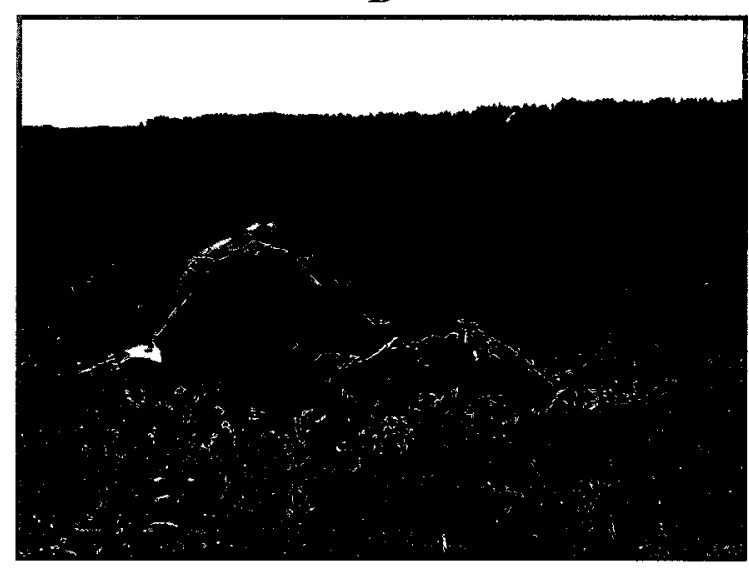

$\mathbf{F}$

Figure 4.4. Views of sounding sites and instruments for the MT survey undertaken in the Mackenzie River valley, summer 2006. (A) MRV005 Taglu, adjacent to a channel of the Mackenzie River delta: partially buried wire connecting electrodes visible in foreground. (B) MRV010 Inuvik: vertical induction coil being installed. (C) MRV020 Mountain River, on the banks of the Mackenzie River. (D) MRV025 Norman Wells: recording instruments. (E) MRV030 Peatland: buried horizontal induction coil in sphagnum moss. (F) MRV035 Fort Simpson airport: installation near a runway. 
Table 4.1. Data acquisition summary for the MRV 2006 magnetotelluric survey

\begin{tabular}{|c|c|c|c|}
\hline $\begin{array}{l}\text { Sounding } \\
\text { Site }\end{array}$ & $\begin{array}{l}\text { Geographic } \\
\text { Coordinates }\end{array}$ & $\begin{array}{l}\text { Recording } \\
\text { Date \& } \\
\text { Duration }\end{array}$ & Site Conditions \\
\hline $\begin{array}{l}\text { MRV005 } \\
\text { Taglu }\end{array}$ & $\begin{array}{l}6922.053 \mathrm{~N} \\
13457.300 \mathrm{~W}\end{array}$ & $\begin{array}{l}\text { Aug. } 23 / 24 \\
\text { MT: } 18 \mathrm{hrs} \\
\text { AMT: } 18 \mathrm{hrs}\end{array}$ & $\begin{array}{l}\text { - Adjacent to a river channel } \\
\text { - Typical Mackenzie Delta } \\
\text { surface conditions: poorly- } \\
\text { drained organic silt with fine } \\
\text { sand } \\
\text { - Permafrost } \approx 600 \mathrm{~m} \text { thick } \\
\end{array}$ \\
\hline $\begin{array}{l}\text { MRV010 } \\
\text { Inuvik, } \\
\text { SuperDarn } \\
\text { Radar Site }\end{array}$ & $\begin{array}{l}6824.841 \mathrm{~N} \\
13346.157 \mathrm{~W}\end{array}$ & $\begin{array}{l}\text { Aug. 21/22 } \\
\text { Aug. } 23 / 24 \\
\text { MT: } 18 \mathrm{hrs} \\
\text { AMT: } 18 \mathrm{hrs}\end{array}$ & $\begin{array}{l}\text { - } 6 \mathrm{~km} \text { north of town } \\
\text { - Alluvial fan consisting of silty } \\
\text { clay and sand with pebbly } \\
\text { layers } \\
\text { - Permafrost } \approx 200 \mathrm{~m} \text { thick }\end{array}$ \\
\hline $\begin{array}{l}\text { MRV015 } \\
\text { Inuvik, } \\
\text { Seismograph } \\
\text { Station } \\
\end{array}$ & $\begin{array}{l}6810.417 \mathrm{~N} \\
133 \quad 31.503 \mathrm{~W}\end{array}$ & $\begin{array}{l}\text { Aug. 21/22 } \\
\text { MT: } 11 \mathrm{hrs} \\
\text { AMT: } 11 \mathrm{hrs}\end{array}$ & $\begin{array}{l}\text { - } 10 \mathrm{~km} \text { southeast of town } \\
\text { - Sphagnum moss and peat } \\
\text { veneer on top of bedrock }\end{array}$ \\
\hline $\begin{array}{l}\text { MRV020 } \\
\text { Mountain River }\end{array}$ & $\begin{array}{l}6539.759 \mathrm{~N} \\
12846.880 \mathrm{~W}\end{array}$ & $\begin{array}{l}\text { Aug. } 27 / 28 \\
\text { MT: } 17 \mathrm{hrs} \\
\text { AMT: } 1 \mathrm{hr}\end{array}$ & $\begin{array}{l}\text { - } 2 \mathrm{~km} \text { south of rivers } \\
\text { confluence } \\
\text { - Alluvial channel deposits on } \\
\text { south bank of Mackenzie } \\
\text { River } \\
\text { - Permafrost } \approx 75 \mathrm{~m} \text { thick }\end{array}$ \\
\hline $\begin{array}{l}\text { MRV025 } \\
\text { Norman Wells }\end{array}$ & $\begin{array}{l}6515.111 \mathrm{~N} \\
12639.866 \mathrm{~W}\end{array}$ & $\begin{array}{l}\text { Aug. } 27 / 28 \\
\text { MT: } 17 \mathrm{hrs} \\
\text { AMT: } 17 \mathrm{hrs}\end{array}$ & $\begin{array}{l}\text { - } 8 \mathrm{~km} \text { southeast of town } \\
\text { - Alluvial terrace, consisting of } \\
\text { sand and silt underlain by } \\
\text { gravel in places } \\
\text { - Permafrost } \approx 50 \mathrm{~m} \text { thick }\end{array}$ \\
\hline $\begin{array}{l}\text { MRV030 } \\
\text { Peatland }\end{array}$ & $\begin{array}{l}6216.564 \mathrm{~N} \\
12236.179 \mathrm{~W}\end{array}$ & $\begin{array}{l}\text { Sept. } 02 / 03 \\
\text { MT: } 15 \mathrm{hrs} \\
\text { AMT: } 15 \mathrm{hrs}\end{array}$ & $\begin{array}{l}\text { - Adjacent to highway, } 90 \mathrm{~km} \\
\text { northeast of Fort Simpson } \\
\text { - Bog dominant peatland } \\
\text { surrounded by till plain } \\
\text { - Permafrost } \approx 7 \mathrm{~m} \text { thick }\end{array}$ \\
\hline $\begin{array}{l}\text { MRV025 } \\
\text { Fort Simpson, } \\
\text { Airport }\end{array}$ & $\begin{array}{l}6146.149 \mathrm{~N} \\
121 \quad 14.378 \mathrm{~W}\end{array}$ & $\begin{array}{l}\text { Sept. } 01 / 02 \\
\text { Sept. } 02 / 03 \\
\text { MT: } 17 \mathrm{hrs} \\
\text { AMT: } 17 \mathrm{hrs}\end{array}$ & $\begin{array}{l}\text { - } 8 \mathrm{~km} \text { southeast of town } \\
\text { - Sandy lacustrine deposits } \\
\text { - Permafrost } \approx 10 \mathrm{~m} \text { thick }\end{array}$ \\
\hline
\end{tabular}




\subsection{Modelling of Earth's Electrical Resistivity}

\subsubsection{Literature-Derived 1D Earth Resistivity Model.}

Depending on the location along the Mackenzie River Valley, the model consists of the following seven or eight layers, from surface downwards: overburden; unconsolidated surficial sediments; sedimentary cover rock (basin); upper crust, middle and/or lower crust; and an upper, middle and lower mantle. Inclusion of a thin overburden layer ( $<6 \mathrm{~m}$ thick), including soil, allowed the model to take into account the uppermost Earth layer in which the pipeline rests and which is commonly permafrost, and to investigate its influence on telluric currents. Surficial sediments comprise a much thicker layer, usually a continuation of the same Earth material as in the overburden layer, and usually unfrozen. The gently dipping sedimentary cover rocks of the Interior Platform (referred here as sedimentary basin) have been considered as a separate homogenous layer on the basis of its low electrical resistivity and approximate 1D structure, even though strictly speaking it is part of the upper crust. For the models constructed, the crust is considered to be the Precambrian basement rock and divided into an upper and mid/lower portion on basis of electrical resistivity. Mantle divisions reflect significant physical and mineral differences which affect the electrical resistivity.

Of particular interest were resistivity measurements obtained from geophysical surveys undertaken in the Mackenzie Valley. Wherever possible these resistivity values were used in construction of the 1D Earth resistivity models. The reason is that geophysical surveys measure an apparent resistivity which better represents the "bulk" resistivity of the earth materials over a larger area than a laboratory sample which is specific to a particular location and / or depth. 
Unlike the methodology followed for the Alaska Highway Corridor (see Section 3.5.2), the Mackenzie River Valley study area was divided into zones on the basis of permafrost distribution and depth (see Figure 4.3). Then for each zone, a 1D Earth resistivity model was constructed. Zone 1 covers the continuous and deepest permafrost region in the valley, down to $600 \mathrm{~m}$ on the Beaufort Sea coast (excluding the Mackenzie Delta itself). Zone 2 is also underlain by continuous permafrost, but with depths anywhere from 50 to $400 \mathrm{~m}$. Zones 3 and 4 cover the transition from extensive discontinuous to intermediate discontinuous permafrost, with depths ever decreasing from 150 to $70 \mathrm{~m}$ or even more shallow. Zone 5 is in the sporadic discontinuous region, and where permafrost occurs the depth is less than $20 \mathrm{~m}$ thick.

As was done with the Alaska Highway Corridor, the assumption is made that the resistivities and layer thicknesses are the same over the entire extent of each individual zone. Because resistivities and layer thicknesses for southernmost Zone 5 were obtained from the Lithoprobe SNORCLE Corridor 1 transect, these parameters were considered to have a higher degree of confidence (being ex-situ measurements obtained from a combined seismic and MT survey) and thus were given greater consideration for application to some of the layers for Zone 4 situated further north. Resistivity values for the bottom half of the Earth models, the mid to lower crust and the mantle, were obtained from the 1D Earth model of the Canadian Prairie provinces as developed by Ferguson and Odwar (1997).

Appendix A4.1 presents the 1D Earth resistivity models that characterize the five resistivity zones along the proposed pipeline corridor as Figures A4.1 to A4.5, as well as 
justification and data source(s) for the assigned layer thicknesses and resistivities. For each model, there is an accompanying summary table (Tables A4.1 to A4.5).

Figure 4.5 is a compilation of all five Earth resistivity models and provides a visual comparison between them. A major difference exists between Zone 1 and the other zones. Surficial sediments have accumulated to a thickness of $600 \mathrm{~m}$ in the Mackenzie Delta (Todd and Dallimore, 1998) and the underlying Beaufort-Mackenzie sedimentary basin is exceptionally thick (> $12 \mathrm{~km}$ ) offshore of Zone 1 .

Overburden and surficial sediments exhibit a variable resistivity ranging from approximately $10 \mathrm{ohm} . \mathrm{m}$ to more than $1000 \mathrm{ohm} . \mathrm{m}$ depending on porosity, groundwater conductivity and clay content. Lowest resistivity values occur in clay dominant sediment, mid-values for silt and / or glacial till, and the highest resistivity in gravel and sand. Where permafrost is present, the resistivity generally doubles in finer sized sediments such as clay and silt, and increases by a half-order magnitude for the coarser sands and gravels (Palacky, 1988). Based on a compilation (Associated Mining, 2004) of resistivity values for frozen and unfrozen soil types in the Fort Simpson area, overburden was assigned a resistivity representing the dominant material (e.g. silt, clayey silt and silty sand) at the location of each Earth model. Typical overburden was silt, clayey silt and silty sand. Surficial sediments were assigned an average resistivity of $60 \mathrm{ohm} . \mathrm{m}$ on the basis of MT results from the SNORCLE transect south of Fort Simpson. Overburden depth was less than $6 \mathrm{~m}$, and depth of surficial sediments ranged between 60 and $150 \mathrm{~m}$. The exception was Zone 1 where frozen sediments extend to a maximum depth of $600 \mathrm{~m}$, with a resistivity greater than $100 \mathrm{ohm} . \mathrm{m}$. 


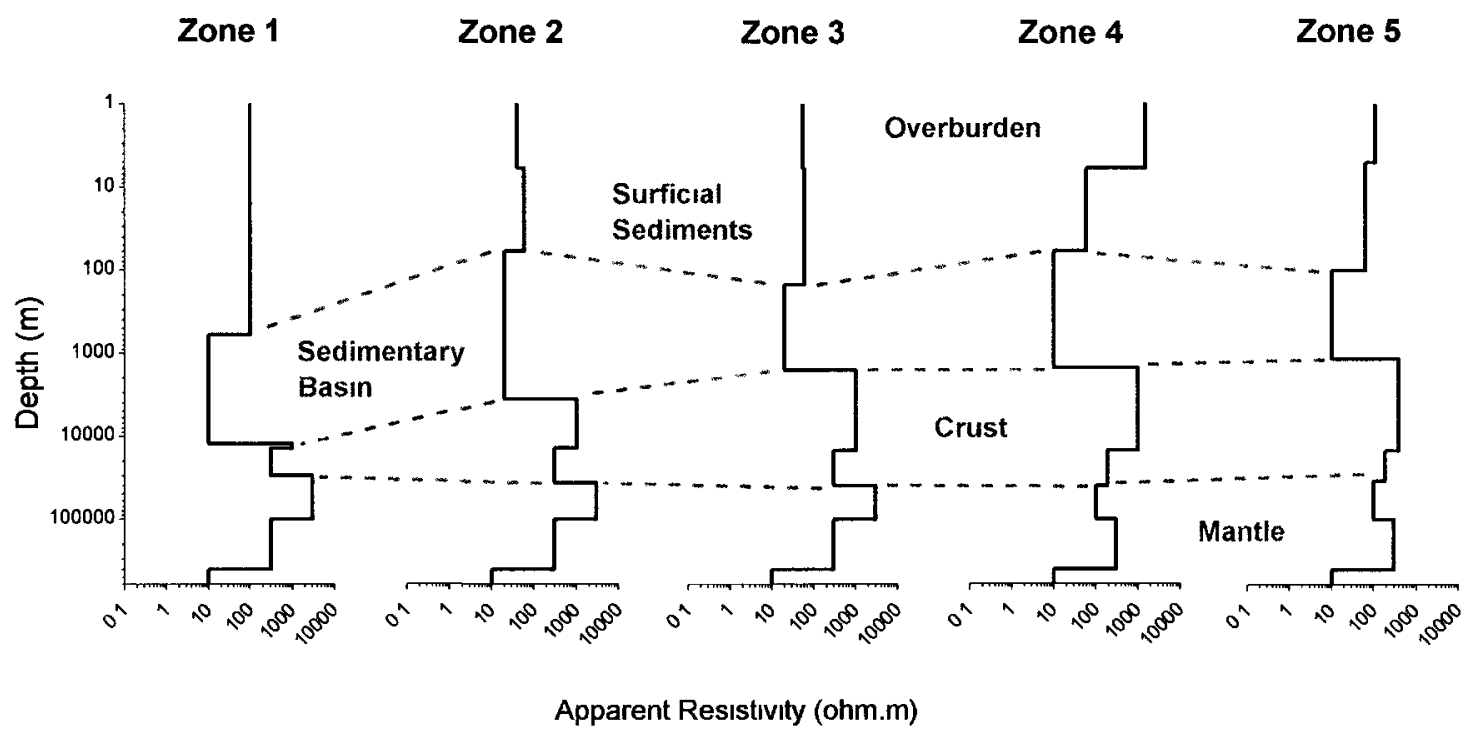

Figure 4.5. Compilation of the five 1D Earth resistivity models along the proposed Mackenzie River valley pipeline route, as shown in Figure 4.3. 
For the sedimentary basin layer, the assigned resistivity ranged from 10 to 20 ohm.m. Average resistivity of unmetamorphosed to slightly-metamorphosed sedimentary basin rocks of the Interior Platform is 10 to $30 \mathrm{ohm} . \mathrm{m}$ (Ferguson and Odwar, 1997). Results from the SNORCLE transect show a $10 \mathrm{ohm} . \mathrm{m}$ resistivity (Wu et al., 2005), although hydrocarbon exploration well logs reveal a range of 8 to greater than 500 ohm.m in the limestone and dolostone dominant rock $(\mathrm{Wu}, 2001)$. Hence, the sedimentary basin layer was given a $10 \mathrm{ohm} . \mathrm{m}$ resistivity for the southern portion (Zones 4 and 5) and an average $20 \mathrm{ohm} . \mathrm{m}$ for the mid-portion (Zones 2 and 3) of the pipeline route. Previous geophysical surveying in the Mackenzie Delta indicated an average resistivity of $10 \mathrm{ohm} . \mathrm{m}$ for sedimentary basin bedrock in Zone 5 (Redman and Bauman, 2004). Proceeding northward, the thickness of the sedimentary basin layer increases from $1000 \mathrm{~m}$ in Zone 5 to $3500 \mathrm{~m}$ in Zone 2, eventually becoming several kilometers thick offshore of the Mackenzie Delta (Zone 1).

The upper crust layer, for Zones 1 to 4 , was assigned a consistent $1000 \mathrm{ohm} . \mathrm{m}$ resistivity which represents the lower end of the resistivity range for crustal rocks in the Prairie provinces. The exception was Zone 5 where the upper crust exhibits a 400 to $1000 \mathrm{ohm} . \mathrm{m}$ resistivity that has been interpreted to represent the buried sedimentary Proterozoic Fort Simpson Basin (Wu et al., 2005). Upper crust thickness increases southward, from possibly less than $2 \mathrm{~km}$ in Zone 1 to about $12-14 \mathrm{~km}$ in Zone 5 . The middle and lower crust were combined into a single layer for all zones. For Zones 1 to 3, mid/lower crust layer was assigned an average resistivity value ( $300 \mathrm{ohm} . \mathrm{m})$, the same as for the Prairie provinces model. For Zones 4 and 5, the resistivity (190 ohm.m) was same as previously determined by $\mathrm{Wu}$ (2001) reflecting the lower resistivity found in the 
mid/lower crust south of Fort Simpson. The 190 to $300 \mathrm{ohm} . \mathrm{m}$ assigned resistivity falls within the global range for mid / lower continental crust as compiled by Simpson and Barr (2005).

Along the pipeline route, depth to the crust-mantle boundary (Moho) varies; however, the exact value was dependent on the quality of available information. Crustal thicknesses have been constrained fairly accurately by deep sensing geophysical surveys using seismics in the north and seismic / magnetotelluric in the south. In the BeaufortMackenzie Basin, at the northern terminus of the pipeline route, depth to Moho varies little, lying between 35 and $38 \mathrm{~km}$ (O'Leary, 1995). For the central portions of the route, a general depth of $40 \mathrm{~km}$ is assumed, the same as quoted in the average 1D Earth resistivity model for the Prairie provinces. At the southern end of the Mackenzie Valley, depth to the Moho beneath Fort Simpson is about $34 \mathrm{~km}$ and increases eastward to either $36-38 \mathrm{~km}$ (Cook et al., 1999) or $32-35 \mathrm{~km}$ (Viejo and Clowes, 2003).

Average resistivity values, based on Ferguson and Odwar's (1997) Prairie provinces Earth model were used for the upper $(3000 \mathrm{ohm} . \mathrm{m})$, middle $(300 \mathrm{ohm} . \mathrm{m})$ and lower $(10 \mathrm{ohm} . \mathrm{m})$ portions of the mantle in Zones 1 to 4 . Again, the exception was Zone 5 where previous MT surveying (Wu et al., 2005) indicated that the upper mantle was less resistive, exhibiting an average resistivity of $100 \mathrm{ohm} . \mathrm{m}$

\subsubsection{MT Survey-Derived Earth Resistivity Model}

Because of the limited number of sounding sites completed during the MRV 2006 MT survey and the ensuing very wide spacing between sites, only 1D models were computed from the field data. A 1D Earth resistivity model was prepared for six of the seven MT sounding sites, excluding the noisy MRV015 located near the Inuvik airport. 


\section{Processing}

Time-series data, for both AMT and MT frequency ranges, from each MT sounding site were converted to frequency spectra to produce apparent resistivity and phase response curves. These curves are presented in an XY mode which corresponds to a north-south geoelectric field and east-west magnetic field, and YX mode corresponding to east-west geoelectric field and north-south magnetic field.

Intermediate processing steps included: (i) the rotation of spectra for each site to geographic north, (ii) either local or remote-reference processing for elimination of extraneous noise and (iii) editing of the response curves to produce gently varying curves wherever possible. A normal procedure using the SSMT2000 software is to first autoedit and then selectively manually-edit the individual "crosspowers" (which are used to calculate each point on the response curves) in order to exclude data that were affected by external noise during the recording. The resulting response curves which represent the smooth variations of apparent resistivity and phase versus frequency are then exported to an inversion software.

Choice of local or remote-reference processing was dependent on the visual quality of the response curves and whether a remote-reference MT station was operating simultaneously (Table 4.2). Generally, it was found that sites located near populated areas benefited from use of remote-reference processing to suppress the effects of cultural electromagnetic interference on the recorded signal. Nevertheless, local processing for MRV005 Taglu gave less distorted response curves than when remote processed using 
Table 4.2. Summary of processing for MRV 2006 magnetotelluric survey

\begin{tabular}{|c|c|c|c|}
\hline $\begin{array}{l}\text { Sounding } \\
\text { Site }\end{array}$ & $\begin{array}{c}\text { Type of } \\
\text { Processing }\end{array}$ & $\begin{array}{l}\text { Data } \\
\text { Type }\end{array}$ & Comments \\
\hline $\begin{array}{l}\text { MRV005 } \\
\text { Taglu }\end{array}$ & $\begin{array}{l}\text { Local-H } \\
\text { MRV005 }\end{array}$ & AMT, MT & \\
\hline $\begin{array}{l}\text { MRV010 } \\
\text { Inuvik }\end{array}$ & $\begin{array}{l}\text { Remote-H, } \\
\text { MRV010 vs. } \\
\text { MRV005 } \\
\text { remote } \\
\text { reference }\end{array}$ & $\mathrm{AMT}, \mathrm{MT}$ & \\
\hline $\begin{array}{c}\text { MRV020 } \\
\text { Mountain River }\end{array}$ & $\begin{array}{l}\text { Local-H } \\
\text { MRV020 }\end{array}$ & $\mathrm{AMT}, \mathrm{MT}$ & $\begin{array}{l}\text { - AMT instrument malfunction; } \\
\text { re-recorded } 1 \text { hour AMT data }\end{array}$ \\
\hline $\begin{array}{c}\text { MRV025 } \\
\text { Norman Wells }\end{array}$ & $\begin{array}{l}\text { Remote-H, } \\
\text { MRV025 vs. } \\
\text { MRV020 } \\
\text { remote } \\
\text { reference }\end{array}$ & MT & $\begin{array}{l}\text { - Suspected EM contamination } \\
\text { of AMT data; used MT data only }\end{array}$ \\
\hline $\begin{array}{l}\text { MRV030 } \\
\text { Peatland }\end{array}$ & $\begin{array}{l}\text { Remote-H, } \\
\text { MRV030 vs. } \\
\text { MRV035 } \\
\text { remote } \\
\text { reference }\end{array}$ & $\mathrm{AMT}, \mathrm{MT}$ & \\
\hline $\begin{array}{l}\text { MRV025 } \\
\text { Fort Simpson }\end{array}$ & $\begin{array}{l}\text { Remote-H, } \\
\text { MRV035 vs. } \\
\text { MRV030 } \\
\text { remote } \\
\text { reference }\end{array}$ & $\mathrm{AMT}, \mathrm{MT}$ & \\
\hline
\end{tabular}


Inuvik as the remote reference site. Due to a lack of simultaneous AMT recording for corecorded sites MRV020 Mountain River and MRV025 Norman Wells, local processing could only be done for MRV020. Furthermore, at MRV025 the AMT portion of the response curve is suspected to have been EM contaminated, possibly due to proximity of the town and local air navigation beacons, and thus was excluded from further processing. Hence, the response curve for site MRV025 has only been derived from broadband MT data.

\section{Inversion}

The 1D inversion of the apparent resistivity and phase response curves was done to produce both a smooth model and a layered model for each of the six MT sounding sites. No rotation of the response curves to align them with the geoelectric strike was done.

For each MT site, the imported response curves were further edited to remove outlier data points, particularly at the lowermost frequencies $(<0.0005 \mathrm{~Hz})$ where data points have large error bars and/or inconsistent trend, either a result of EM noise contamination and/or poor natural signal. The edited response curves were then smoothened using the $\mathrm{D}+$ option (Figure 4.6 ) to produce a gently varying response curve. $\mathrm{D}+$ smoothening finds the 1D model that best fits both apparent resistivity and phase of the same component, XY or YX (Geosystem, 2005).

A dimensionality analysis (see below) demonstrated that since 2D structure is present, invariant curves for resistivity and phase are appropriate for inversion. The invariant resistivity is calculated as the geometric mean of the resistivity in the two orthogonal directions, $\mathrm{XY}$ and $\mathrm{YX}$ (Geosystem, 2005). Invariant phase is calculated as 
the arithmetic mean of the two. Because the invariant mode is a blend of the two directions $(\mathrm{XY}, \mathrm{YX})$, the invariant response curves are similar to the resistivity and phase obtained from a literature-derived 1D Earth resistivity model which, by definition, has no directional bias.

Then, for each MT sounding site, an Occam inversion (developed by Constable et al., 1987) of the $\mathrm{D}+$ smoothed response curves was calculated by the WinGLink software; this is referred to as the "smooth" inversion model. The Occam inversion produces a smooth model (albeit with multiple thin layers) that fits the observed data within certain predefined tolerances and seeks to find the minimum resistivity value for each layer. Essentially, smoothing minimizes unnecessary structure in the model, and is a balance between resolution of the structure and roughness with respect to resistivity changes. The Occam inversion routine was allowed to run with default settings having a maximum amount of 45 layers, automatic determination of minimum and maximum depth, and ten iterations.

It needs to be noted that during the editing of the raw MT response curves, data points at frequencies less than $5 \times 10^{-4} \mathrm{~Hz}$ (except at MRV025) were removed because of high error bars and scatter which is believed to be a consequence of insufficient recording duration. The end result is that the inversion does not have sufficient resolution at lower depths, corresponding to frequencies less than $10^{-3} \mathrm{~Hz}$. The resulting smooth inversion models for the invariant mode of the response curves are presented in Figure 4.7. Next, layered inversions were calculated from the smooth inversion model, for individual $\mathrm{XY}$ and $\mathrm{YX}$ directions, and the invariant mode, (Figure 4.8). The inversion routine was allowed to run without constraints on individual layer resistivity or 

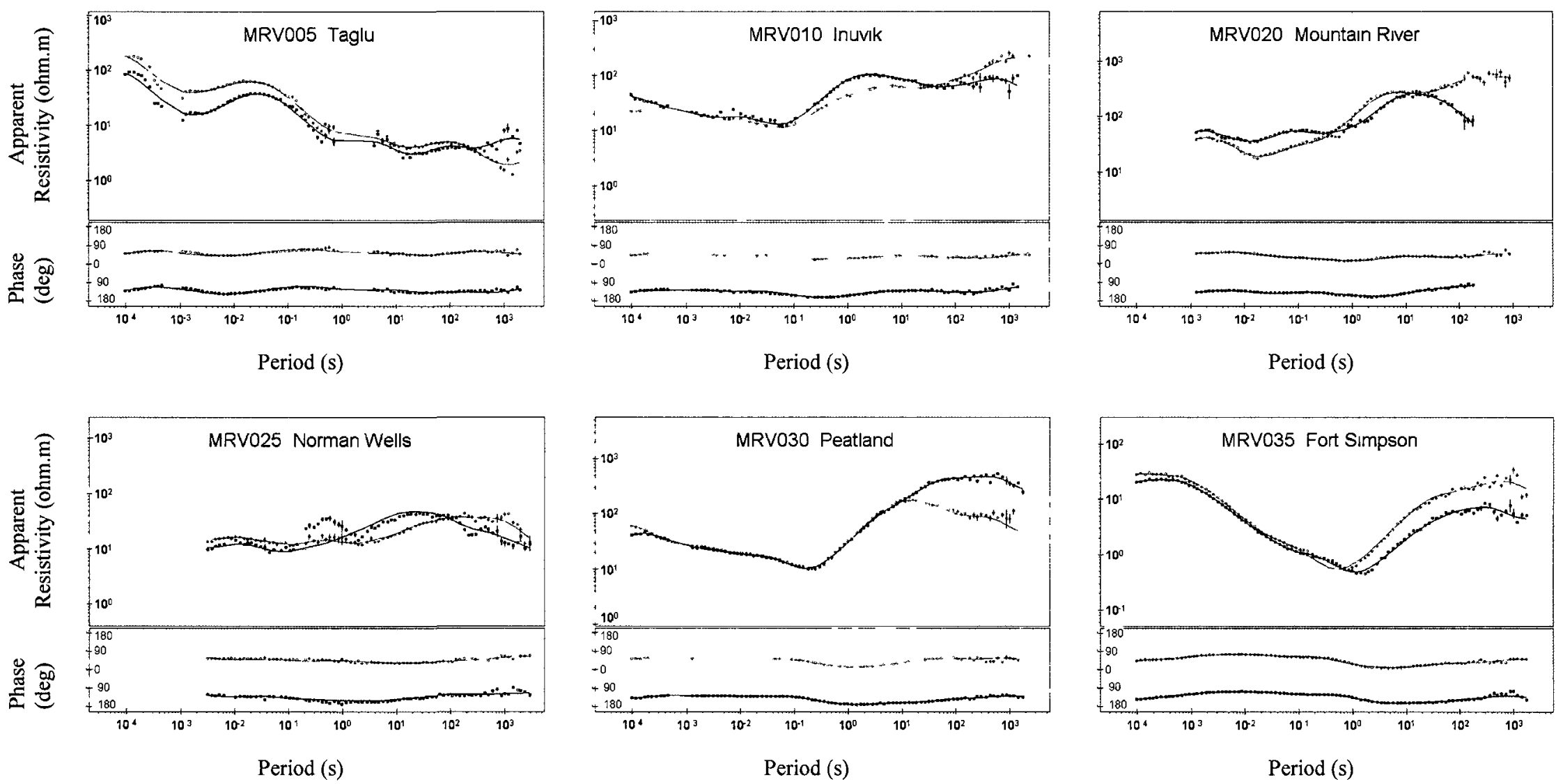

Figure 4.6. Apparent resistivity and phase response curves (unrotated) for six MT sounding sites along the Mackenzie Valley proposed pipeline route. Red and blue symbols and lines correspond to the XY and YX curves, respectively. Lines are the $\mathrm{D}+$ smoothed version of the actual data. Data gaps are where poor quality data (grey symbol) have been edited out. Logarithmic scales; variable ranges for each site. 

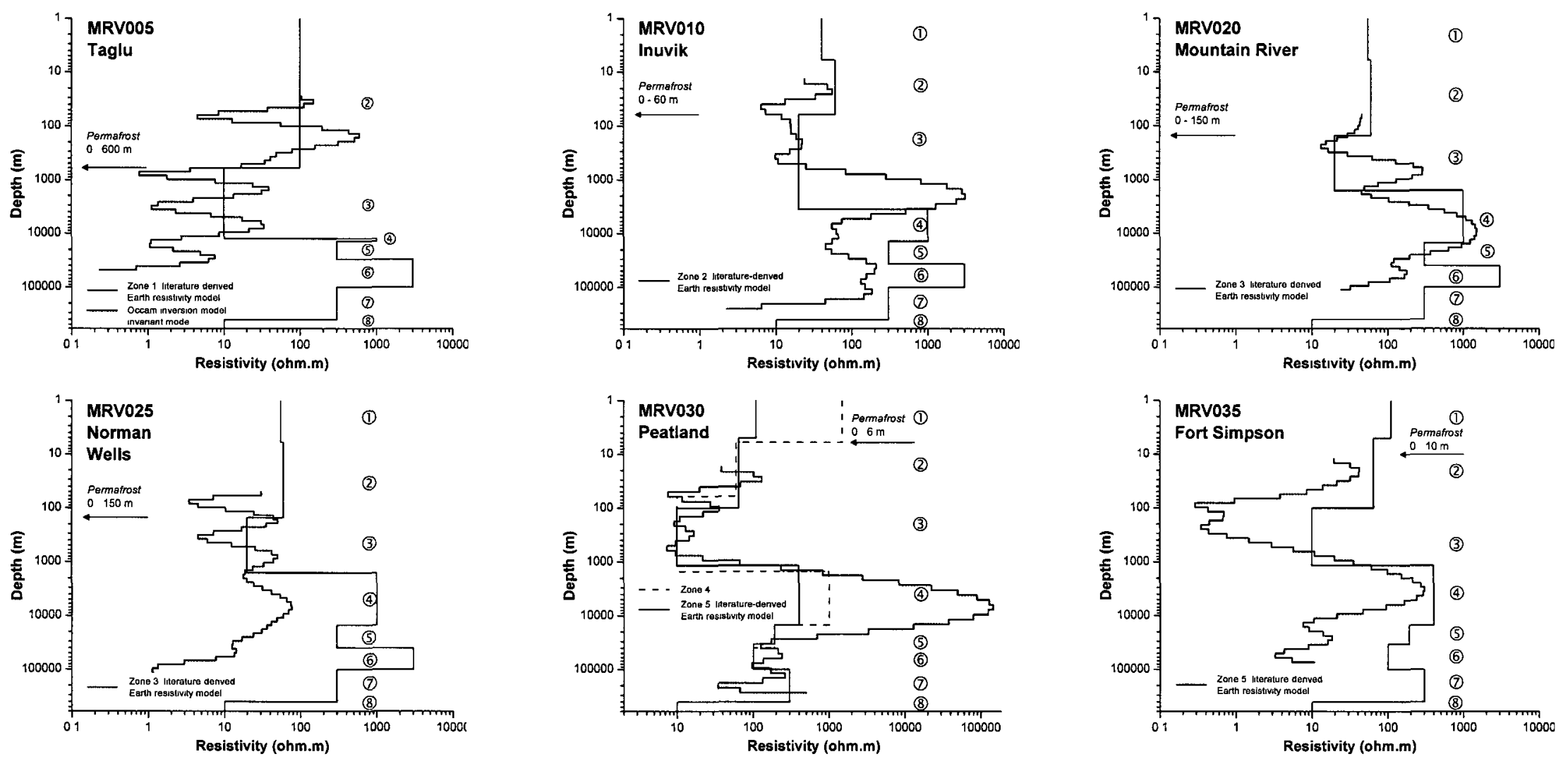

(1) Overburden
(2) Surficial Sediments
(3) Sedimentary Basin

(4) Upper Crust

(5) Middle - Lower Crust

(6) Mantle (upper)

(7) Mantle (middle)

(8) Mantle (lower)

Figure 4.7. Comparison of the smooth (Occam) 1D inversion models (only invariant mode shown) obtained from MT surveying (purple lines) versus the literature-derived 1D Earth resistivity models (black lines). Earth models represent one of the five resistivity zones along the Mackenzie River valley proposed pipeline route. Circled numbers indicate layers within the literature-derived Earth resistivity model. 

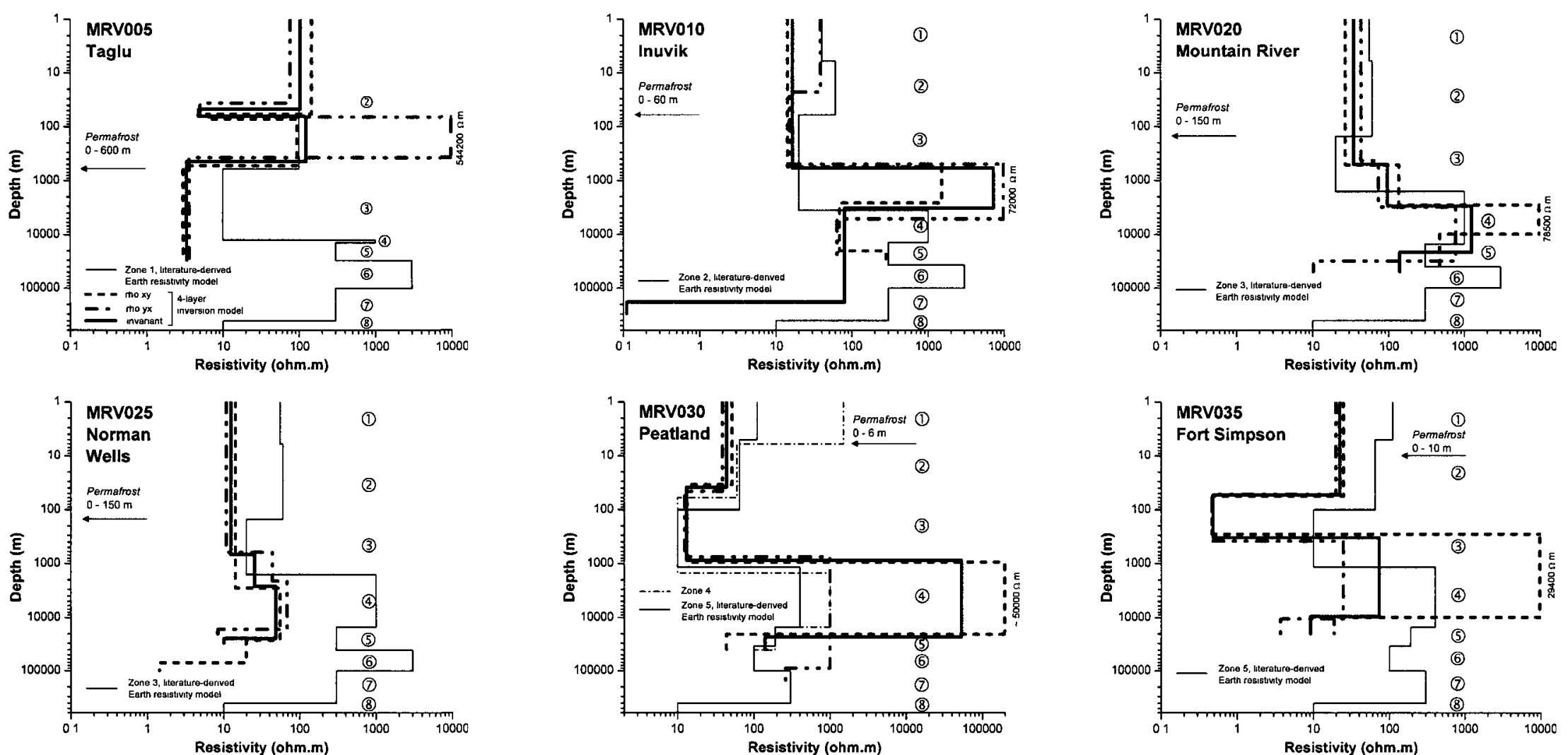

(1) Overburden

(2) Surficial Sediments

(3) Sedimentary Basin

(4) Upper Crust

(5) Middle - Lower Crust

(6) Mantle (upper)

(7) Mantle (middle)

(8) Mantle (lower)

Figure 4.8. Comparison of the 4-layered 1D inversion models (modes XY (red lines), YX (blue lines) and invariant (green lines)) obtained from MT surveying versus the literature-derived 1D Earth resistivity models (black lines). Earth models represent one of the five resistivity zones along the Mackenzie River valley proposed pipeline route. Circled numbers indicate layers within the literaturederived Earth resistivity model. 
thickness, from an initial assumption of $100 \mathrm{ohm} . \mathrm{m}$ that represents the bulk resistivity (down to the upper mantle as obtained from the literature-derived 1D model for Zone 5. Default settings for the inversion parameters of $5 \%$ RMS and 10 iterations were accepted for all runs. A 4-layer inversion was first done given that it would be a minimum layered representation of Earth, consisting of surficial sediments (including overburden), sedimentary basin, crust and mantle. Due to suppressing frequencies lower than $5 \times 10^{-4}$ $\mathrm{Hz}$ (in the MT response curves used as input), the fourth and deepest layer in the inversion should be regarded as possibly representing only the uppermost portion of the mantle. Furthermore, the inversion software only produces the resistivity of the lowermost layer and not the thickness. In Figure 4.8, only the depth to the top of the lowermost $\left(4^{\text {th }}\right)$ layer is shown.

Subsequently, 8-layer inversion models, invariant mode only, were run to obtain layer resistivity and thickness values for calculation of the surface impedance, as described further in Section 4.5.2.

\section{Dimensionality}

For an isotropic distribution of electrical properties in soils and rock, resistivity is of equal value in any direction. If anisotropy is present, resistivity is greatest in a particular direction. By simply rotating the response curves in steps of 20 degree allotments and seeing how much and at what frequencies the curves differ between 0 (geographic north) and each rotation, an appreciation can be gained of the presence of anisotropy. Testing for each MT sounding site showed some changes to the response curves after rotation. Visual examination of the response curves (Figure 4.6) reveals presence of anisotropy to varying degree beneath all MT sounding sites, being dominant 
at sites MRV005, 010, 020 and 025 across the entire period range. The subsurface beneath MRV030 and 035 is isotropic at periods shorter (representing a shallower Earth response) than 10 seconds and 1 second, respectively, becoming anisotropic at the longer periods.

Comparison of all three modes (XY, YX and invariant) can be used to determine where XY and YX coincide, indicating that the subsurface is isotropic. Significant differences between the $\mathrm{XY}$ and $\mathrm{YX}$ modes of an inversion model would imply that the presence of $2 \mathrm{D}$ or $3 \mathrm{D}$ structures causes anisotropy. Figure 4.8 shows the comparison between the XY and YX modes for the 4-layer inversion model. Layers corresponding to surficial sediments and the sedimentary basin show minimal difference between the two modes, indicating that these layers are isotropic. There is an exception at MRV005 Taglu where the lower half of surficial sediments shows anisotropic conditions. For all sites, except MRV025 Norman Wells, resistivity is different in different directions for the crust layer and the deepest layer.

\section{Results}

A comparison (Figures 4.7 and 4.8) of the smooth and layered inversion models against literature-derived Earth resistivity models the reveals the following:

- Permafrost depths are identifiable for MT sites located in deep permafrost regions, such as at MRV005, 010, 020 and 025.

- Exceptionally low resistive (5 ohm.m) data at an approximate depth of $80 \mathrm{~m}$ at MRV005 may correspond to a talik known to exist in the deep permafrost of the Mackenzie Delta (J. Hunter; pers. comm.). 
- MRV005 is distinctly different from other MT sites in that the inversion is restricted to depths shallower than $50 \mathrm{~km}$ depth and shows alternating, narrow, low (1 ohm.m) and high resistive (50 ohm.m) bands within the sedimentary basin. This is interpreted to reflect the varying lithology (shale, limestone, sandstone) comprising the sedimentary formations.

- A definite contrast is observed between the less resistive surficial and sedimentary basin rock (less than 10 - approximately 100 ohm.m) against the more resistive upper crust ( 80 - to greater than $1000 \mathrm{ohm} . \mathrm{m}$ ) for all MT sounding sites except MRV005. AT MRV005, resistivity of upper to lower crust ranges from $1-10$ ohm.m. Best agreement between the inversion and literature-derived models for crust resistivity is at MRV010,020 and 035.

- Depth of the contact between sedimentary basin to upper crust closely follows the literature-derived depths for MRV005, 020, 025 and 030. The agreement is noticeably not as good for MRV010 and 035.

- Higher resistive upper crust is located at MRV010, 020, and 030, with a less resistive upper crust at MRV025 and 035.

- Transition to mid-to lower crust (except for MRV005) tends to be poorly defined, with the sharpest transition seen at MRV010 (50 ohm.m) and MRV035 (10 to 20 ohm.m). The mid- to lower crust is less resistive than the upper crust.

- Depth to the Moho (except for MRV005) is about $40 \mathrm{~km}$ for MRV010 and 020, which closely matches the literature values, and approximately $40 \mathrm{~km}$ for MRV025 and 030 which is reasonably similar to the literature. At MRV005, the Moho depth is considered to have been poorly resolved, if at all, because the 
enormous thickness of the conductive sedimentary basin hampered the penetration of the natural signal. Selection of the Moho depth at MRV035 was problematic; either about 20 or $40 \mathrm{~km}$ depending on this author's interpretation of the smooth inversion model.

- Upper mantle resistivity ranges (except for MRV005) from about $200-300$ ohm.m for the central portion of the valley from MRV010 to MRV030, which closely corresponds to the literature-derived Earth models for Zones 4 and 5 situated at the southern end of the Mackenzie River valley. At MRV035, upper mantle resistivity obtained from the smooth inversion ranges from $5-20 \mathrm{ohm} . \mathrm{m}$, noticeably less than the literature-derived value of $100 \mathrm{ohm} . \mathrm{m}$.

\subsection{Geoelectric Field Modelling}

In this section, the calculation of surface impedance from two different information sources, literature and MT survey, are first described and compared. How the surface impedance affects the resulting geoelectric field is then examined. Finally, a statistical characterization of the geoelectric field is presented which shows the various levels of predicted telluric activity along the pipeline route.

\subsubsection{Literature-Based Surface Impedances Determination}

Surface impedance values were calculated using literature-derived layered Earth resistivity models as previously described in Chapter 3 , section 3.5 .1 , using formulas provided in Chapter 2, section 2.4.1. As shown in Figure 4.9, surface impedances are different for each of the five resistivity zones, i.e., Earth models, along the pipeline route. The most obvious difference is that the surface impedance, both amplitude and phase components, of Zone 1 has a reverse trend compared to the other zones for the frequency 


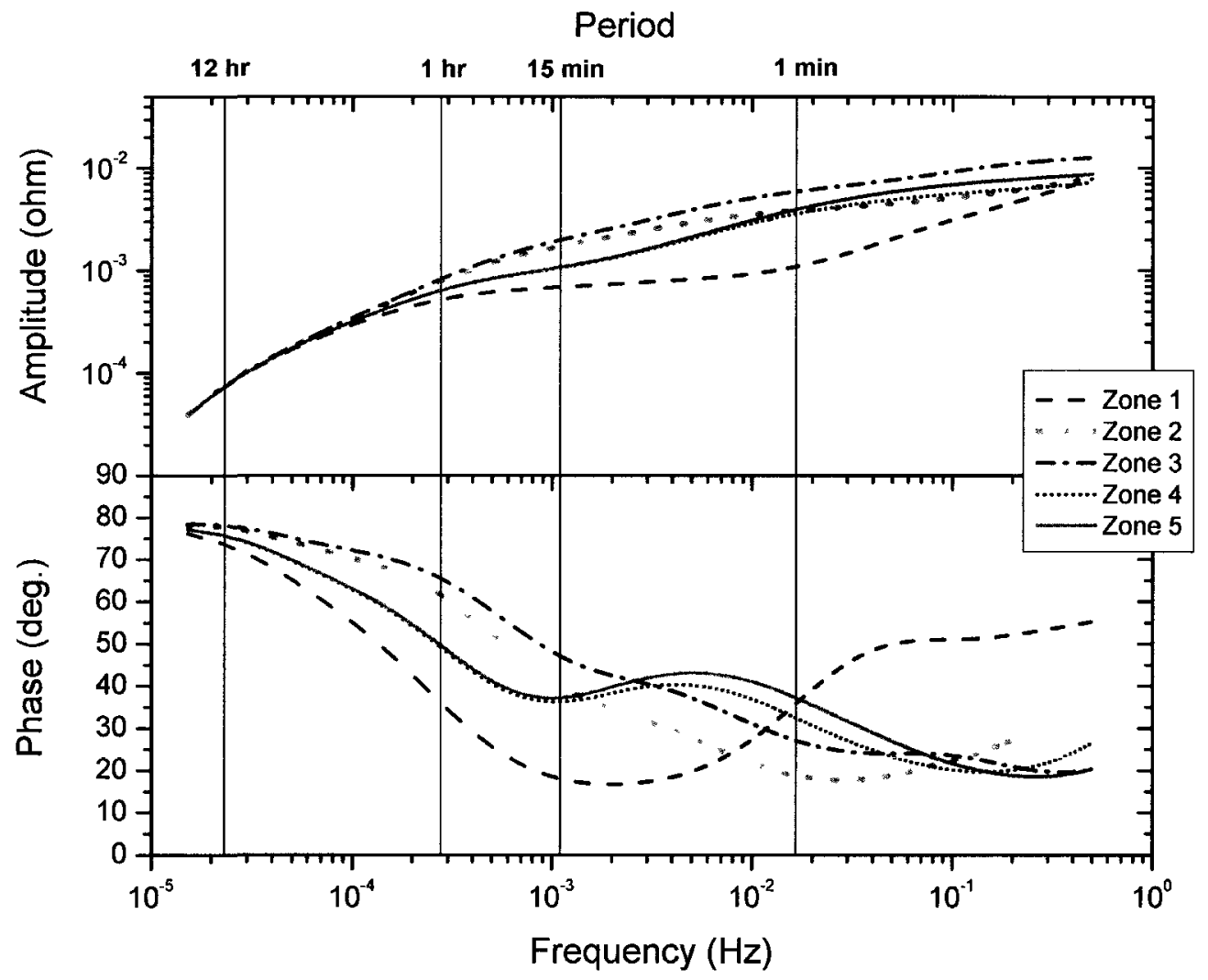

Figure 4.9. Surface impedances for the five resistivity zones along the Mackenzie Valley proposed pipeline, calculated from literature-derived 1D Earth resistivity models (after Boteler et al., 2005, Fig. 4.1). 
range of about $0.1 \mathrm{~Hz}$ to $0.0003 \mathrm{~Hz}$ (period range of 10 seconds to 1 hour). In Zone 1 the $12 \mathrm{~km}$ thick accumulation of sedimentary basin rock and its associated low resistivity (10 ohm-m) dominates the EM response. Although the low resistivity $(10-20$ ohm.m) sedimentary basin rock also occurs in the remaining zones, this layer is considerably thinner, ranging from less than $1000 \mathrm{~m}$ to approximately $3.5 \mathrm{~km}$ thick and does not have significant effects on the surface impedance.

Given that the pipe is buried in the upper two metres of ground, an assessment was made of the effect of permafrost and ground changes from winter to summer. Surface impedance was determined for a frozen - to - thawed active layer of $2 \mathrm{~m}$ depth on top of the $1 \mathrm{D}$ Earth model of Zone 5. The results for two extreme cases of resistivities in the active layer - 2000 ohm.m (frozen) and 2 ohm.m (thawed) - are shown in Figure 4.10. Also shown in Figure 4.10 is the resistivity of $110 \mathrm{ohm} . \mathrm{m}$ for the $6 \mathrm{~m}$ thick frozen overburden assigned to the Zone 5 Earth model. At frequencies greater than $10 \mathrm{~Hz}(0.1$ second), the presence of an active layer starts to have an effect on the surface impedance values. Because there are no geomagnetic observatory data with frequency above $1 \mathrm{~Hz}$ and because the concern is about the natural low frequency variations of the geomagnetic field, the active layer needs not to be incorporated into the 1D Earth model.

\subsubsection{MT-Based Surface Impedances Determination}

To achieve compatibility with the method of calculating surface impedance from literature sources (which used an 8-layer model for all Zones except a 7-layer model for Zone 1), the MT response curves from each sounding site underwent the same processing procedures previously described in section 4.5 .2 to produce an 8-layer 1D inversion model. From the layered inversion model, individual layer resistivity and thickness were 


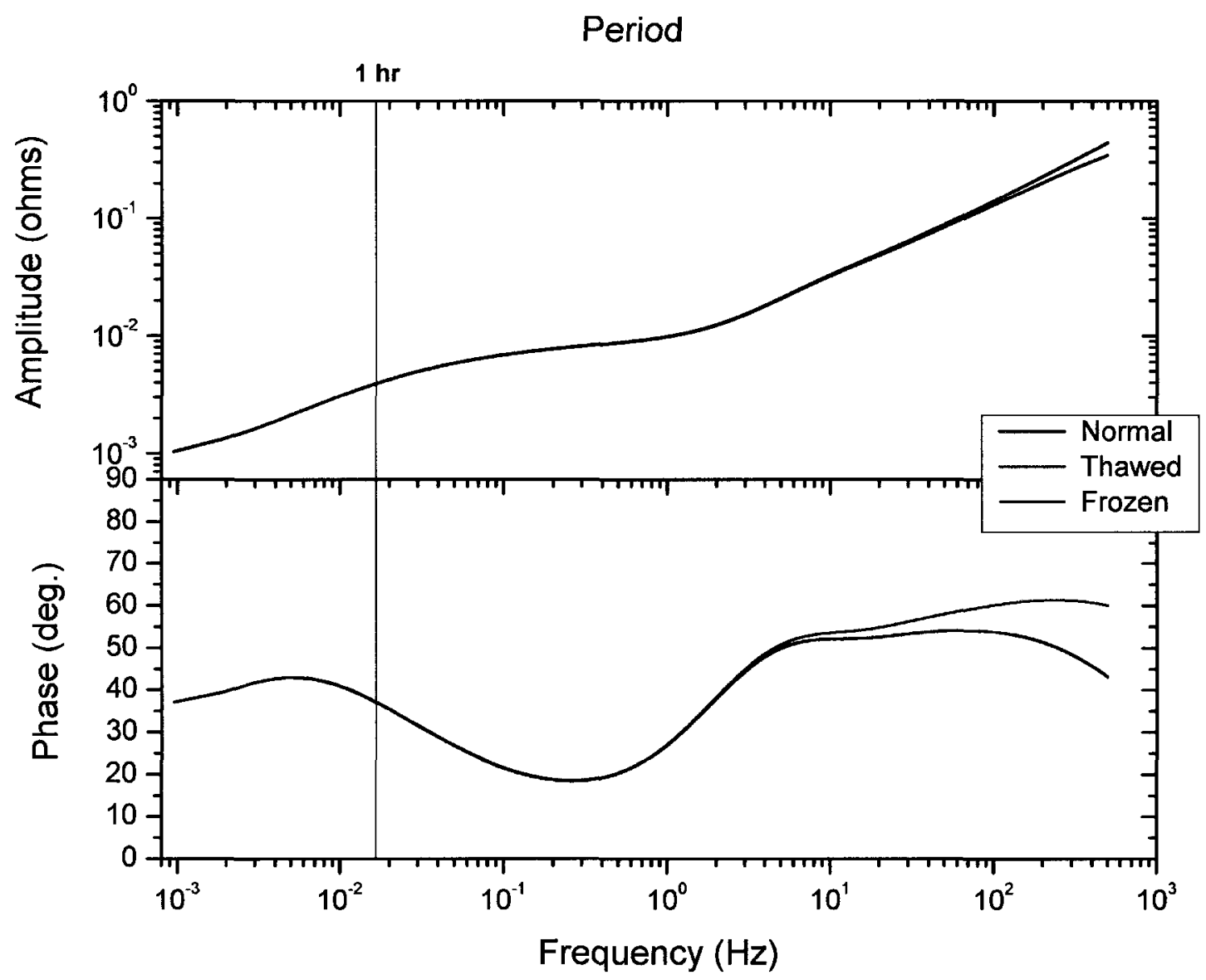

Figure 4.10. Surface impedances for the Zone 5 Earth resistivity model, without an active layer and with a thawed and frozen $2 \mathrm{~m}$ thick active layer (after Boteler et al., 2005, Fig. 4.2). The resulting curves for a no active layer and a frozen active layer conditions are superimposed on each other. 
tabulated and imported into the same algorithm used to calculate the literature-derived surface impedances.

Figure 4.11 provides a comparison of the surface impedances calculated for the six MT sounding sites. Five of the six impedances share an overall similar trend with a comparable rate of amplitude increasing with frequency, the exception being MRV035 which has a slightly slower rate of amplitude increase above $0.1 \mathrm{~Hz}$. More than half of the sites (MRV010, 020, 025 and 030) exhibit less than a half-magnitude difference in amplitude, with MRV035 being obviously different by 1 to 2 orders of magnitude and showing the lowest amplitude across the entire frequency range.

\subsubsection{Comparison of Surface Impedance Determinations}

Another way to assess how representative is a literature-derived 1D model of the underlying Earth was to compare the surface impedances calculated from such a model against surface impedances calculated using MT sounding data. It needs to be noted that the MT sounding sites were not evenly distributed within the five different resistivity zones into which the Mackenzie River valley was divided (see Figure 4.3). Lack of summer road access into Zone 4 meant no soundings were taken in this zone. However, elsewhere along the pipeline route a couple of soundings per zone were possible. Zone 3 included MT sounding sites MRV020 and 025, and Zone 5 had sites MRV030 and 035.

Log-log plots of surface impedance - amplitude versus frequency - were prepared (Figures 4.11 to 4.17). As well in the same figures are comparisons to the MT apparent resistivity response curves, for the same frequency range as the surface impedances. Depicted frequency range starts at $0.5 \mathrm{~Hz}$ (the Nyquist frequency of $1 \mathrm{~Hz}$ ) because the geomagnetic observatory data was limited to a $1 \mathrm{~Hz}$ sampling rate. The lowest frequency 


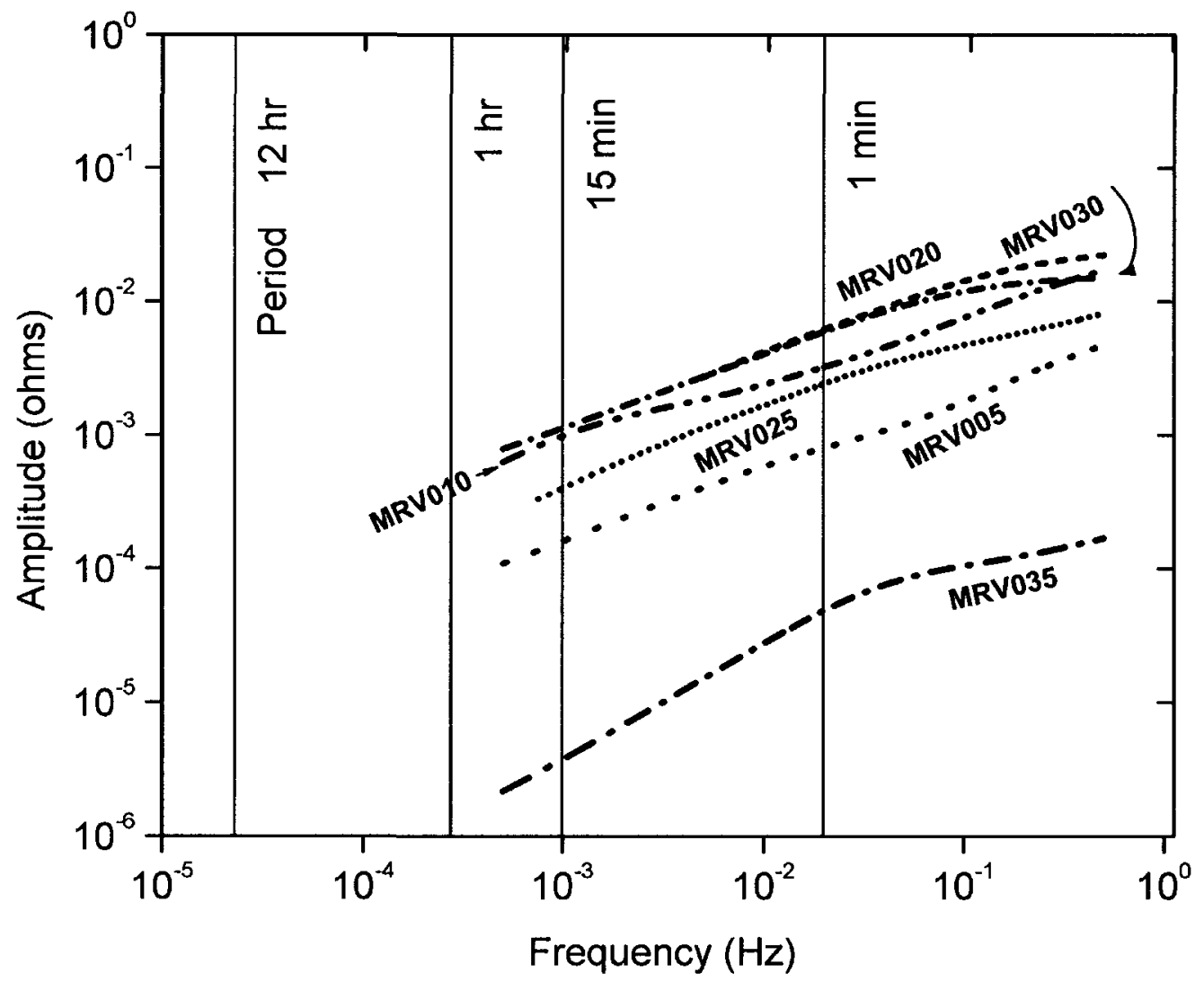

Figure 4.11. Comparison of all calculated surface impedances obtained from 1D inversion of MT measurements. Shown are results from the six MT sounding sites in the Mackenzie Valley. 

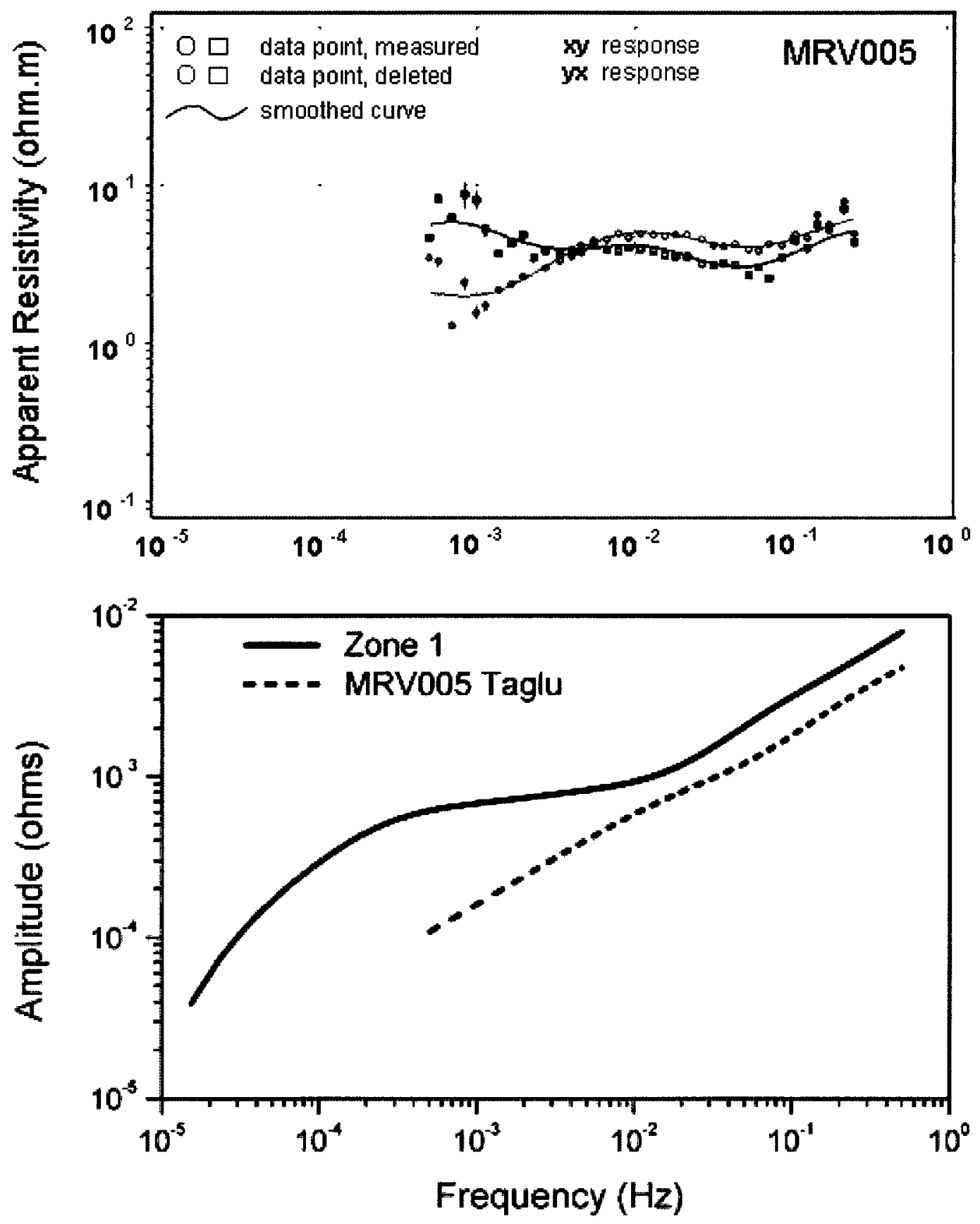

Figure 4.12. Comparison of (top) apparent resistivity response curves from MT sounding site MRV005 Taglu and (bottom) surface impedances calculated from literature for Zone 1 (purple solid line) and calculated from a 1D inversion of MRV005 sounding data (dashed black line). 

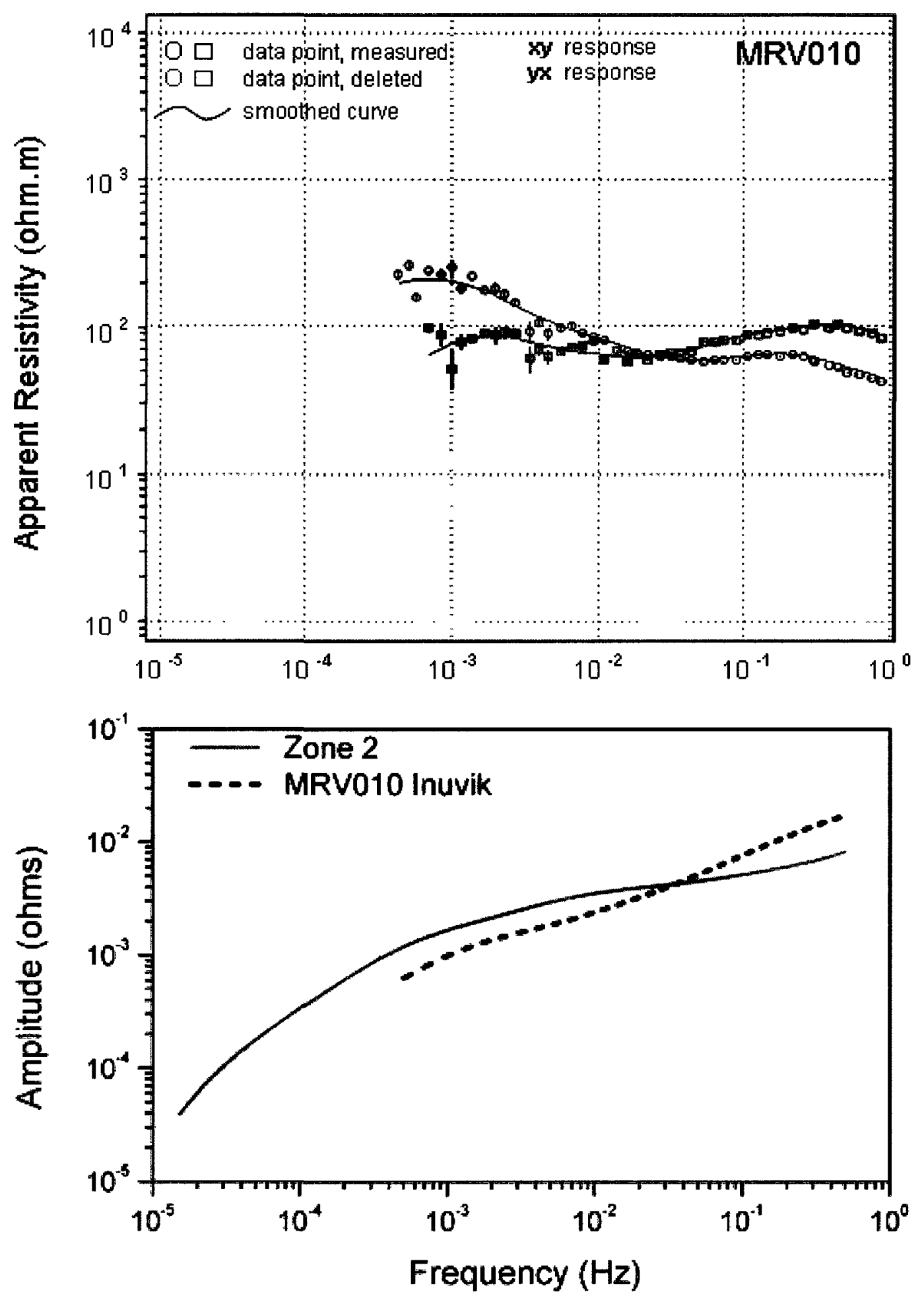

Figure 4.13. Comparison of (top) apparent resistivity response curves from MT sounding site MRV010 Inuvik and (bottom) surface impedances calculated from literature for Zone 2 (orange solid line) and calculated from an inversion of MRV010 sounding data (dashed black line). 

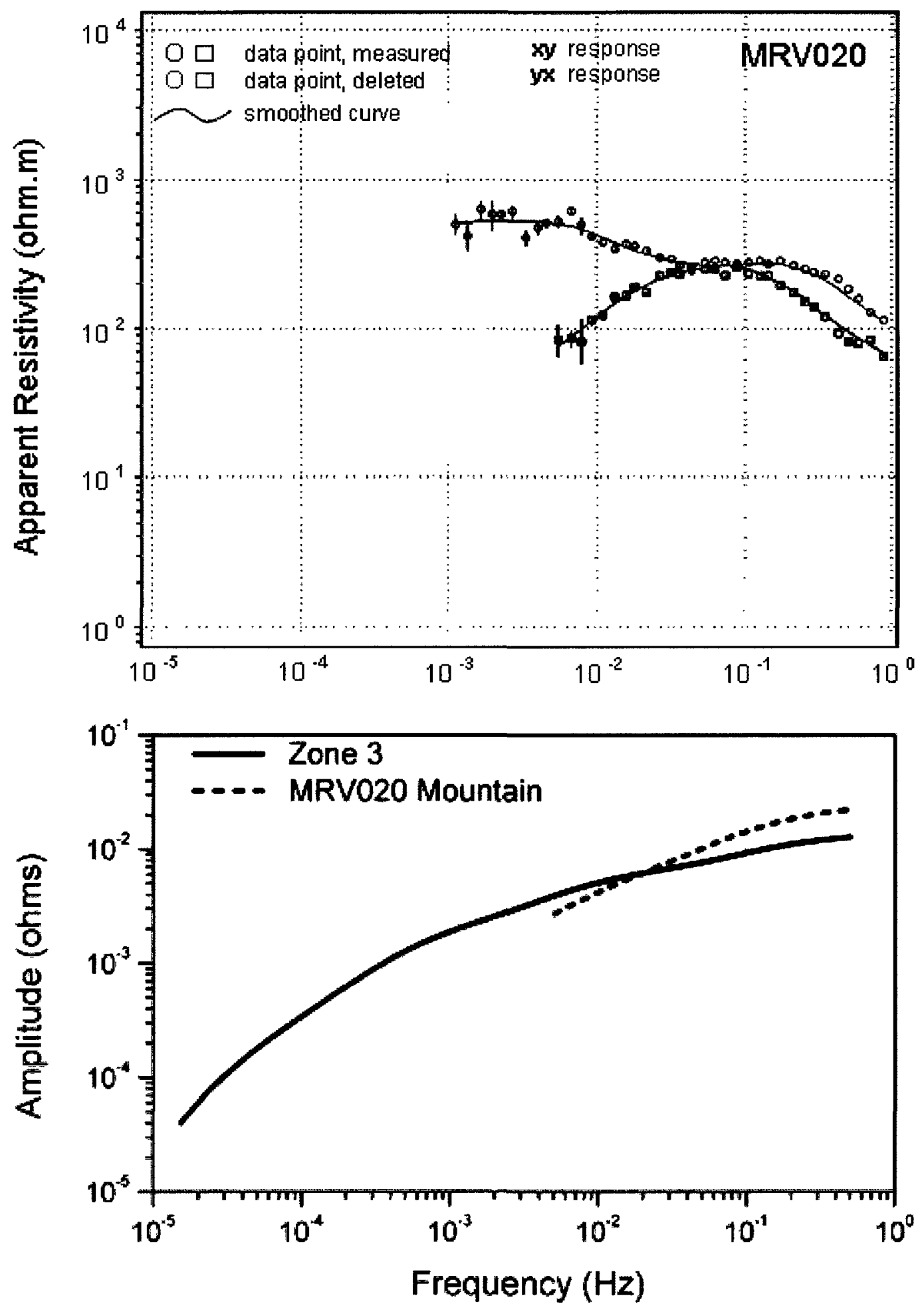

Figure 4.14. Comparison of (top) apparent resistivity response curves from MT sounding site MRV020 Mountain River and (bottom) surface impedances calculated from literature for Zone 3 (green solid line) and calculated from an inversion of MRV020 MT sounding data (dashed black line). 

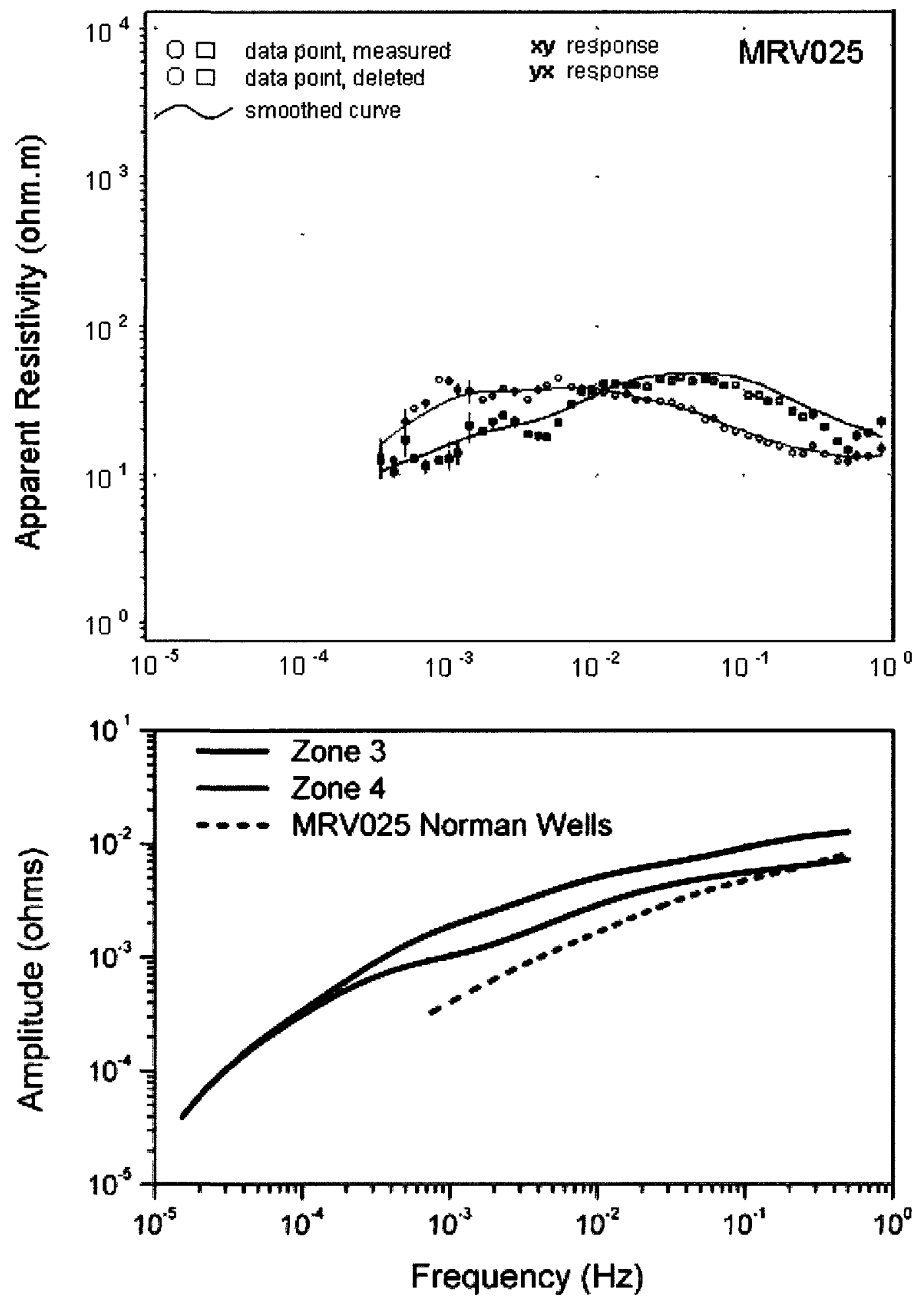

Figure 4.15. Comparison of (top) apparent resistivity response curves from MT sounding site MRV025 Norman Wells and (bottom) surface impedances calculated from literature for Zones 3 (green solid line) and 4 (magenta solid line) and calculated from an inversion of MRV025 sounding data (dashed black line). 

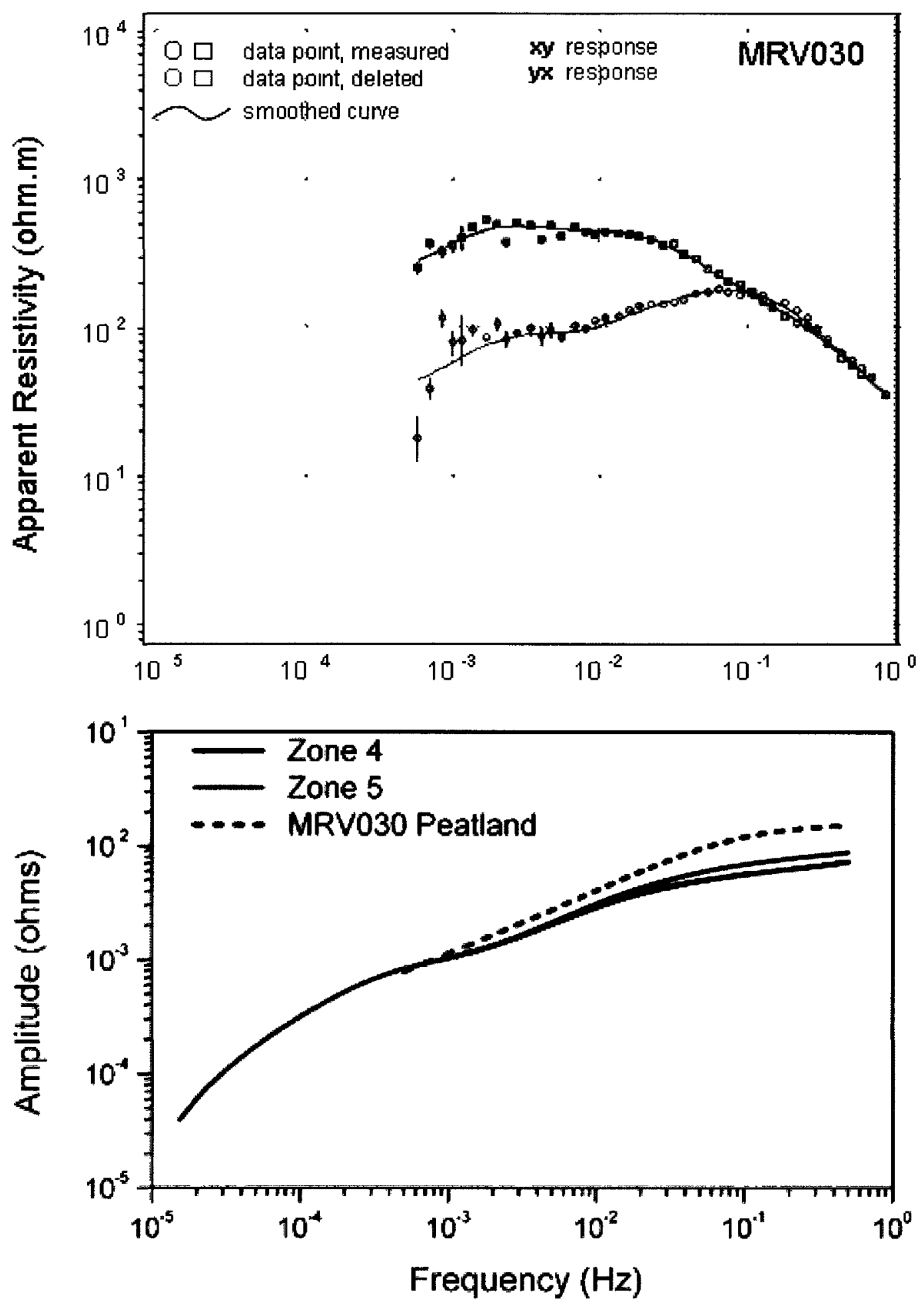

Figure 4.16. Comparison of (top) apparent resistivity response curves from MT sounding site MRV030 Peatland and (bottom) surface impedances calculated from literature for Zones 4 (magenta solid line) and 5 (dark yellow solid line) and calculated from an inversion of MRV030 sounding data (dashed black line). 

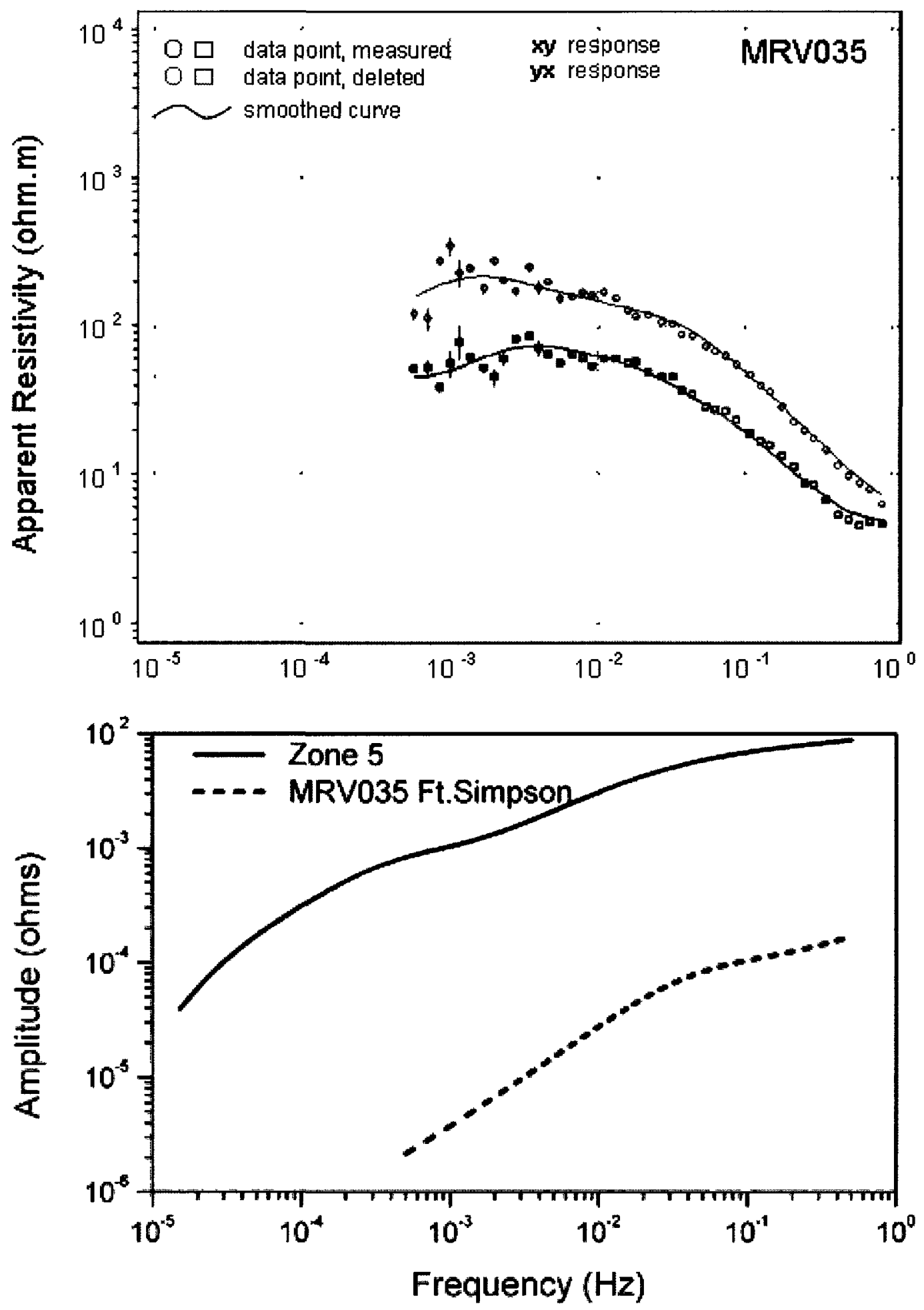

Figure 4.17. Comparison of (top) apparent resistivity response curves from MT sounding site MRV035 Fort Simpson and (bottom) surface impedances calculated from literature for Zone 5 (dark yellow solid line) and calculated from an inversion of MRV035 sounding data (dashed black line). 
plotted differs between literature and MT-derived surface impedances. The former extends to a cutoff near $10^{-5} \mathrm{~Hz}$ (12 hours) representing the theoretical response to mantle depth and the latter usually ends at about $0.0003 \mathrm{~Hz}(3000 \mathrm{sec})$ which was the lowest frequency available as constrained by the duration of the MT recordings. Hence, the common frequency range with sufficient data to examine Earth's response extends only over a half-hour period, both for literature - and MT-derived surface impedances.

Observations specific to each pairing of literature-derived and MT-derived surface impedances are as follows:

- Zone 1 and MRV005 (Figure 4.12): Surface impedances track parallel to each other with a moderate amount of amplitude difference until about $10^{-2} \mathrm{~Hz}$ where they rapidly diverge. The divergence may reflect the situation that Zone 1 represents an extreme model of the Mackenzie Delta with an offshore maximum sedimentary basin thickness greater than $12 \mathrm{~km}$, overlying a thin upper crust (1.5 $\mathrm{km}$ thick, $1000 \mathrm{ohm} . \mathrm{m})$. In reality MT sounding site MRV005 was onshore with possibly less than $4 \mathrm{~km}$ (Dixon et al., 1992) of underlying sedimentary basin in this area of the delta, and on top of a much thicker upper crust.

- Zone 2 and MRV010 (Figure 4.13): Surface impedances closely parallel each other and cross over at about $4 \times 10^{-2} \mathrm{~Hz}$ which roughly coincides with crossing of the MT response curves; this point where both surface impedances are the same possibly due to a $1 \mathrm{D}$ resistive structure at that particular EM penetrative depth.

- Zone 3 and MRV020 (Figure 4.14): Surface impedances again are closely parallel to each other with moderate amplitude difference. However, the comparison was limited to a smaller frequency range because of previous removal 
of excessive error and scatter of data points on the MT response curves at the lowermost frequencies.

- Zones 3 and 4 and MRV025 (Figure 4.15): Surface impedance trends follow each other but there is a lesser amplitude difference between literature data and data from Zone 4 than between literature data and data from Zone 3, although sounding site MRV025 was actually located in Zone 3. The difference between the two zones is that in Zone 4 the sedimentary basin is slightly less resistive (10 instead of $20 \mathrm{ohm} . \mathrm{m}$ ) and the upper mantle layer is considerable less resistive (100 instead of 3000 ohm.m).

- Zones 4 and 5 and MRV030 (Figure 4.16): Closely parallel surface impedance trends occur with moderate to low amplitude difference. At frequencies above $4 \mathrm{x}$ $10^{-2} \mathrm{~Hz}$, Zone 5 surface impedance has a lesser amplitude difference. The biggest difference between the two zones is that the upper crust in Zone 4 is much more resistive (1000 ohm.m) than in Zone 5 (400 ohm.m)

- Zone 5 and MRV035 (Figure 4.17): Amplitudes are separated by two orders of magnitude. Here, the literature-derived Zone 5 was based on the Lithoprobe SNORCLE 1 transect using MT stations located about $25 \mathrm{~km}$ south of Fort Simpson. Therefore it would be expected that MRV035 (located at Fort Simpson airport) surface impedance should have a closer match with Zone 5. Perhaps local geological conditions resulting in a static shift of apparent resistivity values (Jones, 1988) or an unknown technological issue at MRV035 did not permit a better comparison. 
Generally, on the MT response curves the data points typically exhibit greater error and scatter at the lowermost frequencies $\left(<10^{-3} \mathrm{~Hz}\right) /$ longer periods $(1000 \mathrm{~s})$ and may not be truly representative of resistivity at great depth. Therefore the equivalent MT-derived surface impedance could deviate (to an unknown amount) from the literature-derived surface impedance. Error and scatter seen at the low frequency end of the MT response curves could be attributed to an insufficient recording duration at the MT sounding sites that did not provide a statistically robust quantity of data points. The opposite occurs at frequencies higher than $10^{-2} \mathrm{~Hz}(1$ minute) where there is an abundance of data points and thus a good average representation of impedance.

Overall, a reasonable similarity between literature and MT-derived surface impedance amplitude was evident on four comparisons (Zone 2, MRV010; Zone 3, MRV020; Zone 4, MRV025; and Zone 5, MRV030) suggesting that the literature-derived Earth model is a reliable first-order approximation of the underlying geology. It is also of interest to note that in two cases (Zone 4, MRV025, and Zone 5, MRV030) the literaturederived surface impedance of the adjacent resistivity zone had a better match to the MTderived surface impedance than was predicted.

Differences in the calculated surface impedances - literature vs. inverted field data - are a result of differences in thickness and resistivity obtained from either approaches. A literature-derived model cannot by any means be an accurate duplicate of the true Earth structure. On the other hand, a particular MT sounding site could be a localized and unique situation which is not representative of the overall geological structure. Hence, to obtain the best representation of the Earth structure beneath a pipeline route, a sufficient quantity of MT sounding sites are needed along the route, particularly where the route 
passes over lateral resistivity contrasts where abrupt changes could occur. Ample recording duration is also necessary to reduce the error and scatter at the lower frequencies of the response curves, which was observed at most of the Mackenzie Valley MT sounding sites.

\subsubsection{Types of Geoelectric Field Variations}

As was done for the Alaska Highway Corridor, specific days for the year 2004 were identified as being representative of a certain level of geomagnetic activity be it quiet, unsettled, active or stormy (see Section 3.6.3). Using the geomagnetic data from the Yellowknife Geomagnetic Observatory, for selected representative days, in combination with literature-determined surface impedance values (see Section 4.6.1), the geoelectric field was calculated in the $E_{x}$ (northward) and $E_{y}$ (eastward) components. It is the resulting $E_{x}$ and $E_{y}$ values which are then used as an input to the pipeline model for computation of PSP variation along the pipeline route.

The resulting calculated geoelectric field for a geomagnetically quiet and storm day for each of the five 1D Earth resistivity models is presented in Figure 4.18. Amplitude of geoelectric field fluctuations is below $20 \mathrm{mV} / \mathrm{km}$ for a geomagnetically quiet day, and up to $600 \mathrm{mV} / \mathrm{km}$ during a geomagnetic storm. Comparisons between the five zones for the same day demonstrate that differences in the underlying Earth resistivity affect the amplitude of geoelectric field variations. Zone 1 produced the lowest geoelectric field values, while Zone 3 produced the largest. Recall that Zone 1 represents the offshore Mackenzie Delta where there is an exceptionally thick basin of low-resistivity (10 ohm.m) sedimentary rock and a thin crust which dominate the electromagnetic response in this area. Whereas in Zone 3, the much thinner sedimentary 

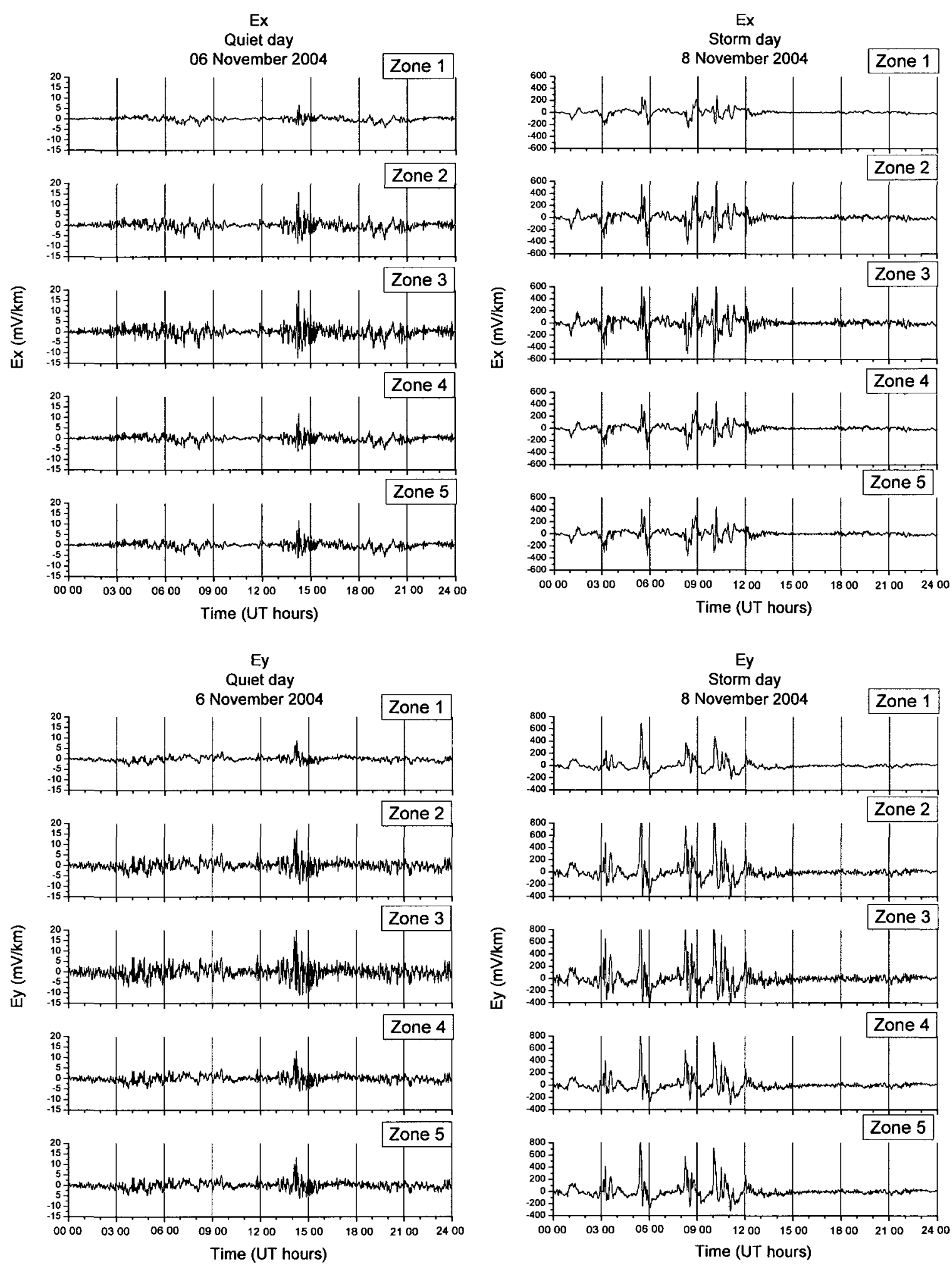

Figure 4.18. Geoelectric field variations in the $E_{x}$ (northward) and $E_{y}$ (eastward) directions for a geomagnetically quiet and stormy day experienced along the five resistivity zones within the Mackenzie River Valley study area (Boteler et al., 2005, Figs. $4.3,4.4,4.11$ and 4.12). Note scale changes of the geoelectric field amplitude. 
basin with slightly higher resistivity (20 ohm.m) and high-resistive (1000 ohm.m) upper crust causes a more resistive response and therefore a higher amplitude geoelectric field.

\subsubsection{Statistical Estimations of Telluric Activity}

Using a statistical approach in a similar manner as done for the Alaska Highway Corridor, telluric activity indices were defined as part of the Study of Telluric Current Impacts on the Mackenzie Gas Project Pipelines. The purpose was to statistically delineate the difference in magnitude of telluric activity between a high-latitude auroral zone, such as Yellowknife, and low-latitude sub-auroral zone represented by Ottawa. The year 2004 was again chosen as being representative of a typical geomagnetic year that experiences an occasional major geomagnetic storm. Literature-derived Earth resistivity models were used as the input for the geoelectric field calculation.

Applying the 1D Earth resistivity model developed for Zone 5 (southern end of pipeline route), the Hourly Maximum Amplitude (HMA) of the geoelectric field was first calculated using Ottawa Geomagnetic Observatory magnetic data to simulate a pipeline situated in the magnetically quiet sub-auroral zone. It was found that HMA is less than $20 \mathrm{mV} / \mathrm{km}$ for $95 \%$ of the time in Ottawa; this level being assigned as the normal level of telluric activity. For comparison, in an auroral zone location, such as Yellowknife (using the Zone 5 Earth resistivity model), for the same 2004 year, a HMA of $20 \mathrm{mV} / \mathrm{km}$ has a only $50 \%$ occurrence, with $95 \%$ occurrence at $140 \mathrm{mV} / \mathrm{km}$, and $99.5 \%$ occurrence at $360 \mathrm{mV} / \mathrm{km}$.

Thus the following scale of HMA telluric activity was inferred to occur in the Mackenzie River Valley study area: normal quiet level $<20 \mathrm{mV} / \mathrm{km}$; normal auroral level $<140 \mathrm{mV} / \mathrm{km}$; and, active auroral level $<360 \mathrm{mV} / \mathrm{km}$. Because only one 
geomagnetic observatory (Yellowknife) has been used, the definitions of the activity levels are simpler and differ from the more complicated case for Alaska where some "grouping" of the activity levels was obvious for HMA calculated using different observatories.

The significance is that a pipeline in northern Canada, beneath the geomagnetic auroral zone, is subjected to a geoelectric field of $<140 \mathrm{mV} / \mathrm{km}$ (normal auroral level) that is seven times higher than what it would be if the pipeline was situated in the subauroral zone that covers the southern half of Canada. In other words, a pipeline that has cathodic protection to counter against a HMA of $20 \mathrm{mV} / \mathrm{km}$ (normal quiet level) would work only for $50 \%$ of the time in the auroral zone but $95 \%$ of the time in the sub-auroral zone where most of Canadian pipelines are located. It therefore becomes apparent that northern pipelines will experience telluric currents considerably larger than the southern pipeline network, thus special design considerations may need to be applied.

To demonstrate how differing Earth resistivity profiles influence the HMA, Figure 4.19 provides a comparison of the telluric activity indices separately determined for each of the five resistivity zones, for representative year 2004. The purpose was to characterize on a statistical basis the number of hours / percentage per year when HMA telluric indices are exceeded because the duration of exceedance represents an unfavourable condition that may impact the pipeline cathodic protection system. For example, in Zone 1 the normal auroral $(<140 \mathrm{mV} / \mathrm{km})$ activity is exceeded about 200 hours ( 8 days $)$ per year but only 6 hours when the more active auroral $(<360 \mathrm{mV} / \mathrm{km})$ level occurs. In comparison, in the more resistive Zone 3 normal auroral activity is 


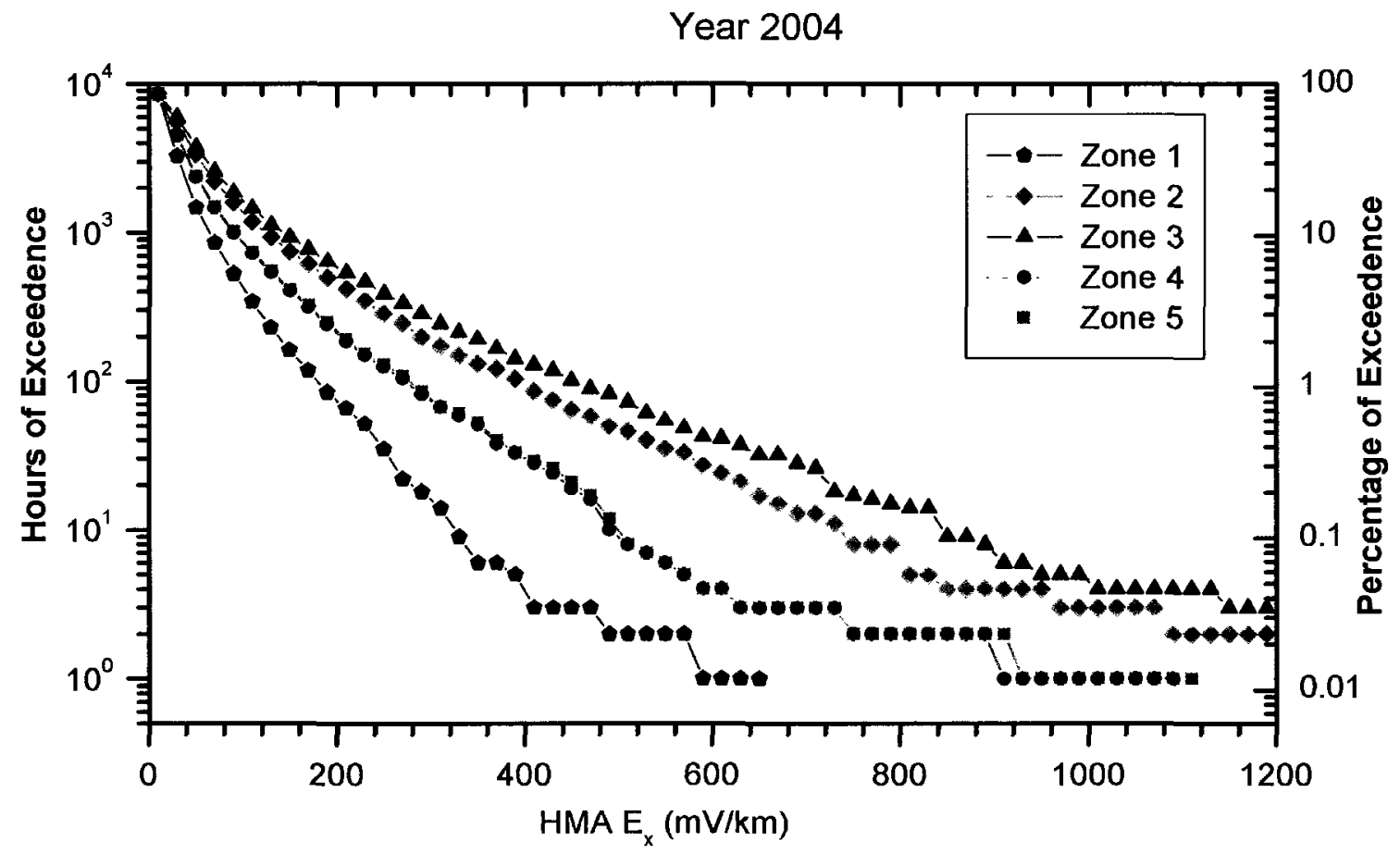

Figure 4.19. Statistical exceedance of the Hourly Maximum Activity (HMA) telluric activity indices, in $E_{x}$ direction, for all five resistivity zones in the Mackenzie River Valley study area for year 2004 (modified from Boteler et al., 2005, Fig. 4.25). Note that Zones 4 and 5 overlap. 
exceeded about 1000 hours (41 days) per year and 200 hours ( 8 days) per year during active auroral times.

Overall, highest values of HMA occurrences are in Zones 2 and 3 and the lowest is in Zone 1. This pattern corresponds to the presence of thinner sedimentary basin rock and a higher resistive upper crust and upper mantle in Zones 2 and 3, whereas a thick accumulation of low-resistive sediments and thinner upper crust occurs in Zone 1. Intermediate values of HMA in Zones 4 and 5 can be attributed to a much less resistive upper crust and upper mantle. The HMA occurrences values for Zones 2 and 3, and for Zones 4 and 5 are very similar. Hence, the number of Earth resistivity zones along the pipeline can be reduced to three geographic areas, North (former Zone 1), Middle (former Zones 2 and 3) and South (former Zones 4 and 5) on the basis of similar telluric activity.

Thus it has been demonstrated how a differing intensity of the regional geomagnetic environment (be it an auroral or sub-auroral zone, or daily changes from quiet to unsettled to storm days) will strongly influence the telluric activity experienced on a pipeline, and how in combination with a more resistive Earth structure the result will be a greater amount of geoelectric field amplitude along a particular section of pipeline route. Once the location of anticipated high telluric activity has been identified, a statistical evaluation of telluric activity allows for the determination on the amount of exceedance to be expected.

\subsection{Applications to PSP Modelling}

As was done for the Alaska Highway Corridor, a distributed-source transmission line (DSTL) model was used to predict PSP variations at different locations on the pipeline. Detailed results are presented in the report Study of Telluric Current Impacts on 
the Mackenzie Gas Project Pipelines (Boteler et al., 2005). Here, in this section, only illustrative examples are discussed. DSTL model inputs included the calculated geoelectric field for each of the resistivity zones along the pipeline route (determined using literature-derived Earth resistivity models) and pipeline physical characteristics supplied by the pipeline company.

A "standard" configuration was used to represent an electrically-continuous pipeline with an initial coating conductance of 5 microSiemens $/ \mathrm{m}^{2}$ (in $10 \mathrm{ohm} . \mathrm{m}$ soil), and terminating resistances of $15 \mathrm{ohm}$ (in frozen ground) and $3.2 \mathrm{ohm}$ (in unfrozen ground) at the northern and southern ends, respectively. A geomagnetically unsettled day, 17 January 2004 (with an HRX magnetic activity index of $300 \mathrm{nT}$ ), was chosen to model the PSP produced by geoelectric fields (Figure 4.20) expected during moderately disturbed geomagnetic conditions, for a pipeline orientated $150^{\circ}$ clockwise from geographic north.

The DSTL model calculations show the characteristic S-shape in the pipe-to-soil potential along the pipeline, with the maximum potentials occurring at the ends of the pipeline (Figure 4.21). These are the features expected for an "electrically long" pipeline, i.e. the largest PSP oscillations occur at the ends of the pipeline and the variations at opposite ends of the pipeline are out of phase with each other. Away from the ends the PSP amplitude falls off exponentially.

To illustrate how PSP is produced in response to a fluctuating geoelectric field during a geomagnetically unsettled day (exhibiting moderate disturbance) such as 17 January 2004, the modelled time variations are shown in Figure 4.22. PSP amplitude variations at the north end of the pipeline (Zone 1; Taglu) intermittently attain $20 \mathrm{~V}$, 


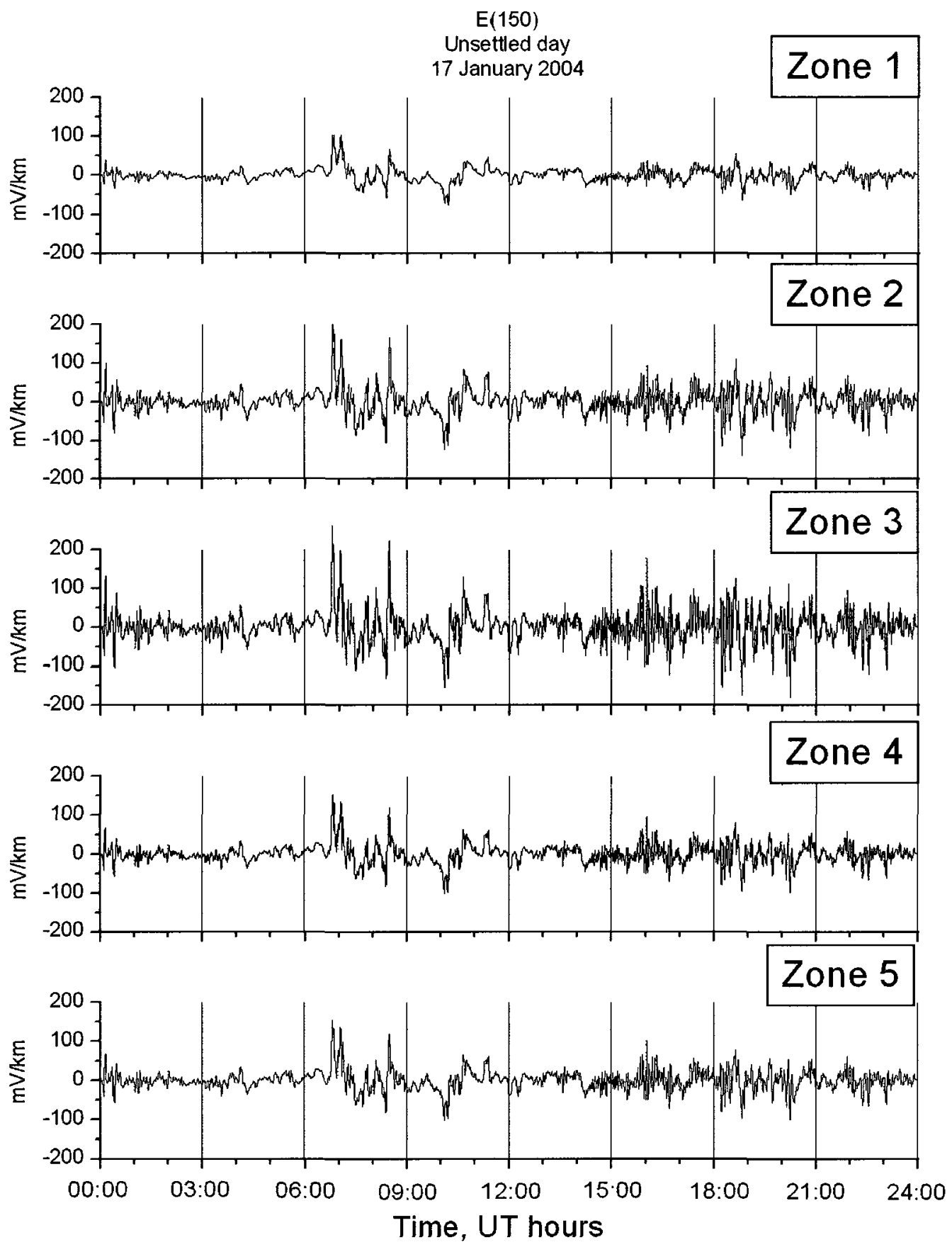

Figure 4.20. Calculated geoelectric field along the pipeline during moderately disturbed geomagnetic conditions, 17 January 2004, using the different layered Earth models (Zones $1-5$ ) and geomagnetic data from Yellowknife Geomagnetic Observatory. (Boteler et al., 2005, Fig. 6.4). 


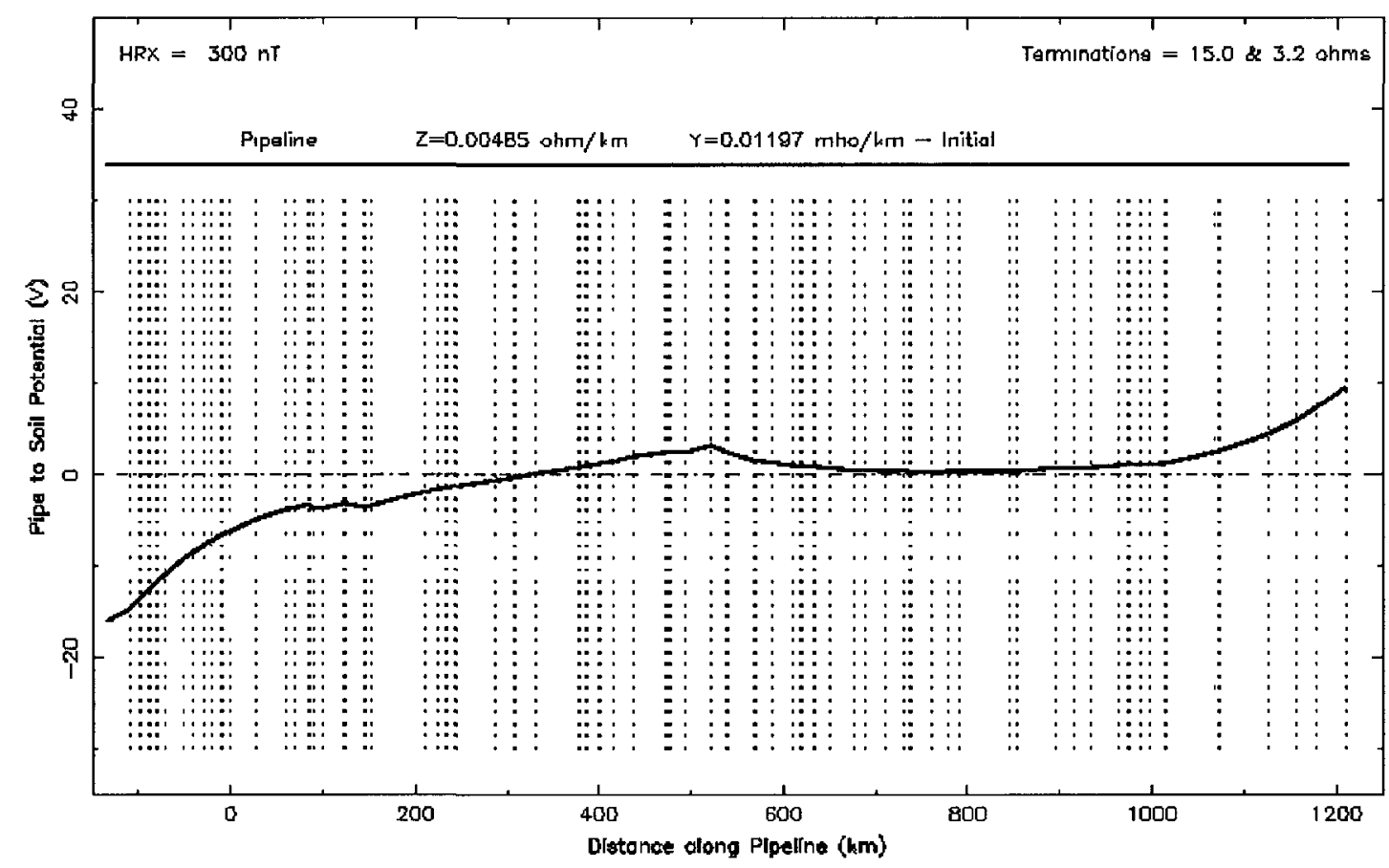

Figure 4.21. Model of PSP, on the proposed Mackenzie River valley pipeline, produced during a moderately disturbed geomagnetic conditions (unsettled day) with an HRX $=300 \mathrm{nT}$, for 17 January 2004 (Boteler et al., 2005, Fig.6.5). Shown is the entire length of the pipeline with a terminating ground bed of 15 and $3.2 \mathrm{ohms}$ at north and south ends, respectively. 

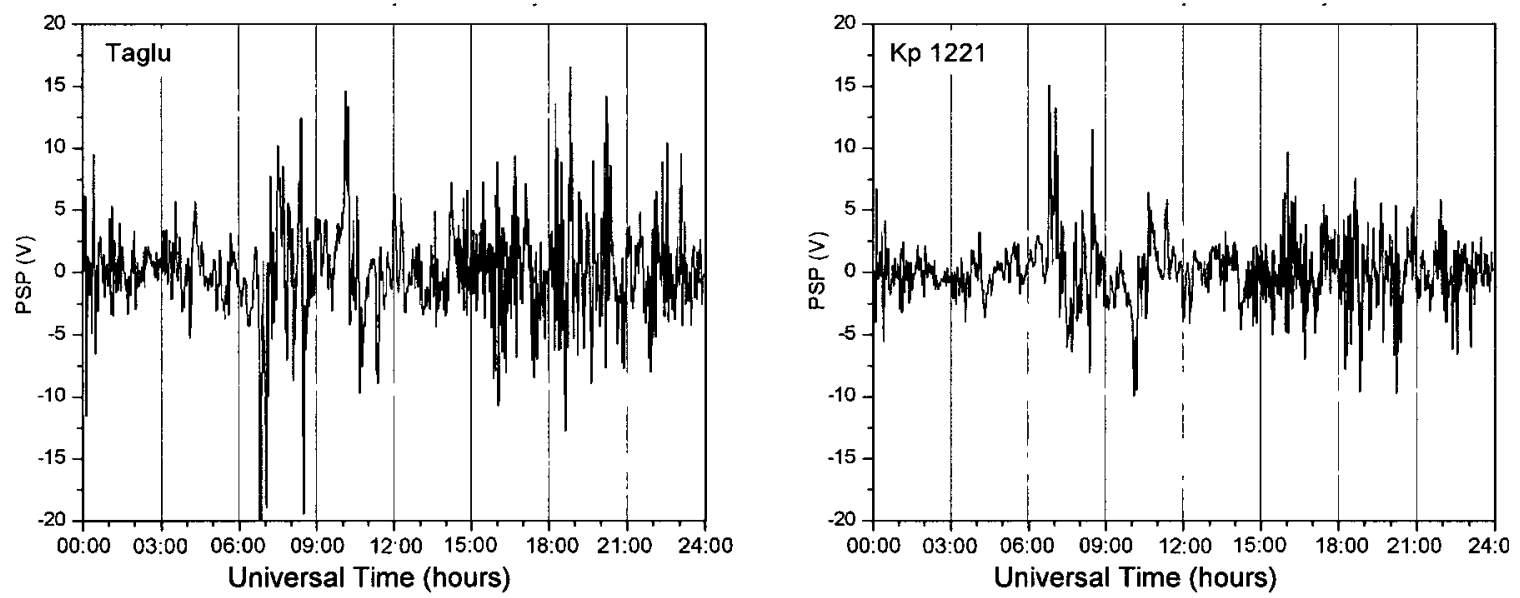

Figure 4.22. PSP variations that would be produced at the north (Zone 1; Taglu) and south (Zone 5; KP1221) ends of the proposed Mackenzie River valley pipeline on 17 January 2004, during moderately disturbed geomagnetic conditions typical of an unsettled day (modified from Boteler et al., 2005, Fig. 6.6). 
regularly achieve $10 \mathrm{~V}$, and often have fluctuations of approximately $5 \mathrm{~V}$. Simultaneously, at the south end of the pipeline (Zone 5; kilometre point KP1221) the PSP variations are in opposite direction and generally of lower amplitude, intermittently reaching $15 \mathrm{~V}$ and regularly $5 \mathrm{~V}$. Although the geoelectric field variations are smallest in Zone 1, possibly due to the presence of the thick low-resistive sedimentary basin, the higher terminating resistance of the ground bed at the north end of the pipeline has a greater influence on final PSP variations, producing larger PSP amplitude in Zone 1 than Zone 5. As can be seen, there is considerable difference in the PSP variation pattern due to the combined effects of Earth resistivity, and the pipeline electrical and geometrical parameters including resistance of the cathodic protection system ground beds.

\subsection{Summary of Findings}

As a result of investigations undertaken on the Mackenzie River valley study area, the following findings and advancements, and recommendation for improvement were made:

a) The first MT survey, of an exploratory nature, along the length of the Mackenzie River valley was completed, comprising seven MT sounding sites, of which six provided useable data.

b) Five new and original, literature-derived 1D Earth resistivity models (representing a zone of resistivity along the pipeline route) were developed.

c) Original 1D inversion models were prepared for each of six MT sounding sites located in the Mackenzie River valley.

d) Reasonably good agreement was found to exist between the literature- and MTderived 1D Earth resistivity models with respect to; (i) base of deep permafrost, (ii) depth of contact between surficial sediments and sedimentary basin rock, but 
lesser agreement of (iii) surficial sediment resistivity, (iv) resistivity and thickness of the sedimentary basin, and (v) depth to Moho for central portion of the Mackenzie River valley. Overall, there was poor agreement between the two approaches for thickness and resistivity of the upper crust.

e) Confirmed that the low-resistance upper crust and upper mantle first identified by Wu (2001) extends $25 \mathrm{~km}$ northward to Fort Simpson.

f) Recognition that there is a similar situation of a low-resistive upper crust and upper mantle situation at Norman Wells.

g) Identification that much of the Mackenzie River Valley is underlain by a lower resistive (200 - 300 ohm.m) upper mantle, in contrast to a much higher resistivity (3000 ohm.m) obtained through a literature compilation.

h) 1D layered inversion models (of the MT sounding data) did not give sufficient resolution of the deeper layers, such as the mantle, possibly due to the following factors: (i) MT survey was done during solar cycle minimum when the natural source signal is at its weakest and may not have been sufficiently strong to penetrate to and illicit a response from the lower most layers of the Earth; (ii) presence of the low-resistance, i.e. conductive, sedimentary basin layer (10-20 ohm.m) could have diminished the natural source signal and its ability to penetrate to deeper layers; and, (iii) recording duration (typically 17 hours) may have been too short to obtain a statistically valid representation of Earth response at the lowermost frequencies.

i) A reasonably close similarity was observed between literature- and MT-derived surface impedance amplitude for several pairings of resistivity zone and MT 
soundings with differences increasing as the frequency decreases; this being attributed to an insufficient recording duration at the MT sounding sites.

j) Presence or not of the seasonally frozen-to-thawed active layer, into which the pipeline is buried, is not a significant factor for inclusion into an Earth resistivity model because its effect on surface impedance values manifests itself at frequencies above $10 \mathrm{~Hz}$, much higher than the natural fluctuations $(<1 \mathrm{~Hz})$ of interest of the geomagnetic field and limitation of geomagnetic observatory data to frequencies at and lower than $1 \mathrm{~Hz}$.

k) Confirmation that large-scale differences in Earth resistivity and layer thickness, affects the geoelectric field and that its amplitude increases where a more resistive Earth structure is found along a pipeline route.

1) Demonstrated that while PSP amplitudes can be elevated as a result of increased geomagnetic activity, pipeline characteristics such as the resistance of ground beds are an important contributing factor that may outweigh the contribution from the underlying Earth structure.

m) For future assessment of Earth resistivity along a pipeline, it would be better to have a few sounding sites (selected on basis of differing gross geology along pipeline route) which record for an extended duration of 1 to 2 weeks, instead of a higher density of 1-day duration recordings, in order to obtain quality data at the lowermost frequencies to improve resolution of the mantle layers. 


\section{CHAPTER 5}

\section{OTTAWA VALLEY PIPELINE}

\subsection{Overview and Objectives}

The Ottawa Valley Pipeline study area comprises a $150 \mathrm{~km}$ long portion of the TransCanada Mainline (see Figure 1.1), a 3,100 km long natural gas pipeline that extends from the Alberta / Saskatchewan provincial boundary east to the Quebec/Vermont international border, and connects with other pipelines in Canada and USA. More specifically, the area of investigation extends from the Village of North Gower (immediately southwest of Ottawa) northwesterly to the Village of Petawawa. The pipeline roughly runs parallel to Highway 17 and the Ottawa River.

As previously introduced in Chapter 1, this study area was selected because it brackets a zone of anomalously high pipe-to-soil (PSP) variations identified in a 1997 telluric current study (Boteler and Trichtchenko, 2000) and it features two major geological settings of contrasting resistivity, the more electrically resistive metamorphic rocks of the older Precambrian Grenville geological province to the west and the more conductive sediments of the younger Paleozoic Ottawa Embayment to the east (Figure 5.1). The 1997 study showed PSP from all recording locations along the pipeline in the Ottawa Valley varied simultaneously but the largest differences in amplitude were observed at Site 3, near the town of Arnprior (Figure 5.1). Changes in the pipeline structure alone, such as bends, could not explain these differences. Later, Boteler et al. (2003) suggested on the basis of modelling that large variations of PSP could possibly 


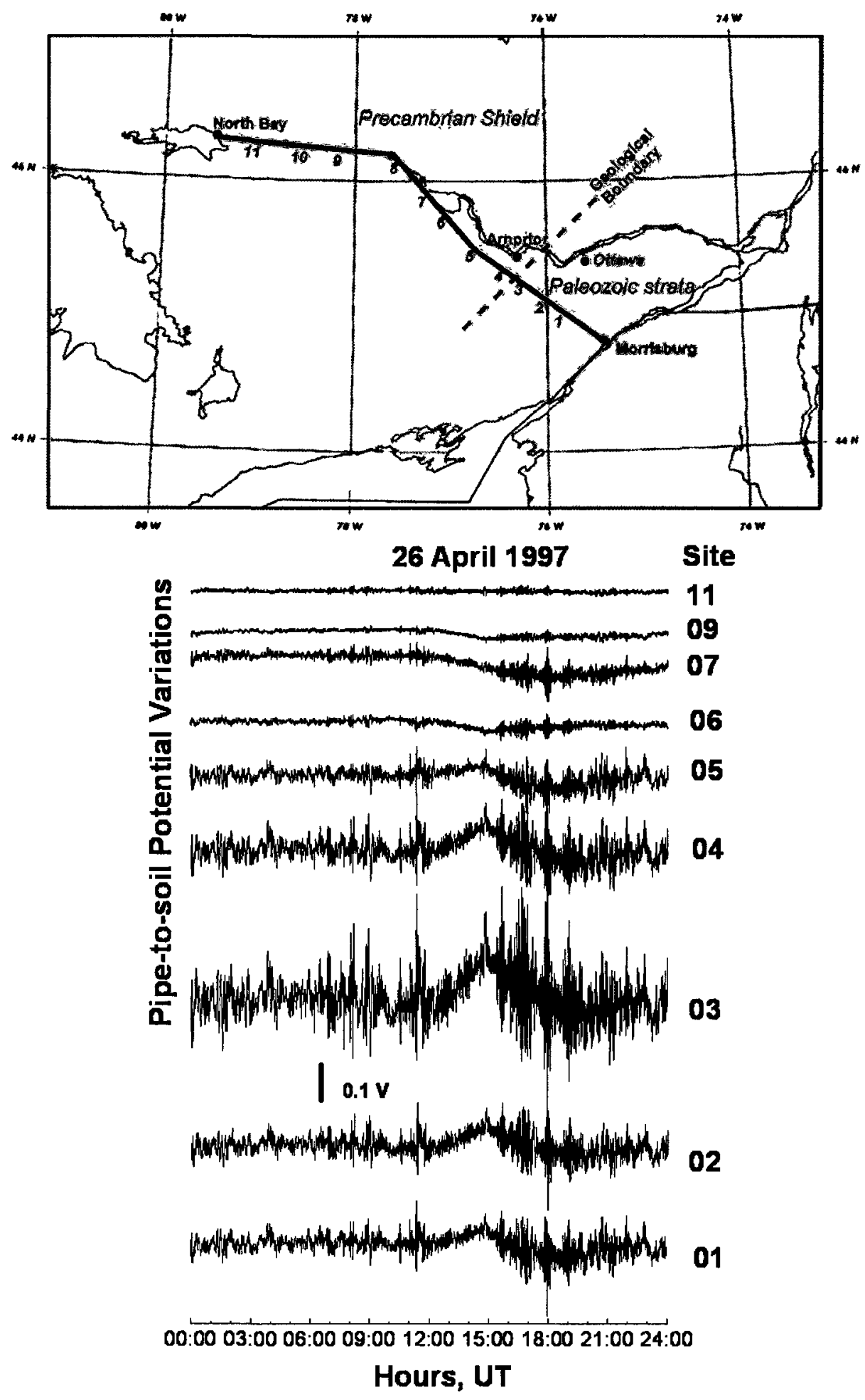

Figure 5.1. Top panel is a map of part of the TransCanada natural gas pipeline showing locations of the 1997 PSP recording sites. Bottom panel shows the simultaneous pipe-tosoil (PSP) recordings at nine sites along the pipeline. The largest PSP variations occur at site 3 near Arnprior (after Boteler and Trichtchenko, 2000, Figs.2.21 and 2.22). 
related to lateral changes of Earth resistivity under the pipeline, perhaps as a consequence of the Precambrian - Paleozoic contact near Arnprior.

Although changes in pipeline structure and orientation have been shown to influence the PSP amplitude (Boteler, 2000; Boteler and Trichtchenko, 2000; Gummow et al., 2001; Rix and Boteler, 2001), Earth resistivity contrasts can also create amplitude variations of the surface geoelectric field resulting in noticeable telluric current variations, in particular where a pipeline crosses a highly resistive intrusive rock (Osella and Favetto, 2000). Geoelectric field amplitude can be altered due to crustal-scale variations of resistivity, particularly at boundaries to tectonic terranes (Beamish et al., 2002). Variations of the geoelectric field in northern England were attributed to complex crustal structure, area faulting and low-resistive anomalies (McKay and Whaler, 2006).

This chapter is mainly based on a published scientific article whose lead author is the author of this thesis (Fernberg et al., 2007). The focus of the chapter is the relation between lateral changes of Earth resistivity and how it affects the amplitude of PSP fluctuations. The main objective was to test the hypothesis that a major geological contrast, i.e. a two-dimensional (2D) variation of resistivity, could be the cause of elevated PSP identified in 1997 along the study pipeline. Secondary objectives were to more precisely identify the zone along the pipeline where large PSP are observed and surmise what geological structure(s) are present which could cause a significant electrical resistivity contrast.

A two-stage investigative process was undertaken to address the objectives, and involved completion of MT and PSP surveys plus data analysis. The first task was to confirm that the high amplitude PSP variations identified during the 1997 International 
Telluric Study (ITS) are a permanent feature of the pipeline study area. The method taken was to measure simultaneously the geoelectric field (using MT instruments) and the PSP (using data loggers) at a number of locations along the pipeline: these being the first surveys of this type ever reported in the literature (Fernberg et al., 2007). Measurements were centered on where anomalous PSP amplitude had earlier been identified, and to bracket both sides of the Precambrian - Paleozoic geological contact.

The second task was to understand the relationship between Earth resistivity structure and observed PSP variations. Instead of using a theoretical 1D Earth model (as done in Chapters 3 and 4) that assumes a regional distribution of resistivity that varies only with depth and ignores lateral variation, the surface impedance was calculated from MT measurements taken at multiple sites along a profile parallel to the TransCanada Mainline route. These are used to calculate a non-uniform, i.e. laterally-varying, surface geoelectrical field, and subsequently a modelled PSP. Comparison of modelled and observed PSP would provide evidence that the underlying geology has a direct influence on the electromagnetic environment experienced by the pipeline. A 2D inversion model, which shows the subsurface distribution of Earth resistivity along the pipeline route, was used to identify whether there exists a correlation between locations of anomalous resistivity, geological structure and large amplitude PSP variation.

\subsection{Geological Setting}

Underlying the entire study area is the Grenville geological province, with Paleozoic sediments covering the southern half. Knobby bedrock outcrops of Grenvillian rocks are common in the northern half of the study area. The Grenville province is a complex assemblage of highly deformed and metamorphosed rocks (Figure 5.2), 


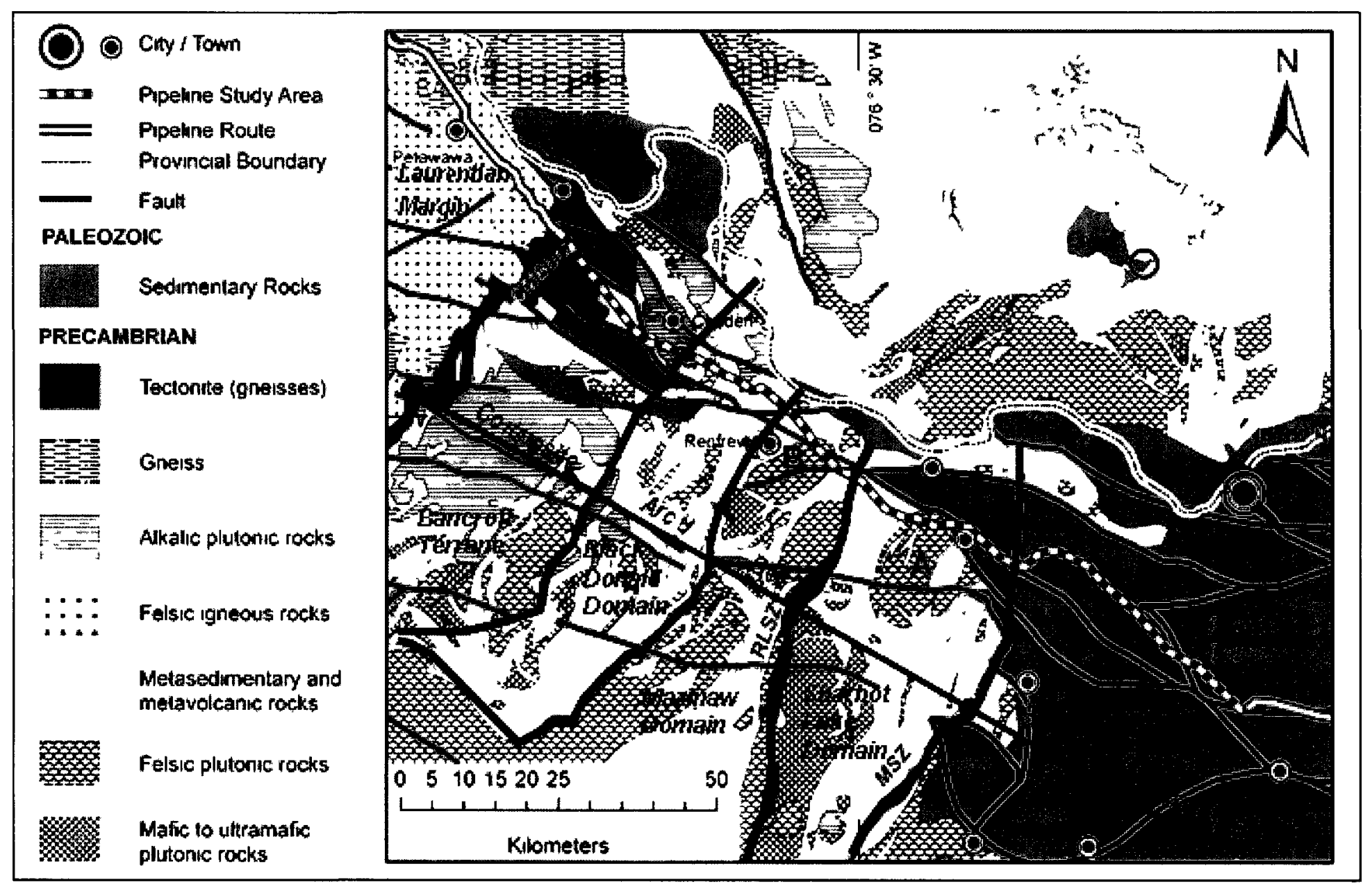

Figure 5.2. Bedrock geology map of the Ottawa Valley, including major divisions and lithotectonic elements, and natural gas pipeline route. Structures: CMBbtz, Central Metasedimentary belt boundary thrust zone; RLSZ, Robertson Lake Shear Zone; MSZ, Maberly Shear Zone. Intrusives: A, Mount Pakenham; B, Hurds Lake; C, Bonnechere Ridge (Ont Geol Surv, 1993). 
representing several cycles of continental-scale collision and subduction 1500 to 900 million years ago. The result is a crustal architecture consisting of accreted tectonic terranes separated by northeasterly tending shear zones, many of which penetrate the full thickness of the crust (Percival et al., 2004). In Ontario, the Grenville province consists of three main divisions (Figure 5.2), the older gneissic Laurentian Margin (also known as the Central Gneiss Belt), the volcanic- and marble-dominated Composite Arc Belt, and the platformal Frontenac-Adirondack Belt (Carr et al., 2000). In addition to crossing the three major divisions of the Grenville province, the pipeline passes over four lithotectonic elements that make up the Composite Arc Belt: Bancroft Terrane, Black Donald Domain, Mazinaw Domain, and Sharbot Lake Terrane.

Major north-easterly trending shear zones cross the pipeline route and form boundaries between different terranes (Figure 5.2). These include the Central Metasedimentary Belt boundary thrust zone (CMBbtz), the Mooronton Shear Zone (MMSZ), the Robertson Lake Shear Zone (RLSZ) - marking a major tectonic boundary with contrasting metamorphic facies and rock types on either side (Busch et al., 1997) and the Maberly Shear Zone (MSZ), with the latter possibly crossing the pipeline route beneath the covering Paleozoic sediments. Part of the pipeline route follows the northwesterly trending Pakenham Fault which locally marks the boundary between the Precambrian and Paleozoic rocks. Seismic surveying in the Ontario part of the Grenville province has revealed that terrane boundaries are coincident with major seismic boundaries (Easton, 1992). The CMBbtz is interpreted (Ouassaa and Forsyth, 2002; Ouassaa et al., 2010) to be a shallow east-dipping structure extending from the near surface to a depth about $24 \mathrm{~km}$. Shallow SE dipping structures extending to depths of 
about $12 \mathrm{~km}$ were also seismically imaged, which could represent the Roberson Lake Shear Zone and / or and Maberly Shear Zone.

Intrusive bodies of late to middle Precambrian age are numerous. The largest along the pipeline route is the Mount Pakenham ski-hill, comprised of granite and granodiorite, followed by the Hurds Lake trondhjemite upland, and the "Bonnechere Ridge" syenite as identified on Figure 5.2.

Paleozoic sedimentary rocks of the Ottawa Embayment (formed 590 to $440 \mathrm{Ma}$ ago during opening and closing of the proto-Atlantic Iapetus Ocean) unconformably cover the eastern half of the Grenville basement rocks in the study area, and also occur as outliers in the western half (Figure 5.2). On the west side of Ottawa, flat-lying Ordovician sandstone, shale, dolostone and limestone can be up to $250 \mathrm{~m}$ thick (Belanger, 2010) shallowing westward to Pakenham where thickness could vary from 50 - 75 m (G. Dix, pers. comm.). Thickness of the Paleozoic outliers between Renfrew and Pembroke are not known.

Development of the Ottawa-Bonnechere Graben, beginning $570 \mathrm{Ma}$ ago, and possibly reactivated 150 Ma ago (Eyles, 2002) have resulted in a series of NW-SE and W-E oriented faults defining a $60 \mathrm{~km}$ wide structural corridor that follows the Ottawa Valley and the pipeline route. Major faults proximal to and sub-parallel to the pipeline route include the Hazeldean, Pakenham, Dore, Douglas and Muskrat faults, which bound the southern edge of the graben.

Overburden in the Ottawa Valley consists of Quaternary glacial tills, gravel and sand, sometimes overlain by an expanse of paleo-Champlain Sea marine clays and silts locally known as Leda clay (Belanger, 2010). Along the pipeline route, Leda clay is 
found mostly in the valleys formed by the Mississippi, Madawaska and Bonnechere Rivers. From Pembroke northwestward is the Petawawa Sand Plain (glaciofluvial outwash deposits), a relic delta formed during retreat of glacial Lake Champlain. Thickness of the unconsolidated sediments is typically between 2 and $4 \mathrm{~m}$, with occasional isolated pockets ranging from 15 to $30 \mathrm{~m}$ along the pipeline route. Geotechnical drilling for construction of a new bridge over the Mississippi River (a tributary of the Ottawa River), $4 \mathrm{~km}$ east of the pipeline, revealed bedrock at a depth of $46 \mathrm{~m}$ (Remisz, 2005).

Electrical resistivity contrasts of bedrock in the study area are considerable due to the geological variety of the Grenville province. Generally, intrusives have a high resistivity (2500 - 7000 ohm.m), metamorphic rocks are intermediate to high (considerable range from 1000 to greater than $10000 \mathrm{ohm} . \mathrm{m}$ ) and consolidated sediments, such as the Paleozoic cover, are lowest (10 - 1000 ohm.m, commonly low 100s ohm.m), depending on local porosity of the rock, salinity of pore water and lithological conditions (Palacky, 1988; Telford et al., 1976; Ferguson and Odwar, 1997). Overburden resistivity is low to moderate $(1-800 \mathrm{ohm} . \mathrm{m})$ depending on type material (clay, silt, sand) and amount of pore water. Resistivity of Leda clay can vary (1 -20 ohm.m), depending on salinity of entrapped pore water (J. Hunter, pers. comm., 2006) which is higher at greater depths. 


\subsection{Geophysical Surveys in the Ottawa Valley Study Area}

\subsubsection{Previous Electromagnetic and Seismic Surveys}

The only known MT survey previously done in the Ottawa Valley Pipeline study area was conducted by Telford et al. (1976) at a location $32 \mathrm{~km}$ west of Ottawa, north of the Ottawa River. The purpose was to measure the apparent resistivity contrast between the Grenville and Paleozoic rocks, which was found to be of the order of 1000 and 10 ohm.m, respectively. This is in agreement with known trends: older rocks are generally more resistive than younger strata.

In 1982, seismic refraction profiles were completed across parts of the Grenville province to investigate the underlying crustal structure (Easton, 1992). Two of the seismic profiles crossed near to the north and south ends of the study area, and a third ran parallel to the pipeline. During summer 2000, the GSC completed a $70 \mathrm{~km}$ long seismic reflection survey along the Upper Dwyer Hill Road, crossing the Paleozoic sediments that cover the eastern half of the Ottawa Valley pipeline study area. Its purpose was to provide constraints on the Grenville crustal structure and the interaction of the Paleozoic sedimentary section with the underlying Precambrian Grenville basement rocks (Ouassaa et al., 2000).

Crustal thicknesses obtained from interpretation of seismic data range widely, from 34.5 to $52.4 \mathrm{~km}$ (Ouassaa and White, 2002; Percival et al., 2004; Eaton et al., 2006) and show regional variances. A strong correlation of crustal-thickness trends was shown to exist with geological belts but not with surface topography (Eaton et al., 2006). Relatively thick crust $(40-44 \mathrm{~km})$ occurs within the Laurentian Margin, occupying the northern most part of the study area. Intermediate crustal thickness $(37-39 \mathrm{~km})$ is situated 
within the Composite Arc Belt, with thinner crust $(34.5-37 \mathrm{~km})$ northeast of the study area. Mereu et al. (1986) observed that the Moho along the Ottawa-Bonnechere Graben is poorly defined and appears to have a step-like $2 \mathrm{~km}$ vertical offset as a result of ancient rifting that formed the graben, suggesting a deep-seated fault zone present along the length of the graben.

\subsubsection{Simultaneous Magnetotelluric and PSP Surveys 2003-2009}

As part of this thesis, four combined MT and PSP surveys (Figure 5.3) were undertaken along a $150 \mathrm{~km}$ long section of the TransCanada Mainline over a six year period, from 2003 to 2009 . Table 5.1 provides a summary of survey statistics. Photographs of selected sites and pipeline right-of-way are provided in Figures 5.4 and 5.5 .

The MT surveys served two purposes. First, the $15 \mathrm{~Hz}$ geoelectric field time series data were used to identify areas of significant amplitude variation along the pipeline, which coincide with a simultaneous PSP response. Secondly, MT data (including lower-frequency broadband MT and higher-frequency AMT recordings) were used to construct a $2 \mathrm{D}$ electrical resistivity profile along the pipeline route in the study area. The profile was used to identify resistivity contrasts which could mark major differences of tectonic terrane, rock type, and / or structural discontinuity, and assess whether these differences could be correlated to observed changes of PSP amplitude ratios.

The purpose of the 2003 Ottawa River Valley (ORV) survey was to test the concept of simultaneous measurements of geoelectric field and PSP variations, this being the first survey of its kind. In addition, the ORV survey was to confirm a rise of PSP 


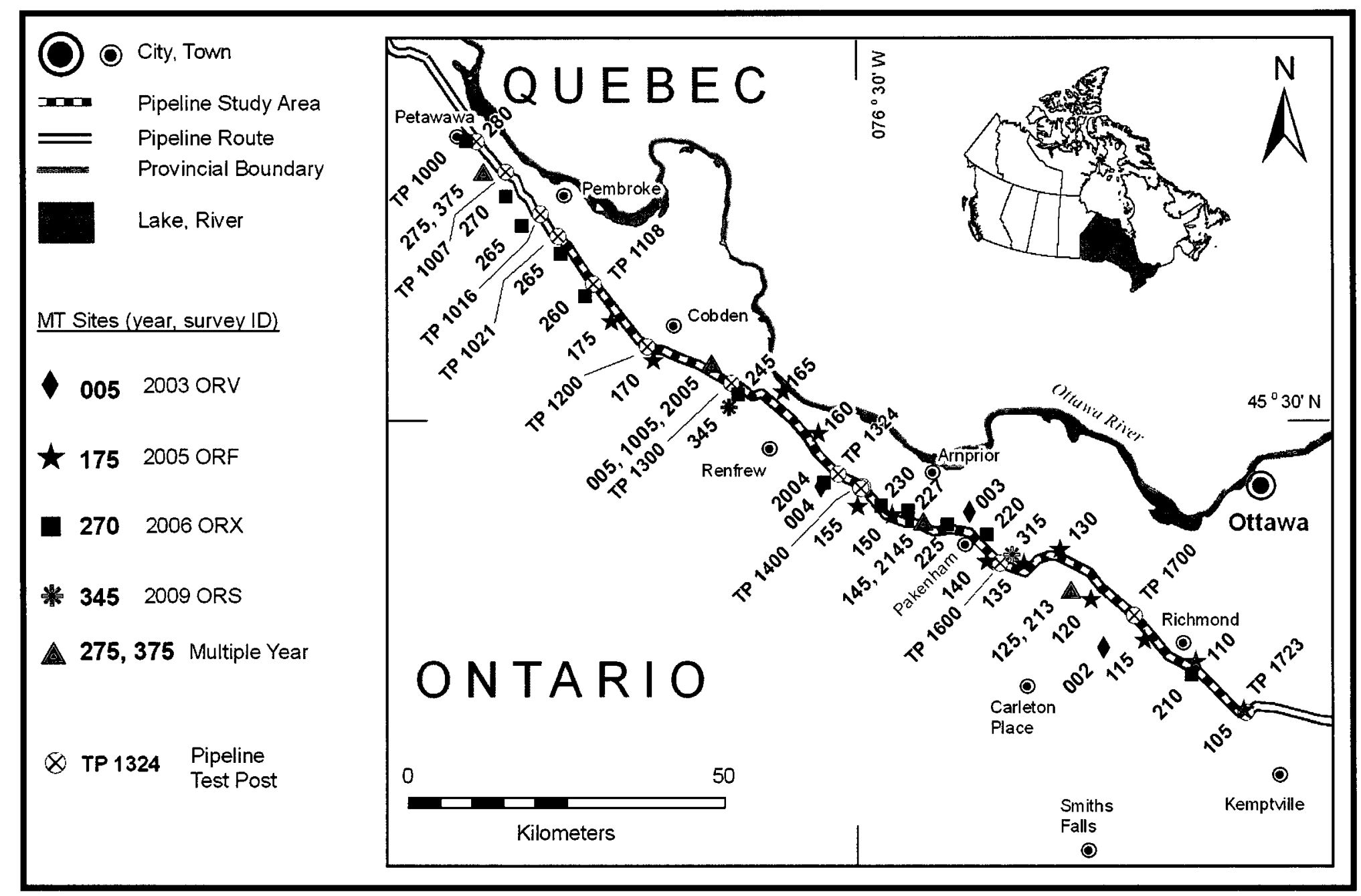

Figure 5.3. Location of MT sounding sites for multiple surveys in the Ottawa Valley study area. Selected test post locations are also shown. 
Table 5.1. Survey statistics and instrument specifications.

\begin{tabular}{|c|c|c|c|c|c|c|c|c|c|}
\hline \multirow{2}{*}{\multicolumn{2}{|c|}{ Survey }} & \multicolumn{4}{|c|}{ PSP } & \multicolumn{4}{|c|}{ MT } \\
\hline & & 2003 ORV & 2005 ORF & 2006 ORX & 2009 ORS & 2003 ORV & 2005 ORF & 2006 ORX & 2009 ORS \\
\hline \multicolumn{2}{|c|}{ Number of Sites } & 9 & 39 & 51 & 9 & 4 & 17 & 15 & 3 \\
\hline \multicolumn{2}{|c|}{$\begin{array}{l}\text { Site Spacing } \\
\text { (average) }\end{array}$} & $9 \mathrm{~km}$ & $3 \mathrm{~km}$ & $1-4 \mathrm{~km}$ & $3-8 \mathrm{~km}$ & $25 \mathrm{~km}$ & $6-9 \mathrm{~km}$ & $5-7 \mathrm{~km}$ & $51-53 \mathrm{~km}$ \\
\hline \multirow{7}{*}{ 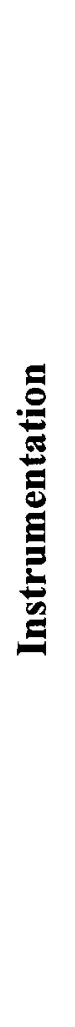 } & Manufacturer & Cath-Tech & \multicolumn{3}{|c|}{ Tinker-Rasor } & \multicolumn{4}{|c|}{ Phoenix Geophysics } \\
\hline & Instrument & $\begin{array}{l}\text { Hexcorder } \\
\text { Millennium }\end{array}$ & \multicolumn{3}{|c|}{ DL - 1 Data Logger } & \multicolumn{4}{|c|}{$\begin{array}{c}\text { MTU-5A } \\
\text { Central Processing Unit }\end{array}$} \\
\hline & $\begin{array}{l}\text { Sampling } \\
\text { Frequency }\end{array}$ & $1 \mathrm{~Hz}$ & \multicolumn{3}{|c|}{$5 \mathrm{~Hz}$} & \multicolumn{4}{|c|}{$\begin{array}{l}\text { MT sampling: } 15,150 \& 2400 \mathrm{~Hz} \\
\text { AMT sampling: } 150,2400 \& 24000 \mathrm{~Hz}\end{array}$} \\
\hline & $\begin{array}{l}\text { Number of } \\
\text { Channels }\end{array}$ & 1 & \multicolumn{3}{|c|}{1} & \multicolumn{4}{|c|}{$\begin{array}{c}5 \\
\text { (electric: } E x, E y \text { ) } \\
\text { (magnetic: } H x, H y, H z \text { ) }\end{array}$} \\
\hline & $\begin{array}{c}\text { Timing } \\
\text { Reference }\end{array}$ & GPS & \multicolumn{3}{|c|}{ Internal Clock } & \multicolumn{4}{|c|}{ GPS } \\
\hline & $\begin{array}{l}\text { Data Storage } \\
\text { Capacity }\end{array}$ & $1 \mathrm{Mb}$ & \multicolumn{3}{|c|}{500,000 samples } & \multicolumn{4}{|c|}{$128-512 \mathrm{~Kb}$} \\
\hline & Power Source & $\begin{array}{l}\text { Internal } \\
\text { Battery }\end{array}$ & \multicolumn{3}{|c|}{$\begin{array}{l}\text { Internal } \\
\text { Battery }\end{array}$} & \multicolumn{4}{|c|}{$\begin{array}{l}\text { External } \\
\text { Battery }\end{array}$} \\
\hline
\end{tabular}



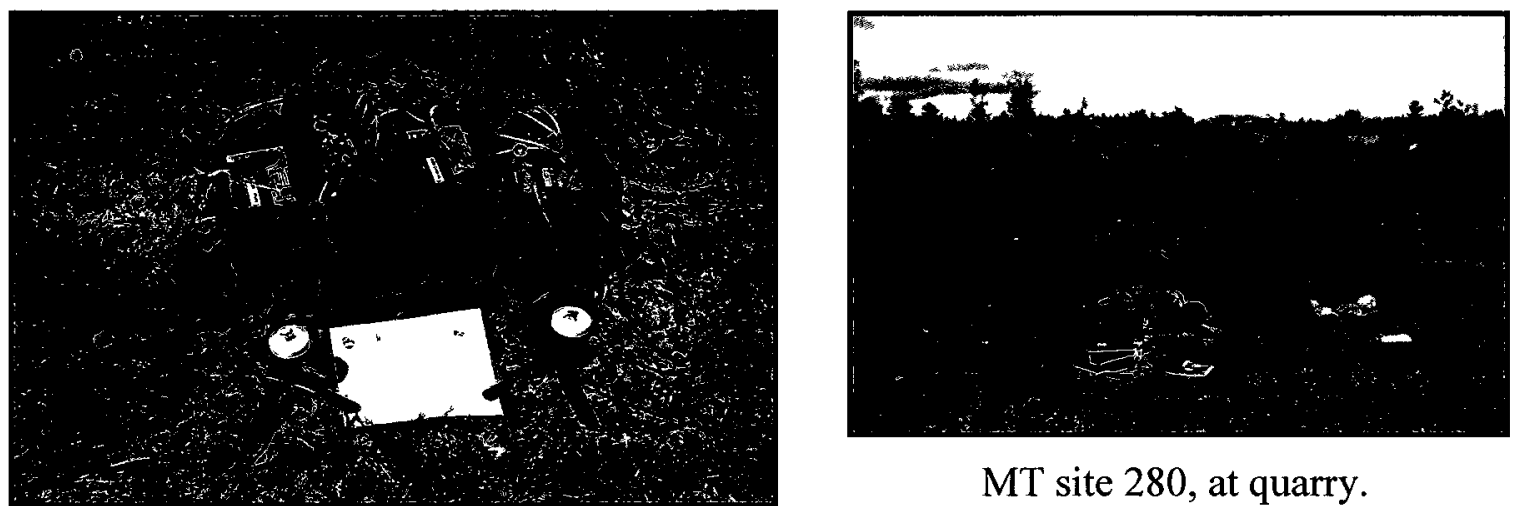

MT site 280 , at quarry.

Two Phoenix Geophysics MTU-5A central processing units using shared electrode lines. GPS receivers on tripods.

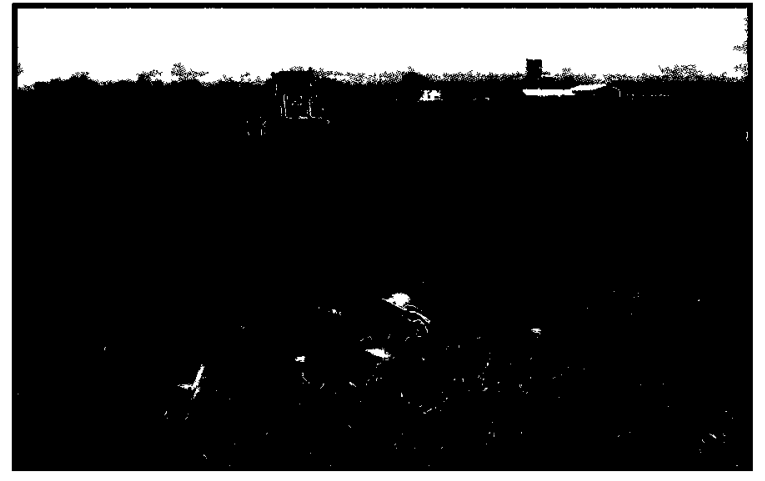

MT site 220, on cropland.

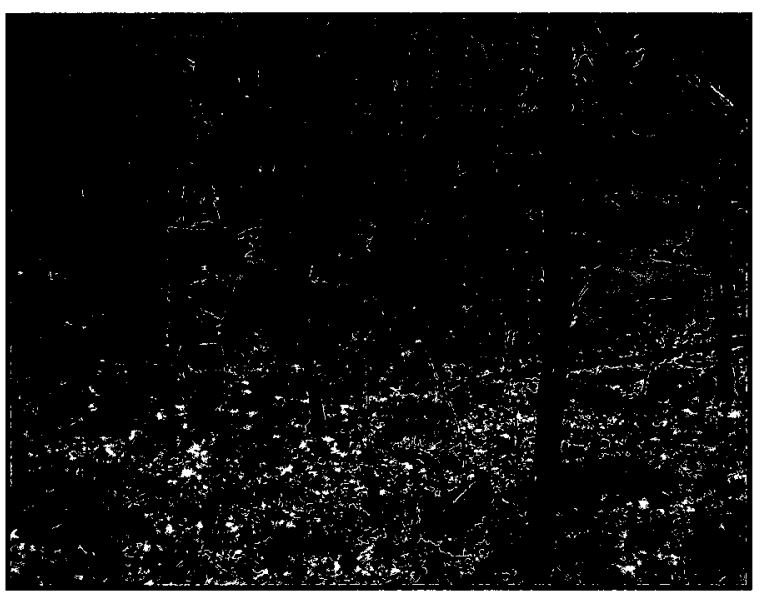

MT site 204 remote-reference, note plastic culvert protecting vertical $H_{z}$ induction coil.

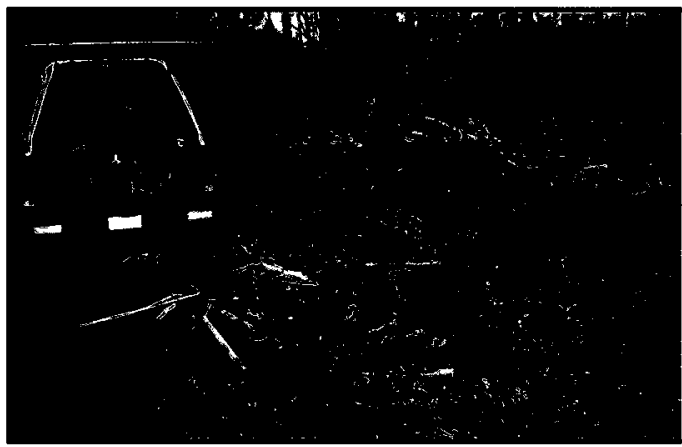

MT site 245 , in county forest reserve. Note induction coils wrapped in protective plastic.

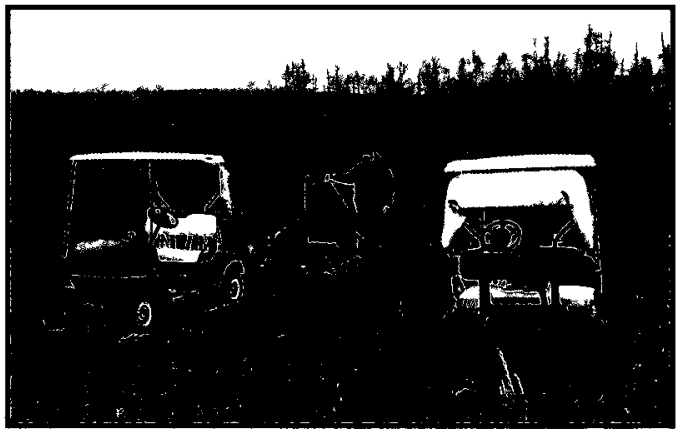

MT site 345, at Renfrew Golf Club surplus lands.

Figure 5.4. Views of MT instruments and sounding sites, Ottawa Valley. 


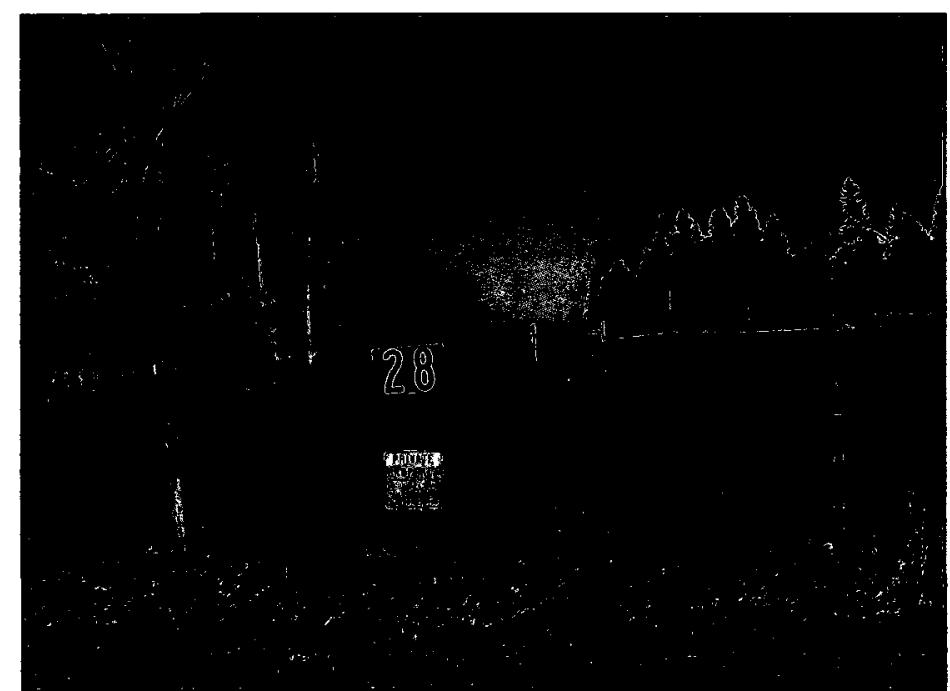

Shut-off valve and right-of-way at Fernbank Road (km 346). Test post 1627 on photograph right side.

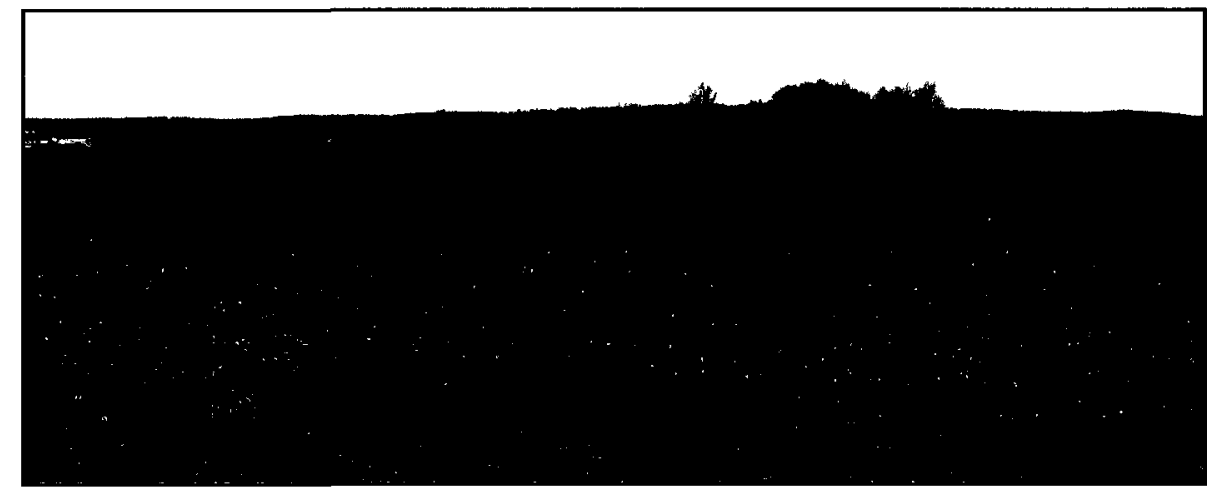

Test post 1518 at Highway 29 / Downey Road \& right-of-way (km 308). Mount Pakenham in background.

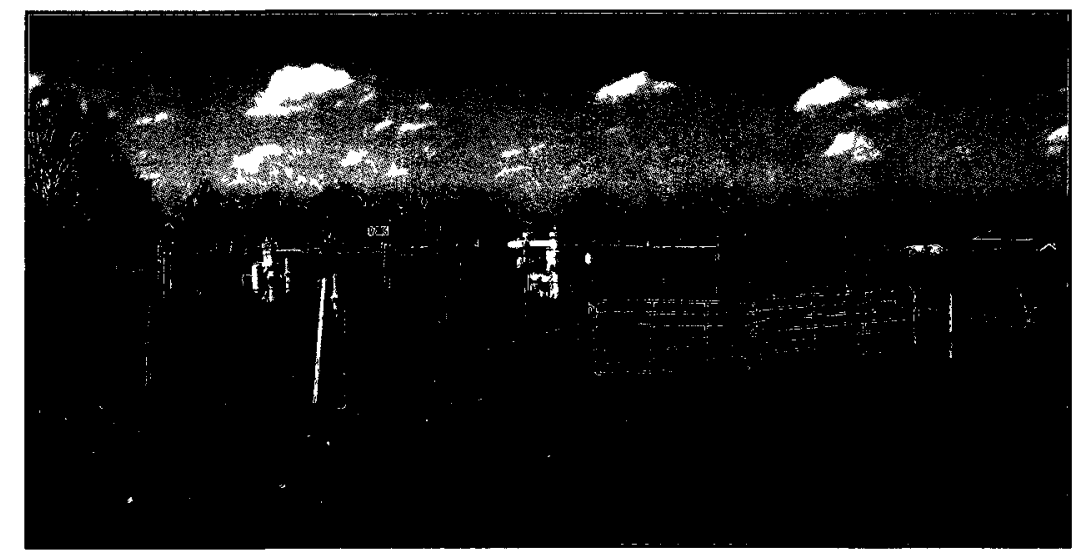

Valve station 1600 (km 318.5), Panmure Road

Figure 5.5. Views of TransCanada mainline right-of-way, Ottawa Valley study area. 
previously identified during the 1997 ITS survey. In 2005, the closer spacing of survey sites for the Ottawa River Follow-up (ORF) survey was designed to enhance the lateral resolution of the geophysical response in order to identify types of geological structures and/or boundaries that may be a cause in the rise of PSP. Then, for the Ottawa River Extension (ORX) survey in 2006, additional measurements were completed, both to infill gaps in the previous year's ORF survey (with a focus on the Mount Pakenham intrusive) and to extend the study area by $55 \mathrm{~km}$ to the northwest to go across the CMBbtz. Also in 2006, some of the PSP measurements duplicated the same test posts used in 2005. The small, supplemental, 2009 ORS survey consisted of three MT soundings and nine PSP test posts, and was done to either replace poor quality or confirm measurements obtained during the ORX survey.

During each survey simultaneous MT and PSP recordings were made. MT sites were situated about one to two $\mathrm{km}$ away from the pipeline to avoid possible electrical interference from the pipeline's cathodic protection system. A series of PSP data loggers were positioned along the pipeline to bracket the nearest MT site. Using this method, the geoelectric field and PSP were measured concurrently over a specific length of the pipeline route, moving each day to a different span of the route. A typical day of recording for the $2005 \mathrm{ORF}$ and $2006 \mathrm{ORX}$ surveys would include two MT instrumented sites and eight PSP data loggers - referred to as "mobile" sites - , in addition to a MT remote-reference site and a PSP reference test post. Appendix A5.1 provides a summary of MT sounding sites and PSP test posts utilized for each of the combined surveys.

Because much of the studied pipeline route passes through the well-populated rural area west of Ottawa, some difficulties were encountered in obtaining access for 
placement of MT sounding sites, and how to locate the sites with adequate separation. MT station spacing and distance from the pipeline were influenced by access to open fields or forest reasonably distant from dwellings, electric fencing and roadside electrical power lines.

A typical combined AMT and MT recording duration was 15 hours, overnight from 18:00 to 09:00 local time (22:00 to 13:00 universal time (UT)), because the natural signal is typically strongest in the early morning hours and cultural electrical noise would likely be less during these "quiet" hours (Garcia and Jones, 2002). PSP recording times were synchronous with the MT survey.

It was necessary to convert the MT instrument's internal recordings (as machinedigital units) by an appropriate scaling factor to obtain geoelectric field values in units of $\mathrm{mV} / \mathrm{km}$. The appropriate scaling factor was obtained from the instrument manufacturer. Geoelectric data subsequently used for analysis consisted of measurements of the electric fields in the north-south $\left(E_{x}\right)$ and east-west directions $\left(E_{y}\right)$ at a sampling frequency of 15 $\mathrm{Hz}$, obtained at MT sounding sites situated parallel to the pipeline. PSP data were acquired at a sampling frequency of $5 \mathrm{~Hz}$ from selected test posts along the entire length of the study pipeline.

\subsection{Geoelectric Field and PSP Time Series Recordings}

\subsubsection{Data Quality Assessment}

The concurrent, raw, $15 \mathrm{~Hz}$ MT and $5 \mathrm{~Hz}$ PSP time series data was visually examined to assess data quality and to validate whether there was a causal relationship between the two data sets, and to select 1-hour intervals of time series data where such a relationship existed. 
Poor quality MT recordings were eliminated. At some MT sounding sites there were problems with the instrument or electrodes such that the time series waveform had an unusual appearance and thus was suspect. In other cases, excessive cultural EM interference had obscured sections of the time series. A particular problem was the widespread use of electric fences surrounding livestock pasture which introduced spiking into the data at a period of $1 \mathrm{~s}$. Other electrical interference is suspected to have originated from nearby dwellings and their groundwater well-pumps, towns, communication signals transmitted through railway track, magnetic interference from passage of trains, and both household electrical power distribution and high-voltage transmission lines. At some MT sites, there was a noticeable positive or negative trend of the $E_{x}$ and or $E_{y}$ data which could have been the result of drift caused by the changing soil conditions around the electrode in response to rain wetting the soil or soil drying afterwards. The trend was removed by applying a linear regression, irrespective of its severity, during the data resampling stage.

Most PSP recordings were of good quality, although on some days a data logger would fail and no data were recorded at that particular test post. At several test posts, the PSP recording stopped early and thus did not overlap in time with the MT recordings, and therefore both the PSP and MT measurements had to be eliminated from some of the subsequent analysis. PSP recordings at the northwest quarter end of the study pipeline, between $\mathrm{km} 200$ and 222 (northwestward of Pembroke), exhibited a noticeably low amplitude variation compared to elsewhere along the pipeline.

Sites with good quality geoelectric field and PSP data then underwent a selection process. Time series plots, at original sampling frequencies, were made for each day's 
recordings and examined to identify 1-hour intervals where there was a simultaneous large-amplitude variation on both the geoelectric field and PSP recordings, concurrent with similar increased amplitude of the geomagnetic field. Typically, the more distinctive and larger amplitude changes were about 30 minutes in duration. As well, the interval chosen was to have the least amount of cultural electromagnetic interference.

Simultaneous, large amplitudes are presumed to be the same response in both the geoelectric field and PSP to changes in the natural signal. An assumption has been made that the impressed DC current on the pipeline (as a result of the cathodic protection system) is constant along the entire length of the study pipeline. Selection of a high amplitude hourly interval in the PSP data that is coincident with similar high amplitude variation in the geoelectric field data (that has been recorded at a location away from the pipeline), indicates that a geomagnetically induced current has occurred and that the observed large-amplitude PSP measurement was not one created by differences in the cathodic protection system.

\subsubsection{Data Processing}

Examination of geoelectric field time-series and spectra revealed considerable spiking at $1 \mathrm{~Hz}$ (common operating frequency of electric fences) and its higher harmonic intervals across the frequency range of measurement, as well as repetitive "burst" like bands of high amplitude geoelectric field values. In addition, the study area was located within an area crossed by multiple power lines $(60 \mathrm{~Hz})$ with numerous cellular / microwave towers, all which would produce higher frequency noise that must be filtered out. The chosen 1-hour intervals from each day's recording (both geoelectric field and PSP) were resampled to a common $1 \mathrm{~Hz}$ rate because of the different sampling rates of 
each data set, to reduce data volume, and more importantly to remove higher-frequency noise and much of the extraneous spiking that was found to be widespread on the geoelectric field recordings.

The process involved the removal of mean from the original $15 \mathrm{~Hz}$ geoelectric field and $5 \mathrm{~Hz}$ PSP time series data, with the resulting values then undergoing a Fast Fourier Transform (FFT) followed by application of a cosine-bell filter for removal of high-frequency noise, then an inverse FFT for conversion back to the time domain, and finally decimation of the filtered time series by averaging each second's worth of data to produce the $1 \mathrm{~Hz}$ data subset.

Two examples of simultaneous geoelectric field and PSP variations are provided in Figure 5.6 and 5.7. On 8 October 2003, a geomagnetic disturbance occurred between 22:55 and 23:10 UT. The MT $E_{x}, E_{y}, H_{x}$ and $H_{y}$ time series from site 002, and PSP recordings from two test posts are plotted (Figure 5.6) together to highlight the coincidence of the variations in the two data sets. In addition, displayed are the time derivatives of the north-south $\left(\mathrm{dB}_{\mathrm{x}} / \mathrm{dt}\right)$ and east-west $\left(\mathrm{dB}_{\mathrm{y}} / \mathrm{dt}\right)$ components of the geomagnetic field recorded at the Ottawa Geomagnetic Observatory. In accordance to Faraday's Law of Induction, the east-west component $\left(E_{y}\right)$ of the recorded geoelectric field is in response to the north-south inducing magnetic field. PSP variations are particularly well coupled with $\mathrm{dB}_{\mathrm{x}} / \mathrm{dt}$ fluctuations at both Ottawa Observatory and MT002 because of the east-west orientation of the pipeline at the measured test posts.

Effect of filtering (Figure 5.7) is shown on time series data collected on 02 June 2005. There is a noticeable reduction of data spikes and the data is less jittery. However, comparison of raw $5 \mathrm{~Hz}$ and filtered $1 \mathrm{~Hz}$ PSP data did not produce any significant 


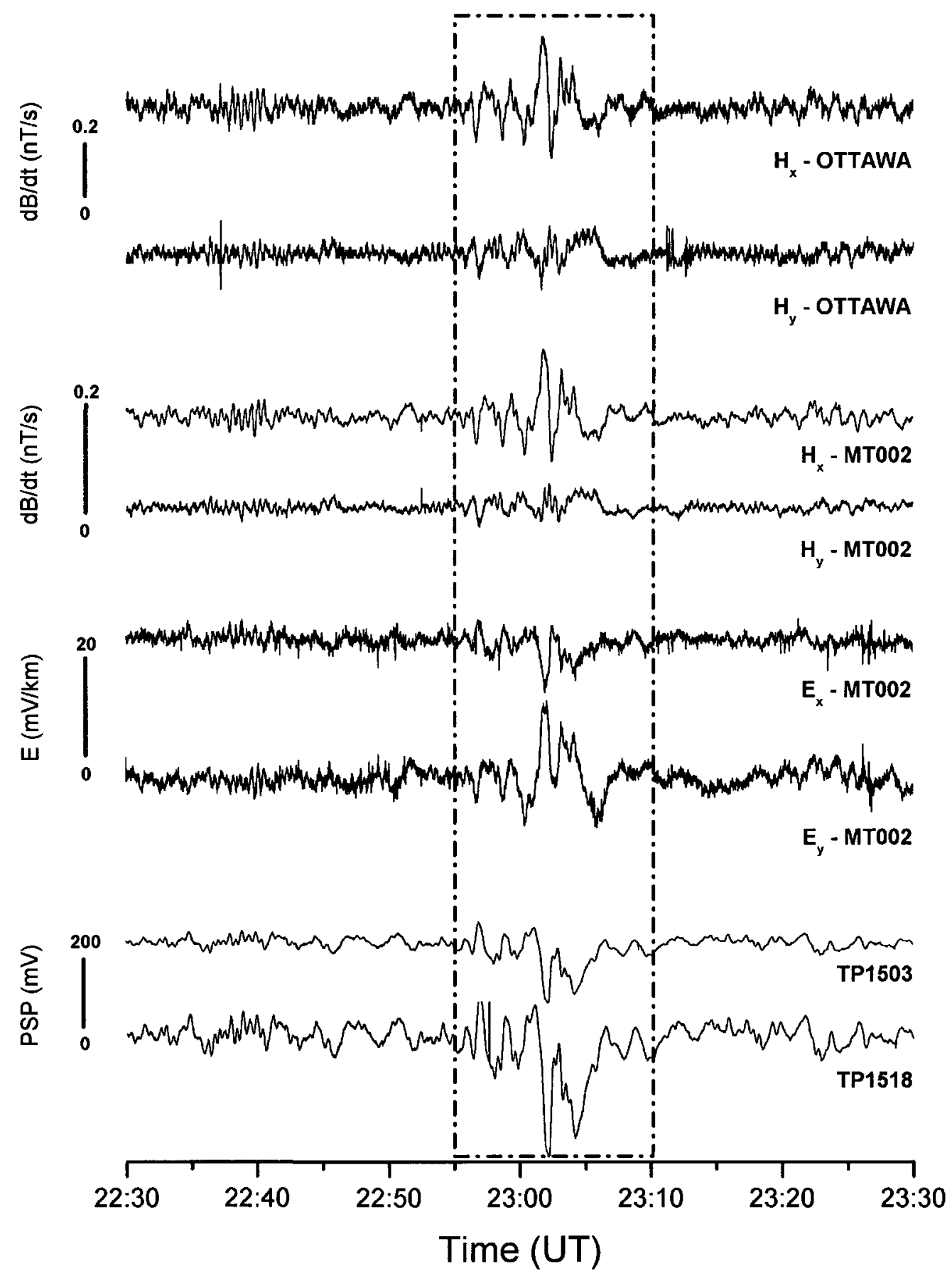

Figure 5.6. An example of simultaneous variation of geomagnetic field rate of change (top two), geoelectric field (middle) and PSP (bottom) measurements obtained on October 8, 2003. Boxed area brackets a geomagnetic disturbance and the coincident variations. Recordings made at Ottawa Geomagnetic Observatory, and at MT site 002 during the 2003 ORV survey. Subscript ${ }_{x}$ and ${ }_{y}$ denote the field directions north-south and east-west, respectively. PSP recorded at two different test post (TP1503 and TP1518) located about $15 \mathrm{~km}$ apart. 
02 June 2005
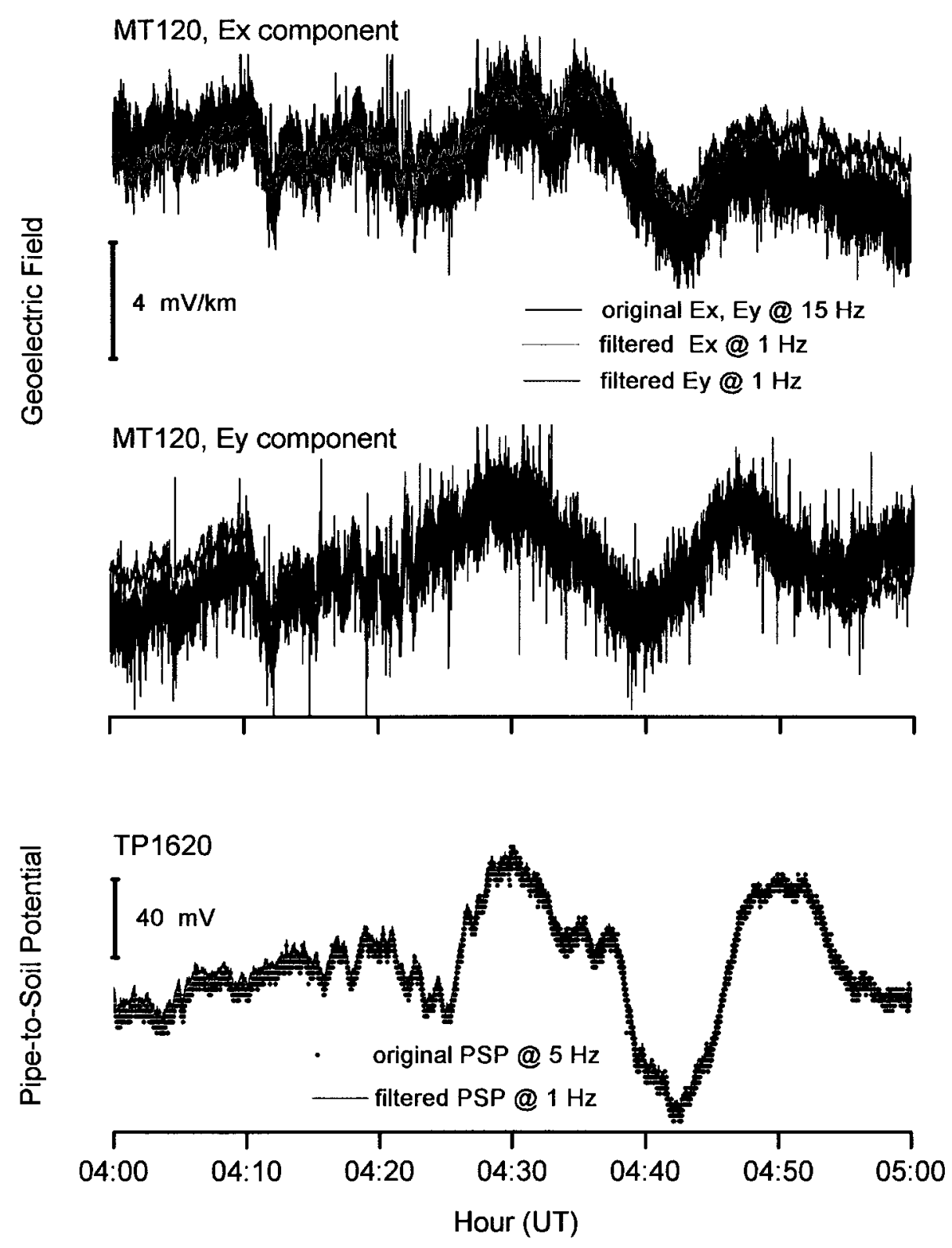

Figure 5.7. An example of simultaneous recorded geoelectric field and PSP data, before and after filtering, obtained from the 2005 ORF survey. MT site (MT120) and PSP test post (TP1620) are $2.5 \mathrm{~km}$ apart. 
improvement indicating that these data were much less contaminated by high-frequency noise.

Because PSP variations were measured along a pipeline orientated in an overall northwest - southeast direction, in order to obtain a comparable representation of the geoelectric field along the pipeline, it was necessary to project the $E_{x}$ and $E_{y}$ components of the geoelectric field into a pipeline orientation of 135 degrees. Although PSP was measured along specific lengths of the pipeline that may have differing orientations, for simplicity the projection of the geoelectric field was to the common 135 degree orientation over which much of the $150 \mathrm{~km}$ long pipeline study area extends. Shorter sections of the pipeline range are up to $8 \mathrm{~km}$ long, and are orientated up to 80 degrees from the main direction. Thus the potential error that could be introduced by the simplifying the projection is estimated to be up to about $5 \%$ (i.e. $8 \mathrm{~km}$ over $150 \mathrm{~km}$ ). All figures plotted with projected geoelectric field are identified as such, from this point onward in the thesis.

Finally, comparison of concurrent geoelectric field versus PSP time series involved some adjustments to the PSP data. A time lag was detected when the geoelectric field and PSP were first compared with each other, whereby a better visual fit was achievable by shifting the PSP time series either forward or backward relative to the geoelectric field time series. PSP data from the year 2005 survey required a 4 to 4.5 minute backward time shift and, for year 2006, a 15 to 30 second forward time shift or none at all depending on the test post. The time lags were attributed to incorrect time synchronization during initialization of the data loggers. For several PSP recordings, the time series had to be inverted to match the polarity of the geoelectric field time series. It 
is believed that at some of the PSP test posts the connections to leads may have been inadvertently reversed by the field assistant, thereby causing the inverted time series.

\subsection{Analysis of Geoelectric Field and PSP Data}

\section{$\underline{5.5 .1 \quad \text { Purpose }}$}

The purpose of this analysis was to (1) demonstrate that PSP variations are the result of fluctuations of the geoelectric field, (2) verify that the anomalously high PSP amplitudes identified by the 1997 ITS investigation were authentic and therefore could be measured again, and (3) test the hypothesis that large variations of the geoelectric field, and hence the PSP in a pipeline, are related to lateral changes of Earth resistivity. Potential scenarios that could create significant change in resistivity and geoelectric field along a pipeline route are discussed later in this chapter. Utilized for the analysis were the $1 \mathrm{~Hz}$ resampled data sets of the simultaneous MT measurements and PSP recordings

\subsubsection{Comparison of Concurrent Geoelectric Field and PSP Time Series}

As shown in Figures 5.8 and 5.9 there is a temporal coincidence of the geoelectric field and PSP amplitude variations, indicating that the same physical phenomena have been measured, respectively, away from and within the pipeline. Of significant interest are the amplitude differences of the geoelectric field for the simultaneous MT recordings along various locations along the pipeline route, reflecting changes in the Earth resistivity. Enhanced PSP amplitude coincides with enhanced geoelectric field amplitude, as shown in the pairing of test post TP1324 and MT site 204 (Figure 5.8), situated about $3 \mathrm{~km}$ apart for each other. 
16 May 2006

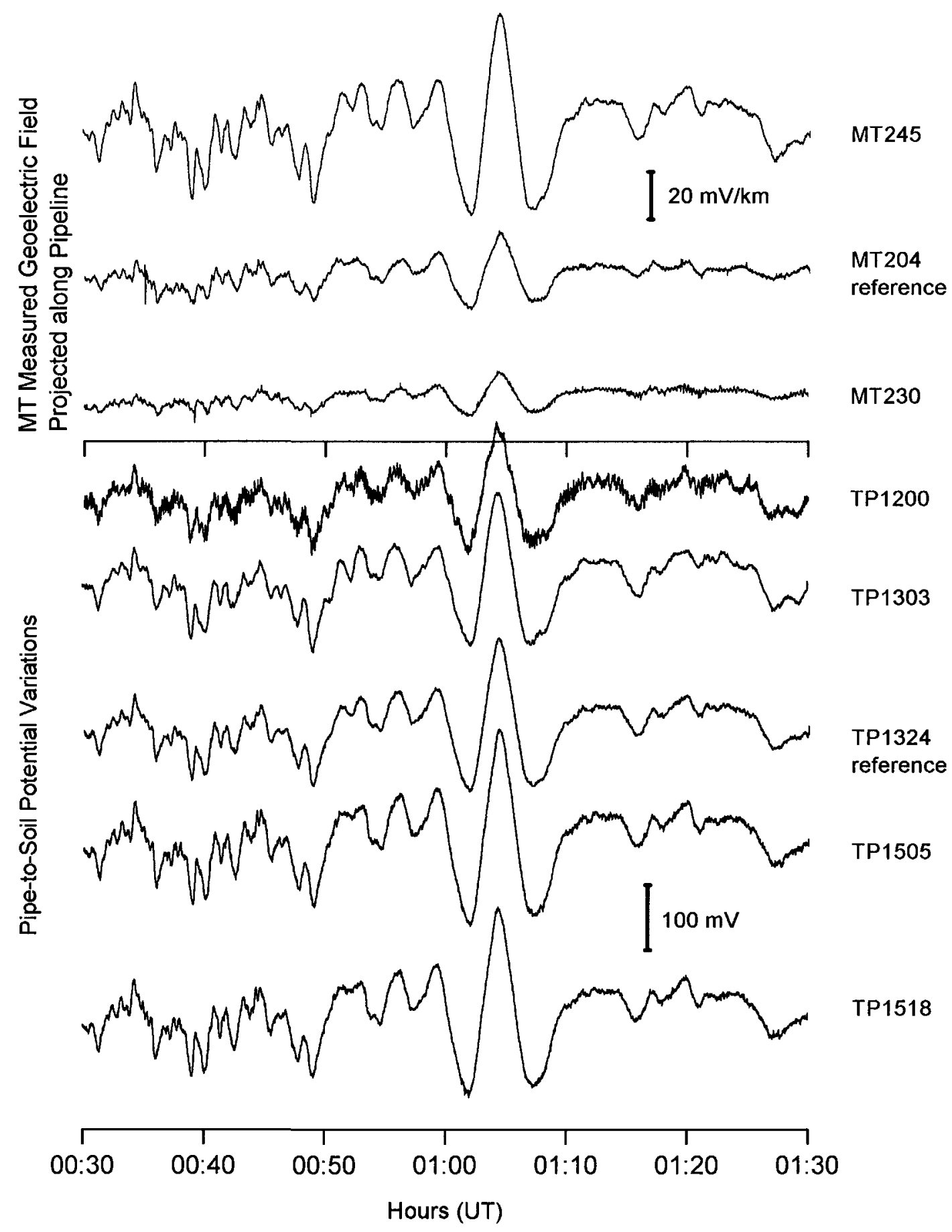

Figure 5.8. Comparison of the time series from simultaneously recorded geoelectric field and PSP along the central portion of the pipeline route, using $1 \mathrm{~Hz}$ data (resampled from original time series). Recorded May 16, 2006. 

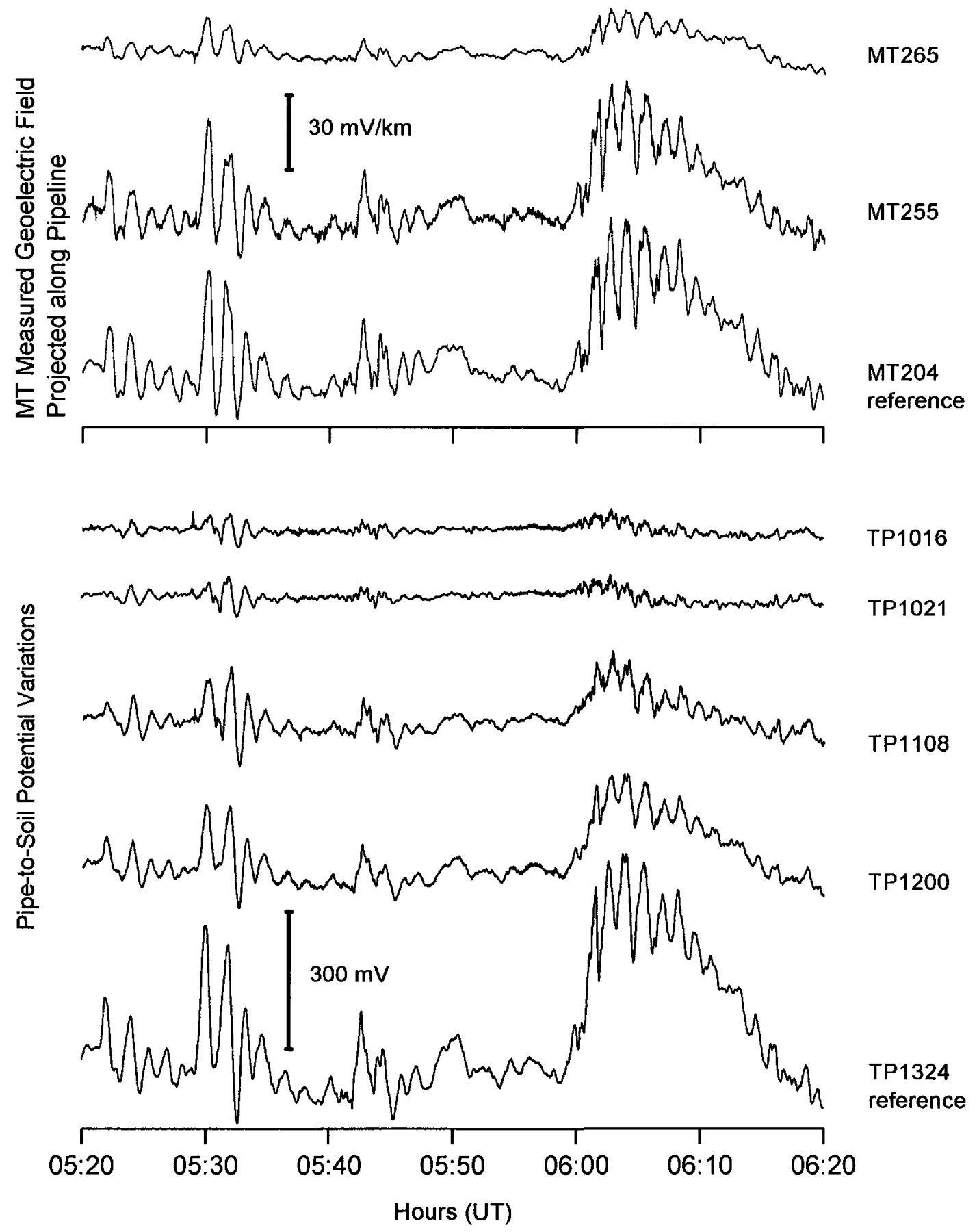

Figure 5.9. Comparison of the time series from simultaneously recorded geoelectric field and PSP along the northern half of the pipeline route, using $1 \mathrm{~Hz}$ data (resampled from original time series). MT and PSP reference sites located within $1 \mathrm{~km}$ away from each other. Recorded May 19, 2006. 


\subsubsection{PSP Amplitude Variations along Pipeline, Time Series Ratio}

Visual inspection of the PSP time series showed simultaneous and similar variations at all measured test posts on any particular survey day. Examples from years 2005 and 2006 are shown in Figures 5.8, 5.9, and 5.10. Enhanced PSP amplitude, relative to other test posts, was observed between test posts 1505 and 1518 on different days. It is of interest that these particular test posts are located in the same area as the one (1518) used during the 1997 ITS investigation which also demonstrated unusually high PSP amplitude compared to elsewhere along the pipeline.

To identify locations along the pipeline where PSP exhibits a significant change of amplitude which could be a reflection of sub-surface geological discontinuity, and to ascertain whether it correlated with any known geological features such as faults or intrusive bodies, ratio comparisons were made for individual recordings of PSP for separate years both in the time (this section) and the frequency (next section) domains. By taking the ratio of amplitude variation between the mobile and reference PSP sites, for the same recording duration, as a function of distance along the study pipeline it was possible to locate areas where the PSP is significantly different .

While it can be demonstrated from multiple PSP surveys that there is a consistency of increased PSP amplitude at certain locations along the pipeline, it is not known if this is due to internal or external influence, or combination of both. An internal influence would be differing pipe characteristics, such as a bend of pipe route orientation or the change from single to dual pipe. However, the largest PSP observed in the area of test post 1518 (Figure 5.10) which lies within a section of the route that remains dual pipe and has only minor bends. In addition, Boteler and Trichtchenko (2000) determined that 
02 / 03 June 2005

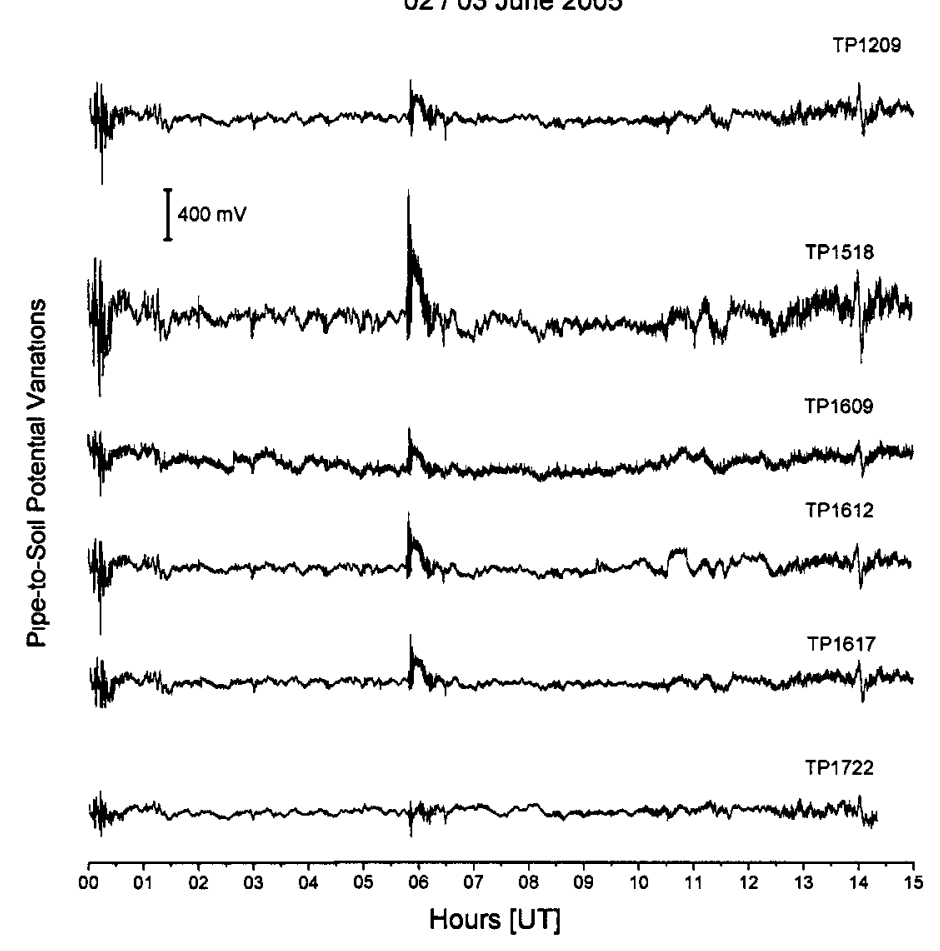

TP1200

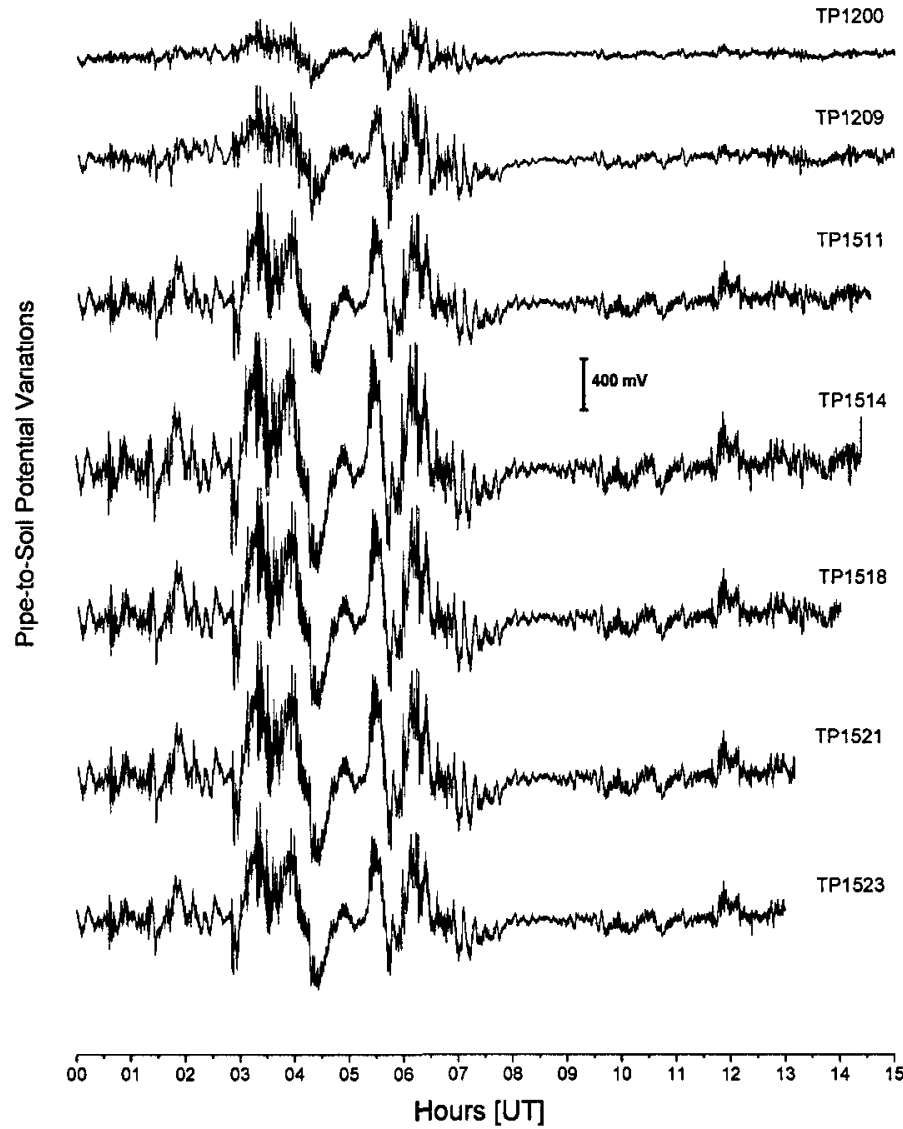

Figure 5.10. Simultaneous PSP recordings at multiple test posts on two different days, June 2, 2005 (left panel) and June 7, 2005 (right panel). On June 7, 2005, a small geomagnetic disturbance was recorded between 02:30 and 07:30 (Samson et al., 2006, Fig. 6.1 and 6.2). 
pipe characteristics could not alone explain the enhanced PSP amplitude. External influence could only be caused by changes of underlying Earth resistivity which are permanently located in the same location year to year. Non-uniform geomagnetic field fluctuations produced by external sources in the ionosphere vary in both location and intensity depending on time. Therefore, enhanced PSP amplitude permanently located in the same area year to year can only be caused by changes of underlying Earth resistivity.

Ratio comparison of PSP amplitudes in the time domain, to distinguish relative differences of PSP along the pipeline, was done in the following manner for the 1997 ITS and 2005 ORF surveys. For each recording day where simultaneous time series measurements were available, the data from different test posts were plotted against a reference test post. Scatter plots were prepared to show the PSP time series variation between a particular test post and the reference test post, with the slope of its linear fit giving the PSP amplitude ratio between these two test posts. A slope with a value greater than 1 indicates that PSP amplitude at the mobile test post are higher than those at the reference test post.

For the 1997 ITS ratio determination (Figure 5.11A) test post location 97-1 was chosen as the reference PSP site. For the 2005 ORF survey, 45 different test post comparisons were made. Each comparison used a four to six hour duration of time series data recorded at $5 \mathrm{~Hz}$, i.e. involving 72,000 to 108,000 samples collected from each test post. Test post 1200 was chosen as the primary reference because it operated the longest during the survey and provided good quality data. For those days when no data logger was operating at primary reference 1200 , secondary reference test posts were used. PSP amplitude ratios computed using the secondary reference test post(s) were referenced 

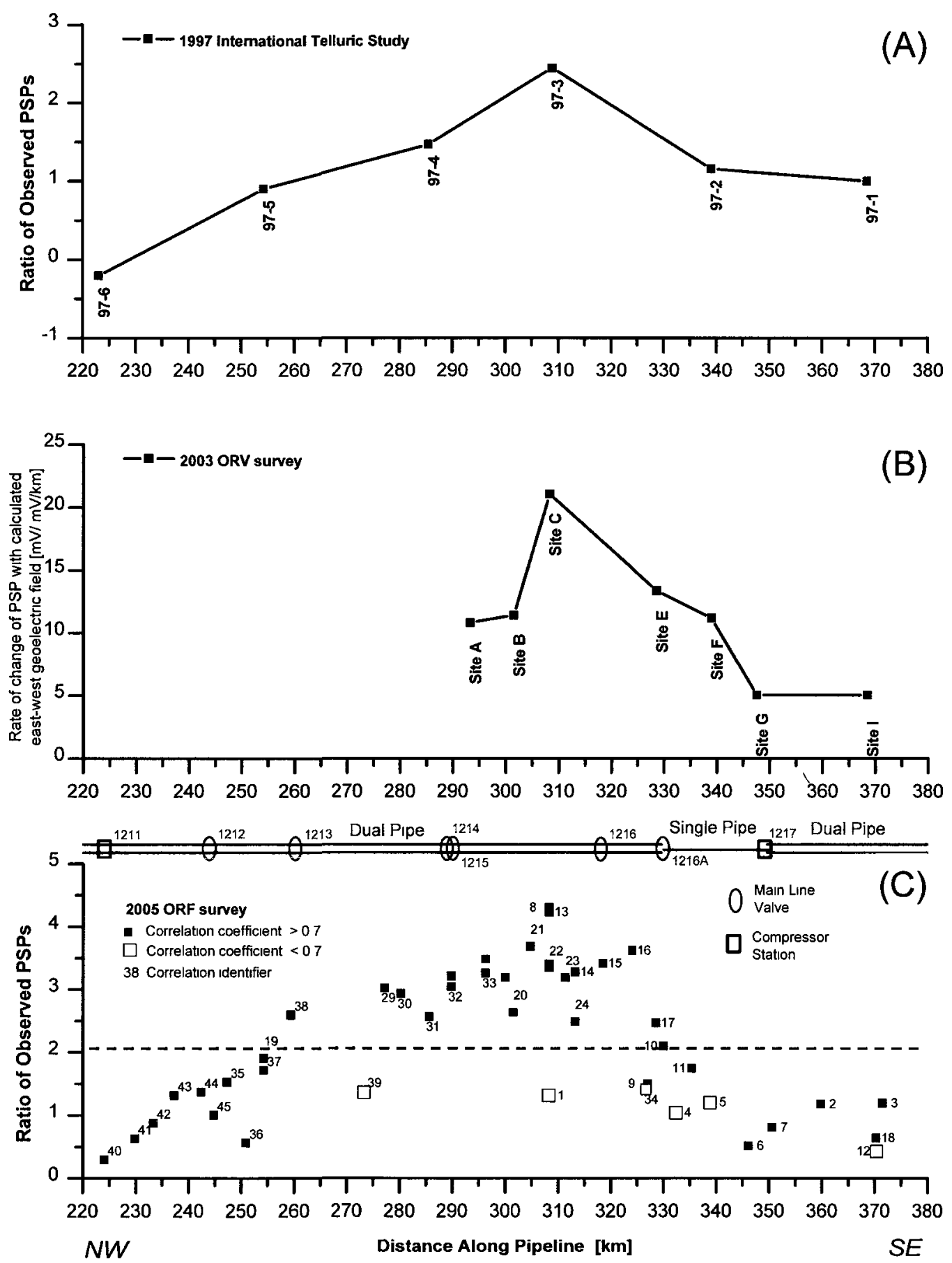

Figure 5.11. Amplitude ratio of observed PSP along the pipeline as determined from the (a) 1997 ITS investigation, (b) 2003 ORV survey (Larocca et al., 2005), and (c) 2005 ORF survey (Samson et al., 2006). Ratio determined using time series data. Distance starts at kilometre point 0 in North Bay. Bottom panel shows pipeline schematic. Correlation identifiers listed in Appendix A5.1. 
back to the primary reference at test post 1200 in order to obtain the equivalent amplitude ratio with respect to the primary reference. Ratios greater than 2 (dashed line in Figure 5.11C) are considered anomalously large.

Larocca et al. (2005) analyzed the 2003 ORV data using a slightly different methodology. In their approach, instead of a reference test post they used a calculated geoelectric field as the reference. The geoelectric field was computed in the same manner previously described in Chapter 2 using a 1D Earth model of Ontario developed by Ferguson and Odwar (1997) and the appropriate daily geomagnetic field data recorded at the Ottawa Geomagnetic Observatory. Slope of the linear fit of scatter plots of PSP variations against the calculated geoelectric field were plotted (Figure 5.11B).

A comparison of PSP amplitude ratios between the sparse sampling of the earlier 1997 ITS and 2003 OTV surveys against the dense sampling obtained in the 2005 ORF survey is displayed in Figure 5.11C. There is an excellent agreement between all three curves representing three separate years of measurement with maximum rise centered at pipeline $\mathrm{km} 310$, which geographically is in the vicinity of the town of Pakenham, the Mississippi River and Mount Pakenham. With respect to the geological setting, the peak of the PSP amplitude ratio is in the vicinity of the eastern margin of the Mount Pakenham intrusive body buried beneath the Paleozoic sedimentary rock, and along the trend of the Pakenham Fault.

A closer examination of PSP amplitude ratios for the 2005 ORF survey (Figure 5.11C) demonstrates the presence of an anomalous zone of high amplitudes (ratio $>2$ ) extending from valve stations $1213(\mathrm{~km} \mathrm{260)}$ to $1216 \mathrm{~A}(\mathrm{~km} \mathrm{328)}$. The largest PSP amplitudes were recorded at test post $1518(\mathrm{~km} \mathrm{308),} \mathrm{within} \mathrm{a} \mathrm{half} \mathrm{kilometre} \mathrm{of} \mathrm{where} \mathrm{the}$ 
largest amplitudes were first observed in 1997, thereby confirming the repeatability of this phenomena. Peak amplitude ratios at test post 1518 drop off in both directions away from this location. The drop off is steeper to the southeast of test post 1518 where the pipeline structure changes from dual to single pipe, and then back to dual pipe.

Correlation coefficients for the $2005 \mathrm{ORF}$ survey were generally greater than 0.7 with only $14 \%$ below a value of 0.7 . Based on the large number of data samples, up to 108,000 (and resulting p-values less than 0.0001 ), the correlations equal to or above 0.7 were considered to be significant. PSP amplitude ratios of the 2005 ORF survey which show deviations from the general pattern (open squares in Figure 5.11C) also have low correlation $(\mathrm{R}<0.7)$ with the reference test post. An examination of correlation coefficients against distance between test posts found that low coefficients were not necessarily related to large separation between test posts. Low correlation coefficients are more likely due to local interference at particular locations, such as loose or broken test post wires, ground conditions that could prevent a good electrical contact for the reference electrode, and nearby presence of rectifiers (cathodic protection system) or other electrical objects like power lines and cattle fences. Therefore, these irregular amplitude ratios were treated as insignificant.

\subsection{Processing, Inversion and Analysis of MT Data}

\section{$\underline{5.6 .1 \quad \text { Procedures }}$}

Processing and inversion of MT data followed the generally accepted procedures used in MT exploration surveys (refer to Sections 2.3.1 and 4.5.2), employing the Phoenix Geophysics SSMT2000 and Geosystem srl WinGLink software. The remote referencing (Gamble et al., 1979) procedure was applied to data from each of the MT 
sites to reduce the effects of local noise. Because the remote referencing method assumes a coherent geomagnetic field over the study area, a check was made to validate this assumption by testing the coherency between the geomagnetic signals from individual MT sites and their reference site (Kay, 1993). Coherence is a dimensionless measure (between 0 to 1) of the linear correlation between two different spectra sources (Simpson and Bahr, 2005). Figure 5.12 shows the results of the coherency analysis for the horizontal geomagnetic components $H_{x}$ and $H_{y}$. The overall coherency is above 0.8 for a broad range of frequencies from 0.001 to $1000 \mathrm{~Hz}$ with which modern MT instrumentation is routine achieved (Simpson and Bahr, 2005). A local coherency minimum at $60 \mathrm{~Hz}$ is due to a notch filter within the MT instrumentation suppressing power line noise. Above $1000 \mathrm{~Hz}$, coherency is low because of the weakness of the natural geomagnetic field. Comparisons were also made of the MT magnetic field recordings versus the Ottawa Geomagnetic Observatory. These showed the magnetic field variations at the different MT sites were coherent and of same amplitude as at Ottawa, implying that the source field is the same over the entire study area.

A suite of 14 MT sites (four from the 2003 ORV and 10 from the 2005 ORF surveys) exhibiting good quality data were used to generate a $2 \mathrm{D}$ inversion model. Unsuitable sites included those contaminated by locally high levels of electrical interference (electric fencing, dewatering pumps, power line proximity, and railroad traffic) or by full or partial instrument failure.

Induction arrows which are pictorial representations of lateral resistivity variations were computed using the WinGLink software. They are used to point to areas of lower resistivity and are perpendicular to geoelectric strike. The induction arrows for a 


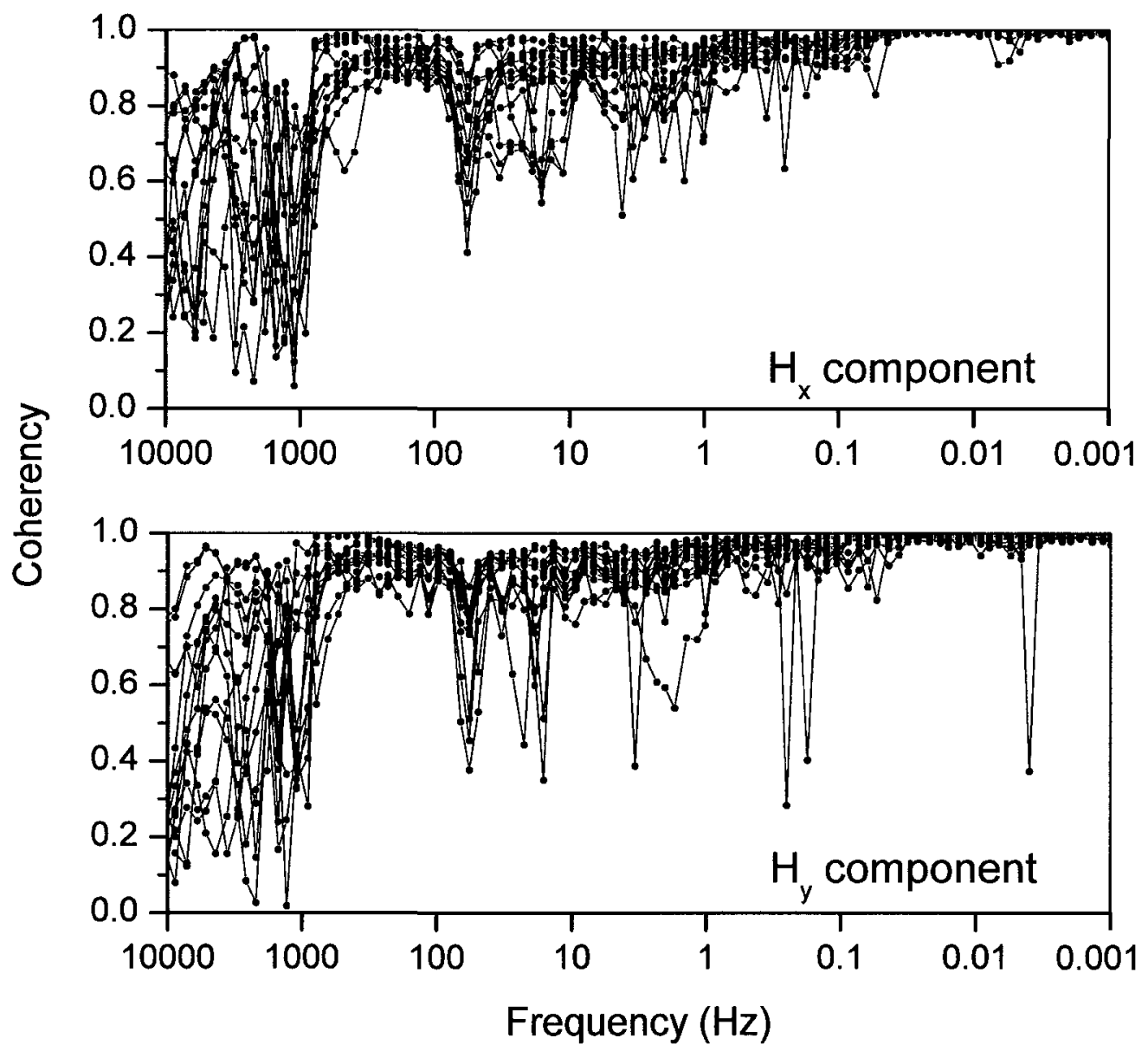

Figure 5.12. Coherency between 14 individual MT sounding sites and its reference sites, from the 2005 ORF survey, as a function of frequency for the horizontal geomagnetic field components $H_{x}$ and $H_{y}$ (Samson et al., 2006, Fig. 7.3). 
frequency of $0.01 \mathrm{~Hz}$ (representing a penetration of the natural source signal to crustal depths) indicate that resistivity is lowest at the southeast end of the pipeline, an observation consistent with the fact that the Paleozoic rocks are overall less resistive than the Precambrian rock. Arrows are also perpendicular to the NE-SW structural trend of the Precambrian rocks and to the deep-seated electrical anisotropy within the crust and mantle reported by Frederiksen et al. (2005).

After examination of the induction arrows, the MT data were rotated $45^{\circ}$ clockwise so they could be decomposed into impedance components parallel (termed "transverse electric" (TE)) and perpendicular ("transverse magnetic" (TM)) to the regional geoelectric strike. The TM impedance was used for further analysis as it relates the geoelectric field (which is parallel to the pipeline) to the magnetic field variations. Rotated impedances from the MT sites were inverted globally to produce the 2D resistivity versus depth cross-section presented in Figure 5.13a.

\section{$\underline{\text { 5.6.2 Geological Interpretation }}$}

The resistivity range (Figure 5.13a) of the Paleozoic and Precambrian basement rocks (to depth of $15 \mathrm{~km}$ ) is $25-100 \mathrm{ohm} . \mathrm{m}$ and $200-5500 \mathrm{ohm} . \mathrm{m}$, respectively. These values are reasonably consistent with the estimates of Telford et al. (1976).

Three, surface exposed, intrusive bodies along the pipeline route approximately coincide with orbicular zones of higher resistivity (1100-5500 ohm.m), extending to depths of 6 to $12 \mathrm{~km}$. The Bonnechere Ridge intrusive (C on Figure 5.13) has the greatest lateral and vertical extent. However, this east dipping high resistive zone may also denote presence of the CMBbtz tectonite known to extend to crustal depths. The Hurds Lake intrusive (B) shows up as a moderately sized resistive body. However, the larger 


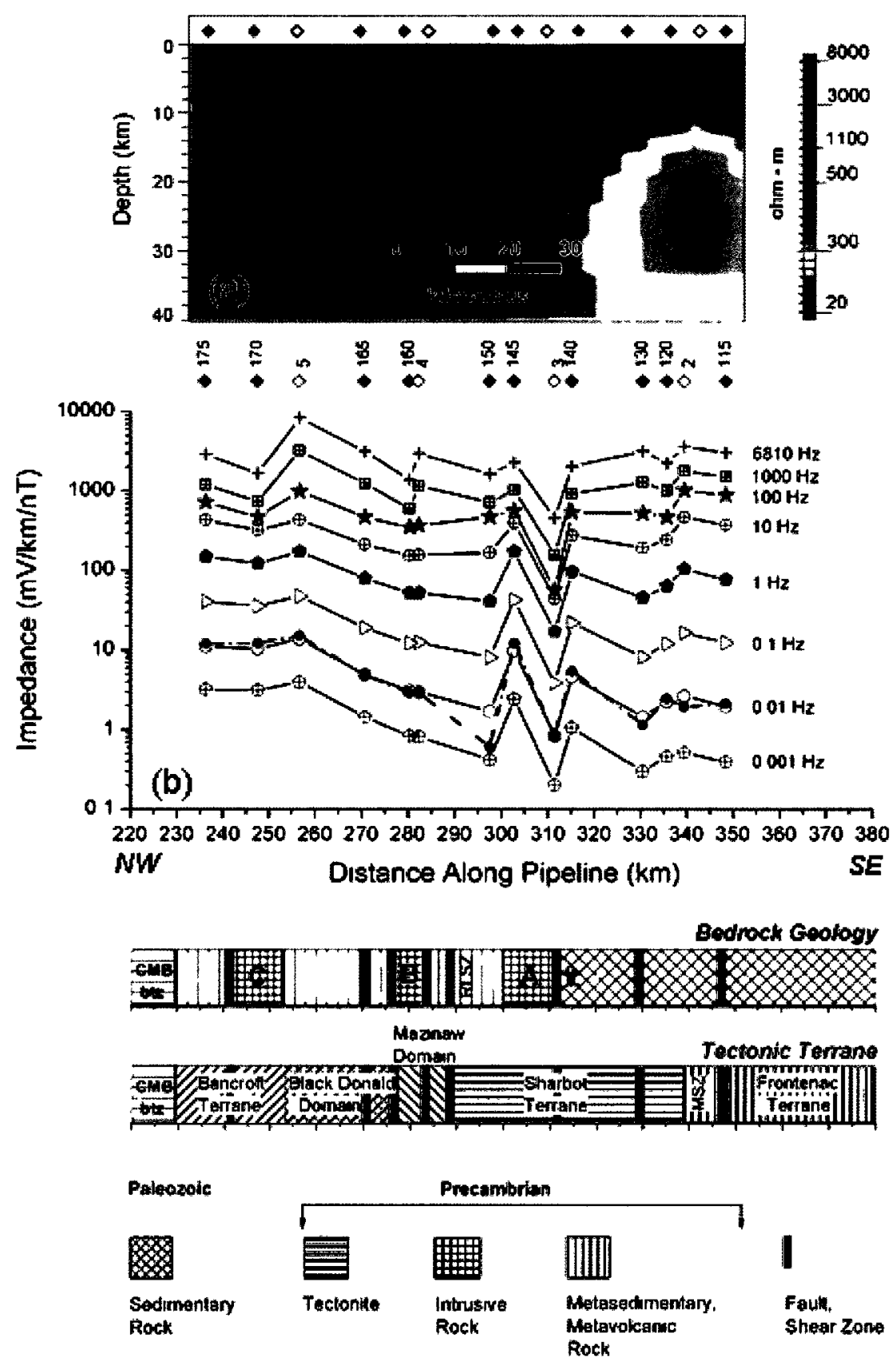

Figure 5.13. (a) 2D inversion model (TM component) beneath pipeline. (b) Measured $Z_{y x}$ (45) surface impedance (dashed line) at $0.01 \mathrm{~Hz}$ used as input to pipeline modelling and modelled response $\boldsymbol{Z}_{y x}$ impedance (solid lines) - at eight different frequencies obtained from 2D inversion model. MT sites from 2003 ORV $(\diamond)$ and 2005 ORF ( $\bullet)$ surveys, and schematics of exposed bedrock and tectonic terranes along the pipeline route in study area are shown. Abbreviations: A, Mount Pakenham; B, Hurds Lake; C, Bonnechere Ridge; CMBbtz, Central Metasedimentary Belt boundary thrust zone; RLSZ, Robertson Lake Shear Zone; PF, Pakenham Fault; MSZ, Maberly Shear Zone (possible north-eastward extension) (from Fernberg et al., 2007, Fig. 7) 
Mount Pakenham intrusive (A) is not as clearly defined in terms of resistivity, perhaps being masked by the covering Paleozoic rock and Leda clay. Two additional orbicular high resistivity bodies situated at the southeast end of the cross-section could be intrusives for they are aligned with exposed intrusives situated just south of the Paleozoic cover rock. Faults generally coincide with zones of lower resistivity between the intrusive bodies. A thin zone of low resistivity ( $30-80 \mathrm{ohm} . \mathrm{m})$ occurs between MT sites 140 and 145 where conductive Leda clays thicken in the local Mississippi River valley. On the scale of tectonic terranes and at mid to lower crustal depths (approximately $15-40 \mathrm{~km}$ ), a large enigmatic zone of low resistance $(45-65 \mathrm{ohm} . \mathrm{m})$ is present in the area underlain by the Frontenac terrane. A transitional moderately resistive region $(80-225$ ohm.m $)$ occurs in the area of the Sharbot Lake terrane. A more resistive region $(225-800$ ohm.m) occupies the Mazinaw and Bancroft terranes.

\section{$\underline{\text { 5.6.3 Surface Impedances and Modelled Geoelectric Field }}$}

The TM impedances, extracted from each individual MT site's processed data, can also be used in the calculation of a non-uniform geoelectric field. Instead of a single, uniform, surface impedance which was computed using a literature-derived 1D Earth model and then applied on a regional or zone basis, as was done with the Alaska (Chapter 3) and Mackenzie (Chapter 4) study areas, a series of surface impedances that are based on actual physical measurements by the MT method can be used to calculate localized lateral variations of the geoelectric field along the pipeline route.

The relation between the horizontal geoelectric and geomagnetic fields can be expressed in terms of the impedance tensor $Z$ whereby the components of the $2 \times 2$ 
matrix are complex ratios of the Fourier coefficients of the horizontal geoelectric $(E x, E y)$ and geomagnetic fields $(H x, H y)$, written as:

$$
\left(\begin{array}{l}
E_{x} \\
E_{y}
\end{array}\right)=\left(\begin{array}{ll}
Z_{x x} & Z_{x y} \\
Z_{y x} & Z_{y y}
\end{array}\right)\left(\begin{array}{l}
H_{x} \\
H_{y}
\end{array}\right) .
$$

Because the MT impedances were measured in a magnetic-north coordinate system, it was necessary to rotate the measured impedance by $45^{\circ}$ clockwise in order to obtain the geoelectric field along the pipeline route. General formulas for rotation of impedance are given by Kaufman and Keller (1981). For the case when $\theta=45^{\circ}$, $\cos 2 \theta=0$ and $\sin 2 \theta=1$, the formulas simplify to:

$$
\begin{aligned}
& Z_{y x}(45)=0.5\left[-Z_{x x}-Z_{x y}+Z_{y x}+Z_{y y}\right] \\
& Z_{y y}(45)=0.5\left[Z_{x x}-Z_{x y}-Z_{y x}+Z_{y y}\right]
\end{aligned}
$$

Now the geoelectric field along the pipeline can be computed from equation (5.1) using:

$$
E_{/ /}=Z_{y x}(45) H_{\perp}+Z_{y y}(45) H_{/ /}
$$

where $/ /$ and $\perp$ denote parallel and perpendicular to the pipeline route.

Examination of the impedances from the Ottawa Valley MT sites revealed that $Z_{y y}(45)$ is an order of magnitude smaller than $Z_{y x}(45)$ and also has more phase variability. A high phase variability $\left(-120^{\circ}\right.$ to $\left.+130^{\circ}\right)$ is indicative of noisy data. Therefore, to reduce the possible effects of noise, the analysis has been simplified by reducing equation (5.4) to:

$$
\boldsymbol{E}_{/ /}=\boldsymbol{Z}_{\boldsymbol{y x}}(45) \boldsymbol{H}_{\perp}
$$

and it is used to calculate a geoelectric field in general alignment with the orientation of the pipeline. Thus, the geoelectric field model is based on a rotated $Z_{y x}(45)$ impedance. 
Assuming a magnetic field variation of 1 nanotesla $(n T)$, the geoelectric field $E$ is numerically the same as the $Z_{y x}(45)$ impedance value obtained from the MT soundings, as follows:

$$
E\left(\frac{m V}{k m}\right)=Z_{y x}(45)\left(\frac{m V}{k m \bullet n T}\right) \bullet 1(n T)
$$

Impedances at $0.01 \mathrm{~Hz}$ were chosen to provide a general representation of overall subsurface geology down to crustal depth. At the $0.01 \mathrm{~Hz}$ frequency, the effective depth of MT imaging of the subsurface ranges from about 20 to $55 \mathrm{~km}$ based on an apparent resistivity range of $500-3000$ ohm.m.

The change of the measured $Z_{y x}(45)$ surface impedance - at $0.01 \mathrm{~Hz}-$ across the pipeline route is shown as the dashed line in Figure $5.13 \mathrm{~b}$. This same impedance also represents the modelled geoelectric field at $0.01 \mathrm{~Hz}$ (based on a uniform geomagnetic field of $1 \mathrm{nT})$. To validate the measured $Z_{y x}(45)$ surface impedance - at $0.01 \mathrm{~Hz}-$ against impedances generated using the 2D inversion WinGLink software, the computed and rotated $Z_{y x}$ impedances at eight different frequencies ranging from 0.001 to $6810 \mathrm{~Hz}$ were extracted from the inversion output files. Figure $5.13 \mathrm{~b}$ shows there to be a close agreement of measured and modelled $Z_{y x}$ impedances (at $0.01 \mathrm{~Hz}$ ), except at MT site $150(\mathrm{~km} \mathrm{297)}$.

The greatest variation of geoelectric field (across all frequencies) is situated over Mount Pakenham (intrusive A, on Figure 5.13b) where there are additional complicating geological features such as the Pakenham Fault, contact with the Paleozoic cover rock and overlying conductive Leda clays. The geoelectric field variation over the Hurds Lake 
pluton (intrusive B), where faults and tectonic terrane boundaries also occur, are only noticeable at the two highest frequencies. Perhaps it could be due to a combination of effects including the relative size of the body, the conductivity contrast between the body and surrounding material, and local noise. As the Bonnechere Ridge (intrusive C) is approached, the geoelectric field amplitude increases with increasing frequency. A small but persistent change across all geoelectric field frequencies occurs in the vicinity of MT sites 002 to 130 . Here, underlying the Paleozoic rock is a resistive orbicular body similar to the other intrusives. In addition, the geoelectric field change roughly coincides with the boundary between the Frontenac and Sharbot Lake tectonic terranes.

Figure 5.13b also shows a trend for the geoelectric field, which is represented by $Z_{y x}(45)$ impedance, to increase (for frequencies at or below $1 \mathrm{~Hz}$ ) as the profile approaches the sheared gneissic rock of the Central Metasedimentary Belt boundary thrust zone ( $\mathrm{km} \mathrm{230)}$ at the northeast extremity of the profile. Superimposed on this trend are peaks and troughs where the geoelectric field abruptly changes, however, some changes are only apparent at or accentuated at higher frequencies. Some of the peaks, for a number of frequencies, coincide with several electrically resistive intrusive bodies, in the first 6 to $12 \mathrm{~km}$ of the crust.

\subsection{Pipeline Modelling}

Summarized here are examples of PSP modelling performed on the study area pipeline. Detailed results are presented in the report Quantitative Analysis of the Earth Conductivity Structures and their Effects on Pipe-to-Soil Potentials along the TransCanada Mainline at Arnprior, Ontario (Samson et al., 2006) and in Fernberg et al. (2007). 
A distributed-source transmission line (DSTL) model was set up for the $160 \mathrm{~km}$ long length of the TransCanada Mainline within the study area. The pipeline, prior to new construction in 2006, consisted of dual line except for a $20 \mathrm{~km}$ long single pipe segment between valve stations 1216A and $1217(\mathrm{~km} 328$ and $\mathrm{km} \mathrm{348).} \mathrm{DSTL} \mathrm{model}$ inputs were the geoelectric field derived from the measured MT impedances, and the electrical properties of the pipeline which are available in the above mentioned references.

Based on rotated $Z_{y x}(45)$ impedances and a magnetic field variation of $1 \mathrm{nT}$ at a frequency of $0.01 \mathrm{~Hz}$, two scenarios (Figure 5.14) of calculated geoelectric field were constructed, with a corresponding PSP as determined from the DSTL pipeline model.

In the Case 1 model, a uniform 1D geoelectric field of $2 \mathrm{mV} / \mathrm{km}$ is assumed across a $160 \mathrm{~km}$ length of pipeline. This is based on the surface impedance at the east end of the pipeline (Figure 5.13b). The purpose of Case 1 is to show the effects of pipeline structure alone on PSP amplitudes, independent of changes in the geoelectric field. PSP is small over much of the pipeline, reaching peak values of $+15 \mathrm{mV}$ and -10 $\mathrm{mV}$ that are associated with the ends of the single pipe section between $\mathrm{km} 328$ and $\mathrm{km}$ 348. Furthermore, the peak at $\mathrm{km} 328$ also reflects a $90^{\circ}$ change of pipeline direction.

In the Case 2 model, the complete spatial variation of the laterally-varying geoelectric field across the same $160 \mathrm{~km}$ of pipeline was used. Recall that the geoelectric field values were obtained from measured $Z_{y x}(45)$ impedances, at $0.01 \mathrm{~Hz}$. The purpose of Case 2 is to demonstrate how and to what degree changes (through the geoelectric field) in the underlying Earth resistivity influences the PSP, in addition to changes caused only by the pipe structure. The specific area of interest along the pipeline was between 


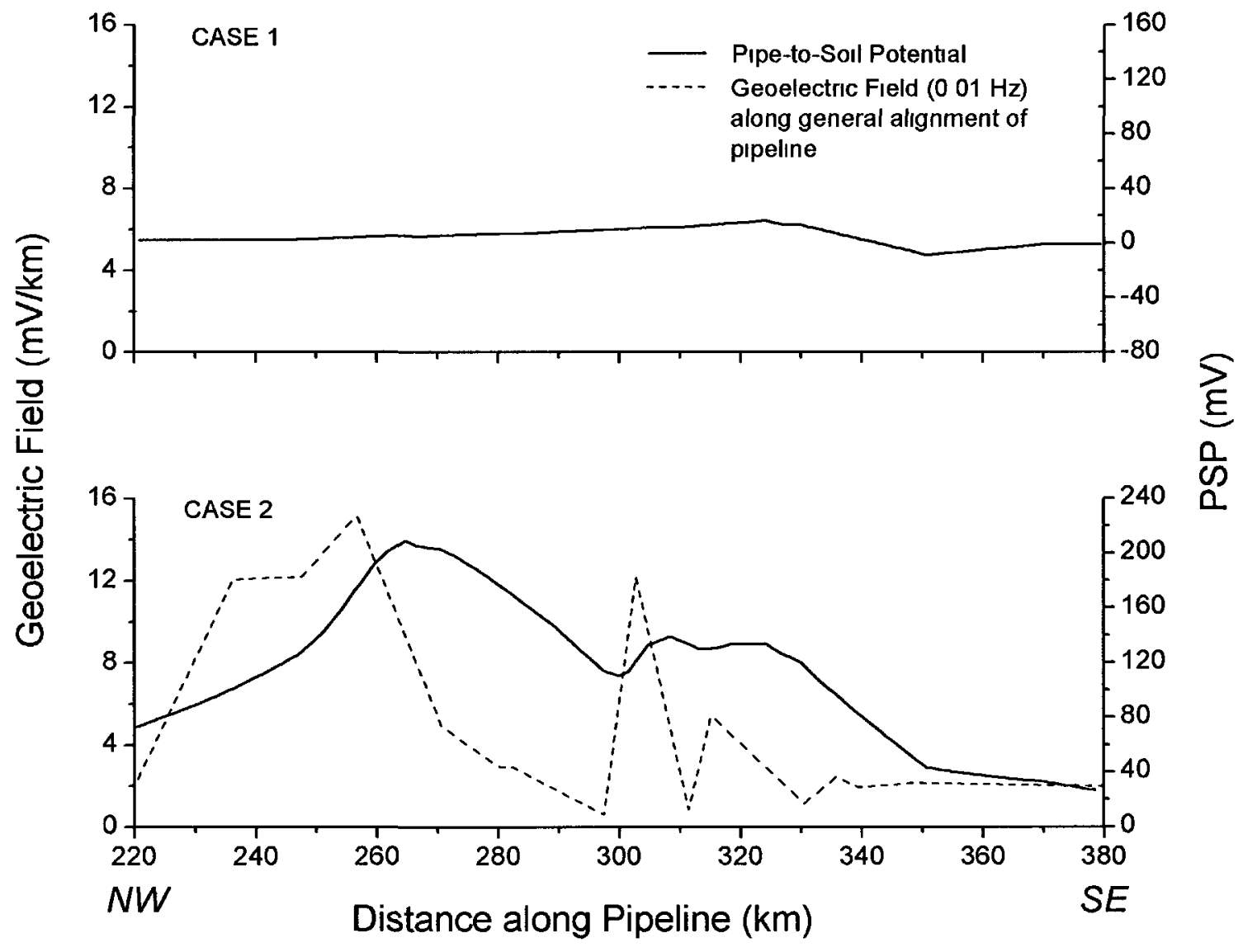

Figure 5.14. Calculated geoelectric field and modelled PSP variations versus distance along pipeline (modified from Fernberg et al., 2007, Fig. 9). Case 1: uniform geoelectric field of $2 \mathrm{mV} / \mathrm{km}$. Case 2: geoelectric field derived from measured $Z_{y x}(45)$ impedances, at $0.01 \mathrm{~Hz}$. 
$\mathrm{km} 290$ and 350 where PSP amplitude enhancement has previously been detected. At the southeast end ( $\mathrm{km} \mathrm{380)}$ of the pipe, the calculated geoelectric field is comprised of a base level of $2 \mathrm{mV} / \mathrm{km}$. Continuing in a northwest direction the geoelectric field exhibits peaks and troughs at several locations, including the area between $\mathrm{km} 290$ and 335 (ranging from 12 to $2.5 \mathrm{mV} / \mathrm{km}$ ) and the broad elevated response between $\mathrm{km} 220$ and 450 with a peak of $16 \mathrm{mV} / \mathrm{km}$ at $\mathrm{km} 257$ (the location of MT site 005). The corresponding modelled PSP averages $150 \mathrm{mV}$ between $\mathrm{km} 290$ and 335, and rises to about $220 \mathrm{mV}$ at $\mathrm{km} \mathrm{257.} \mathrm{Compared} \mathrm{to} \mathrm{Case} \mathrm{1,} \mathrm{the} \mathrm{modelled} \mathrm{PSP} \mathrm{amplitude} \mathrm{is} \mathrm{much}$ larger than the contribution from the pipe structure itself.

A comparison (Figure 5.15) was then made of the observed and modelled PSP amplitudes, as ratios. The results of the modelled PSP profile (Figure 5.14, bottom panel) were rescaled as a plot of amplitude ratio (Figure 5.15, bottom panel) to allow for the direct comparison. This was accomplished by normalizing the modelled PSP results to

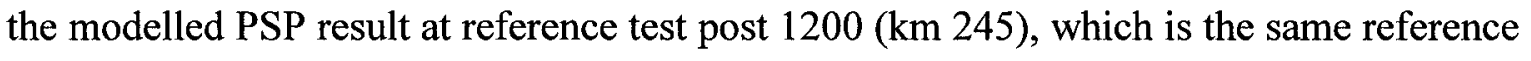
post used to prepare the ratio of observed PSP profile (Figure 5.15, top panel). Locations of mobile and reference test posts used to calculate PSP amplitude ratios are provided in Appendix 5.1. The difference of y-axis values on Figure 5.15, between observed and modelled PSP ratios, could be due to the use of different reference electrodes, $\mathrm{Cu}-\mathrm{CuSO}_{4}$ for PSP measurements and $\mathrm{Pb}-\mathrm{PbCl}$ for geoelectric field measurements. In addition, the DSTL pipeline model used to calculate PSP uses idealized pipeline parameters (e.g. coating and steel resistivity), the values of which could have been modified after years of burial and possible deterioration of the coating and steel. 

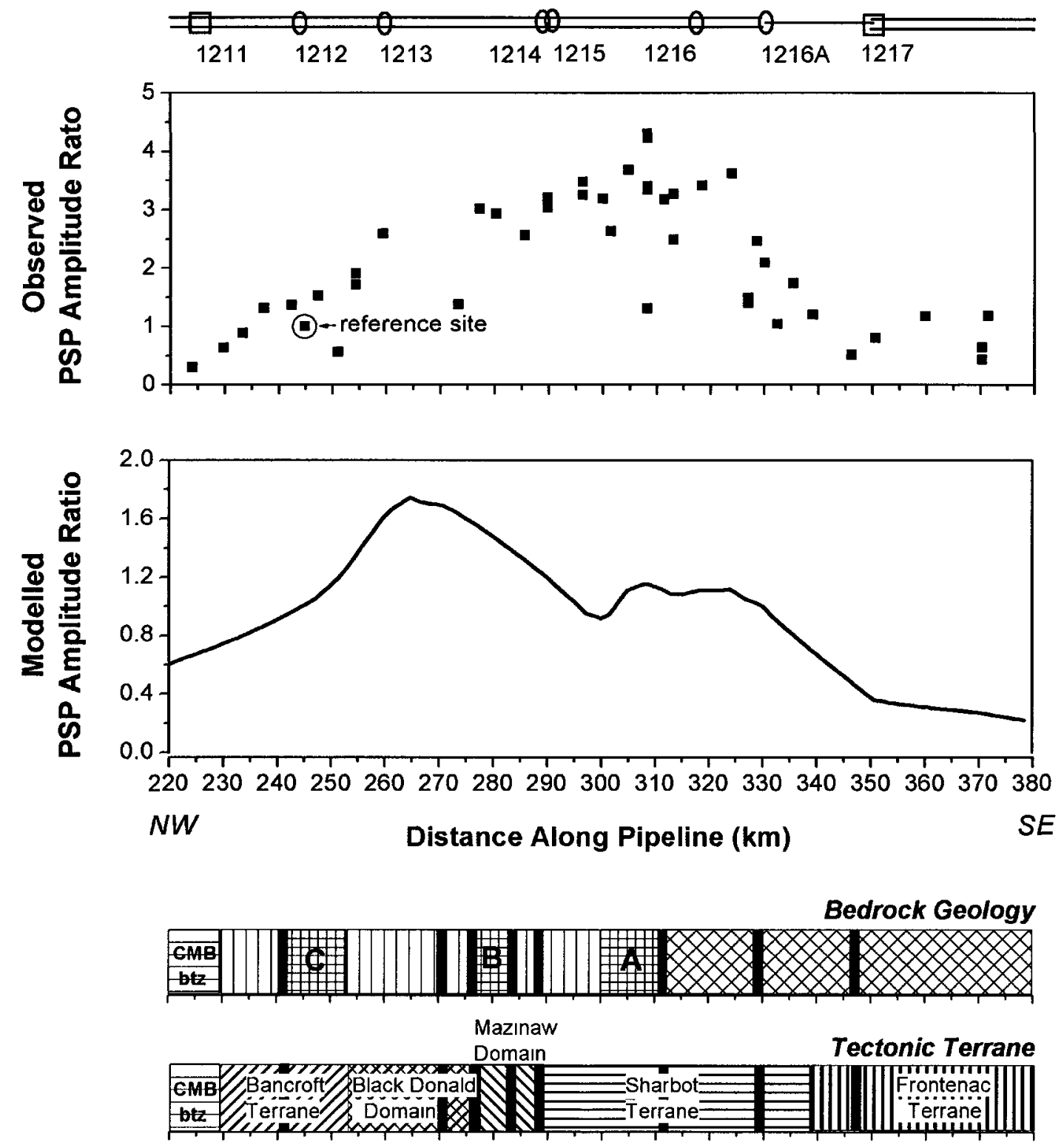

Figure 5.15. Comparison of (a) ratio of observed PSP amplitude, in time domain, and (b) the Case 2 modelled PSP amplitude ratio variations along the pipeline. Pipeline schematic at top of figure (see Figure 5.11 for key). Schematic representation of bedrock geology (see Figure 5.13 for key) and tectonic terrane along the pipeline route are shown at bottom of figure (modified from Fernberg et al., 2007, Fig. 10). 
Figure 5.15 depicts a rise of the modelled PSP amplitude ratio between $\mathrm{km} 250$ and 335 in the northwest half of the pipeline, which is not as well represented when compared to the observed PSP amplitude ratio. There is a lesser density of PSP recording sites where the peak PSP occurs, a data gap which could be a factor why there is not a more direct similarity between modelled and observed PSP ratio. Another possible factor is that nearby MT in the vicinity of $\mathrm{km} 257$ were detrimentally affected by presence of intermittent electrical noise of an unexplained source which was evident in the data, potentially resulting in an upwards biased geoelectric field value. The dissimilarity between and modelled and observed PSP was not anticipated, and therefore warrants further investigation to resolve it.

In the southeast half of the pipeline between $\mathrm{km} 305$ and 328 , the main focus of this investigation, there is a simultaneous rise of PSP amplitude ratio between the modelled and observed results (Figure 5.15) with respect to distance along the pipeline. Coverage of PSP recordings and MT sites in this area was of reasonable density. Geologically, the electrically resistive Mount Pakenham intrusive body is situated along this length of pipeline, as well as the contact between the resistive Precambrian basement and conductive overlying Paleozoic sedimentary cover rock. On a broader scale, the enhanced PSP seen here roughly coincides with the Sharbot Terrane.

\subsection{Summary of Findings}

As a result of investigations undertaken on the Ottawa Valley study area, the following advancements and findings were made:

a) The first, close-spaced MT surveys were completed along a $150 \mathrm{~km}$ transect in the geologically complex Ottawa Valley. 
b) The first known application of simultaneous measurements of the geoelectric field and PSP on a pipeline.

c) Confirmation that a zone of enhanced PSP exists on the pipeline, between $\mathrm{km} 250$ and $\mathrm{km} \mathrm{335}$, as previously identified in the 1997 ITS investigation (Boteler and Trichtchenko, 2000), that this zone is detectable from year to year as a natural phenomena, that it is in response to a deep Earth feature, and that it spatially coincides with the Mount Pakenham intrusive body as well as at the edge of the Paleozoic cover rock plus the Pakenham Fault.

d) Demonstrated that there is a connection between the electrical properties of geological features and PSP amplitudes via the calculation of surface impedances obtained from MT measurements. The use of MT impedance data is a viable method to model a non-uniform geoelectric field.

e) Modelled PSP amplitudes, using a constant geoelectric field, have shown that changes in pipeline structure have only a small effect on resultant PSP amplitudes.

f) Earth resistivity structure has been shown to have a significant effect on the size of PSP variations produced by geomagnetic induction.

Opportunities for future work, and recommendations for improvement to survey techniques include the following:

a) Further work is needed to resolve the relative size of the contribution to PSP amplitudes from the Precambrian Shield / Paleozoic sedimentary boundary around $\mathrm{km} \mathrm{290,} \mathrm{the} \mathrm{presence} \mathrm{of} \mathrm{resistive} \mathrm{intrusive} \mathrm{bodies} \mathrm{and/or} \mathrm{faults} \mathrm{between} \mathrm{km} 245$ and $\mathrm{km} 325$ along the pipeline route, effect of crustal thickness variation, and the 
gross resistivity differences between the various tectonic terranes or that underlie the pipeline route.

b) Finer spacing of the MT sites may provide better resolution in areas of rapid changes of Earth resistivity and hence, contribute in improving the fit between modelled and observed PSP data along such sections of the pipeline. 


\section{CHAPTER 6}

\section{CONCLUSIONS, RECOMMENDATIONS \&}

\section{FUTURE WORK}

The work undertaken for this thesis has demonstrated that knowledge of the Earth resistivity structure is critical for the evaluation of how geomagnetic disturbances affect pipelines and contributes to identifying sections along a pipeline route that may be more at risk from corrosion. Work on this thesis involved a combination of geological literature compilation, geophysical surveys and numerical analysis. The Earth resistivity structure was examined for two proposed pipeline routes in Alaska and northern Canada, and along part of an existing pipeline in southeastern Ontario.

The main conclusions are as follows:

a) The Earth resistivity plays an important role in modifying the geoelectric field and hence, PSP variations, thus interfering with pipeline corrosion mitigation (see Figures 3.19, 4.18 and 4.19).

b) Simple 1D models of Earth resistivity structure - based on a literature review which are applied to regional sections of a pipeline route, in combination with observatory geomagnetic data and the DSTL pipeline model, can be used to predict PSP variations at a broad scale, for example, along the Alaska Highway and Mackenzie River valley pipeline routes (see Sections 3.6 and 4.7). Therefore, the use of these models can provide a valuable contribution into the $\mathrm{CP}$ design considerations for proposed pipelines (refer to pipeline reports prepared by 
Boteler et al., 2005 and 2009), as well as mitigation improvements to existing pipeline.

c) Results of the MT survey undertaken in the McKenzie River valley study area have shown that $1 \mathrm{D}$ Earth resistivity models derived from the literature have a reasonably consistent agreement with 1D models obtained from the inversion of MT survey data (see Figure 4.8). However, dedicated MT surveys are the best approach to obtain subsurface structure of electrical resistivity along a pipeline route.

d) In some circumstances, the geomagnetic activity level and/or pipeline termination have a stronger influence on the resultant PSP than the Earth resistivity structure, as shown for the Prudhoe Bay area of the Alaska Highway pipeline.

e) The Earth resistivity models in conjunction with statistical geomagnetic data are a useful tool in determining the levels of telluric activity that will affect the PSP and location along the pipeline where such effects may occur (see Figure 3.25 for specific exceedance values).

f) Simultaneous measurement of geoelectric field (using MT instrumentation) and PSP were used for the first time in the analysis of how a pipeline responds to different Earth resistivity structures

g) By utilizing 2D Earth resistivity models, constructed using MT survey data obtained along a pipeline route, it has been shown that lateral discontinuities in resistivity structures associated with particular geological structures are likely to produce lateral variations of the geoelectric field and PSP as was demonstrated on part of the Ottawa Valley pipeline route (see Section 5.6.3). 
h) The use of close-spaced MT surveys can assist the pipeline operator in identifying the source of unusual anomalous PSP observations, whether it is of geological origin or physical defect in the pipe, so that mitigative actions can be applied to the best advantage of corrosion protection operations.

Based on experience obtained from data analysis and field work undertaken for this study, it is recommended for further similar studies that:

a) MT site and PSP test post intervals be closely spaced in areas of known or suspected resistivity boundaries so as to improve the lateral resolution of the resistivity boundary, and hence, better define the location of anomalous PSP resulting from such a boundary.

b) Consideration be given to the placement of magnetometers along different sections of a pipeline route (where observatory coverage is lacking) to obtain multi-year data for statistical evaluation of geomagnetic activity in order to determine minimum, maximum and normal values of PSP variations.

c) MT data quality can be improved by obtaining a longer duration (multiple days) of recording to mitigate cultural EM noise (where present) and to obtain a statistically valid response from upper mantle depths.

d) PSP data quality can be improved by use of GPS enabled data loggers to avoid time-lag errors, and by using a single reference test post through the duration of a survey. 
In terms of future work, the Ottawa Valley pipeline should continue to be used as a test bed to undertake:

a) Spectral analysis of the geoelectric field and PSP to better isolate and identify at what particular frequency is the Earth response that has resulted in the observed large amplitude geoelectric field and PSP and how it may correlate to the underlying geology;

b) Forward modelling to test various scenarios of how changes in deep Earth resistivity structure could result in the elevated PSP. Specifically, the forward modelling should determine if the vertical offset of the Moho along the trend of the Ottawa-Bonnechere Graben as postulated by Mereu et al. (1986) is the cause, if broad scale lithological and/or metamorphic grade differences between the lithotectonic domains and terranes are a factor, or if there is some other deepseated geological conditions.

c) MT profile perpendicular to the pipeline to observe at what distance away from the pipeline the MT data is no longer affected by the pipeline structure.

d) Controlled laboratory or field experiments to simulate the effect of major changes in Earth resistivity on a test length of pipe. 


\section{REFERENCES}

Allison, N.J. and Huddleston, WM.E., 1952. Extraneous currents noted on large transmission pipe line system, Corrosion, $8(1)$, p.1.

Arcone, S.A., Chachl, E.F., and Delaney, A.J., 1998. Seasonal structure of taliks beneath arctic streams determined with ground-penetrating radar; in Seventh International conference (Proceedings), Yellowknife (Canada), Collection Nordican No. 55, 19-24.

Aspler, L.W, Pilkington, M. and Miles, W.F., 2003. Interpretations of Precambrian basement based on recent aeromagnetic data, Mackenzie Valley, Northwest Territories., Geol. Surv Can, Current Research 2003-C2

Associated Mining Consultants Ltd., 2004. Report on the application of electrical and electromagnetic techniques in the design and construction of northern pipelines, Geological Survey of Canada, Open File Report.

Atlas of Canada, 2009. Permafrost.

< http://atlas.nrcan.gc.ca/site/english/maps/environment/land/permafrost $>$ [accessed November, 2009].

Aylsworth, J.M., Burgess, M.M., Desrochers, D.T., Duk-Rodkin, A., Robertson, T., and Traynor, J.E., 2000. Surficial geology, subsurface materials, and thaw sensitivity of sediments, in The Physical Environment of the Mackenzie Valley, Northwest Territories: A Base Line for the Assessment of Environmental Change, (ed.) L.D. Dyke and G.R. Brooks, Geological Survey of Canada, Bulletin 547, 41-48. 
Barker, R.H. and Skinner, N.J., 1980. Flow of electric currents of telluric origin in a long metal pipeline and their effect in relation to corrosion control, Materials Performance, 19, Feb. 1980, 25-28.

Beamish, D., Clark, T.D.G., Clarke, E., and Thomson, A.W.P., 2002. Geomagnetically induced currents in the UK: geomagnetic variations and surface electric fields Journal of Atmospheric and Solar-Terrestrial Physics, 64 (16), 1779-1792.

Belanger, R., 2010. Urban Geology of the National Capital Area, Bedrock Stratigraphy, Stratigraphic section along line A - B.

$<$ http://gsc.nrcan.gc.ca/urbgeo/natcap/index_e.php> [accessed August 26, 2010]

Beavers, J.A., 2001. Introduction to corrosion in Peabody's Control of Pipeline Corrosion, Second Edition (ed.), A.W. Peabody, , NACE International, Houston, USA, p.1-6.

Beavers, J.A., 2001b. Cathodic protection - how it works $\underline{i n}$ Peabody's Control of Pipeline Corrosion, Second Edition (ed.), A.W. Peabody, , NACE International, Houston, USA, p.21-47.

Beavers, J.A. and Garrity, K.C., 2001. Criteria for cathodic protection in Peabody's Control of Pipeline Corrosion, Second Edition (ed.), A.W. Peabody, NACE International, Houston, USA, p. 49-64.

Best, M.E., Leveson, V.M., Ferbey, T. and McConnell, D., 2006. Airborne electromagnetic mapping for buried Quaternary sands and gravels in northeast British Columbia, Canada, Journal of Environmental and Engineering Geophysics, v.11, no.1, 17-26. 
Bianchetti, R.L., 2001. survey methods and evaluation techniques $\underline{i n}$ Peabody's Control of Pipeline Corrosion, Second Edition (ed.), A.W. Peabody, , NACE International, Houston, USA, p.65-100.

Boerner, D.E., Kurtz, R.D., Craven, J.A., Ross, G.M. and Jones, F.W., 2000. A synthesis of electromagnetic studies in the Lithoprobe Alberta Basement Transect: constraints on Paleoproterozoic indentation tectonics, Can. J. Earth Sci, v.37, 1509-1534.

Boteler, D.H. and Cookson, M.J., 1986: Telluric currents and their effects on pipelines in the Cook Strait region of New Zealand, Materials Performance, 25(3), p.27-32.

Boteler, D.H., 1997. Distributed source transmission line theory for active terminations, Proc. 1997 Zurich EMC Symposium, Feb. 18-20, URSI Supplement, 401-408.

Boteler, D.H., 2000. Geomagnetic effects on the pipe-to-soil potentials of a continental pipeline, Adv. Space Res. 26 (1), 15-20.

Boteler, D.H. and Seager, W.H., 1998. Telluric currents: A meeting of theory and observation, Corrosion 54 (9), 751-755.

Boteler, D.H. and Trichtchenko, L., 2000. International Study of Telluric Current Effects on Pipelines, Final Report, volumes 1-3, Geological Survey of Canada Open File $3050,372 \mathrm{p}$.

Boteler, D.H., Trichtchenko, L., and Samson, C., 2003. Investigation of earth conductivity influence on pipe-to-soil potentials, Proceedings NACE North Area 2003 Eastern Conference, Ottawa, Sept. 2003. 
Boteler, D.H., Trichtchenko, L., and Fernberg, P., 2005. Study of Telluric Current Impact on Mackenzie Gas Project Pipelines, Final Report, Contract 99C30791871 for ColtKBR, Natural Resources Canada, July 2005, 261 p.

Boteler, D.H., Trichtchenko, L., Fernberg, P., and Harrison, M., 2009. Assessment of Telluric Current Effects on Proposed Alaska Highway Pipeline, Final Report, Contract \# 7248, Natural Resources Canada, December 2009, 170 p.

Bouzidi, Y., Schmitt, D.R., Burwash, R.A., and Kanasewich, E. R., 2002. Depth migration of deep seismic reflection profiles: crustal thickness variation in Alberta, Can. J. Earth Sci, v.39, 331-350.

Brantford, J.H., McNamara, J.P., Bowden, W., and Gooseff, M.N., 2005. Measuring thaw depth beneath peat-lined Arctic streams using ground-penetrating radar, Hydrological Processes (published on-line $<$ http://www3.interscience.wiley.com/cgi-bin/abstract/1 10471861/ABSTRACT> [accessed July 2005].

Brown J., and Kreig, R.A., 1983. 1983, Guidebook to permafrost and related features along the Elliott and Dalton Highways, Fox to Prudhoe Bay, Alaska, Alaska Division of Geological \& Geophysical Surveys, Guidebook 4, 230 p.

Burns, L.E., Fugro Airborne Surveys Corp., and Stevens Exploration Management Corp., 2006., 40,000 coplanar apparent resistivity of the Alaska Highway corridor, eastcentral Alaska, parts of Big Delta and Mt. Hayes quadrangles: Alaska Division of Geological \& Geophysical Surveys Geophysical Report 2006-6-3A, 1 sheet, scale $1: 63,360$. 
Burns, L.E., Fugro Airborne Surveys Corp., and Stevens Exploration Management Corp., 2006., 400 coplanar apparent resistivity of the Alaska Highway corridor, eastcentral Alaska, parts of Mt. Hayes Quadrangle: Alaska Division of Geological \& Geophysical Surveys Geophysical Report 2006-6-6B, 1 sheet, scale 1:63,360.

Busch, J.P., Mezger K., and van der Pluijm, B.A., 1997. Suturing and extensional reactivation in the Grenville orogen, Canada, Geolgy 25 (6), 507-510.

Cagniard, L., 1953. Basic theory of the magneto-telluric method of geophysical prospecting, Geophys., 18, 605-635.

Camitz, G., Edwal, H-E., and Marbe, A., 1997. The influence of telluric currents on the cathodic protection of natural gas pipelines, Proc. CEOCOR $4^{\text {th }}$ Int. Conference, Vienna '97, Sector A, 125-135.

Campbell, D. L.; Sampson, J. A.; Wise, R. A.; Williams, J. M., 2001. Magnetotelluric and audiomagnetotelluric data collected in Alaska by the U. S. Geological Survey, 1985-1992, version 1, U.S. Geological Survey Open-File Report 2001-053, 1 computer optical disk.

Campbell, W.H., 1978. Induction of auroral zone electric currents within the Alaska pipeline, Pure Appl. Geophys., 116, 1143-1173.

Campbell, W.H., 1980. Observation of electric currents in the Alaska oil pipeline resulting form auroral electrojet current sources, Geophys. J. R. astr. Soc., 61 (2), 437-449.

Campbell, W.H., 1986. An interpretation of induced electric currents in long pipelines caused by natural geomagnetic sources of the upper atmosphere, Surveys in Geophysics., 8, 239-259. 
Campbell, W.H., 2003., Introduction to Geomagnetic Fields, $2^{\text {nd }}$ Edition, Cambridge University Press, Cambridge, UK, 352 p.

Carr, S.D., Easton, R.M., Jamieson, R.A. and Culshaw, N.G., 2000. Geologic transect across the Grenville Orogen of Ontario and New York. Canadian Journal of Earth Sciences, 37, 193-216.

Carrara, P.E., 2004. Surficial geologic map of the Tanacross B-5 Quadrangle, eastcentral Alaska, 1 sheet, scale 1:63,360. $<$ http://pubs.er.usgs.gov/usgspubs/sim/sim2856> [accessed November 2009].

Clowes, R. M., and P. T. C. Hammer, 2002. Comparison of lithospheric structures across the Alaskan and Canadian Cordillera: A tale of subduction, accretion, and collision, in Lithoprobe Slave-Northern Cordillera Lithospheric Evolution Transect and Cordilleran Tectonics Workshop, LITHOPROBE Rep. 82, edited by F. A. Cook and P. Erdmer, p. 106- 110, LITHOPROBE Secretariat, Univ. of B. C., Vancouver, B. C., Canada.

Clowes, R.M., Hammer, P.T.C., Fernandez-Viejo, G. and Welford, J.K., 2005. Lithospheric structure in northwestern Canada from Lithoprobe seismic refraction and related studies: a synthesis, Can. J. Earth Sci., v.42, p.1277-1293.

Collett, T. S., Bird, K. J., Kvenvolden, K. A., and Magoon, L. B., 1988. Geologic interrelations relative to gas hydrates within the North Slope of Alaska, U.S. Geological Survey, Open File Report 88-389, 150 p.

Constable, S.C., Parker, R.L., and Constable, C.G., 1987. Occams's inversion: A practical algorithm for generating smooth models from electromagnetic sounding data, Geophysics, 52 (3), 289-300. 
Cook, F.A., Van Der Velden, A.J., Hall, K.W. \& Roberts, B.J., 1999. Frozen subduction in Canada's Northwest Territories: Lithoprobe deep lithospheric reflection profiling of the western Canadian Shield, Tectonics, 18, 1-24.

Cook, F.A. and Erdmer, P., 2005. An $1800 \mathrm{~km}$ cross section of the lithosphere through the northwestern North American plate: lessons from 4.0 billion years of Earth's history, Can. J. Earth Sci, 42, 1295 - 1311.

Craven, J.A., 2007. Synthetic magnetotelluric modelling based on the Mallik gas hydrate research wells, Northwest Territories, Geological Survey of Canada, Current Research 2007-B5, 6 p.

Craven, J.A., Roberts, B.J., Bellefleur, G., Spratt, J., Cingel, J., and Fernberg, P., 2009. Recent magnetotelluric measurements at the Mallik gas hydrate production research well site, Northwest Territories, Geological Survey of Canada, Current Research 2009-5, 7 p.

D-maps.com, 2010. North America $<$ http://maps.com/pays.php?lib=north_america_maps\&num_pay=119\&lang=en> [accessed November, 2010]

Dixon, J., Deitrich, J., and McNeil, D.H., 1992. Jurassic to Pleistocene sequence stratigraphy of the Beaufort-Mackenzie Delta and Banks Island areas, northwest Canada, Geological Survey of Canada, Bulletin 407, 90 p.

Easton, R.M., 1992. The Grenville Province and the Proterozoic history of central and southern Ontario, $\underline{\text { in }}$ Geology of Ontario, Ontario Geological Survey, Special Volume 4, Part 2, (ed.) Thurston, P.C., 714-904. 
Eaton, D.W., Dineva, S., and Mereu, R., 2006. Crustal thickness and $V_{P} / V_{S}$ variations in the Grenville orogen (Ontario, Canada) from analysis of teleseismic receiver functions, Tectonophysics, 420, 223-238.

Edwall, H-E, and Boteler , D.H., 2001. Sutudies of telluric currents on pipelines in southern Sweden, Paper 01315, Proceedings, CORROSION 2001, NACE International, Houston, 11-16 March 2001.

Eyles, N., 2002. Ontario rocks: three billion years of environmental change, Fitzhenry \& Whiteside, Markham, Ontario, 339 p.

Favetto, A. and Osella, A., 1999. Numerical simulation of currents induced by geomagnetic storms on buried pipelines: An application to the Tierra del Fuego, Argentina, gas transmission route, IEEE Transactions on Geoscience and Remote Sensing, 37(1), 614-619.

Ferguson, I.J. and Odwar, H.D., 1997: Appendix 4: Review of conductivity soundings in Canada; $\underline{\text { in }}$ Geomagnetically Induced Currents: Geomagnetic Hazard Assessment Phase II, Final Report, Volume 3; Geological Survey of Canada, Open File Report 3420, p. A3-1-A3-121.

Ferguson, I. J., and Odwar, H.D., 1998. Conductivity structure of Canada, v.1; in Geomagnetically induced currents: Geomagnetic Hazard Assessment Phase II, Final Report, (contributing authors) D.H. Boteler, S. Boutilier and A.K. Wong, D. Swatek, Q. Bui-Van, R.

Fernberg, P.A., Samson, C., Boteler, D.H., Trichtchenko, L., and Larocca, P., 2007a. Earth conductivity structures and their effects on geomagnetic induction in pipelines, Ann. Geophys., 25, 207-218. 
Fernberg, P., Trichtchenko, L., Boteler, D.H., and McKee, L., 2007b. Telluric hazard assessment for northern pipelines, Paper No. 07654, NACE International CORROSION/2007 conference, Nashville, Tennessee, March 12-15, 2007, 11 p.

Fernberg, P., Samson, C. and Boteler, D.H., 2007c. The 2006 MRV survey: magnetotelluric and resistivity sounding in the Mackenzie River valley, Northwest Territories, Seismological Research Letters, 78, 1, 167, Seismological Society of America, Eastern Section; Abstracts of the annual meeting (Ottawa, 24 October 2006), 2007.

Ferrians, Jr., O.J., 1965. Permafrost map of Alaska, U.S. Geological Survey, Miscellaneous Geologic Investigations Map I-445, scale 1, 2,500,000.

Fisher, M.A., Pellerin, L., Ratchkovski, N.A., Nokleberg, W.J., Pellerin, L. and Glen, J.M.G., 2004. Geophysical data reveal the crustal structure of the Alaska Range orogen within the aftershock zone of the M7.9 Denali Fault earthquake, Bull. Seismological Soc. of America, v.94, No.6B, p.5107-5131.

Fisher, M.A., Pellerin, L., Nokleberg, W.J., Ratchkovski, N.A, Glen, J.M.G., 2007. Crustal structure of the Alaska Range orogen and Denali fault along the Richardson Highway, in K.D. Ridgeway, J.M. Trop, J.M.G. Glen, and J.M. O'Neil (eds.), Tectonic Growth of a Collisional Continental margin: Crustal Evolution of Southern Alaska, Geological Society of America Special Paper 431, p.43-53.

Folta, M., 2004. Field deployment and calibration of survey-type magnetotelluric instruments, B.Sc. Thesis, Dept. of Earth Sciences, Carleton University, Ottawa. 
Frederiksen, A.W., Ferguson, I.J., Easton, D, Miong, S.-K. and Gowan, E., 2005, Mantle fabric at multiple scales across an Archean-Proterozoic Boundary, Eastern Ontario, Canada (submitted to Elsevier Science).

Fuis, G.S., Murphy, J.M., Lutter, W.J., Moore, T.E., Bird, K.J., and Christensen, N.I., 1997. Deep seismic structure and tectonics of northern Alaska: crustal-scale duplexing with deformation extending into the upper mantle, J. Geophy. Research, 102 (B9), 20873-20896.

Fuis, G.S., Moore, T.E., Plafker, G., Brocher, T.M., Fisher, M.A., Mooney, W.D., Nokleberg, W.J., Page, R.A., Beaudoin, B.C., Christensen, N.I., Levander, A.R., Lutter, W.J., Saltus, R.W., and Ruppert, N.A., 2008. Trans-Alaska Crustal Transect and continental evolution involving subduction underplaying and synchronous foreland closing, Geology, 36 (3), p.267-270.

Fulton, R.J., 1995. Surficial materials of Canada, Geological Survey of Canada, "A" Series Map 1880A, scale 1:5,000,000.

Gamble, T.D., Goubau, W.M., and Clarke, J., 1979. Magnetotellurics with a remote magnetic reference, Geophysics, 44, 53-68.

Garcia, X., and Jones, A.G., 2002. Atmospheric sources for audio-magnetotelluric (AMT) sounding, Geophysics, 67, 448-458.

Intermagnet, 2010. Geomagnetism Instrumentation

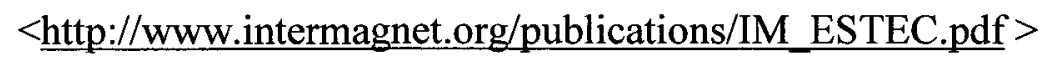
[accessed 04 Oct 2010]

GSC, 2010. Geomagnetism Data, Geological Survey of Canada, $<$ http://gsc.nrcan.gc.ca/geomag/data/index_e.php $>$ [accessed 04 Oct 2010] 
Geosytem SRL, 2005. A guide to using WinGLink, ver 2.10.01, Milan, Italy,

Gideon, D.N., Hopper, A.T., and McClure, G.M., 1968. Earth current effects on buried pipelines, analysis of Ohio and Vancouver field tests, American Gas Association, Catalogue No. L30510, 34 p., 4 appendices.

Gideon, D.N., Hopper, A.T., and Thompson R.E., 1970. Earth current effects on buried pipelines, analysis of telluric gradients and their effects, American Gas Association, Catalogue No. L30570, 77 p.

Gideon, D.N., 1971. Telluric current effects on buried pipelines, Materials Protection and performance, $10(7), 5-10$.

Grantz, A. Moore, T.E., and Roeske, S., 1991. A-3 Gulf of Alaska to Arctic Ocean: Boulder, Colorado, Geological society of America, Centennial Continental/Ocean Transect no. 15, 3 sheets with text, scale 1:500,000.

Gummow, R.A., Boteler, D. H., and Trichtchenko, L., 2001: Telluric and ocean current effects on buried pipelines and their cathodic protection systems, Pipeline Research Council International, Inc., Corrosion Supervisory Committee, Contract No. PR-262-0030, May 2001.

Gummow, R.A., 2002. GIC effects on pipeline corrosion and corrosion control systems, J. Atmospheric and Solar-Terrestrial Physics, 64, 1755-1764.

Hackbarth, D.D., 1978. Hydrogeological map of the Grande Prairie area, Alberta, NTS 83M, Map 125, Alberta Geological Survey, scale 1:250,000.

Hartman, G.M.D. and Clague, J.J., 2008. Geology of northeastern British Columbia and northwestern Alberta; diamonds, shallow gas, gravel and glaciers, Can. J. Earth Sci., v.45, no.5, 549-564. 
Heginbottom, J.A., 2000. Permafrost distribution and ground ice in surficial materials; in The Physical Environment of the Mackenzie Valley, Northwest Territories: a Base Line for the Assessment of Environmental Change, (ed.) L.D. Dyke and G.R. Brooks; Geological Survey of Canada, Bulletin 547, p.31-39.

Henriksen, J.F., Elvik, R., and Granasen, L., 1978. Telluric current corrosion on buried pipelines, $\underline{i n}$ Theory and Practise of Corrosion Prevention, Proceedings of the $8^{\text {th }}$ Scandinavian Corrosion Congress NKM, vol. 8, Helsinki 1978, 167-176.

Jones, A.G. 1988. Static shift of magnetotelluric data and its removal in a sedimentary basin environment, Geophysics, 53 (7), 967-978.

Jones, A.G., 1999. Imaging the continental upper mantle using electromagnetic methods, Lithos, $48,57-80$.

Jones, A.G., Ledo, J., Ferguson, I.J., Farquharson, C., Garcia, X., Grant, N., McNeice, G., Spratt, J., Wennberg, G., Wolynec, L., and Wu, X., 2005. The electrical resistivity structure of Archean to Tertiary lithosphere along $3200 \mathrm{~km}$ of SNORCLE profiles, northwestern Canada, Can. J. Sci. 42, 1257-1275.

Kachadoorian, R., 1971c. Preliminary engineering geologic maps of the proposed TransAlaska pipeline route, Livengood and Tanana quadrangles, U.S. Geological Survey, Open-File Report 71-166, scale 250,000.

Kaufman, A.A. and Keller. G.V., 1981: The Magnetotelluric Sounding Method, Methods in Geochemistry and Geophysics, series 15, Elsevier Scientific Publishing Company, Amsterdam-Oxford-New York, $535 \mathrm{p}$.

Kay, S., 1993. Fundamentals of Statistical Signal Processing, Vol.1 Estimation Theory, Prentice-Hall, Englewood Cliffs, New Jersey. 
Keller, M. A. and Bird, K.J., 2003. Petroleum source potential of the Lower Cretaceous mudstone succession of the NPRA and Colville Delta area, North Slope Alaska, based on sonic and resistivity logs, U.S. Geological Survey, Open-File Report 03325, poster, < http://pubs.er.usgs.gov/usgspubs/ofr/ofr03325> [accessed May 29, 2009]

Klassen, R.W., 1997. Surficial Geology, Coal River [West Half], Yukon Territory, Geological Survey of Canada, Preliminary Map 13-1982, scale 1:250,000.

Kokelji, S.V., 2003. Near-surface ground ice in sediments of the Mackenzie Delta region, Northwest Territories, Unpub. Thesis, Carleton University, Ottawa.

Koziar, A., and Strangway, D.W., 1978. Permafrost mapping by audiofrequency magnetotellurics, Canadian Journal Earth Science, 15, p. 1539-1546.

Kreig, R.A., and Reger, R.D., 1982, Air-photo analysis and summary of landform soil properties along the route of the trans-Alaska pipeline system, Alaska Division of Geological \& Geophysical Surveys, Geologic Report 66, 149 p.

Kumar, N., Bird, K.J., Nelson, P.H., Grow, J.A. and Evans, K.R., 2002. A digital atlas of hydrocarbon accumulations within and adjacent to the National Petroleum Reserve-Alaska (NPRA), U.S. Geological Survey, Open-File Report 02-71, version 1.0., 80 p. <http://pubs.er.usgs.gov/usgspubs/ofr/ofr0271> [accessed May 29, 2009]

Lanzerotti, L.J. and Gregori, G.P., 1986: Telluric currents: The natural environment and interactions with man-made systems $\underline{i n}$ The Earth's Electrical Environment, National Academy Press, 232-257. 
Larocca, P., Trichtchenko, L., and Boteler, D.H., 2005. Telluric current effects and soil resistivity effects on a pipeline, Geological Survey of Canada, unpublished, $35 \mathrm{p}$.

Ledo, J., Jones, A.G., Ferguson, I.J. and L. Wolynec, L.,2004. Lithospheric structure of the Yukon, northern Canadian Cordillera, obtained from magnetotelluric data, J. Geophys. Res., v.109, B04410, 15 p.

Magoon, L.B., Bird, K.J., Claypool, G.E., Weitzman, D.E., and Thompson, R. H., 1988. Organic geochemistry, hydrocarbon occurrence, and stratigraphy of governmentdrilled wells, North Slope, Alaska, in Chapter 19, Geology and Exploration of the National Petroleum Reserve in Alaska, 1974 to 1982, (ed.) G. Gryc, U.S. Professional Paper 1399, 483-488.

Mair, J.L., Hart, C.J.R., and Stephens, J.R., 2006. Deformation history of the northwestern Selwyn Basin, Yukon, Canada: implications for orogen evolution and mid-Cretaceous magmatism, GSA Bulletin, v.118, no.3/4, 304-323.

Marshall, R. A., Waters, C.L., and M. D. Sciffer, M.D., 2010. Spectral analysis of pipe-to-soil potentials with variations of the Earth's magnetic field in the Australian region, Space Weather, 8, 13 p.

Martin, B.A., 1993: Telluric effects on a buried pipeline, Corrosion, 49(4), 343-350.

McCoy, J., 1989. Cathodic protection on the Dampier to Perth pipeline - Australia, Materials Performance, 28 (2), 16-20.

Mackay, D.K., 1979. Electrical resistivity measurements in frozen ground, Mackenzie Delta area, Northwest Territories, in Hydrology of Deltas, Proceeding of the Bucharest Symposium, Vol.2, p.363-375. 
McKay, A.J. and Whaler, K.A., 2006. The electric field in northern England and southern Scotland: implications for geomagnetically induced currents, Geophys. J. Int., 167, 613-625.

Mackenzie Gas Producer Group, 2003.

$<\mathrm{http}: / /$ www.mackenziegas project.com/theProject/overview/index.html $\geq$ [accessed March 2005]

Mereu, R.F., Wang, D., Kuhn, O., and Forsyth, D.A., 1986. Summary of the results of the 1982 COCRUST long-range seismic experiment across the OttawaBonnechere Graben and western Grenville Front, in The Grenville Province, (eds.) J.M. Moore, A. Davidson and A.J. Baer, Geological Association of Canada Special paper 31, 235-240.

Merritt, R.P., 1979. Measurement of the auroral-induced current in the TransAlaska pipeline, Transactions of the American Society of Mechanical Engineers, 101, 156-158.

Milan, S., 2007. Auroral oval in Encyclopedia of Geomagnetism and Paleomagnetism, (ed.) D. Gubbins and E. Herrero-Bervera, Springer, The Netherlands, 33-34.

Moore, T.E., Wallace, W.K., Bird, K.J., Karl, S.M., Mull, C.G., and Dillon, J.T., 1994. Generalized geologic map and sections for Northern Alaska, Plate 6, various scales; in The Geology of Alaska, (ed.) G. Plafker and H.C. Berg, Geological Society of America, The Geology of North America, v. G-1, plate 6, various scales.

Morison, S.R. and Klassen, R.W., 1991. Surficial geology, Whitehorse, Yukon Territory, Geological Survey of Canada, Preliminary Map 12-1990, scale 1:100,000. 
Morison, S.R. and Klassen, R.W., 1997. Surficial geology, Teslin, Yukon Territory, Geological Survey of Canada, "A" Series Map 1891A, scale 1:125,000.

Mull, C.G., and Adams, K.E., 1989, Bedrock geology of the eastern Koyukuk Basin, central Brooks Range, and east central Arctic Slope along the Dalton Highway, Yukon River to Prudhoe Bay, Alaska: Alaska Division of Geological \& Geophysical Surveys Guidebook 7 vol. 2, 167 p., 1 sheet, scale 1:2,851,200.

Nelson, J. and Colpron, M., 2007. Tectonics and Metallogeny of the British Columbia, Yukon and Alaskan Cordillera, 1.8 Ga to Present, in Mineral Deposits of Canada: A Synthesis of Major Deposit-types, District Metallogeny, the Evolution of Geological Provinces, and Exploration Methods, W.D. Goodfellow (ed.), Special Publication 5, Mineral Deposits Division, Geological Association of Canada, 755-792 <http://gsc.nrcan.gc.ca/mindep/synth_prov/cord/index_e.php> [accessed November 2009].

Nelson, P.H., and Kibler, J.E., 2001. Well logs and core data from selected cored intervals, National Petroleum Reserve, Alaska, U.S. Geological Survey, Open File Report 01-167. (well logs available on-line at <http://pubs.er.usgs.gov/ >) [accessed May 29, 2009].

NRCan, 2010. Natural Resources Canada. README for Hourly Range Files $<\mathrm{ftp} / / \mathrm{ftp}$. geolab.nrcan.gc.ca/pub/forecast/hourly_ranges/README $>$ [accessed 04 Oct 2010]

Northern Engineering Services Company Limited, 1972. Cathodic protection tests at the Arctic Test Facility, prepared for Canadian Arctic Gas Study Limited. 
Northern Engineering Services Company Limited, 1976. Geophysical investigations on the rivers of the Arctic Coastal Plain, prepared for Canadian Arctic Gas Study Limited.

Northern Engineering Services Company Limited, 1977. Geotechnical data report permafrost distribution: Willowlake River, NWT to Zama Lake, Alberta

Ogunade, S.O., 1986. Induced electromagnetic field in oil pipelines under electroject current sources, Physis of the Earth and Planetary Interior, 43, 307-315.

O'Leary, D.D., Ellis, R.M., Stephenson, R.A., Lane, L.S., and Zelt, C.A.,1995. Crustal structure of the northern Yukon and Mackenzie Delta, northwestern Canada., Journal of Geophysical Research 100, no.B7, 9905-9920.

Osella, A., Favetto, and Lopez, E., 1999. Corrosion rates of buried pipelines caused by geomagnetic storms, Corrosion, 55(7), 699-705.

Osella, A. and Favetto, A., 2000. Effects of soil resistivity on currents induced on pipelines, Journal of Applied Geophysics, 44, 303-312.

Ouassaa, K., Forsyth, D., and White, D., 2000. The 2000 southern Ontario seismic project, Geological Survey of Canada, Current Research 2002-E9, 9 p.

Ouassaa, K., and D.A. Forsyth, 2002, Interpretation of seismic and potential field data from western New York State and Lake Ontario, Tectonophysics, 353, 115-149.

Ouassaa, K., Forsyth, D., and White, D., 2010. Data processing and preliminary interpretation of the 2000 Southern Ontario Seismic (SOS) project, Open File, Geological Survey of Canada, Open File 5056, 64 p. 
Palacky, G.J., 1988. Resistivity characteristics of geologic targets, in Electromagnetic Methods in Applied Geophysics-Theory, Volume 1, M.N. Nabighian (ed.), Society of Exploration Geophysicists, Tulsa, Oklahoma, p.53-129.

Peabody, A.W., 2000. Control of Pipeline Corrosion, National Association of Corrosion engineers (NACE International), Houston, $360 \mathrm{p}$.

Percival, J.A., Bleeker, W., Cook, F.A., Rivers, T., Ross, G., and van Staal, C.R., 2004. Panlithoprobe workshop IV: Intra-orogen correlations and comparative orogenic anatomy. Geoscience Canada, 31, 23-39.

Pirjola, R. and Lehtinen, M., 1985. Currents produced in the Finnish $400 \mathrm{kV}$ power transmission grid and in the Finnish natural gas pipeline by geomagneticallyinduced electric fields, Annales Geophysica, 3 (4), 485-491.

Pirjola, R., Viljanen, A., and Amm, O., 2000. Space weather risk in power systems and pipelines, Phys. Chem. Earth (C), 25 (4), 333-337.

Place,T.D. and Sneath, T.O., 2001. Practical telluric compensation for pipeline closeinterval surveys, Materials Performance, 40, 22-27.

Prölss, G., 2004. Physics of the Earth's Space Environment: An Introduction, (translated by Michael Keith Bird), Springer, Berlin, New York, 513 p.

Pulkkinen, A., Viljanen, A., Pajuanpää, K., and Pirjola, R., 2001: Recordings and occurrence of geomagnetically induced currents in the Finnish natural gas pipeline network, Journal of Applied Geophysics, 48, 219-231.

Pulkkinen, A., Pirjola, R., Boteler, D., Viljanen, A., and Yegorov, I., 2001. Modelling of space weather effects on pipelines, Journal of Applied Geophysics., 48, 233-256. 
Pulkkinen, A., Pirjola, R., and Viljanen, A., 2007. Determination of ground conductivity and system parameters for optimal modeling of geomagnetically induced current flow in technological systems, Earths Planets Space, 59, 999-1006.

Rawlinson, S.E., 1983, Guidebook to permafrost and related features at Prudhoe Bay, Alaska Division of Geological \& Geophysical Surveys Guidebook 5, 150 p.

Reger, R.D., and Solie, D.N., 2008. Reconnaissance interpretation of permafrost, Alaska Highway corridor, Delta Junction to Dot Lake, Alaska: Alaska Division of Geological \& Geophysical Surveys, Preliminary Interpretive Report 2008-3C, 10 p., 2 sheets, scale 1:63,360.

Remisz, W., 2005: The Mississippi River Bridges 2000-2001, $<\mathrm{http} / / /$ www.remisz.com/misisipi.htm $>$ [accessed,Nov., 2005]

Rix, B.C., and Boteler, D.H., 2001. Telluric current considerations in the CP design for the Maritimes and Northeast Pipeline, Paper 01317, Proceedings, CORROSION 2001, NACE International, Houston, 11-16 March 2001.

Ross, G.M., and Eaton, D.W., 2002. Proterozoic tectonic accretion and growth of western Laurentia: results from Lithoprobe studies in northern Alberta, Can. J. Earth Sci., v.39, p.313-329.

Russell, G.I. and Nelson, L.B., 1954. Extrinsic line current fluctuations seriously restrict progress of coating conductance surveys on large truck line, Corrosion, 10, p.400.

Samson, C., Ferguson, I., Graham, G., Folta, M., Fernberg, P., Larocca, P., Trichtchenko, L., and Boteler, D. 2004, Acquisition of magnetotelluric data for studies of pipeto-soil potentials on pipelines: preliminary results from the 2003 Ottawa River 
Valley Survey, Presentation, Joint Meeting of CGU / AGU Meeting, Montreal, 17-21 May 2004.

Samson, C., Fernberg, P., Trichtchenko, L., and Boteler, D.H., 2006. Quantitative analysis of the Earth conductivity structures and their effects on pipe-to-soil potentials along the TransCanada Mainline at Arnprior, Final Report to TransCanada Pipelines Ltd., 9 January 2006, 85 p.

Schelkunoff, S.A., 1939. On diffraction and radiation of E-M waves, Phys. Rev., August, 1939, p. 308.

Schelkunoff, S.A., 1943. Electromagnetic Waves, D. Van Nostrand Company Inc, New York, $530 \mathrm{p}$.

Scott, W.J., Sellmann, P.V., and Hunter J.A., 1990. Geophysics in the study of permafrost, in Geotechnical and Environmental Geophysics, Vol.1: Review and Tutorial, Society of Exploration Geophysicists, (ed.) S.H. Ward, 355-384.

Shapka, R.S., 1992. Geomagnetic effects on a modern pipeline system, Proc. SolarTerrestrial Predictions Workshop, May 18-22, 1992, Ottawa, vol. 1., 163-170.

Simpson, F., and Bahr, K., 2005. Practical Magnetotellurics, Cambridge University Press, $254 \mathrm{p}$.

Smart, A.L., 1982: The Trans Alaska Pipeline - potential measurements and telluric current, IEEE Transactions on Industry Applications, Vol. 1A-18, No. 5, 557-567.

Smith, S.L., Burgess, M.M., and Heginbottom, J.A., 2001. Permafrost in Canada, a challenge to northern development; in A Synthesis of Geological Hazards in Canada, (ed.) G.R. Brooks; Geological Survey of Canada, Bulletin 548, 241 264. 
Stanley, W.D., Labson, V.F., Nokleberg, W.J., Csejtey, Jr., B., and Fisher, M.A., 1990. The Denali fault system and Alaska Range of Alaska: evidence for underplayed Mesozoic flinch from magneto telluric surveys, Geological Society of America Bulletin. v.102, 160-173.

Stephenson, R.A., Coflin, K.C., Lane, L.S. and Dietrich, J.R., 1994. Crustal structure and tectonics of the southeastern Beaufort Sea continental margin, Tectonics, Vol, 13, No.2, 389-400.

Stott, D.F., and Klassen, R.W., 1993. Geomorphic divisions; subchapter 2C, in Sedimentary Cover of the Craton in Canada, (ed.) D.F. Stott and J.D. Atkin, Geological Survey of Canada, Geology of Canada No.5, 31-44.

Redman, D., and Bauman, P., 2004. Draft - Application of geophysical methods to permafrost, review of literature, Geological Survey of Canada, Open File Report.

Rodi, W., and Mackie, R.L., 2001. Nonlinear conjugate gradients algorithm for 2-D magnetotelluric inversion, Geophysics, 66 (1), 174-187.

Taylor, A.E., Burgess, M.M., Judge, A.S., and Allen, V.S., 2000. Deep ground temperatures, in The Physical Environment of the Mackenzie Valley, Northwest Territories: A Base Line for the Assessment of Environmental Change, (ed.) L.D. Dyke and G.R. Brooks, Geological Survey of Canada, Bulletin 547, 105-109.

Talflove, A., and Dabkowski, J., 1979., Prediction method for buried pipeline voltages due to $60 \mathrm{~Hz}$ AC inductive coupling, IEEE Trans. Power Apparatus \& Systems, vol. PAS-98, 780-794.

Telford, W.M., Geldart, L.P., Sheriff, R.E. and Keys, D.A., 1976. Applied Geophysics, Cambridge University Press, $860 \mathrm{p}$. 
Terrain Science Division, 2005. Regional studies, Geological Survey of Canada, < http://sts.nrcan.gc.ca/permafrost/regional.html > [accessed April 2005]

Tikhonov, A.N., 1950. Determination of the electrical characteristics of the deep strata of the earth;s crust. Dok. Akad. Nauk., USSR, 73 (2), 295-297.

Till A.B., Desmoulins, J.A., Moore, T.E., Black, H.A., and Sawyer, B.R., 2008. Bedrock geologic map of the southern Brooks Range, Alaska, and accompanying condone data, U.S. Geological Survey, Open-file Report 2008-1149, 88 p., 2 sheets, sheet 1-scale 1:500,000, sheet 2-scale 1:600,000.

Todd, B.J. and S.R. Dallimore. 1998. Electromagnetical and geological transect across permafrost terrain, Mackenzie River delta, Canada. Geophysics, 63 (6), 1914 1924.

TransCanada, 2010. Alaska PipelineProject $<$ http://www.thealaskapipelineproject.com/> [accessed 04 Oct 2010]

Trichtchenko, L., and Boteler, D.H., 2001. Specification of geomagnetically induced electric fields and currents in pipelines, J. Geophys. Res., 106, 21 039-21 048.

Trichtchenko, L. and Boteler, D.H., 2002. Modelling of geomagnetic induction in pipelines, Annales Geophysicae, 20, 1063-1072.

Trommelen, M. and Levson, V., 2008. Quaternary stratigraphy of the Prophet River, northeastern British Columbia, Can. J. Earth Sci., v.45, no.5, p.565-575.

Turkoglu, E., Unsworth, M., and Pana, D., 2009. Deep electrical structure of northern Alberta (Canada): implications for diamond exploration, Can. J. Earth Sci., 46, 139-154. 
USGS, 2010. United States Geological Survey (USGS) National Geomagnetism Program. Data, Preliminary and Definitive Data Type $<$ http://geomag.usgs.gov/observatories/data/ $>$ [accessed 04 Oct 2010]

Wait, J.A., 1982. Geo-Electromagnetism, Academic Press, New York, 268 p.

Wallace, W.H., 1978. Induction of auroral zone electric currents within the Alaska pipeline, Pure appl. Geophys., 116, 1143-1173.

Wallace, W.H., 1980. Observation of electric currents in the Alaska oil pipeline resulting from auroral electrojet current sources, Geophys. J. R. astr. Soc., 61, 437-449.

Weaver, J.T., 1994. Mathematical Methods for Geo-electromagnetic Induction. Toronto: John Wiley \& Sons Inc., Toronto, 316 p.

Weber, F.R., 1971. Preliminary engineering geologic maps of the proposed Trans-Alaska pipeline route, Fairbanks and Big Delta quadrangles, U.S. Geological Survey, Open-File Report 71-318, scale 250,000.

Welford, J.K., Clowes, R.M., Ellis, R.M., Spence, G.D., Asudeh, I., and Hajnal, Z., 2001. Lithospheric structure across the craton-Cordilleran transition of northeastern British Columbia, Can. J. Earth Sci., v.38, p.1169-1189.

Wennberg, G., Ferguson, I.J., Ledo.J., and Jones, A.G., 2002. Modeling and interpretation of magnetotelluric data: Watson Lake to Stewart (line2A) and Johnsons's Crossing to Watson Lake, in SNORCLE Transect and Cordilleran Tectonics Workshop Meeting, compiled by F. Cook and P. Erdmer, Lithoprobe Rep. 82, p. 145, Univ. of B. C., Lithoprobe Secr.for the Can. Lithoprobe Program, Vancouver. 
Wu, X., 2001. Determination of near-surface, crustal and lithospheric structures in the Canadian Precambrian Shield using time-domain electromagnetic and magnetotelluric methods, Ph.D. thesis, University of Manitoba, Winnipeg, Manitoba, $541 \mathrm{p}$.

Wu, X., Ferguson, I.J., and Jones, A.G., 2005. Geoelectric structure of the Proterozoic Wopmay orogen and adjacent terranes, Northwest Territories, Canada, Can. J. Earth Sci, 42, $955-981$.

Viejo, G.F., and Clowes, R.M., 2003. Lithospheric structure beneath the Archaean Slave province and Proterozoic Wopmay origin, northwestern Canada, from a Litho probe refraction/wide-angle reflection survey., Geophysics. J. Int. 153, 1-19.

Viljanen, A., 1989. Geomagnetically induced currents in the Finnish Natural Gas Pipeline, Geophysica, 25, 135-159.

Villeneuve, M.E., Ross, G.M., Thériault, R.J., Miles, W., Parrish, R.R., and Broome, J., 1993. Tectonic subdivision and U-Pb geochronology of the crystalline basement of the Alberta Basin, western Canada. Geological Survey of Canada, Bulletin 447.

Vozoff, K., 1991. The magnetotelluric method, in M.N. Nabighian (ed.), Electromagnetic Methods in Applied Geophysics - Applications, Volume 2, Parts A and B, Series: Investigations in Geophysics No. 3, Society of Exploration Geophysicists, 641-712.

Yukon Geological Survey, 2002. Geoprocess file summary report, Whitehorse map area, N.T.S. 105D $<$ http://ygsftp.gov.yk.ca/publications/openfile/2002/of2002_8d_geoprocess_file/ documents/map_specific/105d.pdf> [accessed November, 2009]. 


\section{APPENDIX A3.1 \\ 1D EARTH RESISTIVITY MODELS for ALASKA HIGHWAY CORRIDOR}

Mileage (Alaska portion) and kilometre (Canada portion) points used to identify locations along the pipeline route are the same as utilized by TransCanada Pipeline. Mile point AMP-0 is at the start of the route at Prudhoe Bay, Alaska, with kilometre point (BKP-722) being its termination at Boundary Lake, British Columbia, Canada (Figure A3.1.1).

Figure A3.1.2 provides a visual compilation of the differences of layer and resistivity between the eight models, each of which is applied as a zone of resistivity along the pipeline route. 


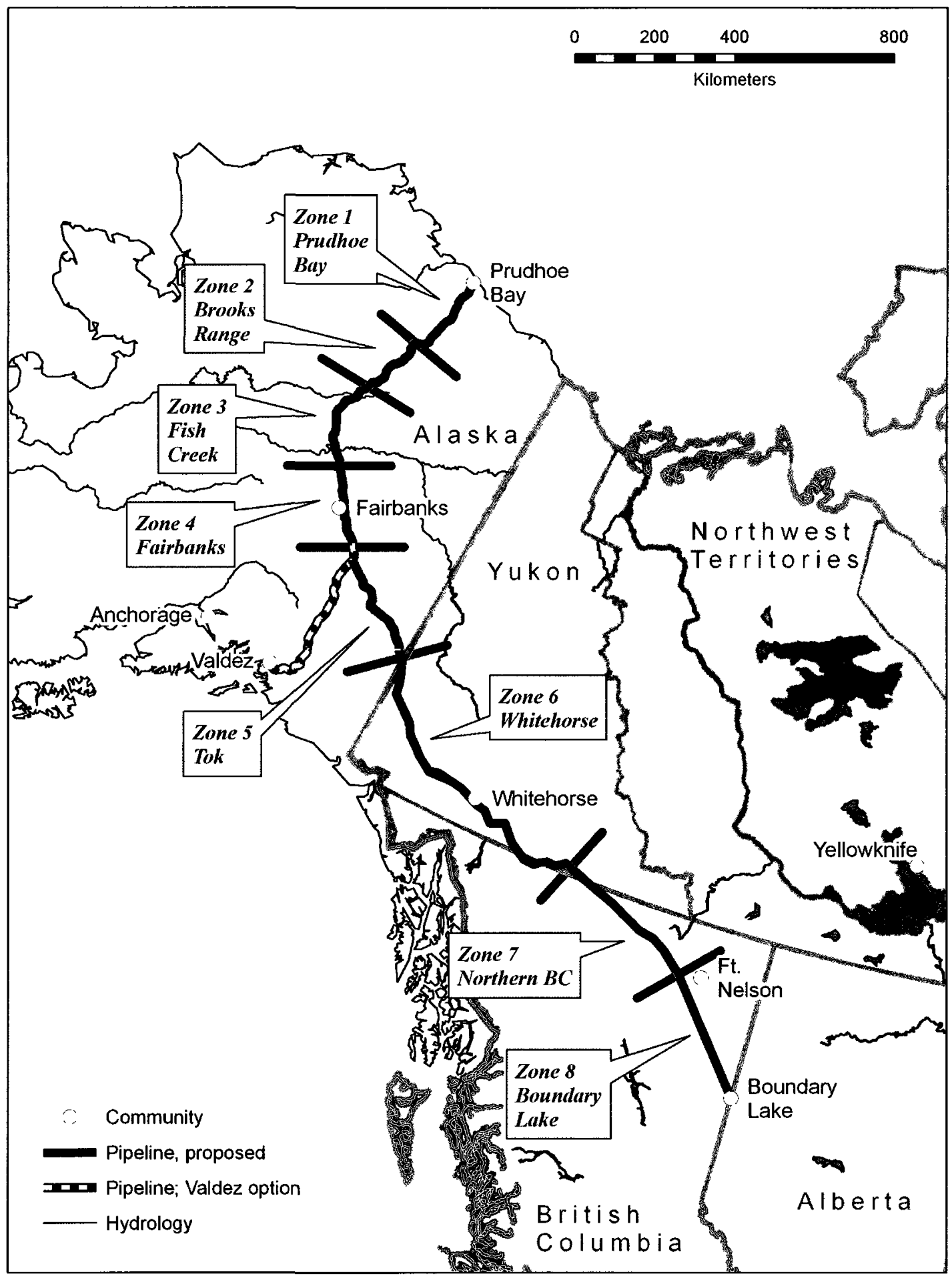

Figure A3.1.1. Zones along the pipeline route used to produce 1D Earth resistivity models. 

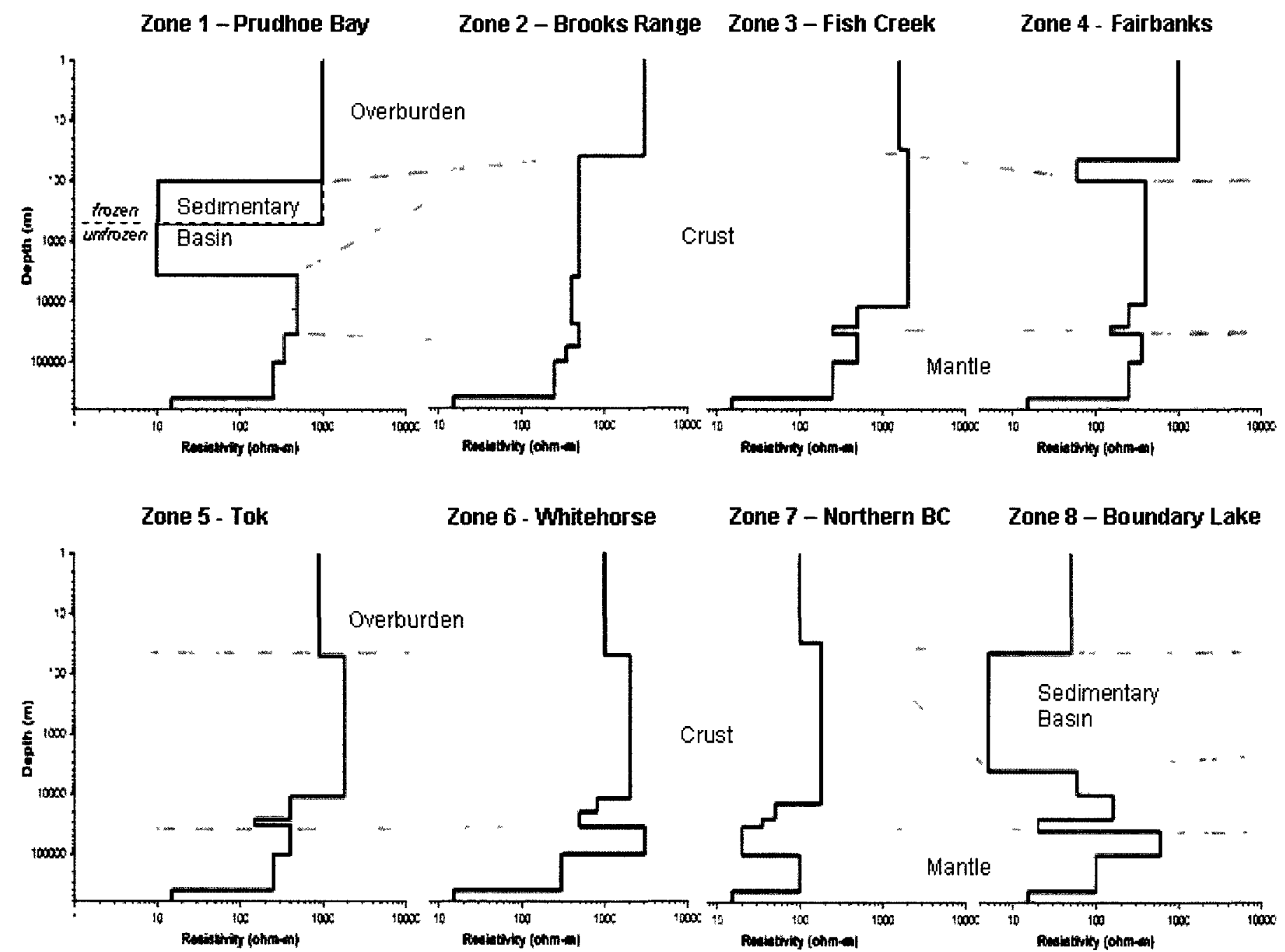

Figure A3.3.2. Compilation of the eight 1D Earth resistivity models along the proposed pipeline route. 
Table A3.1.1. 1D Earth resistivity model for Zone 1 - PRUDHOE BAY

\begin{tabular}{|c|c|c|c|c|c|}
\hline Layer & $\begin{array}{l}\text { Res } \\
(\Omega \mathrm{m} \\
\text { Avg }\end{array}$ & $\begin{array}{l}\text { vity } \\
\text { Range }\end{array}$ & $\begin{array}{l}\text { Determination, } \\
\text { Confidencé }\end{array}$ & $\begin{array}{l}\text { Resistivity } \\
\text { Reference }\end{array}$ & Comments \\
\hline $\begin{array}{l}\text { 1. Overburden } \\
\text { - unconsolidated } \\
\text { stratified sandy- } \\
\text { gravel (Quaternary } \\
\text { Gubik Formation) } \\
\text { ( } 100 \text { m thick) } \\
\text { frozen depth } \\
\sim 500 \mathrm{~m}\end{array}$ & $\begin{array}{r}1000 \\
--\end{array}$ & $\begin{array}{l}1000 \\
\text { to } \\
2000 \\
\text { (well log) } \\
350-1000 \\
\text { rface EM) }\end{array}$ & $\begin{array}{l}\text { well logs } \\
\text { (North Slope) } \\
\text { A }\end{array}$ & $\begin{array}{l}\text { Collett et al } \\
(1988)\end{array}$ & $\begin{array}{l}\text { - depth from cross- } \\
\text { section (Rawlinson, } \\
\text { 1983, Fig.2) } \\
\text { - permafrost depth from } \\
\text { well log Arco Prudhoe } \\
\text { ST-1; 660m max at } \\
\text { North Slope coast } \\
\text { (Rawlinson 1983; } \\
\text { Brown and Krieg, } \\
1983, p .206 ; \text { Collett et } \\
\text { al, } 1988, \text { p.20) } \\
\text { - >1000 } \Omega m \text { for frozen } \\
\text { overburden and } \\
\text { uppermost sandstone } \\
\text { formation (Collett et al, } \\
\text { 1988) } \\
\end{array}$ \\
\hline $\begin{array}{l}\text { 2. Sedimentary } \\
\text { Basin } \\
\text { - shale, siltstone, } \\
\text { sandstone, } \\
\text { (North Slope } \\
\text { Subterrane, } \\
\text { Arctic Alaska } \\
\text { Terrane) } \\
(0.1 \mathrm{~km}-3.6)\end{array}$ & -- & $\begin{array}{l}5-15 \\
\text { upper } \\
\text { 20-200 } \\
\text { lower }\end{array}$ & $\begin{array}{l}\text { well logs } \\
\text { (North Slope) } \\
\text { A }\end{array}$ & $\begin{array}{l}\text { Nelson and Kibler } \\
(2001) ; \text { Kumar et } \\
\text { al (2002); Keller } \\
\text { and Bird (2003); } \\
\text { Magoon et al } \\
\text { (1988) }\end{array}$ & $\begin{array}{l}\text { - basin thickens to } 8 \mathrm{~km} \text {, } \\
\text { southward to Brooks } \\
\text { Range } \\
\text { - basin divisıble into } 7 \\
\text { sub-layers with } \\
\text { average resistivity of } \sim \\
5 \Omega \mathrm{m} \text { in upper half, and } \\
20-200 \Omega \mathrm{m} \text { in bottom } \\
\text { half of basin } \\
\text { - resistivity extrapolated } \\
\text { from wells } 50-120 \mathrm{~km} \\
\text { away } \\
\text { - average resistivity as } \\
\text { mid-point of range from } \\
\text { well logs }\end{array}$ \\
\hline $\begin{array}{l}\text { 3. Upper Crust } \\
\text { - Basement } \\
\text { Complex } \\
\text { (weakly } \\
\text { metamorphosed } \\
\text { sediments, } \\
\pm \text { intrusives) } \\
\\
(3.6-13 \mathrm{~km})\end{array}$ & 500 & $\begin{array}{l}20-30 \\
\text { or } \\
100-1000\end{array}$ & $\begin{array}{l}\text { well logs } \\
\text { (North Slope) } \\
\text { A }\end{array}$ & $\begin{array}{l}\text { Nelson and Kibler } \\
\text { (2001) }\end{array}$ & $\begin{array}{l}\text { Steep dipping argillite, } \\
\text { siltstone, sandstone, } \\
\text { local interbedded } \\
\text { limestone and cherty } \\
\text { conglomerate (Moore } \\
\text { et al, 1994) } \\
\text { - Resistivity extrapolated } \\
\text { from weils } 50-120 \mathrm{~km} \\
\text { away } \\
\text { - Average resistivity } \\
\text { taken as midpoint of } \\
\text { upper range }\end{array}$ \\
\hline $\begin{array}{l}\text { 4. Middle - Lower Crust } \\
(13-33 \mathrm{~km})\end{array}$ & 100 & $\begin{array}{r}25-1000 \\
20-100 \\
10-300\end{array}$ & $\begin{array}{l}\text { MT survey } \\
\text { (SNORCLE) } \\
\text { B } \\
\text { Compilation (regional) } \\
\text { C } \\
\text { Compilation (global) } \\
\text { C }\end{array}$ & $\begin{array}{l}\text { Jones et al } \\
\text { (2005, Fig.7) } \\
\text { Ferguson and } \\
\text { Odwar (1998, } \\
\text { p.42) for range, } \\
\text { northern BC } \\
\text { Simpson and } \\
\text { Bahr (2005, p.11), } \\
\text { mid-lower } \\
\text { continental crust }\end{array}$ & $\begin{array}{l}\text { average resistivity } \\
\text { taken as mid-point of } \\
\text { range from SNORCLE } \\
\text { transect -Corridor } 2 \\
\text { for ancestral North } \\
\text { America }\end{array}$ \\
\hline
\end{tabular}


Table A3.1.1: PRUDHOE BAY continued

\begin{tabular}{|c|c|c|c|c|c|}
\hline $\begin{array}{l}5 . \quad \text { Mantle } \\
(33-100 \mathrm{~km})\end{array}$ & $\begin{array}{l}350 \\
650 \\
300 \\
1000\end{array}$ & $\begin{array}{c}40- \\
-- \\
15-2000\end{array}$ & $\begin{array}{l}\text { MT survey } \\
\text { (SNORCLE) } \\
\text { B } \\
\text { Compilation } \\
\text { (regional) } \\
\text { C } \\
\text { Compllation (global) } \\
\text { C }\end{array}$ & $\begin{array}{l}\text { Jones et al } \\
\text { (2005, Fig.6) } \\
\text { Ferguson and } \\
\text { Odwar (1998, } \\
\text { p.42) for range, } \\
\text { northern BC } \\
\text { Simpson \& Bahr } \\
\text { (2005, p.11) for } \\
\text { range, upper } \\
\text { continental mantle }\end{array}$ & $\begin{array}{l}\text { - depth from Fuis et al } \\
\text { (2008) and Grantz et al } \\
\text { (1991) crustal cross- } \\
\text { sections } \\
\text { - average resistivity taken } \\
\text { as mid-point of range } \\
\text { from SNORCLE } \\
\text { transect-regional profile }\end{array}$ \\
\hline $\begin{array}{l}\text { 6. Mantle } \\
\qquad(100-400 \mathrm{~km})\end{array}$ & $\begin{array}{l}250 \\
100\end{array}$ & -- & $\begin{array}{l}\text { MT survey } \\
\text { (SNORCLE) } \\
\text { B } \\
\text { Compilation } \\
\text { (regional) } \\
\text { C }\end{array}$ & $\begin{array}{l}\text { Jones et al } \\
\text { (2005, Fig.6) } \\
\text { Ferguson and } \\
\text { Odwar (1998, } \\
\text { p.42) for range, } \\
\text { northern BC } \\
\end{array}$ & $\begin{array}{l}\text { average resistivity taken } \\
\text { from dominant resistivity } \\
\text { on SNORCLE transect- } \\
\text { regıonal profile }\end{array}$ \\
\hline $\begin{array}{l}\text { 7. Mantle } \\
(400-600 \mathrm{~km})\end{array}$ & $\begin{array}{l}\sim 15 \\
\sim 5\end{array}$ & 2.6-6.6 & $\begin{array}{l}\text { MT survey } \\
\text { (SNORCLE) } \\
\text { B } \\
\text { Compilation } \\
\text { (regional) } \\
\text { C }\end{array}$ & $\begin{array}{l}\text { Jones et al } \\
(2005, \text { Fig 6) } \\
\text { Jones } \\
(1999, \text { Fig. 9) }\end{array}$ & $\begin{array}{l}\text { - average resistivity taken } \\
\text { as lower end of range } \\
\text { from SNORCLE } \\
\text { transect-regional profile } \\
\text { - range for western North } \\
\text { America; average } \\
\text { resistivity as mid-point of } \\
\text { range }\end{array}$ \\
\hline
\end{tabular}


Table A3.1.2: 1D Earth resistivity model for Zone 2 - BROOKS RANGE

\begin{tabular}{|c|c|c|c|c|}
\hline Layer & $\begin{array}{l}\text { Resistivity } \\
(\Omega \mathrm{m}) \\
\text { Avg Range }\end{array}$ & $\begin{array}{l}\text { Determination, } \\
\text { Confidence }\end{array}$ & $\begin{array}{l}\text { Resistivity } \\
\text { Reference }\end{array}$ & Comments \\
\hline $\begin{array}{l}\text { 1. Overburden } \\
\text { - unconsolidated } \\
\text { gravel, sand and } \\
\text { slit, and tIll } \\
\text { (Quaternary } \\
\text { deposits) } \\
15-40 \mathrm{~m} \\
\text { frozen depth } \\
\text { 15 - } 70 \text { to } 200 \mathrm{~m}\end{array}$ & $\begin{array}{l}\text { Unfrozen gravel } \\
1000500-3000 \\
\text { Frozen gravel } \\
3000800-10000 \\
\text { Unfrozen silty } \\
\text { sand } \\
600 \quad 300-1000 \\
\text { Frozen silty sand } \\
2000 \quad 1000-3000 \\
\text { Unfrozen till } \\
\sim 100 \\
\text { Frozen till } \\
\sim 300 \\
\text { Quaternary } \\
\text { Deposits } \\
1500 \quad 50-3230\end{array}$ & $\begin{array}{l}\text { Compilation (regional) } \\
\text { - as above - } \\
\text { - as above - } \\
\text { - as above - } \\
\text { - as above - } \\
\text { - as above - } \\
\text { MT survey (TACT) } \\
\text { A }\end{array}$ & $\begin{array}{l}\text { Assoc. Mining } \\
\text { (2004) for range; } \\
\text { average is mid- } \\
\text { point } \\
\text { - as above - } \\
\text { - as above - } \\
\text { - as above - } \\
\text { Scott et al (1990) } \\
\text { - as above - } \\
\text { Campbell et al } \\
\text { (2001) }\end{array}$ & $\begin{array}{l}\text { - } 15 \mathrm{~m} \text { minimum depth from } \\
\text { boreholes along TAPS } \\
\text { (Kreig \& Reger 1982, p.73) } \\
\text { - valley floor has } ~ 8 \mathrm{~m} \text { old } \\
\text { alluvium overlain by } \sim 16 \mathrm{~m} \\
\text { modern alluvium, with } \\
16 \mathrm{~m} \text { thick alluvial fans and } \\
\text { colluvium on valley sides } \\
\text { with overlapping alluvium } \\
\text { (Brown \& Kreig, 1983, } \\
\text { p.147) } \\
\text { - permafrost } 15 \mathrm{~m} \text { at Coldfoot } \\
\text { (Kreig and Reger, 1982), } \\
70 \mathrm{~m} \text { in drillhole } 75 \mathrm{~km} \text { west } \\
\text { (Ferrians, 1965), possible } \\
200 \mathrm{~m} \text { at north edge Brooks } \\
\text { Range (Kreig and Reger, } \\
1982 \text { ) } \\
\text { - assigned } 1500 \Omega \mathrm{m} \text { average } \\
\text { based on TACT MT } \\
\text { soundings }\end{array}$ \\
\hline $\begin{array}{l}\text { 2. Sedimentary Basin } \\
\text { (absent) }\end{array}$ & -- & -- & -- & -- \\
\hline $\begin{array}{l}\text { 3a. Upper Crust } \\
(0-4 \mathrm{~km}) \\
\text { - Hammond } \\
\text { Subterrane } \\
0-3.5 \mathrm{~km}\end{array}$ & $15-720$ & $\begin{array}{l}\text { MT survey (TACT) } \\
\text { A }\end{array}$ & $\begin{array}{l}\text { Campbell et al } \\
(2001)\end{array}$ & $\begin{array}{l}\text { - Subterrane and depth from } \\
\text { Fuis et al (2008) crustal } \\
\text { cross section } \\
\text { - weakly metamorphosed } \\
\text { sedimentary rocks; } \\
\text { quartzite, phyllite, schist, } \\
\text { marble, carbonate schist, } \\
\text { metabasalt, tuff, } \\
\text { amphibolite. Devonian to } \\
\text { Proterozoic age (Mull, } \\
\text { 1989) } \\
\text { range and average } \\
\text { resistivity from TACT MT } \\
\text { soundings }\end{array}$ \\
\hline $\begin{array}{l}\text { - Endicott Mountains } \\
\text { Subterrane } \\
(3.5-4 \mathrm{~km})\end{array}$ & $\begin{array}{lr}400 & 15-720 \\
\sim 200 & 40->1000\end{array}$ & $\begin{array}{l}\text { MT survey (TACT) } \\
\text { A } \\
\text { Well logs (North Slope) } \\
\text { B }\end{array}$ & $\begin{array}{l}\text { Campbell et al } \\
\text { (2001) } \\
\text { Magoon et al } \\
\text { (1988, plate 19-16) } \\
\text { Nelson and Kibler } \\
\text { (2001) }\end{array}$ & $\begin{array}{l}\text { metasedimentary rocks; } \\
\text { dolostone, metalimestone, } \\
\text { marble, shale, } \\
\text { conglomerate. Devonian to } \\
\text { Proterozoic age (Till et al } \\
\text { (2008) } \\
\text { - same subterrane near } \\
\text { Prudhoe Bay } \\
\text { - assigned average resistivity } \\
\text { based on mid-point of } \\
\text { TACT MT soundings and } \\
\text { lower end of well log } \\
\text { resistivities }\end{array}$ \\
\hline
\end{tabular}

... Table continued on next page 
Table A3.1.2: BROOKS RANGE continued

\begin{tabular}{|c|c|c|c|c|c|}
\hline \multirow[t]{2}{*}{$\begin{array}{l}\text { 3b. Upper Crust } \\
\text { - Basement } \\
\text { Complex } \\
\text { metasedimentary, } \\
\text { metavolcanic and } \\
\text { plutonic rocks }\end{array}$} & \multirow[t]{2}{*}{500} & \multirow[t]{2}{*}{$15-720$} & \multirow[t]{2}{*}{$\begin{array}{l}\text { MT survey (TACT) } \\
\text { A } \\
\text { well logs (North Slope) } \\
\text { B }\end{array}$} & $\begin{array}{l}\text { Campbell et al } \\
(2001) \\
\text { Nelson and Kıbler } \\
(2001)\end{array}$ & $\begin{array}{l}\text { - } 24 \mathrm{~km} \text { depth from Fuis et al } \\
\text { (2008), incorporates the } \\
\text { Cenozoic duplex zone } \\
\text { - Layer equivalent to } \\
\text { Basement Complex in } \\
\text { Zone } 1 \\
\text { - well logs show variable } \\
\text { resistivity ranges, from }\end{array}$ \\
\hline & & & & \multicolumn{2}{|c|}{$\begin{array}{l}\text { - wells situated } 100-300 \mathrm{~km} \text { from pipeline route; } \\
\text { average resistivity taken as mid-point of range } \\
\text { - average resistivity taken as upper point of range } \\
\text { - assigned average resıstıvity on basis of TACT MT } \\
\text { soundıngs }\end{array}$} \\
\hline \multirow[t]{3}{*}{$\begin{array}{l}\text { 4. Middle-Lower Crust } \\
\qquad(24-57 \mathrm{~km})\end{array}$} & 500 & $25-1000$ & $\begin{array}{l}\text { MT survey (SNORCLE) } \\
\text { B }\end{array}$ & $\begin{array}{l}\text { Jones et al } \\
(2005, \text { Fig } 7)\end{array}$ & $\begin{array}{l}\text { - depth from Fuls et al (2008) } \\
\text { and Grantz et al (1991) } \\
\text { crustal cross-sections }\end{array}$ \\
\hline & 100 & $20-100$ & $\begin{array}{l}\text { Compilation (regional) } \\
\text { C }\end{array}$ & $\begin{array}{l}\text { Ferguson and } \\
\text { Odwar }(1998, p 42) \\
\text { for range, northern } \\
B C\end{array}$ & $\begin{array}{l}\text { doubling of crustal } \\
\text { thickness due North Slope } \\
\text { lithosphere indentıng } \\
\text { ancestral North America }\end{array}$ \\
\hline & -- & $10-300$ & $\begin{array}{l}\text { Compilation (global) } \\
\mathrm{C}\end{array}$ & $\begin{array}{l}\text { Simpson and Bahr } \\
(2005, \text { p.11), mid- } \\
\text { lower continental } \\
\text { crust }\end{array}$ & $\begin{array}{l}\text { - average resistivity taken as } \\
\text { mid-point of range from } \\
\text { SNORCLE transect - } \\
\text { Corridor } 2, \text { for ancestral } \\
\text { North America }\end{array}$ \\
\hline \multirow[t]{3}{*}{$\begin{array}{l}\text { 5. Mantle } \\
\qquad(57-100 \mathrm{~km})\end{array}$} & 350 & $40-650$ & $\begin{array}{l}\text { MT survey (SNORCLE) } \\
\text { B }\end{array}$ & $\begin{array}{l}\text { Jones et al } \\
(2005, \text { Fig.6) }\end{array}$ & $\begin{array}{l}\text { - depth from Fuis et al (2008) } \\
\text { and Grantz et al (1991) } \\
\text { crustal cross-sections }\end{array}$ \\
\hline & 300 & --- & $\begin{array}{l}\text { Compilation (regional) } \\
\text { C }\end{array}$ & $\begin{array}{l}\text { Ferguson and } \\
\text { Odwar (1998, p.42) } \\
\text { for range, northern } \\
B C\end{array}$ & $\begin{array}{l}\text { - average resistivity taken as } \\
\text { mid-point of range from } \\
\text { SNORCLE transect- } \\
\text { regional profile }\end{array}$ \\
\hline & 1000 & $15-2000$ & $\begin{array}{l}\text { Compilation (global) } \\
\mathrm{C}\end{array}$ & $\begin{array}{l}\text { Simpson \& Bahr } \\
(2005, \text { p.11) for } \\
\text { range, upper } \\
\text { continental mantle }\end{array}$ & \\
\hline \multirow[t]{3}{*}{$\begin{array}{l}\text { 6. Mantle } \\
(100-400 \mathrm{~km})\end{array}$} & 250 & $40-650$ & $\begin{array}{l}\text { MT survey (SNORCLE) } \\
\text { B }\end{array}$ & $\begin{array}{l}\text { Jones et al } \\
(2005, \text { Fig.6) }\end{array}$ & $\begin{array}{l}\text { average resistivity taken } \\
\text { from dominant resistivity on } \\
\text { SNORCLE transect- }\end{array}$ \\
\hline & $\sim 100$ & -- & $\begin{array}{l}\text { MT survey } \\
\text { B }\end{array}$ & $\begin{array}{l}\text { Jones et al ( } 2005 \text {, } \\
\text { p. } 1266) \text { for range, } \\
\text { SNORCLE } \\
\text { transect }\end{array}$ & \\
\hline & 100 & -- & $\begin{array}{l}\text { Compilation (regional) } \\
\mathrm{C}\end{array}$ & $\begin{array}{l}\text { Ferguson and } \\
\text { Odwar (1998, p.42) } \\
\text { for range, northern } \\
\text { BC }\end{array}$ & \\
\hline \multirow[t]{2}{*}{$\begin{array}{l}\text { 7. Mantle } \\
\qquad(400-600 \mathrm{~km})\end{array}$} & $\sim 15$ & $15-40$ & $\begin{array}{l}\text { MT survey (SNORCLE) } \\
\text { B }\end{array}$ & $\begin{array}{l}\text { Jones et al } \\
(2005, \text { Fig.6) }\end{array}$ & $\begin{array}{l}\text { - average resistivity taken as } \\
\text { lower end of range from } \\
\text { SNORCLE transect- } \\
\text { regional profile }\end{array}$ \\
\hline & $\sim 5$ & $2.6-6.6$ & $\begin{array}{l}\text { Compllation (regional) } \\
\text { C }\end{array}$ & $\begin{array}{l}\text { Jones } \\
\text { (1999, Fig. 9) }\end{array}$ & $\begin{array}{l}\text { - range for western North } \\
\text { America; average resistivity } \\
\text { as mid-point of range }\end{array}$ \\
\hline
\end{tabular}


Table A3.1.3: 1D Earth resistivity model for Zone 3 - FISH CREEK

\begin{tabular}{|c|c|c|c|c|}
\hline Layer & $\begin{array}{l}\text { Resistivity } \\
(\Omega \mathrm{m}) \\
\text { Avg Range }\end{array}$ & $\begin{array}{l}\text { Determination, } \\
\text { Confidence }\end{array}$ & $\begin{array}{l}\text { Resistivity } \\
\text { Reference }\end{array}$ & Comments \\
\hline $\begin{array}{l}1 \text { Overburden } \\
\text { unconsolıdated } \\
\text { colluvium, } \\
\text { windblown silt, } \\
\text { terrace sands \& } \\
\text { gravels, till } \\
\text { (Quaternary deposits) } \\
15-30 \mathrm{~m} \\
\text { frozen depth } \\
\sim 15-120 \mathrm{~m}\end{array}$ & $\begin{array}{l}\text { Unfrozen gravel } \\
1000500-3000 \\
\text { Frozen gravel } \\
3000800-10000 \\
\text { Unfrozen silty } \\
\text { sand } \\
600 \quad 300-1000 \\
\text { Frozen silty sand } \\
2000 \quad 1000-3000 \\
\text { Unfrozen till } \\
\sim 100 \\
\text { Frozen tIll } \\
\sim 300 \\
\text { Quaternary } \\
\text { Deposits } \\
1500 \quad 550-1600\end{array}$ & $\begin{array}{l}\text { Compilation (regional) } \\
\text { C } \\
\text { - as above - } \\
\text { - as above - }\end{array}$ & $\begin{array}{l}\text { Assoc Mining } \\
\text { (2004) for range, } \\
\text { average is mid- } \\
\text { point } \\
\text { - as above - } \\
\text { - as above - } \\
\text { - as above - } \\
\text { Scott et al (1990) }\end{array}$ & $\begin{array}{l}\text { - unknown thickness for } \\
\text { Kettle Moraine Complex till, } \\
\text { at north end of zone } \\
\text { (Tramway Flats lowland), } \\
\text { terrace sands/gravels up to } \\
23 m \text { thick } \\
\text { - colluvium is dominant along } \\
\text { slopes and covers much of } \\
\text { zone, up to } 15 \mathrm{~m} \text { thick } \\
\text { - silt covers southern-thırd of } \\
\text { zone, up to } 30 \mathrm{~m} \text { thick } \\
\text { (Kachadoorian, } 1971 \mathrm{a}, \mathrm{b}) \\
\text { - northern end of zone } \\
\text { (Tramway Flats lowlands) } \\
\text { mostly underlain by } \\
\text { permafrost up to } 120 \mathrm{~m} \text { thick } \\
\text { (Ferrians, } 1965 \text { ) } \\
\text { - massive ice wedges and } \\
\text { lenses ( up to } 17 \mathrm{~m} \text { thick) } \\
\text { common in frozen silt in } \\
\text { southern half of zone } \\
\text { - average resistıvity taken as } \\
\text { upper end of MT } \\
\text { measurements }\end{array}$ \\
\hline $\begin{array}{l}\text { 2. Sedımentary Basın } \\
\text { (absent) }\end{array}$ & --- & --- & --- & -- \\
\hline $\begin{array}{l}\text { 3. Upper Crust } \\
\text { - Basement } \\
\text { Complex } \\
\text { metasedımentary, } \\
\text { plutonic and } \\
\text { metavolcanic rocks } \\
\text { (Tozitna and Ruby } \\
\text { Terranes) }\end{array}$ & $\begin{array}{l}1800 \\
450 \quad 250-650 \\
\text { (overall range) } \\
3050 \quad 1600-4500 \\
\text { (plutonic rock) }\end{array}$ & $\begin{array}{l}\text { MT survey (TACT) } \\
\text { A }\end{array}$ & $\begin{array}{l}\text { Campbell et al } \\
\text { (2001) }\end{array}$ & $\begin{array}{l}\text { depth from Fuis et al (2008) } \\
\text { crustal cross-section } \\
\text { - predomınately Ruby } \\
\text { Terrane metasediments } \\
\text { (phyllite, schist, marble, } \\
\text { quartzite, calc-schist, } \\
\text { amphibolite) with extensive } \\
\text { granite gneiss intrusıons, } \\
\text { and Tozitna Terrane mafic } \\
\text { volcanıcs }\end{array}$ \\
\hline & & \multicolumn{3}{|c|}{$\begin{array}{l}\text { - Includes lesser metasedımentary terranes, Angayucham, Slate Creek, Prospect } \\
\text { Creek, Livengood, Manley, White Mountain and Wickersham } \\
\text { - varıable resıstivitıes from prelımınary ID models from TACT MT soundıngs, } \\
\text { strongly anısotropıc } \\
\text { - possible zone of higher resıstıvity 6-8km depth, average } 2500 \Omega \mathrm{m} \\
\text { - assigned resıstivity of } 1800 \Omega \mathrm{m} \text {, by takıng average of non-plutonıc rock (450) } \\
\text { and plutonıc rock ( } 3500 \text { ) from MT soundings, higher resistivity at depth and } \\
\text { presence of intrusives }\end{array}$} \\
\hline
\end{tabular}

... Table continued on next page 
Table A3.1.3: FISH CREEK continued

\begin{tabular}{|c|c|c|c|c|c|}
\hline $\begin{array}{l}\text { 4. Middle Crust } \\
\text { - Felsıc rocks } \\
(12-26 \mathrm{~km})\end{array}$ & $\begin{array}{l}-- \\
500 \\
100 \\
120\end{array}$ & $\begin{array}{c}10-100 \\
\text { lower curve } \\
120-820 \\
\text { upper curve } \\
20-100 \\
\\
10-300\end{array}$ & $\begin{array}{l}\text { Compilation (regional) } \\
\text { C } \\
\text { Compilation (global) } \\
\text { C }\end{array}$ & $\begin{array}{l}\text { Campbell et al } \\
\text { (2001) } \\
\text { Ferguson and } \\
\text { Odwar (1998, p 48) } \\
\text { for range, northern } \\
\text { BC } \\
\text { Simpson \& Bahr } \\
\text { (2005, p.11) for } \\
\text { range, mid-lower } \\
\text { continental crust }\end{array}$ & $\begin{array}{l}\text { - depth from Fuis et al (2008) } \\
\text { crustal cross-section } \\
\text { - extremely variable } \\
\text { resistivities from prelımınary } \\
1 \mathrm{D} \text { models from TACT MT } \\
\text { soundings, strongly } \\
\text { anisotropic } \\
\text { - assigned average resistivity } \\
\text { of } 500 \Omega \mathrm{m} \text { on basis of MT } \\
\text { soundıngs indicating higher } \\
\text { resistivity possıbly } \\
\text { perpendicular to pipeline } \\
\text { route }\end{array}$ \\
\hline $\begin{array}{l}\text { 5. Lower Crust } \\
\text { - Mafic rocks } \\
(26-34 \mathrm{~km})\end{array}$ & $\begin{array}{l}-- \\
-- \\
--\end{array}$ & $\begin{array}{c}10-100 \\
2000-8000 \\
20-100 \\
\\
10-300\end{array}$ & $\begin{array}{l}\text { MT survey (TACT) } \\
\text { A } \\
\text { Compilation (regional) } \\
\text { C } \\
\text { Compilation (global) } \\
\text { C }\end{array}$ & $\begin{array}{l}\text { Campbell et al } \\
\text { (2001) } \\
\text { Ferguson and } \\
\text { Odwar (1998,p.48) } \\
\text { for range, northern } \\
\text { BC } \\
\text { Simpson \& Bahr } \\
(2005, \text { p.11) for } \\
\text { range, mid-lower } \\
\text { continental crust }\end{array}$ & $\begin{array}{l}\text { - depth from Fuis et al (2008) } \\
\text { crustal cross-section } \\
\text { - extremely variable } \\
\text { resistivities from preliminary } \\
1 D \text { models from TACT MT } \\
\text { soundings, strongly } \\
\text { anisotropic } \\
\text { - assigned higher end of } \\
\text { global range resistivity } \\
250 \Omega \text { m on basis of MT } \\
\text { sounding indicating higher } \\
\text { resistivity }\end{array}$ \\
\hline $\begin{array}{l}\text { 6. Mantle } \\
(34-100 \mathrm{~km})\end{array}$ & $\begin{array}{l}830 \mathrm{~m} \\
500 \mathrm{~m} \\
- \\
1000 \\
500 \\
300 \\
1000\end{array}$ & $\begin{array}{l}\text { lean } \\
\text { ledian } \\
15-2200 \\
\sim 100-3000 \\
(40 \mathrm{~km}) \\
\sim 30-300 \\
(100 \mathrm{~km}) \\
\cdots \\
\\
15-2000\end{array}$ & $\begin{array}{l}\text { MT survey (TACT) } \\
\text { A } \\
\text { MT survey (SNORCLE) } \\
\text { B } \\
\text { Compilation (regional) } \\
\text { C } \\
\text { Compilation (global) } \\
\text { C }\end{array}$ & $\begin{array}{l}\text { Campbell et al } \\
\text { (2001) } \\
\text { Jones et al (2005), } \\
\text { Fig. 4) } \\
\text { Ferguson and } \\
\text { Odwar (1998, p.42) } \\
\text { for range, northern } \\
\text { BC } \\
\text { Simpson \& Bahr } \\
\text { (2005, p 11) for } \\
\text { range, upper } \\
\text { continental mantle }\end{array}$ & $\begin{array}{l}\text { - depth from Fuis et al (2008) } \\
\text { crustal cross-section } \\
\text { - Averaged resıstıvity ranges } \\
\text { at } 40 \text { and } 100 \mathrm{~km} \text { depths } \\
\text { from SNORCLE transect in } \\
\text { Whitehorse area } \\
\text { - assigned median resistivity } \\
500 \Omega m \text { on basis of MT } \\
\text { soundıngs indicatıng higher } \\
\text { resistivity }\end{array}$ \\
\hline $\begin{array}{l}\text { 7. Mantle } \\
\qquad(100-400 \mathrm{~km})\end{array}$ & $\begin{array}{l}250 \\
100\end{array}$ & -- & $\begin{array}{l}\text { MT survey (SNORCLE) } \\
\text { B } \\
\text { Compilation (regional) } \\
\text { C }\end{array}$ & $\begin{array}{l}\text { Jones et al } \\
\text { (2005, Fig.6) } \\
\text { Ferguson and } \\
\text { Odwar (1998, p 42) } \\
\text { for range, northern } \\
\text { BC }\end{array}$ & $\begin{array}{l}\text { - average resistıvity taken } \\
\text { from dominant resistivity on } \\
\text { SNORCLE transect- } \\
\text { regional profile }\end{array}$ \\
\hline $\begin{array}{l}\text { 8. Mantle } \\
\qquad(400-600 \mathrm{~km})\end{array}$ & $\begin{array}{l}\sim 15 \\
\sim 5\end{array}$ & $2.6-6.6$ & $\begin{array}{l}\text { MT survey (SNORCLE) } \\
\text { B } \\
\text { Complation (regional) } \\
\text { C }\end{array}$ & $\begin{array}{l}\text { Jones } \\
(1999, \text { Fig. } 9)\end{array}$ & $\begin{array}{l}\text { - average resistivity taken as } \\
\text { lower end of range from } \\
\text { SNORCLE transect- } \\
\text { regional profile } \\
\text { - range for western North } \\
\text { America; average resistivity } \\
\text { as mid-point of range } \\
\end{array}$ \\
\hline
\end{tabular}


Table A3.1.4: 1D Earth resistivity model for Zone 4 - FAIRBANKS

\begin{tabular}{|c|c|c|c|c|}
\hline Layer & 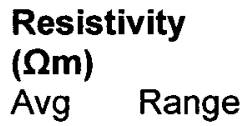 & $\begin{array}{l}\text { Determination, } \\
\text { Confidence }\end{array}$ & $\begin{array}{l}\text { Resistivity } \\
\text { Reference }\end{array}$ & Comments \\
\hline 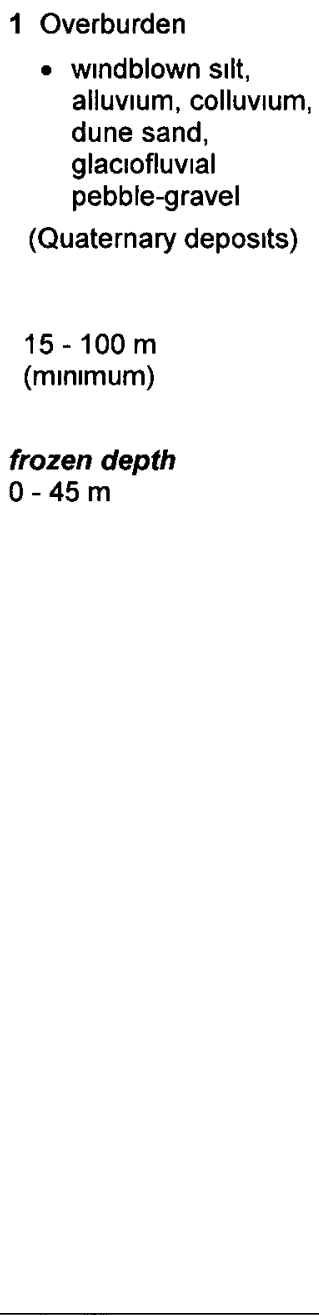 & 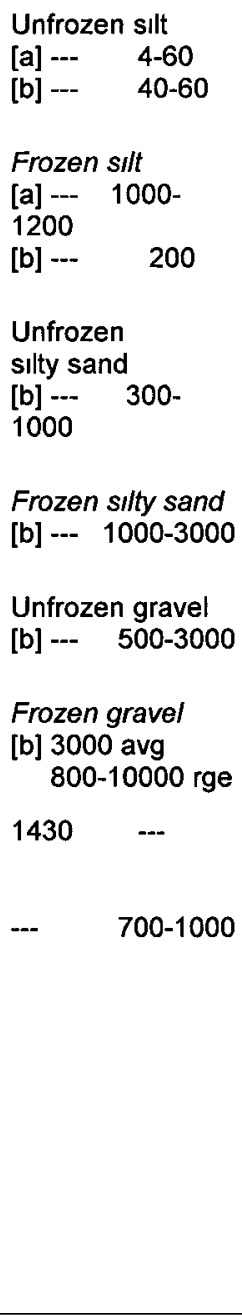 & $\begin{array}{l}\text { - lowlands (Tanana R } \\
\text { numerous Isolated } \\
\text { - single TACT-AMT s } \\
1430 \Omega \mathrm{m} \text { to } 55 \mathrm{~m} \text { de } \\
\text { - assigned maximum } \\
\text { range of frozen ove } \\
\text { and possible confirn } \\
\text { - assigned resistivity }\end{array}$ & $\begin{array}{l}\text { Campbell et al } \\
(2001) \\
\text { Burns et al } \\
(2006 a, b) \text {, } \\
\text { for range } \\
\text { alley, southeastwaro } \\
\text { es of permafrost, up t } \\
\text { ng at northern end o } \\
\text { afrost depth } 45 \mathrm{~m} \text {, an } \\
\text { en - on basis of airbc } \\
\text { by AMT sounding } \\
\Omega m \text { for unfrozen silt }\end{array}$ & $\begin{array}{l}\text { - bedrock hill slopes } \\
\text { generally permafrost free, } \\
\text { covered by wind-blown } \\
\text { loess, lowland slopes, } \\
\text { creek valleys and river } \\
\text { floodplains typically } \\
\text { underlain by permafrost, ice } \\
\text { rich (Brown and Kreıg, } \\
\text { 1983) } \\
\text { - windblown silt predomınant } \\
\text { in northern-third of zone, up } \\
\text { to } 30 \mathrm{~m} \text { thick, colluvium on } \\
\text { slopes, up to } 15 \text { m thick } \\
\text { (Kachadoorian, } 1971 \mathrm{c} \text { ) } \\
\text { central-third of zone } \\
\text { covered mainly by wind- } \\
\text { blown silt, up to } 60 \mathrm{~m} \text { thick, } \\
\text { coarse alluvium along } \\
\text { Tanana River, } 60-200 \mathrm{~m} \\
\text { thick, with lesser colluvium, } \\
\text { up to } 3 \mathrm{~m} \text { thick (Weber, } \\
\text { 1971a) } \\
\text { southern-third of zone } \\
\text { covered by frozen silt, up to } \\
90 \mathrm{~m} \text { thick, and dune sand, } \\
\text { up to } 60 \mathrm{~m} \text { thick (Weber, } \\
1971 \mathrm{a} \text { ) }\end{array}$ \\
\hline $\begin{array}{l}\text { 2. Sedımentary Basın } \\
\text { (absent) }\end{array}$ & --- & --- & $\cdots$ & --- \\
\hline
\end{tabular}

... Table continued on next page 
Table A3.1.4: FAIRBANKS continued

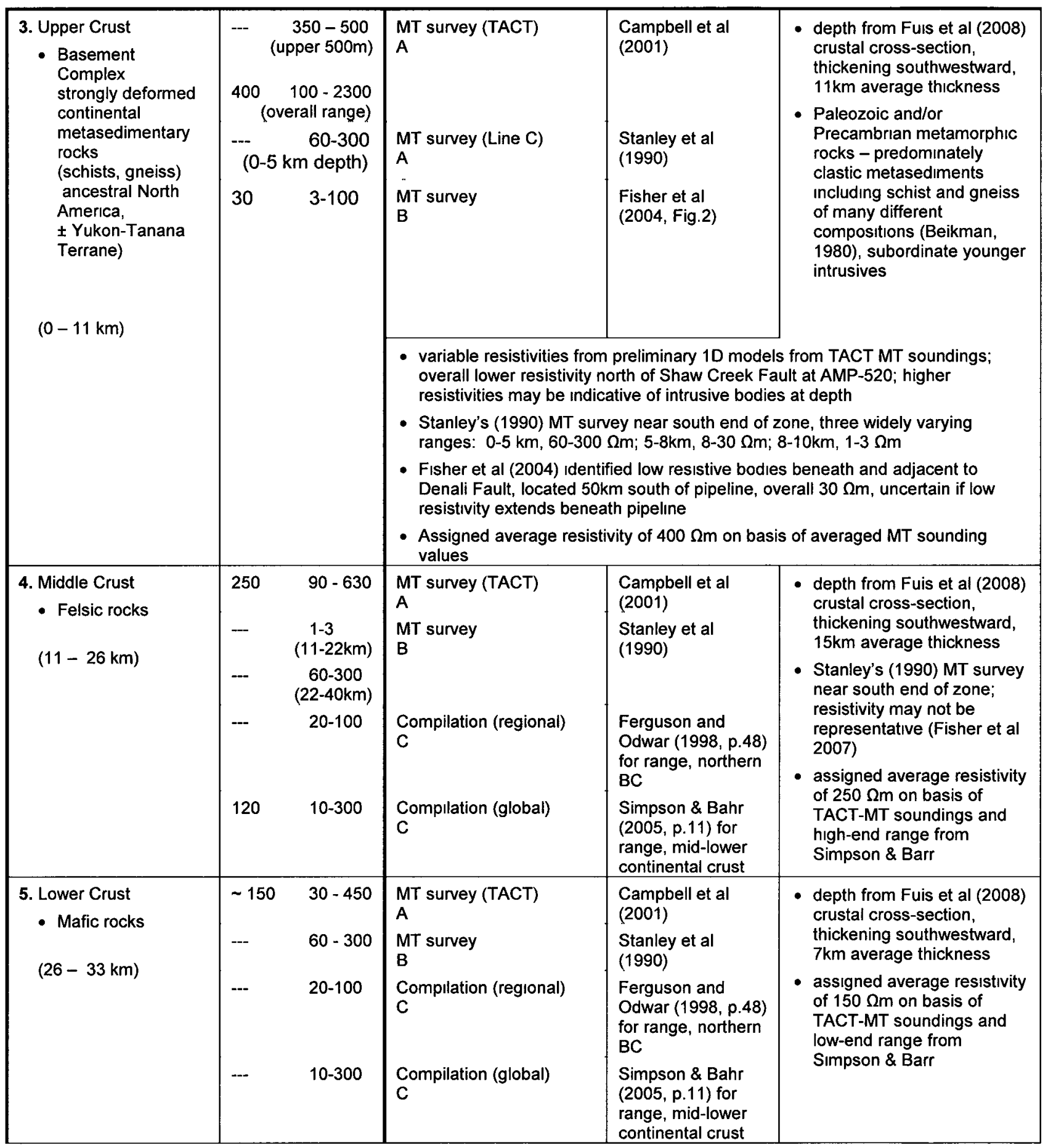

... Table continued on next page 
Table A3.1.4: FAIRBANKS continued

\begin{tabular}{|c|c|c|c|c|c|}
\hline $\begin{array}{l}\text { 6. Mantle } \\
\qquad(33-100 \mathrm{~km})\end{array}$ & $\begin{array}{l}350 \\
300 \\
1000\end{array}$ & 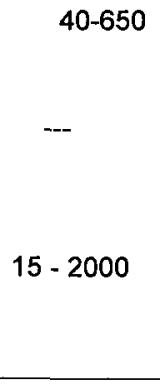 & $\begin{array}{l}\text { MT survey (SNORCLE) } \\
\text { B } \\
\text { Compilation (regional) } \\
\text { C } \\
\text { Compilation (global) } \\
\text { C }\end{array}$ & $\begin{array}{l}\text { Jones et al } \\
\text { (2005, Fig.6) } \\
\text { Ferguson and } \\
\text { Odwar }(1998, \text { p.42) } \\
\text { for range, northern } \\
\text { BC } \\
\text { Simpson \& Bahr } \\
\text { (2005, p 11) for } \\
\text { range, upper } \\
\text { continental mantle }\end{array}$ & $\begin{array}{l}\text { average resistivity taken } \\
\text { from dominant resistivity on } \\
\text { SNORCLE transect- } \\
\text { regional profile }\end{array}$ \\
\hline $\begin{array}{l}\text { 7. Mantle } \\
\qquad(100-400 \mathrm{~km})\end{array}$ & $\begin{array}{l}250 \\
100\end{array}$ & $40-650$ & $\begin{array}{l}\text { MT survey (SNORCLE) } \\
\text { B } \\
\text { Compilation (regional) } \\
\text { C }\end{array}$ & $\begin{array}{l}\text { Jones et al } \\
(2005, \text { Fig.6) } \\
\text { Ferguson and } \\
\text { Odwar (1998, p.42) } \\
\text { for range, northern } \\
\text { BC }\end{array}$ & $\begin{array}{l}\text { average resistivity taken } \\
\text { from dominant resistivity on } \\
\text { SNORCLE transect- } \\
\text { regional profile }\end{array}$ \\
\hline $\begin{array}{l}\text { 8. Mantle } \\
\qquad(400-600 \mathrm{~km})\end{array}$ & $\begin{array}{l}\sim 15 \\
\sim 5\end{array}$ & $\begin{array}{l}15-40 \\
2.6-6.6\end{array}$ & $\begin{array}{l}\text { MT survey (SNORCLE) } \\
\text { B } \\
\text { Compilation (regional) } \\
\text { C }\end{array}$ & $\begin{array}{l}\text { Jones et al } \\
(2005, \text { Fig.6) } \\
\text { Jones } \\
\text { (1999, Fig. 9) }\end{array}$ & $\begin{array}{l}\text { - average resistivity taken as } \\
\text { lower end of range from } \\
\text { SNORCLE transect- } \\
\text { regional profile } \\
\text { - range for western North } \\
\text { America; average resistivity } \\
\text { as mid-point of range }\end{array}$ \\
\hline
\end{tabular}


Table A3.1.5: 1D Earth resistivity model for Zone 5 - TOK

\begin{tabular}{|c|c|c|c|c|}
\hline Layer & $\begin{array}{l}\text { Resistivity } \\
(\Omega \mathrm{m}) \\
\text { Avg Range }\end{array}$ & $\begin{array}{l}\text { Determination, } \\
\text { Confidence }\end{array}$ & $\begin{array}{l}\text { Resistivity } \\
\text { Reference }\end{array}$ & Comments \\
\hline \multirow[t]{2}{*}{$\begin{array}{l}1 \text { Overburden } \\
\text { - unconsolıdated, } \\
\text { stratıfied pebble- } \\
\text { gravel, some sand } \\
\text { and silt } \\
\text { (Quaternary deposits) }\end{array}$} & 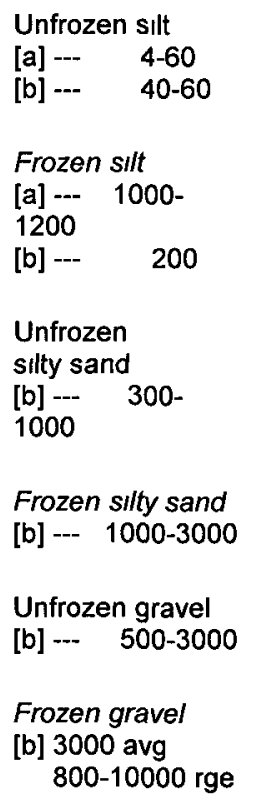 & $\begin{array}{l}\text { Compilation (regional) } \\
\text { C }\end{array}$ & $\begin{array}{l}\text { [a] Mackay (1970), } \\
\text { [b] Assoc Mınıng } \\
\text { (2004) }\end{array}$ & $\begin{array}{l}\text { - northwest end of zone } \\
\text { underlaın by glaciofluvial } \\
\text { deposits (stratified outwash } \\
\text { gravels with some sand), } \\
\text { sporadically frozen (10-50\% } \\
\text { permafrost) with low to } \\
\text { moderate Ice content } \\
\text { (Reger and Solıe, 2008) } \\
\text { - west-central part of zone } \\
\text { underlaın by mix of river } \\
\text { and creek alluvium } \\
\text { (predominant), glaciofluvial } \\
\text { deposits and colluvium, } \\
\text { discontınuously frozen (50 } \\
\text {-90\% permafrost) with low } \\
\text { to moderate ice content } \\
\text { (Reger and Solie, 2008) } \\
\text { - east-central half of zone } \\
\text { underlaın by alluvial fans, } \\
\text { some colluvium, floodplain } \\
\text { alluvium in the upper } \\
\text { Tanana River valley, and at } \\
\text { extreme southeast end is } \\
\text { windblown sand Mınımum } \\
\text { thickness of deposits varies } \\
\text { from } 30 \text { to } 50 \text { m (Carrara, } \\
2007 \text { ) }\end{array}$ \\
\hline & & \multicolumn{3}{|c|}{$\begin{array}{l}\text { - permafrost minımum depth } 6 \mathrm{~m} \text { (Reger and Solıe, 2008), drill holes Indicate } \\
\text { depths of } 37 \mathrm{~m} \text { near Tok (Reger and Solie, 2008), and } 27-63 \mathrm{~m} \text { at Northway } \\
\text { Junction area (Ferrians, 1965) } \\
\text { - numerous Isolated masses of permafrost underlie the Alaska Highway } \\
\text { - assıgned resistivity based on mid-point of aurborne EM survey }\end{array}$} \\
\hline $\begin{array}{l}\text { 2. Sedımentary Basın } \\
\text { (absent) }\end{array}$ & -- & --- & $\ldots$ & -- \\
\hline
\end{tabular}

... Table continued on next page 
Table A3.1.5: TOK continued

\begin{tabular}{|c|c|c|c|c|c|}
\hline \multirow[t]{2}{*}{$\begin{array}{l}\text { 3. Upper Crust } \\
\text { - Basement } \\
\text { Complex: } \\
\text { strongly deformed } \\
\text { continental } \\
\text { metasedimentary } \\
\text { (schists \& gneiss), } \\
\text { plutonıc and } \\
\text { volcanic rocks } \\
\text { (Yukon-Tanana } \\
\text { Terrane) }\end{array}$} & $\begin{array}{l}-- \\
1800 \\
-- \\
(0-1 \\
30\end{array}$ & $\begin{array}{r}350-500 \\
\text { upper } 500 \mathrm{~m} \text { ) } \\
1000-8700 \\
\text { verall range) } \\
200-10000 \\
\mathrm{~km} \text { depth) } \\
3-100 \\
\sim 600-6000\end{array}$ & $\begin{array}{l}\text { MT survey (TACT) } \\
\text { A } \\
\text { MT survey (Line D) } \\
\text { A } \\
\text { MT survey } \\
\text { B } \\
\text { MT survey (SNORCLE) } \\
\text { B }\end{array}$ & $\begin{array}{l}\text { Campbell et al } \\
\text { (2001) } \\
\text { Stanley et al } \\
\text { (1990), for range } \\
\text { Fisher et al } \\
\text { (2004, Fig. 2) } \\
\text { Jones et al (2005), } \\
\text { Fig. 4) }\end{array}$ & $\begin{array}{l}\text { - extrapolated depth from } \\
\text { Fuis et al (2008) crustal } \\
\text { cross-section, 11km } \\
\text { average thickness; MT } \\
\text { survey (Stanley et al, 1990) } \\
\text { shows dramatic resistivity } \\
\text { contrast at } 11 \mathrm{~km} \text { depth } \\
\text { - Paleozoic and/or } \\
\text { Precambrian metamorphic } \\
\text { rocks - predomınately } \\
\text { clastic metasediments } \\
\text { including schist and gneiss } \\
\text { of many different } \\
\text { compositions (Beikman, } \\
\text { 1980); extensive Paleozoic } \\
\text { and Mesozoic felsic } \\
\text { intrusives (granite to } \\
\text { granodiorite) occupy about } \\
\text { half of zone; younger } \\
\text { Tertiary and Paleozolc } \\
\text { volcanic rocks (basalts) } \\
\text { within the intrusives }\end{array}$ \\
\hline & & & \multicolumn{3}{|c|}{$\begin{array}{l}\text { - variable resistivities from preliminary } 1 \mathrm{D} \text { models from TACT MT soundings } \\
\text { - Stanley's (1990) MT survey -Line D - crosses central portion of zone } \\
\text { - Fisher et al (2004) identified low resistive bodies beneath and adjacent to } \\
\text { Denali Fault, located } 50 \mathrm{~km} \text { south of pipeline, overall } 30 \Omega \mathrm{m} \text {, uncertain if low } \\
\text { resistivity extends beneath pipeline } \\
\text { - SNORCLE MT survey shows averaged resistivity at } 5 \mathrm{~km} \text { depth in Whitehorse } \\
\text { area } \\
\text { - Assigned average resistivity of } 1800 \Omega \mathrm{m} \text { on basis of overall averaged MT } \\
\text { soundıng values, reflecting extensive exposure of intrusive rocks }\end{array}$} \\
\hline $\begin{array}{l}\text { 4. Middle Crust } \\
\text { - Felsic rocks }\end{array}$ & & $\begin{array}{c}90-740 \\
1-3 \\
(11-22 \mathrm{~km}) \\
\sim 300-3000 \\
20-100\end{array}$ & $\begin{array}{l}\text { MT survey (TACT) } \\
\text { A } \\
\text { MT survey (Line D) } \\
\text { A } \\
\text { MT survey (SNORCLE) } \\
\text { B } \\
\text { Compilation (regional) } \\
\text { C }\end{array}$ & $\begin{array}{l}\text { Campbell et al } \\
(2001) \\
\text { Stanley et al } \\
\text { (1990) } \\
\text { Jones et al (2005), } \\
\text { Fig. 4) } \\
\text { Ferguson and } \\
\text { Odwar (1998, p.48) } \\
\text { for range, northern } \\
\text { BC } \\
\text { Simpson \& Bahr } \\
\text { (2005, p.11) for } \\
\text { range, mid-lower } \\
\text { continental crust }\end{array}$ & $\begin{array}{l}\text { - extrapolated depth from } \\
\text { Fuis et al (2008) crustal } \\
\text { cross-section, 15km } \\
\text { average thickness } \\
\text { - Stanley's (1990) MT survey } \\
\text { across central part of zone; } \\
\text { resistivity may not be } \\
\text { representative (Fisher et al } \\
2007) \\
\text { - SNORCLE MT survey } \\
\text { shows averaged resistivity } \\
\text { at } 20 \text { km depth in } \\
\text { Whitehorse area } \\
\text { - assigned average resistivity } \\
\text { of } 400 \Omega \text { Mm on basis of } \\
\text { TACT-MT soundings and } \\
\text { higher resistivities mapped } \\
\text { in Whitehorse area }\end{array}$ \\
\hline
\end{tabular}

... Table continued on next page 
Table A3.1.5: TOK continued

\begin{tabular}{|c|c|c|c|c|c|}
\hline $\begin{array}{l}\text { 5. Lower Crust } \\
\text { - Mafic rocks } \\
(26-33 \mathrm{~km})\end{array}$ & $\begin{array}{l}\sim 150 \\
-- \\
--\sim 5 \\
\ldots \\
\cdots\end{array}$ & $\begin{array}{r}30-200 \\
60-300 \\
20-100 \\
10-300\end{array}$ & $\begin{array}{l}\text { MT survey (TACT) } \\
\text { A } \\
\text { MT survey (Line D) } \\
\text { A } \\
\text { MT survey (SNORCLE) } \\
\text { B } \\
\text { Compilation (regional) } \\
\text { C } \\
\text { Compilation (global) } \\
\text { C }\end{array}$ & $\begin{array}{l}\text { Campbell et al } \\
(2001) \\
\text { Stanley et al } \\
\text { (1990) } \\
\text { Ledo et al (2004, } \\
\text { Fig 4) } \\
\text { Ferguson and } \\
\text { Odwar (1998, p 48) } \\
\text { for range, northern } \\
\text { BC } \\
\text { Simpson \& Bahr } \\
\text { (2005, p.11) for } \\
\text { range, mid-lower } \\
\text { continental crust }\end{array}$ & $\begin{array}{l}\text { - extrapolated depth from } \\
\text { Fuis et al (2008) crustal } \\
\text { cross-section, } 7 \mathrm{~km} \text { average } \\
\text { thickness } \\
\text { - SNORCLE MT survey } \\
\text { shows resistive mid-lower } \\
\text { crust and upper mantle } \\
\text { beneath Whitehorse area } \\
\text { - assigned average resistivity } \\
\text { of } 150 \Omega \text { m on basis of } \\
\text { TACT-MT soundings and } \\
\text { low-end ranges from } \\
\text { Stanley, and Simpson \& } \\
\text { Barr }\end{array}$ \\
\hline $\begin{array}{l}\text { 6. Mantle } \\
(33-100 \mathrm{~km})\end{array}$ & $\begin{array}{l}\sim 400 \\
\cdots \\
\cdots \\
350 \\
300 \\
1000\end{array}$ & $\begin{array}{r}340-530 \\
\sim 100-3000 \\
(40 \mathrm{~km}) \\
\sim 100-300 \\
(100 \mathrm{~km}) \\
40-650 \\
\cdots\end{array}$ & $\begin{array}{l}\text { MT survey (TACT) } \\
\text { A } \\
\text { MT survey (SNORCLE) } \\
\text { B } \\
\text { MT survey (SNORCLE) } \\
\text { B } \\
\text { Compilation (regional) } \\
\text { C } \\
\text { Compilation (global) } \\
\text { C }\end{array}$ & $\begin{array}{l}\text { Campbell et al } \\
\text { (2001) } \\
\text { Jones et al (2005), } \\
\text { Fig. 4) } \\
\text { Jones et al } \\
\text { (2005, Fig.6) } \\
\text { Ferguson and } \\
\text { Odwar (1998, p.42) } \\
\text { for range, northern } \\
\text { BC } \\
\text { Simpson \& Bahr } \\
\text { (2005, p.11) for } \\
\text { range, upper } \\
\text { continental mantle }\end{array}$ & $\begin{array}{l}\text { - limited TACT-MT sound Ings } \\
\text { that penetrate to mantle } \\
\text { depth } \\
\text { - SNORCLE MT survey } \\
\text { (Fig.4) shows averaged } \\
\text { resistivity at } 40 \mathrm{~km} \text { and } 100 \\
\text { km depths in Whitehorse } \\
\text { area, and dominant } \\
\text { resistivity on regional profile } \\
\text { (Fig.6) } \\
\text { - assigned average resistivity } \\
\sim 400 \Omega m \text { on basis of mid- } \\
\text { point of TACT-MT } \\
\text { soundings, and higher } \\
\text { resistivities indicated from } \\
\text { SNORCLE-MT survey }\end{array}$ \\
\hline $\begin{array}{l}\text { 7. Mantle } \\
\qquad(100-400 \mathrm{~km})\end{array}$ & $\begin{array}{l}250 \\
100\end{array}$ & $40-650$ & $\begin{array}{l}\text { MT survey (SNORCLE) } \\
\text { B } \\
\text { Compilation (regional) } \\
\text { C }\end{array}$ & $\begin{array}{l}\text { Jones et al } \\
\text { (2005, Fig.6) } \\
\text { Ferguson and } \\
\text { Odwar (1998, p.42) } \\
\text { for range, northern } \\
\text { BC }\end{array}$ & $\begin{array}{l}\text { average resistivity taken } \\
\text { from dominant resistivity on } \\
\text { SNORCLE transect- } \\
\text { regional profile }\end{array}$ \\
\hline $\begin{array}{l}\text { 8. Mantle } \\
(400-600 \mathrm{~km})\end{array}$ & $\sim 5$ & 2.6-6.6 & $\begin{array}{l}\text { MT survey (SNORCLE) } \\
\text { B } \\
\text { Compilation (regional) } \\
\text { C }\end{array}$ & $\begin{array}{l}\text { Jones et al } \\
(2005 \text {, Fig.6) } \\
\text { Jones } \\
(1999, \text { Fig. 9) }\end{array}$ & $\begin{array}{l}\text { - average resistivity taken as } \\
\text { lower end of range from } \\
\text { SNORCLE transect- } \\
\text { regıonal profile } \\
\text { - America; average resistivity } \\
\text { as mid-point of range }\end{array}$ \\
\hline
\end{tabular}


Table A3.1.6: 1D Earth resistivity model for Zone 6 - WHITEHORSE

\begin{tabular}{|c|c|c|c|c|}
\hline Layer & $\begin{array}{l}\text { Resistivity } \\
\text { ( } \mathbf{\Omega m}) \\
\text { Avg Range }\end{array}$ & $\begin{array}{l}\text { Determination, } \\
\text { Confidence }\end{array}$ & $\begin{array}{l}\text { Resistivity } \\
\text { Reference }\end{array}$ & Comments \\
\hline \multirow[t]{2}{*}{$\begin{array}{l}\text { 1. Overburden } \\
\text { - unconsolidated, } \\
\text { sand and gravel, } \\
\text { silt and clay } \\
\text { (Quaternary deposits) }\end{array}$} & \multirow[t]{2}{*}{ 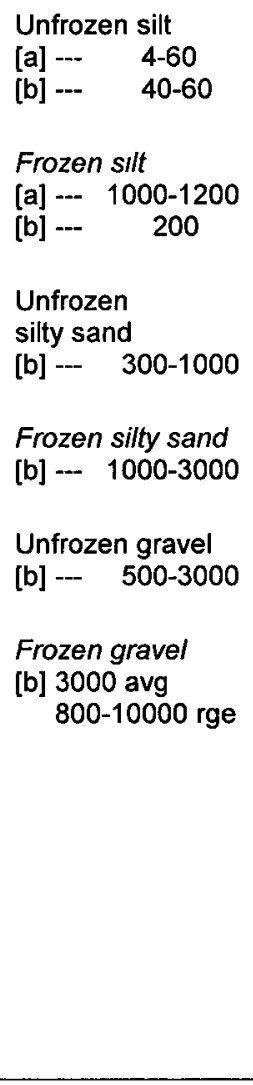 } & $\begin{array}{l}\text { Compilation (regional) } \\
\mathrm{C}\end{array}$ & $\begin{array}{l}\text { [a] Mackay (1970), } \\
\text { [b] Assoc. Mining } \\
(2004)\end{array}$ & $\begin{array}{l}\text { - underlain by sporadic; } \\
\text { permafrost depths less than } \\
10 \mathrm{~m} \text { (Atlas of Canada) to } \\
\text { occasional thicker } 16 \mathrm{~m} \text { in } \\
\text { Whitehorse area (Burn, } \\
2005 \text { ) } \\
\text { - northern end of zone has } \\
\text { alluvial plains and fans 35- } \\
60 \mathrm{~m} \text { thick; outwash plains } \\
\text { up to } 60 \mathrm{~m} \text { thick, till up to } \\
50 \mathrm{~m} \text { (map 6-1978) } \\
\text { central and southern part of } \\
\text { zone, outside of the Takhini } \\
\text { River valley, majority of } \\
\text { route crosses till blanket } \\
\text { (less than } 30 \text { thick) to till } \\
\text { veneer (less 1m thick) on } \\
\text { bedrock. Glaciolacustrine } \\
\text { deposits (clay, silt and } \\
\text { sand; } 5-10 \mathrm{~m} \text { thick) cover } \\
\text { river and creek channel } \\
\text { floors and lower slopes of } \\
\text { large valleys (Yukon Geol. } \\
\text { Surv., 2002; Morison and } \\
\text { Klassen, 1991). }\end{array}$ \\
\hline & & \multicolumn{3}{|c|}{$\begin{array}{l}\text { Where crosses or follows river valley bottoms is underlain by alluvium (stratified } \\
\text { gravel, sand, silt) of variable thickness (Morison and Klassen, 1997). Outwash } \\
\text { plains containing gravel, sand and silt, } 5-20 \mathrm{~m} \text { thick also along the route. Up to } \\
75 \mathrm{~m} \text { thick silt and clay deposits (from glacial lake Champagne) underlie the } \\
\text { Takhini river valley (Yukon Geol. Surv., 2002) } \\
\text { - assigned resistivity of } 1000 \Omega \mathrm{m} \text { for frozen silt, covering major portion of route in } \\
\text { Whitehorse area }\end{array}$} \\
\hline $\begin{array}{l}\text { 2. Sedimentary Basin } \\
\text { (absent) }\end{array}$ & $\cdots$ & $\cdots$ & -- & -- \\
\hline $\begin{array}{l}\text { 3. Upper Crust } \\
\text { metamorphosed } \\
\text { volcanic and } \\
\text { sedimentary rock, } \\
\text { extensive intrusive } \\
\text { rock } \\
\text { (Nislıng, Kooteney, } \\
\text { Stıkıne, Cache } \\
\text { Creek, Slide } \\
\text { Mountain, Dorsey } \\
\text { \& Cassier } \\
\text { Terranes) }\end{array}$ & $\begin{array}{cc}2000 & 1000-6000 \\
& \text { (Corridor } 3) \\
1800 & 600-6000 \\
& (5 \mathrm{~km} \text { depth })\end{array}$ & $\begin{array}{l}\text { MT survey (SNORCLE) } \\
\text { A } \\
\text { MT survey (SNORCLE) } \\
\text { A }\end{array}$ & $\begin{array}{l}\text { Jones et al (2005), } \\
\text { Fig. 7) } \\
\text { Jones et al (2005), } \\
\text { Fig. 4) }\end{array}$ & $\begin{array}{l}\text { - crustal depth from Clowes } \\
\text { et al (2005, Fig.4) } \\
\text { - SNORCLE-Corridor } 3 \text { gives } \\
\text { coarse resolution of crust, } \\
\text { showing wide resistivity } \\
\text { range ( } 300-10000 \Omega \mathrm{m}) \text {, } \\
\text { with dominant range being } \\
1000-3000 \Omega \mathrm{m} \text {; averaged } \\
\text { resistivity at } 5 \mathrm{~km} \text { depth also } \\
\text { shows wide range with } \\
\text { dominant range being } 600- \\
3000 \Omega \mathrm{m} \\
\text { - Assigned average resistivity } \\
\text { of } 2000 \Omega \mathrm{m} \text { as mid-point of } \\
\text { dominant ranges, also } \\
\text { reflecting presence of } \\
\text { intrusive rocks }\end{array}$ \\
\hline
\end{tabular}

... Table continued on next page 
Table A3.1.6: WHITEHORSE continued

\begin{tabular}{|c|c|c|c|c|}
\hline $\begin{array}{l}\text { 4. Middle Crust } \\
\qquad(12 \sim 20 \mathrm{~km})\end{array}$ & $\begin{array}{cr}3000-10000+ \\
\text { (Corridor 3) } \\
800 & 100-3000 \\
& (20 \mathrm{~km} \text { depth) } \\
-- & 20-100 \\
& \\
& \\
120 & 10-300\end{array}$ & $\begin{array}{l}\text { MT survey (SNORCLE) } \\
\text { A } \\
\text { MT survey (SNORCLE) } \\
\text { A } \\
\text { Compilation (regional) } \\
\text { C } \\
\text { Compilation (global) } \\
\text { C }\end{array}$ & $\begin{array}{l}\text { Jones et al (2005), } \\
\text { Fig. } 7) \\
\text { Jones et al (2005), } \\
\text { Fig 4) } \\
\text { Ferguson and } \\
\text { Odwar (1998, p.48) } \\
\text { for range, northern } \\
\text { BC } \\
\text { Simpson \& Bahr } \\
\text { (2005, p.11) for } \\
\text { range, mid-lower } \\
\text { continental crust }\end{array}$ & $\begin{array}{l}\text { - crustal depth from Clowes } \\
\text { et al }(2005, \text { Fig. } 4) \\
\text { - SNORCLE-Corridor } 3 \\
\text { shows resistive mid-lower } \\
\text { crust and upper mantle } \\
\text { beneath Whitehorse area } \\
\text { - averaged resistivity at } 20 \mathrm{~km} \\
\text { depth also shows wide } \\
\text { range with dominant range } \\
\text { being } 600-1000 \Omega \mathrm{m} \\
\text { - assigned average resistivity } \\
\text { of } 800 \Omega \mathrm{m} \text { as mid-point of } \\
\text { dominant range at } 20 \mathrm{~km} \\
\text { depth }\end{array}$ \\
\hline $\begin{array}{l}\text { 5. Lower Crust } \\
(\sim 20 \sim 35 \mathrm{~km})\end{array}$ & $\begin{array}{cr}-- & 1000-10000+ \\
550 & 10-3000 \\
& (40 \mathrm{~km} \text { depth }) \\
-- & 20-100 \\
& \\
-- & 10-300\end{array}$ & $\begin{array}{l}\text { MT survey (SNORCLE) } \\
\text { A } \\
\text { MT survey (SNORCLE) } \\
\text { A } \\
\text { Compilation (regional) } \\
\text { C } \\
\text { Compilation (global) } \\
\text { C }\end{array}$ & $\begin{array}{l}\text { Jones et al (2005), } \\
\text { Fig 7) } \\
\text { Jones et al (2005), } \\
\text { Fig 4) } \\
\text { Ferguson and } \\
\text { Odwar (1998, p.48) } \\
\text { for range, northern } \\
\text { BC } \\
\text { Simpson \& Bahr } \\
\text { (2005, p.11) for } \\
\text { range, mid-lower } \\
\text { continental crust } \\
\end{array}$ & $\begin{array}{l}\text { - crust/ mantle depth from } \\
\text { Clowes et al (2005, Fig 4) } \\
\text { and Ledo et al (2004, Fig.7) } \\
\text { - averaged resistivity at } 40 \mathrm{~km} \\
\text { depth also shows wide } \\
\text { range with dominant range } \\
\text { being } 100-1000 \Omega \mathrm{m} \\
\text { - assigned average resistivity } \\
\text { of } 550 \Omega \mathrm{m} \text { as mid-point of } \\
\text { dominant range at } 40 \mathrm{~km} \\
\text { depth }\end{array}$ \\
\hline $\begin{array}{l}\text { 6. Mantle } \\
\qquad(\sim 35-100 \mathrm{~km})\end{array}$ & 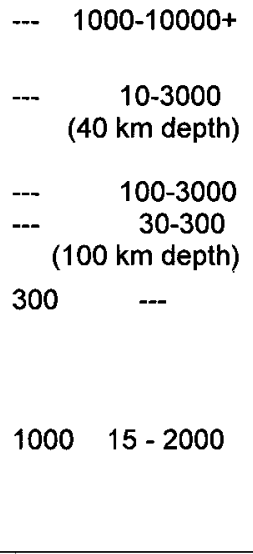 & $\begin{array}{l}\text { MT survey (SNORCLE) } \\
\text { A } \\
\text { MT survey (SNORCLE) } \\
\text { A } \\
\text { Compilation (regional) } \\
\text { C } \\
\text { Compilation (global) } \\
\text { C }\end{array}$ & $\begin{array}{l}\text { Jones et al (2005), } \\
\text { Fig. 7) } \\
\text { Jones et al (2005), } \\
\text { Fig. 4) } \\
\\
\text { Ferguson and } \\
\text { Odwar (1998, p 42) } \\
\text { for range, northern } \\
\text { BC } \\
\text { Simpson \& Bahr } \\
\text { (2005, p 11) for } \\
\text { range, upper } \\
\text { continental mantle }\end{array}$ & $\begin{array}{l}\text { - SNORCLE Corridor } 3 \\
\text { shows very high resistivity } \\
\text { beneath Whitehorse area } \\
\text { - assigned average resistivity } \\
3000 \Omega m \text { on basis of high- } \\
\text { end resistivity at } 40 \text { and } \\
100 \mathrm{~km} \text { depths }\end{array}$ \\
\hline $\begin{array}{l}\text { 7. Mantle } \\
(100-400 \mathrm{~km})\end{array}$ & $\begin{array}{cc}300 & 30-600 \\
(100 \mathrm{~km} \text { depth}) \\
375 & 40-700 \\
\text { (regional profile) } \\
100 & ---\end{array}$ & $\begin{array}{l}\text { MT survey (SNORCLE) } \\
\text { A } \\
\text { MT survey (SNORCLE) } \\
\text { A } \\
\text { Compilation (regional) } \\
\text { C }\end{array}$ & $\begin{array}{l}\text { Jones et al (2005), } \\
\text { Fig. } 4 \text { ) } \\
\text { Jones et al (2005), } \\
\text { Fig. } 6) \text {, for range } \\
\text { Ferguson and } \\
\text { Odwar (1998, p.42) } \\
\text { for range, northern } \\
\text { BC }\end{array}$ & $\begin{array}{l}\text { - assigned average resistivity } \\
300 \Omega \mathrm{m} \text { on basis of mid- } \\
\text { point of averaged resistivity } \\
\text { range at } 100 \mathrm{~km} \text { depth }\end{array}$ \\
\hline $\begin{array}{l}\text { 8. Mantle } \\
\qquad(400-600 \mathrm{~km})\end{array}$ & $\begin{array}{l}15-40 \\
2.6-6.6\end{array}$ & $\begin{array}{l}\text { MT survey (SNORCLE) } \\
\text { B } \\
\text { Compilation (regional) } \\
\text { C }\end{array}$ & $\begin{array}{l}\text { Jones et al } \\
(2005, \text { Fig 6) } \\
\text { Jones } \\
(1999, \text { Fig. 9) }\end{array}$ & $\begin{array}{l}\text { - average resistivity taken as } \\
\text { lower end of range from } \\
\text { SNORCLE transect- } \\
\text { regional profile } \\
\text { - range for western North } \\
\text { America; average resistivity } \\
\text { as mid-point of range }\end{array}$ \\
\hline
\end{tabular}


Table A3.1.7: 1D Earth resistivity model for Zone 7 - NORTHEASTERN BC

\begin{tabular}{|c|c|c|c|c|}
\hline Layer & $\begin{array}{l}\text { Resistivity } \\
(\boldsymbol{\Omega m}) \\
\text { Avg Range }\end{array}$ & $\begin{array}{l}\text { Determination, } \\
\text { Confidence }\end{array}$ & $\begin{array}{l}\text { Resistivity } \\
\text { Reference }\end{array}$ & Comments \\
\hline $\begin{array}{l}\text { 1. Overburden } \\
\text { - Gravel, sand and } \\
\text { silt, till } \\
\text { (Quaternary deposits) } \\
5-30 \mathrm{~m} \\
\text { frozen depth } \\
0-\leq 10 \mathrm{~m}\end{array}$ & $\begin{array}{l}\text { Unfrozen } \\
\text { sand and gravel } \\
\text { [a]-- } \quad 70-100 \\
\text { Unfrozen } \\
\text { silty sand } \\
\text { [b]--- 300-1000 } \\
\text { Unfrozen TIll } \\
\text { [a]-- } \\
\text { [c]--- } \\
\text { [d] } 100-15\end{array}$ & $\begin{array}{l}\text { [a] Airborne EM } \\
\text { B (northeast BC) } \\
\text { [b] Compilation (regional) } \\
\text { C } \\
\text { [c] Compilation } \\
\text { C (Saskatchewan) } \\
\text { [d] Compilation } \\
\text { C }\end{array}$ & $\begin{array}{l}\text { [a] Best et al } \\
(2006) \\
\text { [b] Assoc Mining } \\
(2004) \\
\text { [c] Palacky (1988, } \\
\text { p 101) } \\
\text { [d] Scott et al } \\
(1990)\end{array}$ & $\begin{array}{l}\text { - sporadic discontinuous } \\
\text { permafrost (10-50\%) (Atlas } \\
\text { of Canada, 2009) } \\
\text { - northwestern half of zone } \\
\text { commonly underlain by } \\
\text { glaciofluvial deposits (5- } \\
20 \mathrm{~m} \text { thick outwash plains, } \\
5-50 \mathrm{~m} \text { thick terraces, 5-20m } \\
\text { thick modern alluvium) } \\
\text { consisting of gravel, sand } \\
\text { and silt (Klassen and } \\
\text { Morison, 1981, Klassen, } \\
\text { 1997) }\end{array}$ \\
\hline & & $\begin{array}{l}\text { - southeastern half comm } \\
30 \mathrm{~m} \text { thick), with areas } \\
\text { plains, } 5-50 \mathrm{~m} \text { thick terr } \\
\text { - predominately a thick a } \\
\text { glaciofluvial deposits of } \\
\text { - assigned resistivity of } 1 \\
\text { infilled with unfrozen }\end{array}$ & $\begin{array}{l}\text { nly underlain by a } \\
\text { tIll veneer; glacioflu } \\
\text { es, } 5-20 \mathrm{~m} \text { alluvium } \\
\text { continuous till bla } \\
\text { and and gravel in ri } \\
0 \Omega \mathrm{m} \text { on basis maje } \\
\text { d and gravel }\end{array}$ & $\begin{array}{l}\text { and continuous till blanket ( } \leq \\
\text { deposits ( } 5-20 \mathrm{~m} \text { thick outwash } \\
\text { sand and gravel in river valleys } \\
\text { with areas of till veneer; } \\
\text { alleys (Fulton, 1995) } \\
\text { f route follows river valleys }\end{array}$ \\
\hline $\begin{array}{l}\text { 2. Sedimentary Basin } \\
\text { (absent) }\end{array}$ & --- & - & --- & - \\
\hline $\begin{array}{l}\text { 3. Upper Crust } \\
\text { - limestone, shale, } \\
\text { siltstone, } \\
\text { sandstone, } \\
\text { dolostone } \\
\text { (Rocky Mountain } \\
\text { Fold Belt) }\end{array}$ & 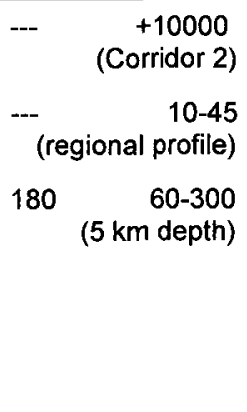 & $\begin{array}{l}\text { MT survey (SNORCLE) } \\
\text { A } \\
\text { MT survey (SNORCLE) } \\
\text { A } \\
\text { MT survey (SNORCLE) } \\
\text { A }\end{array}$ & $\begin{array}{l}\text { Jones et al }(2005, \\
\text { Fig. } 7) \\
\text { Jones et al }(2005, \\
\text { Fig } 6) \\
\text { Jones et al }(2005, \\
\text { Fig. 4) }\end{array}$ & $\begin{array}{l}\text { approximate, varying } \\
\text { crustal depth }(10-18 \mathrm{~m}) \\
\text { from Welford et al }(2001 \text {, } \\
\text { Fig. 12); took mid-point for } \\
\text { profile depth } \\
\text { - upper } 2 \mathrm{~km} \text { portion is } \\
\text { sediments of the Rocky } \\
\text { Mountain Fold Belt, of the } \\
\text { Ancestral North America } \\
\text { craton margin; a strongly } \\
\text { deformed and thrust-faulted } \\
\text { package of sandstone, }\end{array}$ \\
\hline & & \multicolumn{3}{|c|}{$\begin{array}{l}\text { shale and carbonate rocks, sometimes weakly metamorphosed (Mair et al, 2006) } \\
\text { - SNORCLE-Corridor } 2 \text { gives coarse resolution of crust, showing varying and } \\
\text { high resistivity SE of Tintina Fault } \\
\text { - averaged resistivity at } 5 \mathrm{~km} \text { depth becomes less resistive SE toward Fort } \\
\text { Nelson } \\
\text { - assigned average resistivity } 180 \Omega \mathrm{m} \text { as mid-point of resistivity at } 5 \mathrm{~km} \text { depth }\end{array}$} \\
\hline
\end{tabular}

... Table continued on next page 
Table A3.1.7: NORTHEASTERN BC continued

\begin{tabular}{|c|c|c|c|c|}
\hline $\begin{array}{l}\text { 4. Middle Crust } \\
\qquad(\sim 14-\sim 25 \mathrm{~km})\end{array}$ & $\begin{array}{rr}-- & 60-10000+ \\
& \text { (Corridor 2) } \\
\cdots & 10-300 \\
& (20 \mathrm{~km} \text { depth) } \\
-- & 20-100 \\
& \\
--- & 10-300\end{array}$ & $\begin{array}{l}\text { MT survey (SNORCLE) } \\
\text { A } \\
\text { MT survey (SNORCLE) } \\
\text { A } \\
\text { Compilation (regional) } \\
\text { C } \\
\text { Compilation (global) } \\
\text { C }\end{array}$ & $\begin{array}{l}\text { Jones et al (2005, } \\
\text { Fig } 7) \\
\text { Jones et al (2005, } \\
\text { Fig. } 4) \\
\text { Ferguson and } \\
\text { Odwar (1998, p.48) } \\
\text { for range, northern } \\
\text { BC } \\
\text { Simpson \& Bahr } \\
\text { (2005, p.11) for } \\
\text { range, mid-lower } \\
\text { continental crust }\end{array}$ & $\begin{array}{l}\text { - approximate crustal depth } \\
\text { from Welford et al ( } 2001 \text {, } \\
\text { Fig.12); took mid-point for } \\
\text { profile depth } \\
\text { - SNORCLE-Corridor } 2 \\
\text { shows coarse resolution of } \\
\text { crust, with considerable } \\
\text { variation of resistivity } \\
\text { - assigned average resistivity } \\
50 \Omega m \text { as mid-point of } \\
\text { dominant range (10-100 } \\
\Omega m \text { ) at } 20 \mathrm{~km} \text { depth } \\
\end{array}$ \\
\hline $\begin{array}{l}\text { 5. Lower Crust } \\
\qquad(\sim 25-\sim 33 \mathrm{~km})\end{array}$ & $\begin{array}{rr}-- & 10000+ \\
& \text { (corridor 2) } \\
-- & 10-65 \\
& \text { (regional profile) } \\
-- & 20-100 \\
& \\
-- & 10-300\end{array}$ & $\begin{array}{l}\text { MT survey (SNORCLE) } \\
\text { A } \\
\text { MT survey (SNORCLE) } \\
\text { A } \\
\text { Compilation (regional) } \\
\text { C } \\
\text { Compilation (global) } \\
\text { C }\end{array}$ & $\begin{array}{l}\text { Jones et al }(2005, \\
\text { Fig. } 7) \\
\text { Jones et al ( } 2005, \\
\text { Fig. } 6) \\
\text { Ferguson and } \\
\text { Odwar (1998, p.48) } \\
\text { for range, northern } \\
\text { BC } \\
\text { Simpson \& Bahr } \\
\text { (2005, p.11) for } \\
\text { range, mid-lower } \\
\text { continental crust }\end{array}$ & $\begin{array}{l}\text { - average crust / mantle depth } \\
\text { from Clowes et al ( } 2005 \text {, } \\
\text { Fig 4) } \\
\text { - assigned average resistivity } \\
35 \Omega \mathrm{m} \text { as mid-point of } \\
\text { range on regional profile }\end{array}$ \\
\hline $\begin{array}{l}\text { 6. Mantle } \\
\qquad(\sim 33-100 \mathrm{~km})\end{array}$ & 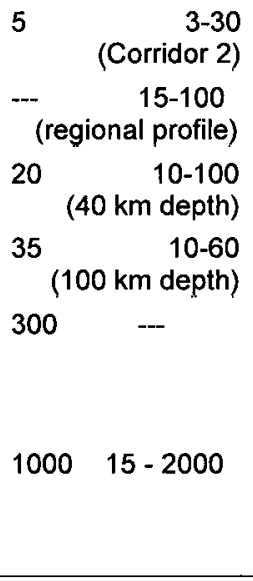 & $\begin{array}{l}\text { MT survey (SNORCLE) } \\
\text { A } \\
\text { MT survey (SNORCLE) } \\
\text { A } \\
\text { MT survey (SNORCLE) } \\
\text { A } \\
\text { Compilation (regional) } \\
\text { C } \\
\text { Compilation (global) } \\
\text { C }\end{array}$ & $\begin{array}{l}\text { Jones et al (2005), } \\
\text { Fig. } 7 \text { ) } \\
\text { Jones et al (2005), } \\
\text { Fig. } 7) \\
\text { Jones et al (2005), } \\
\text { Fig. 4) } \\
\\
\text { Ferguson and } \\
\text { Odwar (1998, p.42) } \\
\text { for range, northern } \\
\text { BC } \\
\text { Simpson \& Bahr } \\
\text { (2005, p 11) for } \\
\text { range, upper } \\
\text { continental mantle }\end{array}$ & $\begin{array}{l}\text { - SNORCLE Corridor } 2 \\
\text { shows very low resistivity } \\
\text { east of Watson Lake to } \\
\text { Laird RIver area } \\
\text { - averaged resistivity at } 40 \\
\text { and } 100 \mathrm{~km} \text { depths, chosen } \\
\text { from mid-point of domınant } \\
\text { ranges } \\
\text { - assigned average resistivity } \\
\text { of } 20 \Omega m \text { as an average of } \\
\text { mid-points of ranges }\end{array}$ \\
\hline $\begin{array}{l}\text { 7. Mantle } \\
\qquad(100-400 \mathrm{~km})\end{array}$ & $\begin{array}{r}15-250 \\
\text { (regional profile) } \\
10-60 \\
(100 \mathrm{~km} \text { depth) } \\
100 \quad--\end{array}$ & $\begin{array}{l}\text { MT survey (SNORCLE) } \\
\text { A } \\
\text { MT survey (SNORCLE) } \\
\text { A } \\
\text { Compilation (regional) } \\
\text { C }\end{array}$ & $\begin{array}{l}\text { Jones et al (2005), } \\
\text { Fig.6) } \\
\text { Jones et al (2005), } \\
\text { Fig 6) } \\
\text { Ferguson and } \\
\text { Odwar (1998, p.42) } \\
\text { for range, northern } \\
\text { BC }\end{array}$ & $\begin{array}{l}\text { - assıgned average resistivity } \\
100 \Omega m \text { on basis of } \\
\text { averaging mid-points } \\
\text { SNORCLE ranges and } \\
\text { regional complation values }\end{array}$ \\
\hline $\begin{array}{l}\text { 8. Mantle } \\
\qquad(400-600 \mathrm{~km})\end{array}$ & $\begin{array}{l}15-40 \\
2.6-6.6\end{array}$ & $\begin{array}{l}\text { MT survey (SNORCLE) } \\
\text { B } \\
\text { Compilation (regional) } \\
\text { C }\end{array}$ & $\begin{array}{l}\text { Jones et al } \\
\text { (2005, Fig.6) } \\
\text { Jones } \\
\text { (1999, Fig. 9) }\end{array}$ & $\begin{array}{l}\text { - average resistivity taken as } \\
\text { lower end of range from } \\
\text { SNORCLE transect- } \\
\text { regional profile, for } \\
\text { Proterozoic mantle } \\
\text { - range for western North } \\
\text { America; average resistivity } \\
\text { as mid-point of range }\end{array}$ \\
\hline
\end{tabular}


Table A3.1.8: 1D Earth resistivity model for Zone 8 - BOUNDARY LAKE

\begin{tabular}{|c|c|c|c|c|}
\hline Layer & $\begin{array}{l}\text { Resistivity } \\
(\Omega \mathrm{m}) \\
\text { Avg Range }\end{array}$ & $\begin{array}{l}\text { Determination, } \\
\text { Confidence }\end{array}$ & $\begin{array}{l}\text { Resistivity } \\
\text { Reference }\end{array}$ & Comments \\
\hline $\begin{array}{l}\text { 1. Overburden } \\
\text { - till, silt and clay } \\
\text { (Quaternary deposits) }\end{array}$ & 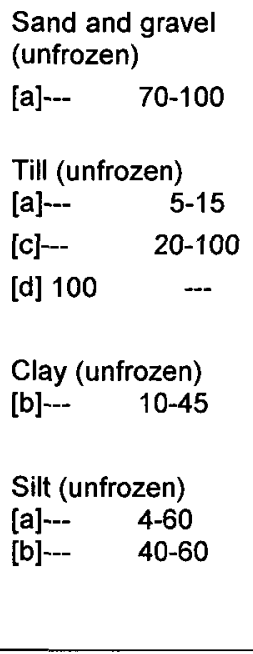 & $\begin{array}{l}\text { [a] Airborne EM } \\
\text { B (northeast BC) } \\
\text { [b] Compilation (regional) } \\
\text { C } \\
\text { [c] Compllation } \\
\text { C (Saskatchewan) } \\
\text { [d] Compilation } \\
\text { C }\end{array}$ & $\begin{array}{l}\text { [a] Best et al } \\
\text { (2006) } \\
\text { [b] Assoc. Mining } \\
\text { (2004) } \\
\text { [c] Palacky (1980, } \\
\text { p.101) } \\
\text { [d] Scott et al } \\
(1990)\end{array}$ & $\begin{array}{l}\text { - no permafrost } \\
\text { - predomınately a thick and } \\
\text { continuous till blanket, with } \\
\text { areas of tıll veneer, and } \\
\text { glaciolacustrine / lacustrine } \\
\text { deposits of silt and clay in } \\
\text { river valleys (Fulton, 1995) } \\
\text { - till thicknesses varies } 20 \text { - } \\
60 \mathrm{~m} \text { (Trommelen and } \\
\text { Levson, 2009, Hartman and } \\
\text { Clague, 2008); } 15-45 \mathrm{~m} \\
\text { thick in Alberta provinclal } \\
\text { boundary area (Hackbath, } \\
\text { 1978) } \\
\text { - assigned resistivity } 50 \Omega \mathrm{m} \\
\text { on basis of mid-point } \\
\text { resistivities of unfrozen till } \\
\text { measurements, for typical } \\
\text { depth of } 45 \mathrm{~m}\end{array}$ \\
\hline \multirow[t]{2}{*}{$\begin{array}{l}\text { 2. Sedimentary Basin } \\
\text { - upper half, clastic } \\
\text { dominant: shale, } \\
\text { siltstone, sandstone, } \\
\text { some limestone } \\
\text { - lower half, } \\
\text { carbonate dominate: } \\
\text { limestone, shale } \\
(0 \mathrm{~km}-3 \text { to } 4 \mathrm{~km})\end{array}$} & $\begin{array}{ll}\cdots & 10-15 \\
5 & \cdots\end{array}$ & $\begin{array}{l}\text { MT survey (Corridor 1) } \\
\text { B (1D interpretation) } \\
\text { Compilation (Alberta) } \\
\text { C } \\
\text { Compilation (regional) } \\
\text { C }\end{array}$ & $\begin{array}{l}\text { Wu et al (2005, } \\
\text { Fig.7) } \\
\text { Boerner et al } \\
\text { (2000, Fig.9) } \\
\text { Ferguson and } \\
\text { Odwar (1998; } \\
\text { p.41-42) }\end{array}$ & \multirow{2}{*}{$\begin{array}{l}\text { - Western Canada } \\
\text { Sedimentary Basin (Interior } \\
\text { Platform) thickens } \\
\text { westward } \\
\text { - exposed sedimentary } \\
\text { bedrock is Kaskapau } \\
\text { Formation: Cretaceous, } \\
\text { shale with thin ironstone } \\
\text { beds, and in lower portion } \\
\text { is interbedded with } \\
\text { quartzitic sandstone and } \\
\text { mudstone (Ab. Geol Surv., } \\
2009 \text { ) } \\
\text { - } 5 \Omega \text { m average resistivity of } \\
\text { WCSB, based on induction } \\
\text { logs from drill holes } \\
\text { al, 2000) } \\
\text { Idary Lake zone } \\
\text { T surveys by Turkoglu and }\end{array}$} \\
\hline & $\begin{array}{lc}100 & \text { Edmonton } \\
300 & \text { Northern BC }\end{array}$ & \multicolumn{2}{|c|}{$\begin{array}{l}\text { penetrating to Precambrian basement (Boerner et al, 2000) } \\
\text { - SNORCLE Corridor } 1 \text { located } 500 \mathrm{~km} \mathrm{~N} \text { of Boundary Lake zone } \\
\text { - assigned average resistivity } 5 \Omega \mathrm{m} \text { on basis of MT surveys by Turkoglu and } \\
\text { Boerner }\end{array}$} & \\
\hline \multirow[t]{2}{*}{$\begin{array}{l}\text { 3. Upper Crust } \\
\text { - Basement } \\
\text { Complex. volcanic } \\
\text { and sedimentary } \\
\text { rock, extensive } \\
\text { intrusive rock } \\
\\
\text { (Ksituan, } \\
\text { Kiskatinaw, Nova, } \\
\text { Fort Simpson } \\
\text { terranes) }\end{array}$} & $\begin{array}{r}25-60 \\
\text { (overall range) } \\
--\quad 7.5-30 \\
\text { (dominant range) }\end{array}$ & $\begin{array}{l}\text { MT Survey (ABT) } \\
A \text { (2D interpretation) }\end{array}$ & $\begin{array}{l}\text { Boerner et al } \\
(2000, \text { Fig. 15) }\end{array}$ & $\begin{array}{l}\text { very approximate } 10 \mathrm{~km} \\
\text { crustal depth interpreted } \\
\text { from Welford et al ( } 2001 \text {, } \\
\text { Fig. } 12) \\
\text { - assigned } 60 \Omega \mathrm{m} \text { on basis of } \\
\text { dominant resistivity in area } \\
\text { of Boundary Lake }\end{array}$ \\
\hline & $30-300$ & $\begin{array}{l}\text { MT Survey (Corridor 1) } \\
\text { B (1D interpretation) }\end{array}$ & $\begin{array}{l}\text { Wu et al } \\
(2005, \text { Fig.7) }\end{array}$ & \\
\hline
\end{tabular}

... Table continued on next page 
Table A3.1.8: BOUNDARY LAKE continued

\begin{tabular}{|c|c|c|c|c|}
\hline $\begin{array}{l}\text { 4. Middle Crust } \\
\qquad(\sim 15-\sim 25 \mathrm{~km})\end{array}$ & $\begin{array}{rr}160 & 20-300 \\
(20.5 \mathrm{~km} \text { depth }) \\
600 & 200-1000 \\
& \\
1000 & -- \\
\cdots & 200-400 \\
\cdots & 20-100 \\
--- & \\
& 10-300\end{array}$ & $\begin{array}{l}\text { MT survey } \\
\text { A (3D interpretation) } \\
\text { MT survey } \\
\text { A (2D interpretation) } \\
\text { MT Survey (ABT) } \\
\text { A (2D interpretation) } \\
\text { MT Survey (Corridor } 1 \text { ) } \\
\text { B (2D interpretation) } \\
\text { Compilation (regional) } \\
\text { C } \\
\text { Compilation (global) } \\
\text { C }\end{array}$ & $\begin{array}{l}\text { Turkoglu et al } \\
\text { (2009, Fig.8) } \\
\text { Turkoglu et al } \\
\text { (2009, Fig.7) } \\
\text { Boerner et al } \\
\text { (2000, Fig. 15) } \\
\text { Wu et al } \\
\text { (2005, Fig. 10) } \\
\text { Ferguson and } \\
\text { Odwar (1998, p.48) } \\
\text { for range, northern } \\
\text { BC } \\
\text { Simpson \& Bahr } \\
\text { (2005, p 11) for } \\
\text { range, mid-lower } \\
\text { continental crust }\end{array}$ & $\begin{array}{l}\text { very approxımate } 15 \mathrm{~km} \\
\text { crustal thickness } \\
\text { interpreted from Welford et } \\
\text { al (2001, Fig.12) } \\
\text { - assigned average resistivity } \\
160 \Omega \mathrm{m} \text { as mid-point of } \\
\text { dominant range at } 20 \mathrm{~km} \\
\text { depth }\end{array}$ \\
\hline $\begin{array}{l}\text { 5. Lower Crust } \\
\qquad(\sim 25-\sim 40 \mathrm{~km})\end{array}$ & \begin{tabular}{lr}
20 & $1-80$ \\
& \multicolumn{1}{c}{$(41 \mathrm{~km}$ depth $)$} \\
600 & $300-1000$ \\
$\cdots$ & $600-1000$ \\
$\cdots$ & $200-400$ \\
$\cdots$ & $20-100$ \\
-- & \\
& \\
--- & $10-300$
\end{tabular} & $\begin{array}{l}\text { MT survey } \\
\text { A (3D interpretation) } \\
\text { MT survey } \\
\text { A (2D interpretation) } \\
\text { MT Survey (ABT) } \\
\text { A (2D interpretation) } \\
\text { MT Survey (Corridor } 1 \text { ) } \\
\text { B (2D interpretation) } \\
\text { Compilation (regional) } \\
\text { C } \\
\text { Compilation (global) } \\
\text { C }\end{array}$ & $\begin{array}{l}\text { Turkoglu et al } \\
\text { (2009, Fig.8) } \\
\text { Turkoglu et al } \\
\text { (2009, Fig.7) } \\
\text { Boerner et al } \\
\text { (2000, Fig. 15) } \\
\text { Wu et al } \\
\text { (2005, Fig. 10) } \\
\text { Ferguson and } \\
\text { Odwar (1998, p.48) } \\
\text { for range, northern } \\
\text { BC } \\
\text { Simpson \& Bahr } \\
\text { (2005, p.11) for } \\
\text { range, mid-lower } \\
\text { continental crust }\end{array}$ & $\begin{array}{l}\text { crust / mantle depth from } \\
\text { Turkoglu et al (2009), } \\
\text { Clowes et al (2005, Fig.4), } \\
\text { and Bouzidi et al (2002, } \\
\text { Fig.8) } \\
\text { - assigned } 20 \text { Sm layer } \\
\text { resistivity on basis of most } \\
\text { recent MT survey; low } \\
\text { resistive zone follows } \\
\text { pipeline route }\end{array}$ \\
\hline $\begin{array}{l}\text { 6. Mantle } \\
(\sim 40-100 \mathrm{~km})\end{array}$ & $\begin{array}{cc}200 & 30-600 \\
& \text { (65 km depth) } \\
600 & \cdots \\
& \text { (at pipe end) } \\
250 & 200-300 \\
& \\
600 & 300-1000 \\
(40-50 \mathrm{~km} \text { depth }) \\
300 \quad 200-400 \\
300 \\
\end{array}$ & $\begin{array}{l}\text { MT survey } \\
\text { A (3D interpretation) } \\
\text { MT survey } \\
\text { A (2D interpretation) } \\
\text { MT Survey (ABT) } \\
\text { A (2D interpretation) } \\
\text { MT Survey (Corridor 1) } \\
\text { B (2D interpretation) } \\
\text { Compilation (regional) } \\
\text { C } \\
\text { Compilation (global) } \\
\text { C }\end{array}$ & $\begin{array}{l}\text { Turkoglu et al } \\
(2009, \text { Fig. } 8) \\
\text { Turkoglu et al } \\
\text { (2009, Fig.7) } \\
\text { Boerner et al } \\
\text { (2000, Fig. 15) } \\
\text { Wu et al } \\
\text { (2005, Fig 10) } \\
\text { Ferguson and } \\
\text { Odwar (1998, p.42) } \\
\text { for range, northern } \\
\text { BC } \\
\text { Simpson \& Bahr } \\
\text { (2005, p.11) for } \\
\text { range, upper } \\
\text { continental mantle }\end{array}$ & $\begin{array}{l}\text { assigned } 600 \Omega \mathrm{m} \text { layer } \\
\text { resistivity on basis of most } \\
\text { recent MT survey, } 100 \mathrm{~km} \\
\text { depth at pipe end }\end{array}$ \\
\hline
\end{tabular}

... Table continued on next page 
Table A3.1.8: BOUNDARY LAKE continued

\begin{tabular}{|c|c|c|c|c|c|}
\hline $\begin{array}{l}\text { 7. Mantle } \\
(100-400 \mathrm{~km})\end{array}$ & $\begin{array}{l}100 \\
(200- \\
\text { depth } \\
\\
(175- \\
\text { depth } \\
100\end{array}$ & $\begin{array}{l}20-200 \\
\mathrm{~km} \\
1-10 \\
\mathrm{~km} \\
-\end{array}$ & $\begin{array}{l}\text { MT survey } \\
\text { A (3D interpretation) } \\
\text { MT survey } \\
\text { A (2D interpretation) } \\
\text { Compilation (regional) } \\
\text { C }\end{array}$ & $\begin{array}{l}\text { Turkoglu et al } \\
\text { (2009, Fig.8) } \\
\text { Turkoglu et al } \\
(2009, \text { Fig.7) } \\
\text { Ferguson and } \\
\text { Odwar (1998, p.42) } \\
\text { for range, northern } \\
\text { BC }\end{array}$ & $\begin{array}{l}\text { assigned } 100 \Omega m \text { layer } \\
\text { resistivity on basis of most } \\
\text { recent } 3 D-M T \text { survey }\end{array}$ \\
\hline $\begin{array}{l}\text { 8. Mantle } \\
\qquad(400-600 \mathrm{~km})\end{array}$ & $\begin{array}{l}\sim 15 \\
\sim 5\end{array}$ & $\begin{array}{l}15-40 \\
2.6-6.6\end{array}$ & $\begin{array}{l}\text { MT survey (SNORCLE) } \\
\text { B } \\
\text { Compilation (regional) } \\
\text { C }\end{array}$ & $\begin{array}{l}\text { Jones et al } \\
(2005, \text { Fig 6) } \\
\text { Jones } \\
(1999, \text { Fig. 9) }\end{array}$ & $\begin{array}{l}\text { - average resistivity taken as } \\
\text { lower end of range from } \\
\text { SNORCLE transect- } \\
\text { regional profile, for } \\
\text { Proterozoic mantle } \\
\text { - range for western North } \\
\text { America; average resistivity } \\
\text { as mId-point of range }\end{array}$ \\
\hline
\end{tabular}

NOTE:

1. Determination - geophysical method used to determine the resistivity, or compilation form variety of sources.

2. Confidence - judgment as to how representative is the resistivity value, based on following criteria;

* $\mathrm{A}=$ best representative (measurements from site specific or a part of a regional MT survey near site)

* $\mathrm{B}=$ likely representative (resistivity values extrapolated from measurements taken at some distance from the site; either well logs or regional MT survey)

* $\mathrm{C}=$ possibly representative (measurements from general compilations, either regional or global, typically obtained from regional MT surveys)

\section{ABBREVIATIONS}

$\begin{array}{ll}\text { avg } & \text { average } \\ \text { BC } & \text { British Columbia } \\ \text { EM } & \text { electromagnetic } \\ \text { MT } & \text { magnetotelluric } \\ \text { rge } & \text { range } \\ \text { SNORCLE } & \text { Slave-Northern Cordillera Lithospheric Evolution } \\ \text { TACT } & \text { Trans-Alaska Crustal Transect } \\ \text { TAPS } & \text { Trans-Alaska Pipeline System } \\ \text { WCSB } & \text { Western Canada Sedimentary Basin }\end{array}$




\section{APPENDIX A4.1}

\section{D EARTH-RESISTIVITY MODELS for MACKENZIE RIVER VALLEY STUDY AREA}

Kilometer distance used to describe points along the pipeline route (Figure A4.Index) is the same as utilized by the Mackenzie Gas Producers Group. Starting at kilometer point KP 0 at Inuvik, the pipeline right-of-way (ROW) continues southeasterly to KP 473, near Norman Wells, where it runs parallel to the existing right-of-way for the Enbridge crude oil pipeline, with both then continuing to KP 1221 at the Alberta Northwest Territories provincial boundary.

North of KP 0 at Inuvik, extending another $133 \mathrm{~km}$ to Taglu on the coast of the Beaufort Sea the pipeline ROW becomes a gathering lateral line to the natural gas fields in the Mackenzie delta area.

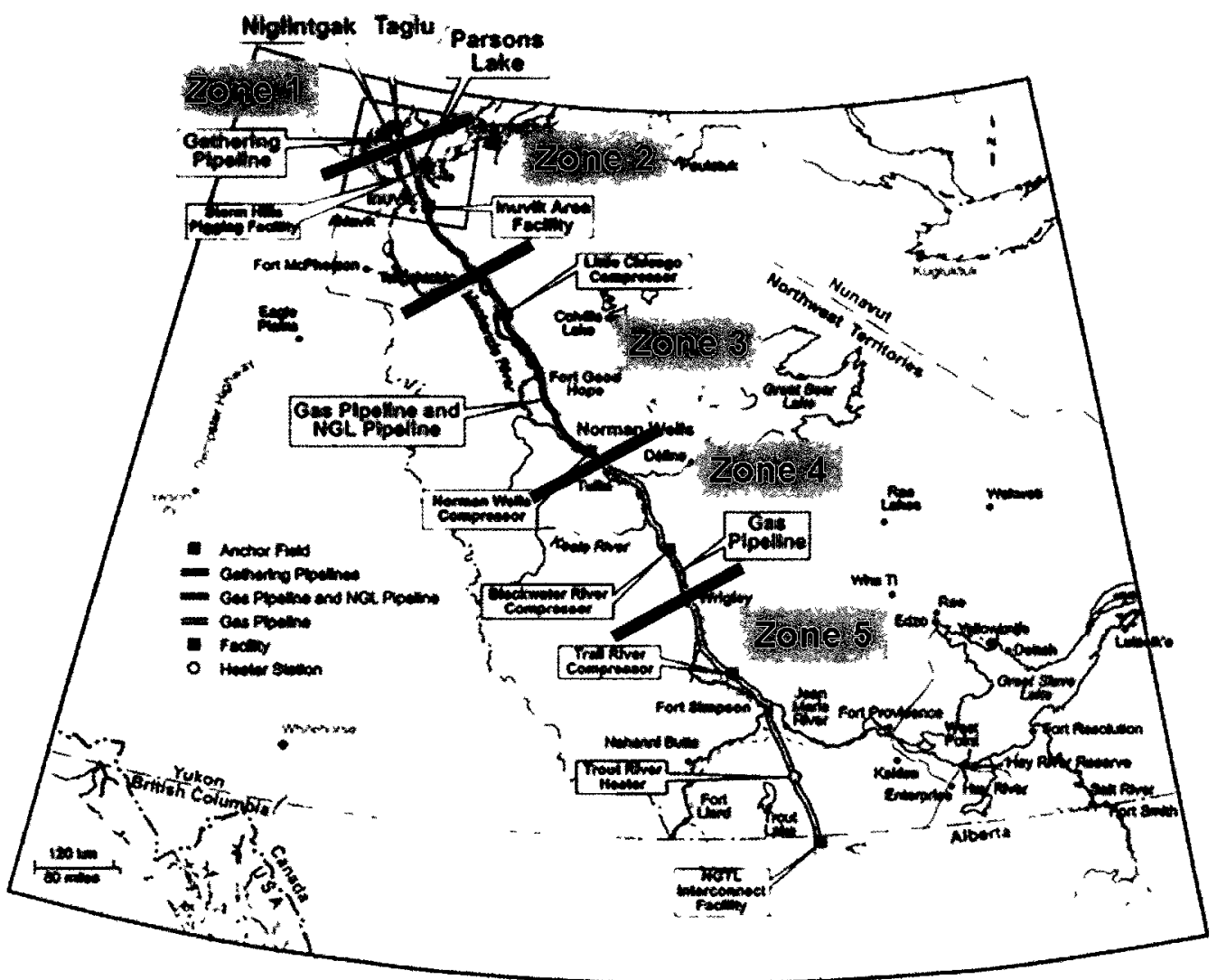

Figure A4.Index. Zones along the pipeline route used to produce 1D Earth-resistivity models (from Mackenzie Gas Project, 2005). 


\section{Surficial Sediments and Permafrost}

Surficial sediments, for the purpose of the 1D model, are considered to be unconsolidated. In general, these surficial sediments will have variable resistivity ranging from about $10 \mathrm{Ohm}-\mathrm{m}$ to around $1000 \mathrm{Ohm}-\mathrm{m}$ dependent on the porosity, groundwater conductivity, and clay content (Ferguson and Odwar, 1997). Palacky (1988) shows that glacial sediments have a resistivity range of $<10-10,000 \mathrm{Ohm}-\mathrm{m}$ with the lowest values in clays, mid values for till, and highest in gravel and sand. Where permafrost is present, the resistivity generally doubles in fine sized sediments such as clay and silt, and increases for a half-order magnitude for the coarser sands and gravels.

For the 1D Earth-resistivity models, resistivity values were obtained from; (1) the 1996 SNORCLE transect, (2) a compilation of electrical resistivity for frozen and unfrozen soils in the Fort Simpson region, and (3) a geophysical survey in the Mackenzie Delta transitional to the Tuktoyaktuk highlands.

Surficial sediments located in the southern end of the pipeline corridor were assigned an average resistivity (60 Ohm-m) the same as obtained from the 1996 geophysics survey. On the assumption that the 1996 survey crossed surficial sediments representative of the region, the same $60 \mathrm{Ohm}-\mathrm{m}$ average resistivity was applied to many of the $1 \mathrm{D}$ model locations. A possible range of resistivity was also considered, using the values from Fort Simpson, and selected to represent the dominant surficial sediment (e.g. clay, silt, sand) at the location of the $1 \mathrm{D}$ model.

North of Inuvik, where deep permafrost occurs, the average resistivity $(>100$ $\mathrm{Ohm}-\mathrm{m}$ ) is much greater as based on geophysical survey results. Presence of ice lenses, which can be common, will increase the resistivity several magnitudes ( $>5000 \mathrm{Ohm}-\mathrm{m})$, and would form the upper end of the resistivity range in a $1 \mathrm{D}$ model.

\section{Sedimentary Bedrock}

According to Ferguson and Odwar (1997) the average resistivity of unmetamorphosed to slightly-metamorphosed sedimentary rocks in the Western Canadian Basin (i.e. Interior Platform geological province) is $10-30 \mathrm{Ohm}-\mathrm{m}$. Resistance will vary among the different types of sedimentary rock, being higher where there is proportionally more limestone than shale and sandstone, and least for shale dominant rock.

Results from the 1996 SNORCLE Lithoprobe survey across the south end of the Mackenzie Valley show that the Phanerozoic sedimentary rocks (of the Interior Platform) form a relatively thick, conductive, near surface layer $(\sim 10 \mathrm{Ohm}-\mathrm{m})(\mathrm{Wu}, 2001)$. This sedimentary cover rock thins to the east and west of Fort Simpson, but its northerly depth is not known. Hydrocarbon exploration drilling in the area reveals a range of $8->500$ $\mathrm{Ohm}-\mathrm{m}$ in the underlying limestone and dolostone dominant sedimentary rock (Wu, 2001). The $\sim 10 \mathrm{Ohm}-\mathrm{m}$ value obtained from the MT survey was adopted for $1 \mathrm{D}$ models 
situated along the south half of the pipeline route as being the most broadly representative of overall sedimentary bedrock.

For the central portion of the route, the average resistivity value for sedimentary bedrock (20 Ohm-m) based on Ferguson and Odwar's (1997) prairie model was used. For some 1D model locations, on the basis of the on the underlying bedrock geology, a range of resistivity values was chosen to reflect the dominant underlying bedrock geology as shown on geological maps or exploration well logs. As an alternative, global resistivity ranges (Simpson and Bahr, 2005) for old sediments ( 20 - $800 \mathrm{Ohm}-\mathrm{m})$ can be used.

At the north end of the pipeline route, the resistivity values were obtained from a surface geophysical survey and are in agreement with values used for other 1D model locations.

\section{Crustal and Mantle Layers}

Along the pipeline route, the depth to the crust - mantle (Moho) boundary was found to range from about $34 \mathrm{~km}$ to $40 \mathrm{~km}$, but this value is dependent on the quality of available information. At the south and north ends of the route, crustal thicknesses have been determined fairly accurately by deep sensing geophysical surveys using seismic / magnetotelluric in the south and seismic in the north. For the central portions of the route, a general depth of $40 \mathrm{~km}$ has been applied, the same as the average 1D resistivity model for the provinces adopted by Ferguson and Odwar (1997). Exceptions are in Zone 1 where there is a thick $(>12 \mathrm{~km})$ sedimentary basin overlying thinned upper crust with the Moho imaged at a depth of $30 \mathrm{~km}$, and in Zone 5 where the Moho shallows to a depth of $34 \mathrm{~km}$.

For the upper crust layer a minimum resistivity value of $1000 \mathrm{ohm}-\mathrm{m}$ was applied to Zones 1 to 4, this being the higher end of a previously interpreted resistivity along the Lithoprobe transect (outside of any anomalous conditions) near the south end of the corridor. The $1000 \mathrm{ohm}-\mathrm{m}$ value is also at the lower end of the $1000-10000 \mathrm{ohm}-\mathrm{m}$ range for upper crustal rocks in the Prairie Provinces 1D layered Earth model developed by Ferguson and Odwar (1997). Middle and lower crustal layers, also in Zones 1 to 4, were assigned a resistivity of $300 \mathrm{ohm}-\mathrm{m}$ being the average resistivity found in Ferguson and Odwar's Prairie provinces. Zone 5 is the exception. Wu et al (2005) identified crustal rocks, along a 100 to $150 \mathrm{~km}$ long zone following Highways 7 and 1, in the Fort Simpson area to be less resistive. It was suggested that the decreased resistivity may be due to modification of the crust during rifting or basin formation associated with development of the Proterozoic metasedimentary Fort Simpson Basin. On the basis of Wu et al's findings, a lower resistivity value of $400 \mathrm{ohm} . \mathrm{m}$ was assigned to the upper crustal rocks, and a mid-range value of $190 \mathrm{ohm}-\mathrm{m}$ to the mid and lower crustal rocks in Zone 5.

Average resistivity values, based on Ferguson and Odwar's (1997) prairie provinces model were used for the upper (3000 Ohm-m), middle (300 Ohm-m) and lower portions $(10 \mathrm{Ohm}-\mathrm{m})$ of the mantle. The exception was at the south end of the route where a 1996 MT survey indicated that the $30-100 \mathrm{~km}$ upper mantle $(100 \mathrm{Ohm}-\mathrm{m})$ has 
an anomalous zone of lower resistivity attributed to deep seated structures (Wu et al., 2005).

Electrical conductivity surveys have shown that the conductivity structure of Precambrian Shield regions, comprised of crystalline metamorphic and igneous rocks, usually differs from that of Phanerozoic regions (Ferguson and Odwar, 1997). MT studies in adjacent Slave craton show step-like change in conductivity at Moho depth due to enhanced electrical conductivity (Jones and Ferguson, 2001). 


\section{Zone 1}

Zone 1 is a composite model of the offshore region north of the coastline, covering the Beaufort Sea and Mackenzie Delta. In Zone 1 permafrost is the deepest, extending some 400 to $600 \mathrm{~m}$ deep, in a thick layer of surficial sediments with a resistivity of $100 \mathrm{ohm}-\mathrm{m}$. Below this is an exceptionally thick $(>12 \mathrm{~km})$ succession of sediments of the BeaufortMackenzie Basin and underlying with low resistivity $(10 \mathrm{ohm}-\mathrm{m})$. Maximum thickness of the basin is attained offshore.

The deeper structure comprises an upper crust ever thinning northward beneath the Beaufort-Mackenzie Basin. Below is assumed the typical model of a moderately resistive middle/lower crust, followed by a resistive upper mantle on top of a lower mantle that becomes less resistive with increasing depth.

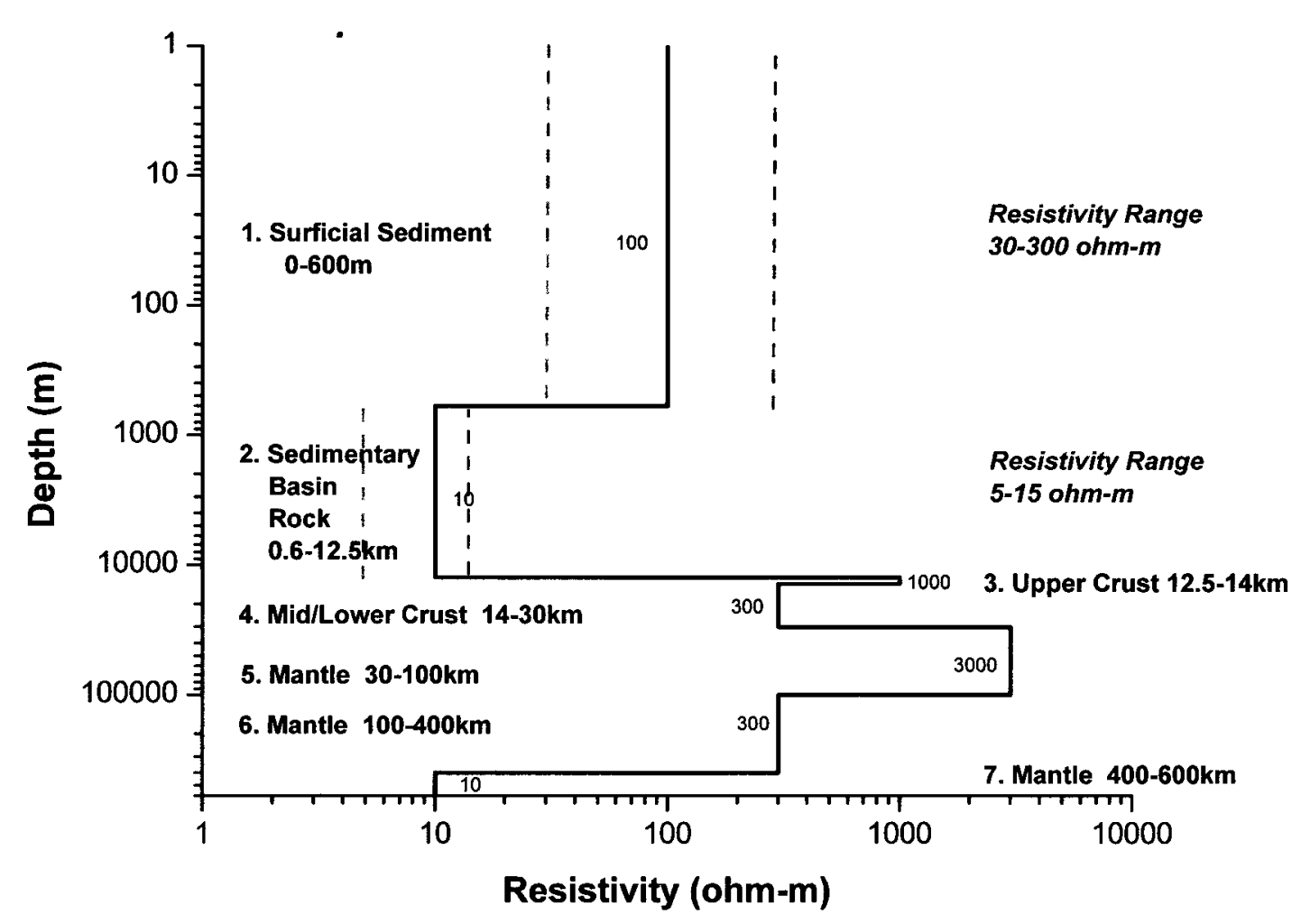

Figure A4.1. 1D Earth-resistivity model for Zone 1. Refer to Table A4.1 for additional details. 


\section{Zone 2}

In Zone 2, the area around Inuvik, the permafrost depth was assumed to be the same as depth of surficial sediments, being about $60 \mathrm{~m}$, although permafrost can be anywhere from 50 to $400 \mathrm{~m}$ deep. The sedimentary basin is shallower than Zone 1 and slightly more resistive. The higher resistivity of the upper crust gives a more resistive response for this model.

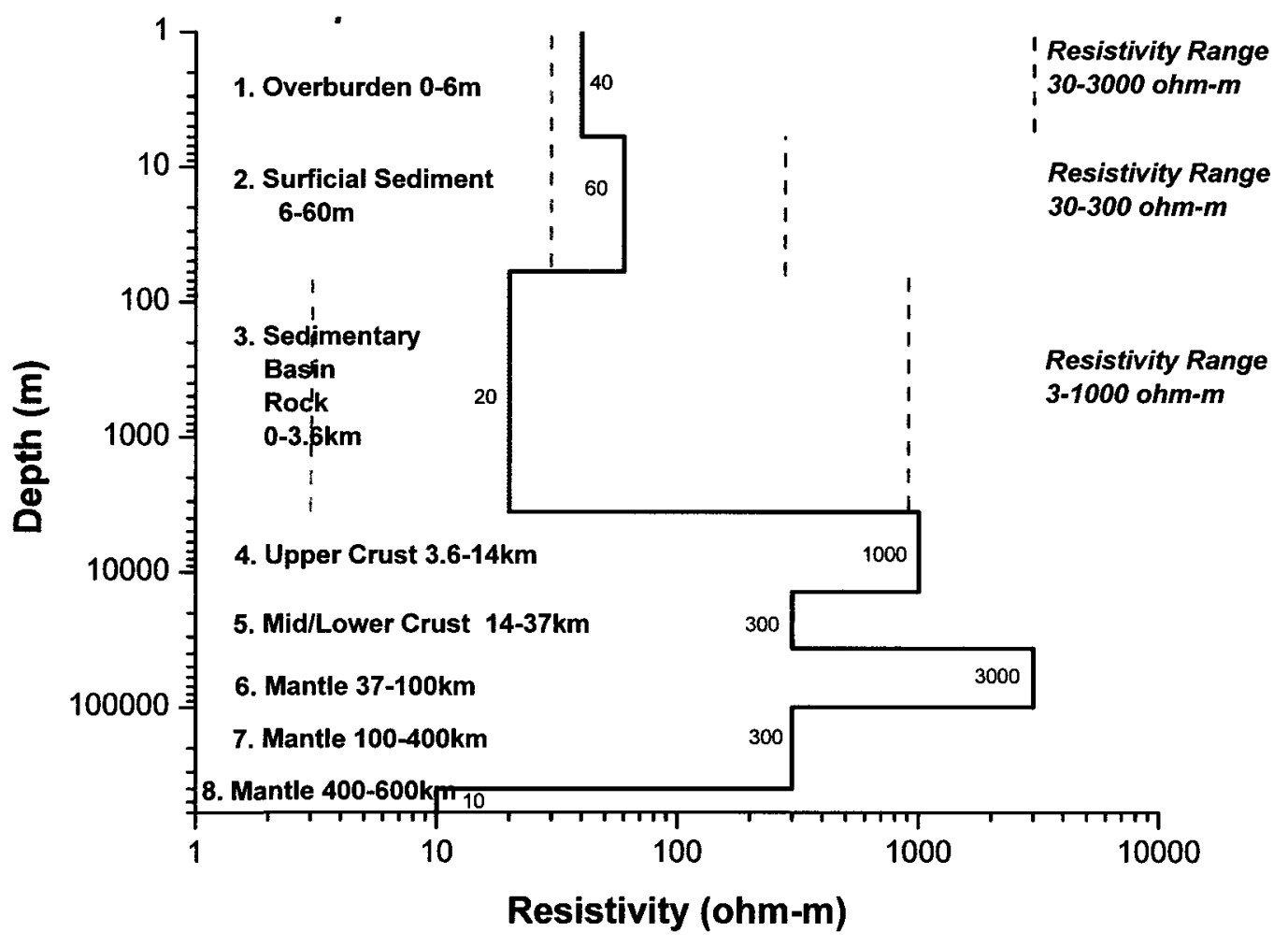

Figure A4.2. 1D Earth-resistivity model for Zone 2. Refer to Table A4.2 for additional details. 


\section{Zone 3}

Zone 3 covers a broader area than the previous two zones. Permafrost in this region is about $150 \mathrm{~m}$ deep. Below the surficial sediments is the sedimentary basin that underlies Zone 2 and which shallows further southward. In this model the decreased thickness ( $1600 \mathrm{~m}$ ) of the sedimentary basin is replaced by a thicker upper crust. The higher resistivity $(1000 \mathrm{ohm}-\mathrm{m})$ and thickness $(13.5 \mathrm{~km})$ of the upper crust gives a more resistive response to this model

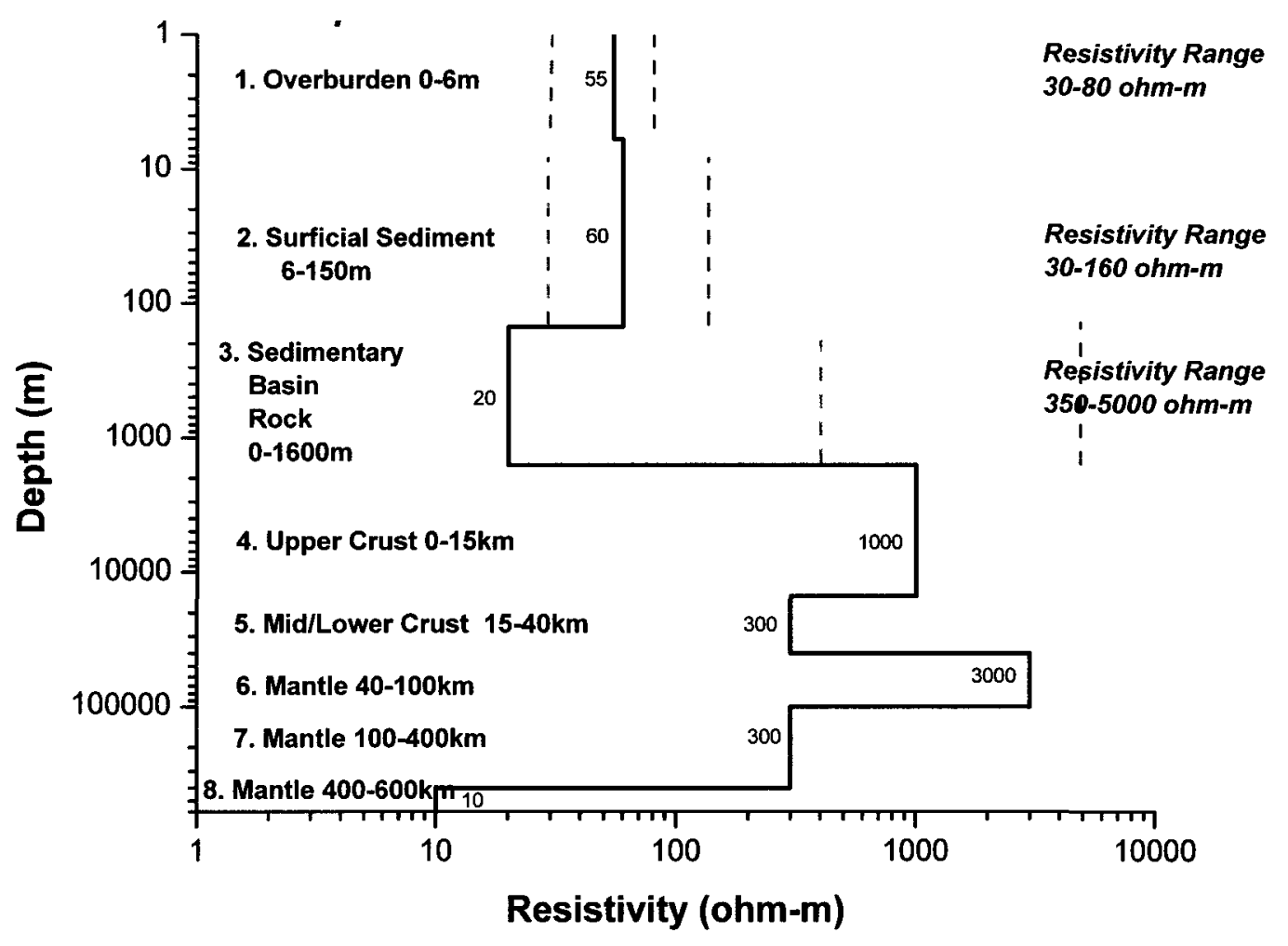

Figure A4.3. 1D Earth-resistivity model for Zone 1. Refer to Table A4.3 for additional details. 


\section{Zone 4}

In Zone 4, where present permafrost may extend to a depth of about $70 \mathrm{~m}$. Sedimentary basin rock is thin $(\sim 1500 \mathrm{~m})$, in contrast to Zones 1 and 2 models, and its depth is based on exploration wells and therefore likely to be representative for this zone. For the upper crust, a resistivity of $1000 \mathrm{ohm}-\mathrm{m}$ was assigned, being the higher end of a previously interpreted resistivity range $(\mathrm{Wu}, 2001)$ in the nearby Fort Simpson area. The upper mantle was assigned the same resistivity value used for Zone 5 to the south assuming similar deep resistivity structure, however, the $40 \mathrm{~km}$ depth to the upper mantle is a general value used for continental structure in western Canada.

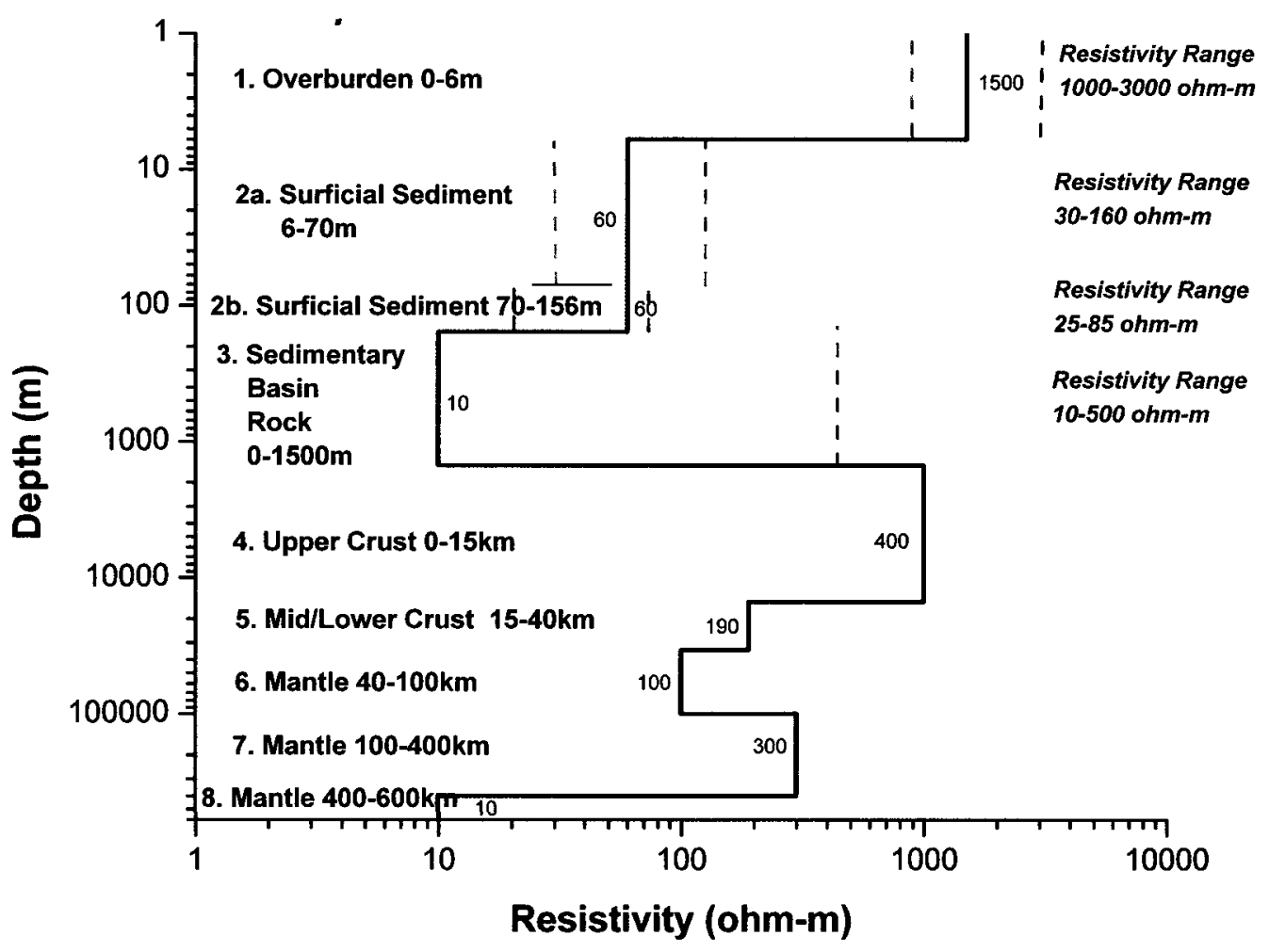

Figure A4.4. 1D Earth-resistivity model for Zone 4. Refer to Table A4.4 for additional details. 


\section{Zone 5}

In Zone 5, the thicknesses and resistivity of surficial sediments and sedimentary basin rock were based on previous MT survey interpretation and exploration well logs, and therefore considered to be the best representation of layer characteristics compared to all other zones. Sedimentary basin is thin $(\sim 1000 \mathrm{~m})$ compared to Zones 1 and 2 . Crustal and upper mantle sensitivities are lower compared to Zones 1 to 3 due to the presence of anomalously conductive areas.

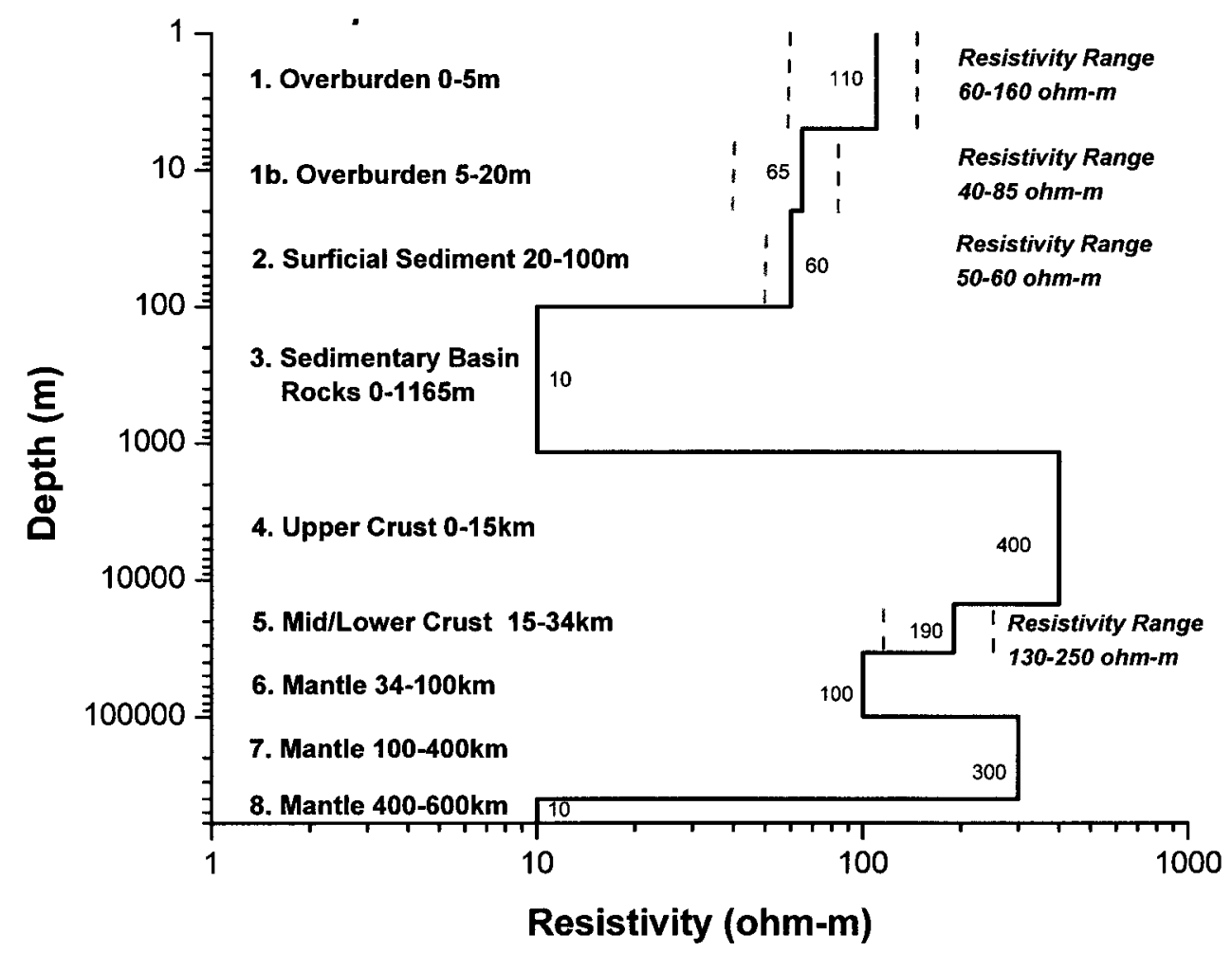

Figure A4.5. 1D Earth-resistivity model for Zone 5. Refer to Table A4.5 for additional details. 
Table A4.1. 1D Earth-resistivity model for Zone 1

\begin{tabular}{|c|c|c|c|c|c|}
\hline Geological Unit & \multicolumn{2}{|c|}{$\begin{array}{ll}\text { Resistivity }(\Omega \mathrm{m}) \\
\text { Avg Range }\end{array}$} & $\begin{array}{l}\text { Determination, } \\
\text { Confidence }\end{array}$ & $\begin{array}{l}\text { Resistivity } \\
\text { Reference }\end{array}$ & Comments \\
\hline $\begin{array}{l}1 \text { Surficial Sedıments } \\
\text { (sılt, fine sand, } \\
\text { clayey sılt), } \\
\text { frozen } \\
(0-\sim 600 \mathrm{~m})\end{array}$ & $\begin{array}{r}>100 \\
>5,00\end{array}$ & $\begin{array}{l}30-300 \\
0 \text { ice lens }\end{array}$ & $\begin{array}{l}\text { In-situ (laboratory), } \\
\text { A for avg }>100 \\
\text { Ex-situ (TDEM } \\
\text { survey), } \\
\text { A, for range } 30-300 \\
\text { Ex-situ (DC restv'y) } \\
\text { B for }>5000 \text { for high- } \\
\text { Ice content silts }\end{array}$ & $\begin{array}{l}\text { Todd \& Dallımore } \\
\text { 1998, Fig } 8 \\
\text { Todd \& Dallımore } \\
\text { 1998, Fig } 8 \\
\text { Assoc Mınıng } \\
\text { 2004, p } 64\end{array}$ & $\begin{array}{l}\text { - Geol unit source } \\
\text { Bull } 547 \text { Fig 1a, map } \\
\text { shows alluvial plain } \\
\text { - area of abundant massive } \\
\text { ice } \\
\text { - } 600 \text { m depth to bedrock } \\
\text { measured from Todd \& } \\
\text { Dallımore } 1988 \text { Fig } 8 \text {, } \\
\text { uncertain if incorporates } \\
\text { older sedımentary rock } \\
\text { (depth to bedrock is } \\
\text { reported as } 60 \mathrm{~m} \text { on } \\
\text { Richards island) } \\
\end{array}$ \\
\hline $\begin{array}{l}\text { 2. Sedımentary Basın } \\
\text { Rock } \\
(\sim 06 \mathrm{~km} \sim 125 \\
\text { km) }\end{array}$ & & $5 \cdot 15$ & $\begin{array}{l}\text { Ex-situ (TDEM } \\
\text { survey), } \\
\text { A, for average \& } \\
\text { range }\end{array}$ & $\begin{array}{l}\text { Todd \& Dallımore } \\
\text { 1998, Fig } 8\end{array}$ & $\begin{array}{l}125 \mathrm{~km} \text { depth hand- } \\
\text { scaled from crustal } \\
\text { seismic lines in Aspler et } \\
\text { al 2003, O'Leary } 1995\end{array}$ \\
\hline $\begin{array}{l}\text { 3. Upper Crust } \\
(\sim 0-125 \mathrm{~km})\end{array}$ & $\begin{array}{l}>100 \\
\text { rge } 1\end{array}$ & avg & $\begin{array}{l}\text { Ex-situ (MT survey), } \\
\mathrm{C}\end{array}$ & $\begin{array}{l}\text { Wu et al 2005, } \\
\text { p } 25, \text { p } 31 \text { p } 71, \text { for } \\
\text { value } \\
\text { Ferguson \& Odwar } \\
\text { for range }\end{array}$ & $\begin{array}{l}\text { - } 14 \mathrm{~km} \text { depth hand-scaled } \\
\text { from crustal x-section in } \\
\text { Aspler et al 2004, O'Leary } \\
\text { et al } 1995 \\
\text { - used Wu's average value } \\
\text { from site } 07 \text { located } 1100 \\
\text { km south of site } 53 \\
\text { - used Ferguson's range } \\
\text { value from resistivity } \\
\text { model for Prairie } \\
\text { Provinces } \\
\end{array}$ \\
\hline $\begin{array}{l}\text { 4. Middle - Lower } \\
\text { Crust } \\
(125-30 \mathrm{~km})\end{array}$ & 300 & $10-200$ & $\begin{array}{l}\text { Ex-situ (MT survey), } \\
\text { C }\end{array}$ & $\begin{array}{l}\text { Ferguson \& Odwar } \\
\text { for average } \\
\text { Simpson \& Bahr } \\
2005, \text { p } 11 \text { for } \\
\text { range }\end{array}$ & $\begin{array}{l}\text { Depth from Ferguson \& } \\
\text { Odwar's Prairie } \\
\text { Provinces model } \\
\text { - avg resistivity value from } \\
\text { Ferguson \& Odwar's } \\
\text { Prairie Provinces model } \\
\text { - range resistivity for mid- } \\
\text { lower contınental crust } \\
\end{array}$ \\
\hline $\begin{array}{l}\text { 5. Mantle } \\
(30-100 \mathrm{~km})\end{array}$ & 3000 & $15-2000$ & $\begin{array}{l}\text { Ex-situ (MT survey), } \\
\mathrm{C}\end{array}$ & $\begin{array}{l}\text { Ferguson \& Odwar } \\
\text { for average } \\
\text { Simpson \& Bahr } \\
2005, \text { p } 11 \text { for } \\
\text { range }\end{array}$ & $\begin{array}{l}\text { - } 30 \mathrm{~km} \text { upper depth from } \\
\text { gravity model by } \\
\text { Stephenson et al 1994, } \\
\text { p } 385 \\
\text { - } 100 \mathrm{~km} \text { lower depth from } \\
\text { Ferguson's resistivity } \\
\text { model for Prairie } \\
\text { Provinces } \\
\text { - used avg value from } \\
\text { Ferguson's resistivity } \\
\text { model for Prairie } \\
\text { Provinces } \\
\text { - used Simpson's range } \\
\text { value for mid-lower } \\
\text { continental crust } \\
\end{array}$ \\
\hline $\begin{array}{l}\text { 6. Mantle } \\
(100-400 \mathrm{~km})\end{array}$ & 300 & -- & $\begin{array}{l}\text { Ex-situ (MT survey), } \\
\text { C }\end{array}$ & $\begin{array}{l}\text { Ferguson \& Odwar } \\
\text { for average }\end{array}$ & $\begin{array}{l}\text { depth \& resistıvity from } \\
\text { Ferguson \& Odwar's } \\
\text { Prairle Provinces model }\end{array}$ \\
\hline $\begin{array}{l}\text { 7. Mantle } \\
(400-600 \mathrm{~km})\end{array}$ & 10 & $\cdots$ & $\begin{array}{l}\text { Ex-situ (MT survey), } \\
\text { C }\end{array}$ & $\begin{array}{l}\text { Ferguson \& Odwar } \\
\text { for average }\end{array}$ & $\begin{array}{l}\text { - depth \& resistivity from } \\
\text { Ferguson \& Odwar's } \\
\text { Prairie Provinces model }\end{array}$ \\
\hline
\end{tabular}


Table A4.2. 1D Earth-resistivity model for Zone 2

\begin{tabular}{|c|c|c|c|c|c|}
\hline Geological Unit & \multicolumn{2}{|c|}{$\begin{array}{ll}\text { Resistivity }(\Omega \mathrm{m}) \\
\text { Avg } \quad \text { Range }\end{array}$} & $\begin{array}{l}\text { Determination, } \\
\text { Confidence }\end{array}$ & $\begin{array}{l}\text { Resistivity } \\
\text { Reference }\end{array}$ & Comments \\
\hline $\begin{array}{l}\text { 1a. Overburden } \\
\text { (silt, silty sand, } \\
\text { clay), } \\
\text { frozen } \\
\text { [ice layers, ice } \\
\text { bonded] } \\
(0-6 \mathrm{~m})\end{array}$ & \multicolumn{2}{|c|}{$\begin{array}{l}>40 \quad 30-3,000 \\
>5,000 \text { ice } \\
\text { lenses }\end{array}$} & $\begin{array}{l}\text { In-situ (laboratory), } \\
\text { A for avg }>40 \\
\text { In-situ (laboratory), } \\
\text { B, for range } 30-3000 \\
\text { based on Ft Simpson } \\
\text { measurements } \\
\text { Ex-situ (DC restv'y) } \\
\text { B for }>5000 \text { for high- } \\
\text { ice content silts }\end{array}$ & $\begin{array}{l}\text { Assoc. Mining } \\
\text { 2004, p.63 } \\
\text { Todd \& Dallimore } \\
\text { 1998, Fig. } 8 \\
\text { Assoc Mining } \\
\text { 2004, p.64 }\end{array}$ & $\begin{array}{l}\text { unit source Bull.547. } \\
\text { Fig } 1 \text { BH53 } \\
\text { - area of abundant massive } \\
\text { ice; Irregular large ice } \\
\text { masses likely } \\
\text { - depth from BH53 log }\end{array}$ \\
\hline $\begin{array}{l}\text { 2. Surficial Sediments } \\
\text { (silt, sand, clay, } \\
\text { pebbly till), } \\
\text { frozen } \\
(6-60 \mathrm{~m})\end{array}$ & 60 & $30-300$ & $\begin{array}{l}\text { In-situ (laboratory), } \\
\text { B, for average of } \\
\text { typical frozen clay tıll } \\
\text { Ex-situ (EM survey), } \\
\text { A, for range of frozen } \\
\text { unconsolidated local } \\
\text { sediment }\end{array}$ & $\begin{array}{l}\text { Scott, p.356, for } \\
\text { avg } \\
\text { Todd \& Dallımore } \\
1998 \text { (abstract) for } \\
\text { range }\end{array}$ & $\begin{array}{l}\text { - unit source: Allen } 1998 \\
\text { p.40 } \\
\text { - permafrost depth } \sim 200 \mathrm{~m} \\
\text { hand-scaled from Smith et } \\
\text { al } 2001, \text { Fig } 3 \\
\text { - bedrock depth variable } \\
60-70 \mathrm{~m} \text {, reported in EIS } \\
\text { reports, Kokelj } 2003 \text { p.49, }\end{array}$ \\
\hline $\begin{array}{l}\text { 3. Sedimentary Basın } \\
\text { Rock } \\
(\sim 0-\sim 3.6 \mathrm{~km})\end{array}$ & 20 & $\begin{array}{l}3-1,000 \\
5-500\end{array}$ & $\begin{array}{l}\text { Ex-situ (MT survey), } \\
\mathrm{C}, \text { for avg and range } \\
\text { Ex-situ (MT survey, } \\
\mathrm{C} \text {, for range }\end{array}$ & $\begin{array}{l}\text { Ferguson \& Odwar } \\
\text { for avg and range } \\
3-1,000 \text { in prairie } \\
\text { prov } \\
\text { Simpson \& Bahr, } \\
\text { p.11 for range 5- } \\
500 \text { global }\end{array}$ & $\begin{array}{l}3.6 \mathrm{~km} \text { depth hand-scaled } \\
\text { from crustal seismic lines } \\
\text { in O'Leary 1995, } \\
\text { coincides with Parson } \\
\text { Lake gas field geol. X-sec } \\
\text { in EIS reports. }\end{array}$ \\
\hline $\begin{array}{l}\text { 4. Upper Crust } \\
(\sim 3.6-14 \mathrm{~km})\end{array}$ & $\begin{array}{l}>10 \\
\text { rge }\end{array}$ & $\begin{array}{l}\text { avg } \\
00-10,000\end{array}$ & $\begin{array}{l}\text { Ex-situ (MT survey), } \\
\text { C }\end{array}$ & $\begin{array}{l}\text { Wu et al } 2005, \\
\text { p.25, p.31 p.71, for } \\
\text { value } \\
\text { Ferguson \& Odwar } \\
\text { for range }\end{array}$ & $\begin{array}{l}\text { - } 14 \mathrm{~km} \text { depth hand-scaled } \\
\text { from crustal x-section in } \\
\text { Aspler et al 2004, O'Leary } \\
\text { et al } 1995 \\
\text { - used Wu's average value } \\
\text { from site } 07 \text { located } 1100 \\
\text { km south of site } 53 \\
\text { - used Ferguson's range } \\
\text { value from resistivity } \\
\text { model for Prairie Prov. }\end{array}$ \\
\hline $\begin{array}{l}\text { 5. Middle - Lower } \\
\text { Crust } \\
(14-37 \mathrm{~km})\end{array}$ & 300 & $10-200$ & $\begin{array}{l}\text { Ex-situ (MT survey), } \\
\mathrm{C}\end{array}$ & $\begin{array}{l}\text { Ferguson \& Odwar } \\
\text { for average } \\
\text { Simpson \& Bahr } \\
2005, \mathrm{p} 11 \text { for } \\
\text { range }\end{array}$ & $\begin{array}{l}\text { - used avg value from } \\
\text { Ferguson's resistivity } \\
\text { model for Prairie } \\
\text { Provinces } \\
\text { - used Simpson's range } \\
\text { value for mid-lower } \\
\text { continental crust } \\
\end{array}$ \\
\hline \multirow[t]{2}{*}{$\begin{array}{l}\text { 6. Mantle } \\
(37-100 \mathrm{~km})\end{array}$} & & & \multirow[t]{2}{*}{$\begin{array}{l}\text { Ex-situ (MT survey), } \\
\text { C }\end{array}$} & $\begin{array}{l}\text { Ferguson \& Odwar } \\
\text { for average } \\
\text { Simpson \& Bahr } \\
2005, \text { p } 11 \text { for } \\
\text { range }\end{array}$ & $\begin{array}{l}\text { - } 37 \mathrm{~km} \text { upper depth from } \\
\text { gravity model by } \\
\text { Stephenson et al 1994, } \\
\text { p. } 385 \\
100 \mathrm{~km} \text { lower depth from } \\
\text { Ferguson's resistivity } \\
\text { model for Prairie Prov. }\end{array}$ \\
\hline & & & & \multicolumn{2}{|c|}{$\begin{array}{l}\text { - used avg value from Ferguson's resistivity model } \\
\text { for Prairie Provinces } \\
\text { - used Simpson's range value for mid-lower }\end{array}$} \\
\hline $\begin{array}{l}\text { 7. Mantle } \\
(100-400 \mathrm{~km})\end{array}$ & 300 & --- & $\begin{array}{l}\text { Ex-situ (MT survey), } \\
\mathrm{C}\end{array}$ & $\begin{array}{l}\text { Ferguson \& Odwar } \\
\text { for average }\end{array}$ & $\begin{array}{l}\text { - depth \& restv'y values } \\
\text { from Ferguson's resistivity } \\
\text { model for Prairie Prov }\end{array}$ \\
\hline $\begin{array}{l}\text { 8. Mantle } \\
(400-600 \mathrm{~km})\end{array}$ & 10 & -- & $\begin{array}{l}\text { Ex-situ (MT survey), } \\
\mathrm{C}\end{array}$ & $\begin{array}{l}\text { Ferguson \& Odwar } \\
\text { for average }\end{array}$ & $\begin{array}{l}\text { - depth \& restv'y values } \\
\text { from Ferguson's resistivity } \\
\text { model for Prairie Prov }\end{array}$ \\
\hline
\end{tabular}


Table A4.3. 1D Earth-resistivity model for Zone 3

\begin{tabular}{|c|c|c|c|c|c|}
\hline Geological Unit & \multicolumn{2}{|c|}{ Resistivity ( $\Omega \mathrm{m}$ ) } & $\begin{array}{l}\text { Determination, } \\
\text { Confidence }\end{array}$ & $\begin{array}{l}\text { Resistivity } \\
\text { Reference }\end{array}$ & Comments \\
\hline $\begin{array}{l}\text { 1a Overburden } \\
\text { (silty clay), } \\
\text { frozen } \\
(0-6 \mathrm{~m}) \\
\end{array}$ & -- & $30-80$ & $\begin{array}{l}\text { In-situ (laboratory), } \\
\text { B }\end{array}$ & $\begin{array}{l}\text { Assoc Mınıng } \\
2004\end{array}$ & $\begin{array}{l}\text { - from previous compilation } \\
\text { of resistivity values at } \mathrm{Ft} \\
\text { Simpson }\end{array}$ \\
\hline $\begin{array}{l}\text { 2a. Surficıal Sedıments } \\
\text { frozen } \\
(6-150 \mathrm{~m})\end{array}$ & 60 & $30-160$ & $\begin{array}{l}\text { Ex-situ (MT survey), } \\
\text { B, for value } \\
\text { In-situ (lab), } \\
\text { B, for range }\end{array}$ & $\begin{array}{l}\text { Wu } 2001, p 365 \\
\text { Wu et al } 2005, \mathrm{p} 20 \\
\text { for value } \\
\text { Assoc Mıning } \\
2004, \mathrm{p} 10 \text { for } \\
\text { range }\end{array}$ & $\begin{array}{l}\text { - permafrost depth }(\sim 140 \mathrm{~m}) \\
\text { hand-scaled from Smith et } \\
\text { al } 2001 \text {, Fig } 3 \\
\text { - minımum } 150 \mathrm{~m} \text { depth } \\
\text { from well Richfield OII } \\
\text { Corp et al Grandview HIlls } \\
\text { No } 1 \text { located } 40 \mathrm{~km} \text { NNW } \\
\text { in the valley } \\
\text { - assume sediments mostly } \\
\text { silt and clay - using Wu's } \\
\text { value from site } 07 \text { located } \\
800 \mathrm{~km} \text { south of site } 45\end{array}$ \\
\hline $\begin{array}{l}3 \text { Sedımentary Basın } \\
\text { Rocks } \\
(\sim 0-\sim 1600 \mathrm{~m})\end{array}$ & & $350-5000$ & $\begin{array}{l}\text { Ex-situ (MT survey), } \\
\mathrm{C} \text { for value } \\
\text { In-situ (lab), } \\
\mathrm{C} \text { for range }\end{array}$ & $\begin{array}{l}\text { Ferguson \& Odwar, } \\
\text { for value } \\
\text { Telford } 1976, p 455 \\
\text { for range }\end{array}$ & $\begin{array}{l}\text { - mınımum } 1600 \mathrm{~m} \text { depth } \\
\text { from prelımınary cross- } \\
\text { section (Williams } 1990 \text {, } \\
\text { Sectıon E-F) } \\
\text { - avg value from resıstıvity } \\
\text { model for Praırie } \\
\text { Provinces } \\
\text { - range value is for } \\
\text { dolostone - predomınant } \\
\text { sedımentary rock on } \\
\text { cross-section }\end{array}$ \\
\hline $\begin{array}{l}\text { 4. Upper Crust } \\
(\sim 0-15 \mathrm{~km})\end{array}$ & $\begin{array}{l}>1000 \\
\text { rge }\end{array}$ & avg & $\begin{array}{l}\text { Ex-situ (MT survey), } \\
\text { C }\end{array}$ & $\begin{array}{l}\text { Wu et al } 2005, \\
\text { p } 25 \text { p } 31 \text { p } 71 \text {, for } \\
\text { value } \\
\text { Ferguson \& Odwar } \\
\text { for range }\end{array}$ & $\begin{array}{l}\text { - using Wu's value from site } \\
07 \text { located } 800 \mathrm{~km} \text { south } \\
\text { of site } 45 \\
\text { - range value from } \\
\text { resistivity model for } \\
\text { Prairie Provinces } \\
\end{array}$ \\
\hline $\begin{array}{l}\text { 5. Middle - Lower } \\
\text { Crust } \\
(15-40 \mathrm{~km})\end{array}$ & 300 & $10-200$ & $\begin{array}{l}\text { Ex-situ (MT survey), } \\
\text { C }\end{array}$ & $\begin{array}{l}\text { Ferguson \& Odwar } \\
\text { for average } \\
\text { Simpson \& Bahr } \\
2005, p 11 \text { for } \\
\text { range }\end{array}$ & $\begin{array}{l}\text { - depth from resistivity } \\
\text { model for Prairie } \\
\text { Provinces } \\
\text { - avg value from resistivity } \\
\text { model for Prairie } \\
\text { Provinces } \\
\text { - range value for mid-lower } \\
\text { contınental crust }\end{array}$ \\
\hline $\begin{array}{l}\text { 6. Mantle } \\
(40-100 \mathrm{~km})\end{array}$ & 3000 & $15-2000$ & $\begin{array}{l}\text { Ex-situ (MT survey), } \\
\text { C }\end{array}$ & $\begin{array}{l}\text { Ferguson \& Odwar } \\
\text { for average } \\
\text { Simpson \& Bahr } \\
2005 \text { for range } \\
\end{array}$ & $\begin{array}{l}\text { - resistivity model for } \\
\text { Prairie Provinces for } \\
\text { average } \\
\text { - upper continental mantle } \\
\text { for range } \\
\end{array}$ \\
\hline $\begin{array}{l}\text { 7. Mantle } \\
(100-400 \mathrm{~km})\end{array}$ & 300 & & $\begin{array}{l}\text { Ex-situ (MT survey), } \\
\mathrm{C}\end{array}$ & Ferguson \& Odwar & $\begin{array}{l}\text { - resistivity model for } \\
\text { Prairie Provinces }\end{array}$ \\
\hline $\begin{array}{l}\text { 8. Mantle } \\
(400-600 \mathrm{~km})\end{array}$ & 10 & --- & $\begin{array}{l}\text { Ex-situ (MT survey), } \\
\mathrm{C}\end{array}$ & Ferguson \& Odwar & $\begin{array}{l}\text { - resistivity model for } \\
\text { Prairie Provinces }\end{array}$ \\
\hline
\end{tabular}


Table A4.4. 1D Earth-resistivity model for Zone 4

\begin{tabular}{|c|c|c|c|c|c|}
\hline Geological Unit & $\begin{array}{l}\text { Resist } \\
\text { Avg }\end{array}$ & $\begin{array}{r}\text { ivity }(\Omega \mathrm{m}) \\
\text { Range }\end{array}$ & $\begin{array}{l}\text { Determination, } \\
\text { Confidence }\end{array}$ & $\begin{array}{l}\text { Resistivity } \\
\text { Reference }\end{array}$ & Comments \\
\hline $\begin{array}{l}\text { 1a Overburden } \\
\text { (silty sand), } \\
\text { frozen } \\
(0-6 \mathrm{~m})\end{array}$ & \multicolumn{2}{|r|}{$1000-3000$} & $\begin{array}{l}\text { In-situ (laboratory), } \\
\text { B }\end{array}$ & $\begin{array}{l}\text { Assoc Minıng } \\
2004\end{array}$ & $\begin{array}{l}\text { - from previous compilation } \\
\text { of resıstıvity values at Ft } \\
\text { Sımpson }\end{array}$ \\
\hline $\begin{array}{l}\text { 2a. Surficial Sedıments } \\
\text { frozen } \\
(6-70 \mathrm{~m})\end{array}$ & 60 & $30-160$ & $\begin{array}{l}\text { Ex-situ (MT survey), } \\
\text { B, for value } \\
\text { In-situ (lab), } \\
\text { B, for range }\end{array}$ & $\begin{array}{l}\text { Wu 2001, p } 365 \\
\text { Wu et al 2005, p } 20 \\
\text { for value } \\
\text { Assoc Minıng } \\
2004, \mathrm{p} 10 \text { for } \\
\text { range }\end{array}$ & $\begin{array}{l}\text { - permafrost depth hand- } \\
\text { scaled from Smith et al } \\
2001, \text { Fig } 3 \\
\text { - depth from well Aquit Old } \\
\text { Fort Point E-30 (Yorath \& } \\
\text { Cook 1981) } \\
\text { - assume sediments mostly } \\
\text { silt and clay - used Wu's } \\
\text { values from site } 07 \\
\text { located } 500 \mathrm{~km} \text { south of } \\
\text { site } 29\end{array}$ \\
\hline $\begin{array}{l}\text { 2b. Surficıal } \\
\text { Sedıments } \\
(70-156 \mathrm{~m})\end{array}$ & 60 & $25-85$ & $\begin{array}{l}\text { Ex-situ (MT survey), } \\
\text { B, for value } \\
\text { In-situ (lab), } \\
\text { B, for range }\end{array}$ & $\begin{array}{l}\text { Wu 2001, p } 365 \\
\text { Wu et al 2005, p } 20 \\
\text { Assoc Mıning } \\
2004, \text { p } 10 \text { for } \\
\text { range }\end{array}$ & $\begin{array}{l}\text { - depth from well Aquit Old } \\
\text { Fort Point E-30 (Yorath \& } \\
\text { Cook 1981) } \\
\text { - uncertain if all is } \\
\text { unconsolıdated surficial } \\
\text { sediments } \\
\text { - assume sediments mostly } \\
\text { silt and clay - used Wu's } \\
\text { value from site } 07 \text { located } \\
500 \mathrm{~km} \text { south of site } 29 \\
\end{array}$ \\
\hline $\begin{array}{l}3 \text { Sedımentary Basın } \\
\text { Rocks } \\
(\sim 0->780 \mathrm{~m} \text { to } \\
1500 \mathrm{~m}) \\
-\underset{\text { from geologıcal well }}{\text { log }} \\
(156-274 \mathrm{~m}, \\
\text { shale }) \\
(275-780 \mathrm{~m}, \\
\text { dolostone })\end{array}$ & $\begin{array}{l}\text { rge } \\
\text { rge }\end{array}$ & $\begin{array}{l}20-2000 \\
350-5000\end{array}$ & $\begin{array}{l}\text { Ex-situ (MT survey), } \\
\text { B }\end{array}$ & $\begin{array}{l}\text { Wu 2001, p } 365 \\
\text { Wu et al } 2005, \mathrm{p} 20 \\
\text { for average } \\
\text { Simpson \& Bahr } \\
2005, \mathrm{p} 11, \text { for } \\
\text { range } \\
\text { Telford 1976, p } 455 \\
\text { for well log values }\end{array}$ & $\begin{array}{l}\text { - minımum 780m depth } \\
\text { from well Aquit Old Fort } \\
\text { Point E-30 (Yorath \& } \\
\text { Cook 1981) } \\
\text { - mınımum 1078m depth } \\
\text { from well Imperial Canol } \\
\text { Bluefish 1-A (Tassonyı } \\
1968 \text { ) } \\
\text { - 1500m depth from DNAG } \\
5, \text { Fig } 55 \\
\text { - using Wu's value from } \\
\text { site } 07 \text { located } 500 \mathrm{~km} \\
\text { south of site } 29 \\
\end{array}$ \\
\hline $\begin{array}{l}\text { 4. Upper Crust } \\
(\sim 0-15 \mathrm{~km})\end{array}$ & $>1000$ & & $\begin{array}{l}\text { Ex-situ (MT survey), } \\
\text { C }\end{array}$ & $\begin{array}{l}\text { Wu et al 2005, } \\
\text { p 25, p } 31 \text { p } 71\end{array}$ & $\begin{array}{l}\text { - using Wu's value from site } \\
07 \text { located } 500 \mathrm{~km} \text { south } \\
\text { of site } 29\end{array}$ \\
\hline $\begin{array}{l}\text { 5. Middle - Lower } \\
\text { Crust } \\
(15-40 \mathrm{~km})\end{array}$ & 300 & $10-200$ & $\begin{array}{l}\text { Ex-situ (MT survey) } \\
\text { C }\end{array}$ & $\begin{array}{l}\text { Ferguson \& Odwar } \\
\text { for average } \\
\text { Simpson \& Bahr } \\
2005, p 11 \text { for } \\
\text { range }\end{array}$ & $\begin{array}{l}\text { - depth from resistivity } \\
\text { model for Prairie } \\
\text { Provinces } \\
\text { - avg value from resıstivity } \\
\text { model for Prairie } \\
\text { Provinces } \\
\text { - range value for mid-lower } \\
\text { continental crust } \\
\end{array}$ \\
\hline $\begin{array}{l}\text { 6. Mantle } \\
(40-100 \mathrm{~km})\end{array}$ & 3000 & $15-2000$ & $\begin{array}{l}\text { Ex-situ (MT survey), } \\
\text { C }\end{array}$ & $\begin{array}{l}\text { Ferguson \& Odwar } \\
\text { for average } \\
\text { Simpson \& Bahr } \\
2005 \text { for range }\end{array}$ & $\begin{array}{l}\text { - resistıvity model for } \\
\text { Prairie Provinces for } \\
\text { average } \\
\text { - upper contınental mantle } \\
\text { for range }\end{array}$ \\
\hline $\begin{array}{l}\text { 7. Mantle } \\
(100-400 \mathrm{~km})\end{array}$ & 300 & & $\begin{array}{l}\text { Ex-situ (MT survey), } \\
\mathrm{C}\end{array}$ & Ferguson \& Odwar & $\begin{array}{l}\text { - resistivity model for } \\
\text { Prairie Provinces }\end{array}$ \\
\hline $\begin{array}{l}\text { 8. Mantle } \\
(400-600 \mathrm{~km})\end{array}$ & 10 & $\cdots$ & $\begin{array}{l}\text { Ex-situ (MT survey), } \\
\mathrm{C}\end{array}$ & Ferguson \& Odwar & $\begin{array}{l}\text { - resistivity model for } \\
\text { Prairie Provinces }\end{array}$ \\
\hline
\end{tabular}


Table A4.5. 1D Earth-resistivity model for Zone 5

\begin{tabular}{|c|c|c|c|c|}
\hline Geological Unit & $\begin{array}{l}\text { Resistivity }(\Omega \mathrm{m}) \\
\text { Avg Range }\end{array}$ & $\begin{array}{l}\text { Resistivity } \\
\text { Determination }\end{array}$ & $\begin{array}{l}\text { Resistivity } \\
\text { Reference }\end{array}$ & Comments \\
\hline $\begin{array}{l}1 \text { Overburden (silt) } \\
\text { frozen } \\
(2-5 \mathrm{~m})\end{array}$ & $\begin{array}{l}-- \\
160\end{array}$ & $\begin{array}{l}\text { In-situ (laboratory), } \\
\text { A }\end{array}$ & $\begin{array}{l}\text { Assoc Mınıng } \\
2004\end{array}$ & $\begin{array}{l}\text { - from previous compilation } \\
\text { of resistivity values at } \mathrm{Ft} \\
\text { Simpson } \\
\end{array}$ \\
\hline $\begin{array}{l}\text { 2a Overburden (silt), } \\
\text { unfrozen } \\
(5-20 \mathrm{~m})\end{array}$ & $40-85$ & $\begin{array}{l}\text { In-situ (laboratory), } \\
\text { A }\end{array}$ & $\begin{array}{l}\text { Assoc Mınıng } \\
2004\end{array}$ & $\begin{array}{l}\text { - from previous compilation } \\
\text { of resistivity values at } \mathrm{Ft} \\
\text { Simpson } \\
\end{array}$ \\
\hline $\begin{array}{l}\text { 2b. Surfıcial } \\
\text { Sedıments } \\
(20-100 \mathrm{~m})\end{array}$ & $50-60$ & $\begin{array}{l}\text { Ex-situ (MT survey), } \\
\text { A }\end{array}$ & $\begin{array}{l}\text { Wu 2001, p } 365 \\
\text { Wu et al 2005, p } 20\end{array}$ & $\begin{array}{l}\text { - depth from MT survey } \\
\text { near site }\end{array}$ \\
\hline $\begin{array}{l}3 \text { Sedımentary Basın } \\
\text { Rocks } \\
(\sim 0 \text { to } \\
1000 / 1165 \mathrm{~m}) \\
\text { from geological } \\
\text { well log } \\
(0-215 \mathrm{~m}) \\
(215-810 \mathrm{~m}) \\
(810-864 \mathrm{~m}) \\
(864-907 \mathrm{~m}) \\
(907-940 \mathrm{~m})\end{array}$ & $\begin{array}{l}\sim 10 \quad-- \\
\\
\\
\\
\sim 50 \quad \text { Imst } \\
\sim 8 \quad \text { shale, Imst } \\
\sim 300 \text { Imst } \\
25 \quad \text { dolost, sst } \\
>500 \text { Imst, dolost }\end{array}$ & $\begin{array}{l}\text { Ex-situ (MT survey), } \\
\text { A } \\
\text { In-situ (well } \log \text { ), A }\end{array}$ & $\begin{array}{l}\text { Wu 2001, p } 365 \\
\text { Wu et al 2005, p } 20 \\
\text { Wu 2001, p } 378\end{array}$ & $\begin{array}{l}\text { - } 1165 \mathrm{~m} \text { depth from MT } \\
\text { survey near site, generally } \\
\text { coincident with petroleum } \\
\text { exploration well Jean } \\
\text { Marie E-7 }\end{array}$ \\
\hline $\begin{array}{l}\text { 4. Upper Crust } \\
(0-15 \mathrm{~km})\end{array}$ & $>400->1000$ & $\begin{array}{l}\text { Ex-situ (MT survey), } \\
\text { B }\end{array}$ & $\begin{array}{l}\text { Wu et al } 2005 \\
\text { p 25, p } 31 \text { p } 71\end{array}$ & $\begin{array}{l}\text { - Proterozoic } \\
\text { (meta)sedimentary rocks } \\
\text { - conflictıng values in } \\
\text { reference }\end{array}$ \\
\hline $\begin{array}{l}\text { 5. Middle - Lower } \\
\text { Crust } \\
(15-34 \mathrm{~km})\end{array}$ & $\sim 130-250$ & $\begin{array}{l}\text { Ex-situ (MT survey), } \\
\text { B }\end{array}$ & Wu et al 2005, p 25 & $\begin{array}{l}\text { - unusual conductive zone } \\
\text { in upper crust near Ft } \\
\text { Simpson } \\
\end{array}$ \\
\hline $\begin{array}{l}\text { 6. Mantle } \\
(34-\sim 100 \mathrm{~km})\end{array}$ & 100 & $\begin{array}{l}\text { Ex-situ (MT survey), } \\
\text { A }\end{array}$ & Wu et al 2005 & $\begin{array}{l}\text { - mantle depth from MT } \\
\text { survey }\end{array}$ \\
\hline $\begin{array}{l}\text { 7. Mantle } \\
(100-400 \mathrm{~km})\end{array}$ & 300 & $\begin{array}{l}\text { Ex-situ (MT survey), } \\
\text { C }\end{array}$ & Ferguson \& Odwar & $\begin{array}{l}\text { - resistivity model for } \\
\text { Praine Provinces }\end{array}$ \\
\hline $\begin{array}{l}\text { 8. Mantle } \\
(400-600 \mathrm{~km})\end{array}$ & 10 & $\begin{array}{l}\text { Ex-situ (MT survey), } \\
\mathrm{C}\end{array}$ & Ferguson \& Odwar & $\begin{array}{l}\text { - resistivity model for } \\
\text { Prairle Provinces }\end{array}$ \\
\hline
\end{tabular}

Determination - in-situ (laboratory) or ex-situ (geophysical) method used to determıne the resistivity Confidence - judgment as to how representative is the value, based on following criteria,

* $\mathrm{A}=$ best representative (measurements from site or nearby),

- surficial sediments - value obtained by laboratory measurement, from local area

- sedimentary basin - value obtained by MT survey near the site

- crust - value obtained by MT survey near the site

- mantle - value obtained by MT survey near the site

* $\mathrm{B}=$ likely representative extrapolated

- values extrapolated from previous measurements taken at some distance from the site

- surficial sediments - value obtained by laboratory measurement or geophysical measurement

- sedimentary basın - value obtained by regional MT survey

- crust - value obtained by regional MT survey

- mantle - value obtained by regional MT survey

$* \mathrm{C}=$ possibly representative (measurements from general complations)

\section{ABBREVIATIONS}

Dolost dolostone, dolomite

Lmst limestone

MT magnetotelluric

Sst

sandstone 


\section{APPENDIX A5.1 \\ COORDINATES OF \\ PSP DATA LOGGER \& MT SOUNDING SITE LOCATIONS}

Pipeline test posts are listed in this appendix by the identifiers used by TransCanada Corporation, whereby the test post is numbered by the distance from a particular valve station. For example, test post $1215+17.86$ is located $17.86 \mathrm{~km}$ east of valve station 1215 . In the text of Chapter 5 , the test post identifiers have been abbreviated for simplicity. For example, test post $1215+17.86$ becomes 1518 .

\section{UTM COORDINATES OF DATA LOGGER LOCATIONS}

\begin{tabular}{|c|c|c|c|c|c|}
\hline \multicolumn{6}{|c|}{2003 ORV SURVEY } \\
\hline $\begin{array}{c}\text { PSP } \\
\text { test post }\end{array}$ & $\begin{array}{l}\text { General } \\
\text { Location }\end{array}$ & $\begin{array}{c}\text { GPS } \\
\text { UTM coordinate } \\
\text { (northing) }\end{array}$ & $\begin{array}{c}\text { GPS } \\
\text { UTM } \\
\text { coordinate } \\
\text { (easting) }\end{array}$ & $\begin{array}{c}\text { Number } \\
\text { of } \\
\text { Pipes }\end{array}$ & Comments \\
\hline $1215+2.84$ & --- & 5027150 & 384457 & 2 & $\begin{array}{l}\text { Site A } \\
\text { (survey identifier) }\end{array}$ \\
\hline $1215+11.09$ & $\begin{array}{l}9 \text { Concession } \\
\text { Rd (off Waba) }\end{array}$ & 5023806 & 391806 & 2 & $\begin{array}{l}\text { Site B } \\
\text { (survey identifier) }\end{array}$ \\
\hline $1215+17.86$ & $\begin{array}{l}\text { Highway } 29 \\
\text { (off Downey) }\end{array}$ & 5022762 & 398224 & 2 & $\begin{array}{l}\text { Site C } \\
\text { (survey identifier) }\end{array}$ \\
\hline $1216+0.04$ & & 5017450 & 405270 & 2 & $\begin{array}{l}\text { Site D } \\
\text { (survey identifier) } \\
\text { Adjacent valve } \\
\text { station. }\end{array}$ \\
\hline $1216+10.23$ & $\begin{array}{l}\text { Vaughan } \\
\text { Side Rd }\end{array}$ & 5018690 & 412988 & 2 & $\begin{array}{l}\text { Site E } \\
\text { (survey identifier) } \\
\text { Valve station. } \\
2 \text { pipes entering. }\end{array}$ \\
\hline $1216+20.63$ & $\begin{array}{l}\text { Richardson Rd } \\
\text { \#2715 }\end{array}$ & 5013753 & 421268 & 2 & $\begin{array}{l}\text { Site F } \\
\text { (survey identifier) } \\
\text { Communications } \\
\text { tower }\end{array}$ \\
\hline $1216+29.19$ & --- & 5017328 & 413763 & 1 & $\begin{array}{l}\text { Site G } \\
\text { (survey identifier) }\end{array}$ \\
\hline $1217+8.91$ & --- & 5001790 & 433974 & 1 & $\begin{array}{l}\text { Site } \mathrm{H} \\
\text { (survey identifier) }\end{array}$ \\
\hline $1217+20.06$ & --- & 4994657 & 441912 & 2 & $\begin{array}{l}\text { Site I } \\
\text { (survey identifier) }\end{array}$ \\
\hline
\end{tabular}




\section{UTM COORDINATES OF DATA LOGGER LOCATIONS}

\begin{tabular}{|c|c|c|c|c|c|}
\hline \multicolumn{6}{|c|}{2005 ORV SURVEY } \\
\hline $\begin{array}{c}\text { PSP } \\
\text { test post }\end{array}$ & $\begin{array}{l}\text { General } \\
\text { Location }\end{array}$ & $\begin{array}{c}\text { GPS } \\
\text { UTM coordinate } \\
\text { (northing) }\end{array}$ & $\begin{array}{c}\text { GPS } \\
\text { UTM } \\
\text { coordinate } \\
\text { (easting) }\end{array}$ & $\begin{array}{c}\text { Number } \\
\text { of } \\
\text { Pipes }\end{array}$ & Comments \\
\hline $1210+21.06$ & Witt Rd & 5068740 & 335145 & 2 & $\begin{array}{l}\text { Compressor station } 8 \\
\text { pipes on west side of } \\
\text { Highway } 41 \text {. }\end{array}$ \\
\hline $1211+0.71$ & Whitewater Rd & 5067409 & 336628 & 2 & \\
\hline $1211+6.48$ & --- & 5062773 & 339768 & 2 & \\
\hline $1211+10.00$ & Mountain Rd & 5059904 & 342066 & 2 & \\
\hline $1211+13.92$ & Bromley & 5057012 & 344376 & 2 & \\
\hline $1211+19.00$ & Pit Rd & 5052602 & 347835 & 2 & \\
\hline $1200+0.00$ & Cobden & 5051378 & 349243 & 2 & \\
\hline $1212+1.984$ & McPeak & 50509407 & 351037 & 2 & $\begin{array}{l}\text { Additional test post } \\
\text { location. Not a PSP } \\
\text { recording site. }\end{array}$ \\
\hline $1212+2.57$ & $\begin{array}{l}\text { McPeat to } \\
\text { Patterson }\end{array}$ & 5050986 & 351600 & 2 & \\
\hline $1212+6.10$ & $\begin{array}{l}\text { Rox Side / } \\
\text { Wilkow }\end{array}$ & 5049608 & 354657 & 2 & 1 test post \\
\hline $1212+9.49$ & Utronki & 5048776 & 357239 & 2 & \\
\hline $1212+14.57$ & Haley Rd & 5046200 & 361524 & 2 & $\begin{array}{l}\text { Adjacent railway } \\
\text { track. }\end{array}$ \\
\hline $\begin{array}{l}1213+0.98 \\
1213+1.02\end{array}$ & $\begin{array}{l}\text { Haley to } \\
\text { Godfrey } \\
\text { to Gardens of } \\
\text { Eden }\end{array}$ & 5045386 & 363619 & 2 & \\
\hline $1213+3.972$ & Garden of Eden & 5043706 & 365970 & 2 & $\begin{array}{l}\text { Additional test post } \\
\text { location. Not a PSP } \\
\text { recording site. }\end{array}$ \\
\hline $1213+5.54$ & $\begin{array}{l}\text { Storyland on } \\
\text { Bennet Lake }\end{array}$ & 5044254 & 367316 & 2 & \\
\hline $1213+12.63$ & Castleford & 5040112 & 372264 & 2 & \\
\hline
\end{tabular}




\section{UTM COORDINATES OF DATA LOGGER LOCATIONS}

\begin{tabular}{|c|c|c|c|c|c|}
\hline \multicolumn{6}{|c|}{2005 ORV SURVEY - continued } \\
\hline $\begin{array}{c}\text { PSP } \\
\text { test post }\end{array}$ & $\begin{array}{l}\text { General } \\
\text { Location }\end{array}$ & $\begin{array}{c}\text { GPS } \\
\text { UTM coordinate } \\
\text { (northing) }\end{array}$ & $\begin{array}{c}\text { GPS } \\
\text { UTM } \\
\text { coordinate } \\
\text { (easting) }\end{array}$ & $\begin{array}{l}\text { Number } \\
\text { of } \\
\text { Pipes }\end{array}$ & Comments \\
\hline $\begin{array}{r}1213+ \\
16.475\end{array}$ & Lockwinnock & 5037446 & 374537 & 2 & \\
\hline $1213+19.52$ & $\begin{array}{l}\text { Yantha } \\
\text { (off Gosken) }\end{array}$ & 5037414 & 376186 & 2 & \\
\hline $1213+24.87$ & Calabogie Rd & 5031372 & 379527 & 2 & \\
\hline $1213+28.00$ & $\cdots$ & 5029950 & 382613 & 2 & $\begin{array}{l}\text { Additional test post } \\
\text { location. Not a PSP } \\
\text { recording site. }\end{array}$ \\
\hline $1213+29.07$ & Flat Rapids Rd & 5029526 & 383276 & 2 & \\
\hline $1215+5.81$ & White Lake Rd & 5025182 & 386982 & 2 & \\
\hline $1215+9.57$ & $\begin{array}{l}8 \text { Concession } \\
\text { Rd }\end{array}$ & 5023878 & 389944 & 2 & \\
\hline $1215+11.09$ & $\begin{array}{l}9 \text { Concession } \\
\text { Rd } \\
\text { (off Waba) }\end{array}$ & 5023806 & 391806 & 2 & \\
\hline $1215+14.32$ & $\begin{array}{l}10 \text { Concession } \\
\text { Rd } \\
\text { (off Deer Rd) }\end{array}$ & 5022496 & 394742 & 2 & Power line crosses. \\
\hline $1215+17.42$ & -- & 5022828 & 397296 & 2 & $\begin{array}{l}\text { Additional test post } \\
\text { location. Not a PSP } \\
\text { recording site. }\end{array}$ \\
\hline $1215+17.86$ & $\begin{array}{l}\text { Highway } 29 \\
\text { (off Downey) }\end{array}$ & 5022762 & 398224 & 2 & \\
\hline $1215+20.93$ & $\begin{array}{l}\text { Hanson side Rd } \\
\text { (off Darkside } \\
\text { Rd) }\end{array}$ & 5022284 & 400327 & 2 & \\
\hline $\begin{array}{l}1215+ \\
22.73\end{array}$ & Timmins & 5020818 & 401693 & 2 & \\
\hline $1216+0.00$ & Panmure Rd & 5017484 & 405256 & 2 & Valve station. \\
\hline $1216+5.62$ & $\begin{array}{l}\text { Upper Dwyer } \\
\text { Hill Rd } \\
\text { \# } 2206\end{array}$ & 5016101 & 409144 & 2 & \\
\hline $1216+08.64$ & Marshwood Rd & 5018058 & 411168 & 2 & Adjacent rectifier. \\
\hline $1216+10.23$ & $\begin{array}{l}\text { Vaughan Side } \\
\text { Rd }\end{array}$ & 5018690 & 412988 & 2 & $\begin{array}{l}\text { Valve station. } \\
2 \text { pipes entering. }\end{array}$ \\
\hline
\end{tabular}




\section{UTM COORDINATES OF DATA LOGGER LOCATIONS}

\begin{tabular}{|c|c|c|c|c|c|}
\hline \multicolumn{6}{|c|}{2005 ORV SURVEY - continued } \\
\hline $\begin{array}{c}\text { PSP } \\
\text { test post }\end{array}$ & $\begin{array}{l}\text { General } \\
\text { Location }\end{array}$ & $\begin{array}{c}\text { GPS } \\
\text { UTM coordinate } \\
\text { (northing) }\end{array}$ & $\begin{array}{c}\text { GPS } \\
\text { UTM } \\
\text { coordinate } \\
\text { (easting) }\end{array}$ & $\begin{array}{c}\text { Number } \\
\text { of } \\
\text { Pipes }\end{array}$ & Comments \\
\hline $1216+11.67$ & Bearkill Rd & 5018562 & 414327 & 1 & \\
\hline $1216+14.01$ & March Rd & 5017551 & 416388 & 1 & \\
\hline $1216+17.00$ & McGee Rd & 5016094 & 419310 & 1 & \\
\hline $1216+20.62$ & $\begin{array}{l}\text { Richardson Rd } \\
\text { \# } 2715\end{array}$ & 5013753 & 421268 & 1 & $\begin{array}{l}\text { Communications } \\
\text { tower. }\end{array}$ \\
\hline $1216+27.73$ & $\begin{array}{l}\text { Fernbank Rd } \\
\# 6774\end{array}$ & 5009257 & 426487 & 1 & \\
\hline $1217+2.17$ & $\begin{array}{l}\text { Mansfield Rd \# } \\
6678\end{array}$ & 5006070 & 429276 & 2 & \\
\hline $1217+6.35$ & Franktown Rd & 5002908 & 431885 & 2 & \\
\hline $1217+11.36$ & Century Rd & 5000648 & 436450 & 2 & \\
\hline $1217+11.97$ & $\begin{array}{l}\text { Century Rd } \\
\text { (to Goodstown) }\end{array}$ & 5000648 & 436450 & 2 & \\
\hline $1217+15.26$ & Malakoff Rd & 4998328 & 438688 & 2 & \\
\hline $\begin{array}{l}1217+ \\
21.848\end{array}$ & Mackay Rd & 4993834 & 443331 & 2 & Adjacent rectifier. \\
\hline $\begin{array}{c}1217+ \\
23.056\end{array}$ & McCordick & 4993988 & 444309 & 2 & \\
\hline
\end{tabular}

Abbreviations:

GPS Global Positioning System

PSP Pipe-to-Soil Potential

UTM Universal Transverse Mercator (Zone 18, NAD-83) 


\section{UTM COORDINATES OF MT SOUNDING SITES}

\begin{tabular}{|c|c|c|c|c|}
\hline \multicolumn{5}{|c|}{2003 ORV SURVEY } \\
\hline $\begin{array}{l}\text { MT } \\
\text { Site }\end{array}$ & $\begin{array}{l}\text { General } \\
\text { Location }\end{array}$ & $\begin{array}{c}\text { GPS } \\
\begin{array}{c}\text { UTM coordinate } \\
\text { (northing) }\end{array}\end{array}$ & $\begin{array}{c}\text { GPS } \\
\text { UTM coordinate } \\
\text { (easting) }\end{array}$ & Comments \\
\hline ORV2 & $\begin{array}{l}10 \mathrm{~km} \text { southwest } \\
\text { of Stittsville }\end{array}$ & 5004201 & 421606 & $\begin{array}{l}\text { - open area in forest } \\
\text { - limestone bedrock at } \\
\text { surface } \\
\text { - house } 500 \mathrm{~m} \text { south } \\
\end{array}$ \\
\hline ORV3 & $\begin{array}{l}4 \mathrm{~km} \text { northeast of } \\
\text { Pakenham }\end{array}$ & 5025508 & 400344 & $\begin{array}{l}\text { - grass field in orchard, } \\
\text { clay soil } \\
\text { - house } 200 \mathrm{~m} \text { south }\end{array}$ \\
\hline ORV4 & $\begin{array}{l}5.5 \mathrm{~km} \text { west of } \\
\text { Stewardville }\end{array}$ & 5029564 & 376719 & $\begin{array}{l}\text { - fallow field, bouldery } \\
\text { clay soil }\end{array}$ \\
\hline ORV5 & $\begin{array}{l}9 \mathrm{~km} \text { southeast of } \\
\text { Cobden }\end{array}$ & 5048912 & 359177 & $\begin{array}{l}\text { - open field, sandy soil } \\
\text { - campground } 100 \mathrm{~m} \\
\text { north } \\
\text { - railway track } 200 \mathrm{~m} \\
\text { south }\end{array}$ \\
\hline
\end{tabular}

\begin{tabular}{|c|c|c|c|c|}
\hline \multicolumn{5}{|c|}{2005 ORF SURVEY } \\
\hline $\begin{array}{l}\text { MT } \\
\text { Site }\end{array}$ & $\begin{array}{l}\text { General } \\
\text { Location }\end{array}$ & $\begin{array}{c}\text { GPS } \\
\begin{array}{c}\text { UTM coordinate } \\
\text { (northing) }\end{array}\end{array}$ & $\begin{array}{c}\text { GPS } \\
\text { UTM coordinate } \\
\text { (easting) }\end{array}$ & Comments \\
\hline ORV5 & $\begin{array}{l}9 \mathrm{~km} \text { southeast of } \\
\text { Cobden }\end{array}$ & 5048827 & 359132 & $\begin{array}{l}\text { - open field, sandy soil } \\
\text { - campground } 150 \mathrm{~m} \\
\text { north } \\
\text { - railway track } 150 \mathrm{~m} \\
\text { south } \\
\end{array}$ \\
\hline ORF105 & $\begin{array}{l}4 \mathrm{~km} \text { south of } \\
\text { North Gower }\end{array}$ & 4994447 & 443817 & $\begin{array}{l}\text { - grass field, clay soil } \\
\text { - adjacent nursery } \\
\text { (small) } \\
\text { - roadside power line } \\
\text { within } 80 \mathrm{~m}\end{array}$ \\
\hline ORF110 & $\begin{array}{l}3 \mathrm{~km} \text { southeast of } \\
\text { Richmond }\end{array}$ & 5002073 & 436234 & $\begin{array}{l}\text { - ploughed farm field, } \\
\text { wet clay soil } \\
\text { - drainage pump } \\
\text { house within } 50 \mathrm{~m} \\
\text { - communication tower } \\
\text { within } 0.7 \mathrm{~km} \\
\end{array}$ \\
\hline ORF115 & $\begin{array}{l}7 \mathrm{~km} \\
\text { west-northwest } \\
\text { of Richmond }\end{array}$ & 5005419 & 428127 & $\begin{array}{l}\text { - pastured farm field, } \\
\text { clay soil } \\
\text { - limestone bedrock } \\
1.5 \mathrm{~m} \text { deep } \\
\text { - farmstead within } \\
300 \mathrm{~m}\end{array}$ \\
\hline
\end{tabular}


UTM COORDINATES OF MT SOUNDING SITES

\begin{tabular}{|c|c|c|c|c|}
\hline \multicolumn{5}{|c|}{2005 ORV SURVEY - continued } \\
\hline $\begin{array}{l}\text { MT } \\
\text { Site }\end{array}$ & $\begin{array}{l}\text { General } \\
\text { Location }\end{array}$ & $\begin{array}{c}\text { GPS } \\
\begin{array}{c}\text { UTM coordinate } \\
\text { (northing) }\end{array}\end{array}$ & $\begin{array}{c}\text { GPS } \\
\text { UTM coordinate } \\
\text { (easting) }\end{array}$ & Comments \\
\hline ORF120 & $\begin{array}{l}8 \mathrm{~km} \text { west of } \\
\text { Stittsville }\end{array}$ & 5011881 & 419604 & $\begin{array}{l}\text { - harvested crop field, } \\
\text { clay soil } \\
\text { - houses within } 600 \mathrm{~m}\end{array}$ \\
\hline ORF125 & $\begin{array}{l}11.5 \mathrm{~km} \text { northwest } \\
\text { of Stittsville }\end{array}$ & 5013262 & 416457 & $\begin{array}{l}\text { - ploughed farm field, } \\
\text { clay soil } \\
\text { - farmstead within } \\
500 \mathrm{~km}\end{array}$ \\
\hline ORF130 & $\begin{array}{l}4 \mathrm{~km} \text { southwest of } \\
\text { Carp }\end{array}$ & 5019625 & 414731 & $\begin{array}{l}\text { - crop field, clay soil } \\
\text { - farmstead within } \\
300 \mathrm{~m} \\
\text { - communications } \\
\text { tower within } 1.5 \mathrm{~km}\end{array}$ \\
\hline ORF135 & $\begin{array}{l}3 \mathrm{~km} \text { southeast of } \\
\text { Panmure }\end{array}$ & 5017362 & 408916 & $\begin{array}{l}\text { - open field on Carp } \\
\text { Ridge } \\
\text { - limestone bedrock, } \\
\text { soil pockets (clayey) } \\
\text { - house within } 150 \mathrm{~m} \text {, } \\
\text { electric fence turned } \\
\text { off }\end{array}$ \\
\hline ORF140 & $\begin{array}{l}4 \mathrm{~km} \text { west of } \\
\text { Panmure }\end{array}$ & 5017879 & 403055 & $\begin{array}{l}\text { - pasture, clay soil } \\
\text { - electric fence off }\end{array}$ \\
\hline ORF141 & $\begin{array}{l}2 \mathrm{~km} \text { west of } \\
\text { Pakenham }\end{array}$ & 5019702 & 395546 & $\begin{array}{l}\text { - Mt. Pakenham ski hill } \\
\text { (landing) } \\
\text { - ski-lift towers \& } \\
\text { cables; } \\
\text { electric transformers } \\
\text { - } 3 \text { communications } \\
\text { towers within } 0.5 \mathrm{~km}\end{array}$ \\
\hline ORF145 & $\begin{array}{l}7 \mathrm{~km} \text { northwest of } \\
\text { Pakenham }\end{array}$ & 5024035 & 393019 & $\begin{array}{l}\text { - fallow field, clay soil } \\
\text { - limestone bedrock } \\
\text { surfaces (patchy) } \\
\text { - farmstead within } \\
100 \text { m, electric fence } \\
\text { turned off } \\
\text { - operating quarry } 2.5 \\
\text { km north } \\
\end{array}$ \\
\hline ORF150 & $\begin{array}{l}7 \mathrm{~km} \text { southeast of } \\
\text { Stewardville }\end{array}$ & 5025137 & 388051 & $\begin{array}{l}\text { - fallow \& crop fields, } \\
\text { clay soil } \\
\text { - farmstead within } \\
150 \mathrm{~m} \\
\text { - area electric fence } \\
\text { operating } \\
\end{array}$ \\
\hline ORF155 & $\begin{array}{l}3 \mathrm{~km} \text { south of } \\
\text { Stewardville }\end{array}$ & 5026456 & 382607 & $\begin{array}{l}\text { - fallow field, sandy } \\
\text { loam soil } \\
\text { - houses \& roadside } \\
\text { power lines within } \\
200 \mathrm{~m}\end{array}$ \\
\hline
\end{tabular}


UTM COORDINATES OF MT SOUNDING SITES

\begin{tabular}{|c|c|c|c|c|}
\hline \multicolumn{5}{|c|}{2005 ORV SURVEY - continued } \\
\hline $\begin{array}{l}\text { MT } \\
\text { Site }\end{array}$ & $\begin{array}{l}\text { General } \\
\text { Location }\end{array}$ & $\begin{array}{c}\text { GPS } \\
\underset{\text { UTM coordinate }}{\text { (northing) }}\end{array}$ & $\begin{array}{c}\text { GPS } \\
\text { UTM coordinate } \\
\text { (easting) }\end{array}$ & Comments \\
\hline ORF160 & $\begin{array}{l}8 \mathrm{~km} \text { east of } \\
\text { Renfrew }\end{array}$ & 5037872 & 376288 & $\begin{array}{l}\text { - brushy headland } \\
\text { beside crop field, clay } \\
\text { soil } \\
\text { - adjacent pole- } \\
\text { mounted transformer }\end{array}$ \\
\hline ORF165 & $\begin{array}{l}8 \mathrm{~km} \text { northeast of } \\
\text { Renfrew }\end{array}$ & 5044463 & 370702 & $\begin{array}{l}\text { - pasture field, sandy } \\
\text { loam soil } \\
\text { - houses \& roadside } \\
\text { power line within } 30 \mathrm{~m} \\
\text { - area electric fences } \\
\text { operating }\end{array}$ \\
\hline ORF170 & $\begin{array}{l}5 \mathrm{~km} \text { southwest of } \\
\text { Cobden }\end{array}$ & 5049417 & 350232 & $\begin{array}{l}\text { - hay fields, clay soil } \\
\text { - roadside power line } \\
\text { within } 150 \mathrm{~m} \\
\text { - area electric fences } \\
\text { operating }\end{array}$ \\
\hline ORF175 & $\begin{array}{l}10 \mathrm{~km} \text { west of } \\
\text { Cobden }\end{array}$ & 5055574 & 343588 & $\begin{array}{l}\text { - reclaimed gravel pit, } \\
\text { sand/gravel soil } \\
\text { - nursery } 400 \mathrm{~m} \text { north }\end{array}$ \\
\hline
\end{tabular}

UTM Universal Transverse Mercator (Zone 18, NAD-83) 
PSP CORRELATION COEFFICIENT SUMMARY (2005 ORF Data Loggers)

\begin{tabular}{|c|c|c|c|c|c|c|c|c|}
\hline Date & $\begin{array}{l}\text { Correlation } \\
\text { Identifier }\end{array}$ & $\begin{array}{l}\text { Reference } \\
\text { Site }\end{array}$ & vs. & $\begin{array}{l}\text { Recording } \\
\text { Site }\end{array}$ & $\begin{array}{c}\text { Distance } \\
\text { Between } \\
\text { Testposts } \\
\text { (km) }\end{array}$ & $\begin{array}{l}\text { Duration } \\
\text { (UT) }\end{array}$ & $\begin{array}{l}\text { Correlation } \\
\text { Coefficient }\end{array}$ & $\begin{array}{l}\text { Slope } \\
\text { Ratio }\end{array}$ \\
\hline \multirow{3}{*}{ May 31 / June 01} & 1 & $1217+21.85$ & & $1217+17.86$ & 61.98 & $00: 00-04: 30$ & 0.46157 & 1.30283 \\
\hline & 2 & $1217+21.85$ & vs. & $1217+11.36$ & 10.49 & $00: 00-04: 30$ & 0.97602 & 1.18347 \\
\hline & 3 & $1217+21.85$ & & $1217+23.06$ & 1.21 & $00: 00-04: 30$ & 0.98248 & 1.16946 \\
\hline \multirow{4}{*}{ June 01 / 02} & 4 & $1217+2185$ & & $1216+1101$ & 3780 & $01.00-06.00$ & 056068 & 103580 \\
\hline & 5 & $1217+21.85$ & vs. & $1216+20.62$ & 31.28 & $01: 00-06: 00$ & 0.62172 & 1.19701 \\
\hline & 6 & $1217+21.85$ & & $1216+27.73$ & 24.17 & $01: 00-06: 00$ & 0.82226 & 0.50904 \\
\hline & 7 & $1217+21.85$ & & $1217+2.17$ & 19.68 & $01: 00-06: 00$ & 0.91586 & 0.79773 \\
\hline \multirow{5}{*}{ June 02 / 03} & 8 & $1212+9.49$ & & $1217+17.86$ & 54 & $04: 00-09: 00$ & 0.84789 & 2.25697 \\
\hline & 9 & $1212+9.49$ & & $1216+8.64$ & 72.72 & $04: 00-09: 00$ & 0.73204 & 0.7839 \\
\hline & 10 & $1212+9.49$ & vs. & $1216+11.67$ & 75.75 & $04: 00-09: 00$ & 0.90019 & 1.09897 \\
\hline & 11 & $1212+9.49$ & & $1216+17.00$ & 81.08 & $04: 00-09: 00$ & 0.91257 & 0.91532 \\
\hline & 12 & $1212+9.49$ & & $1217+21.85$ & 115.98 & $04: 00-09: 00$ & 0.34155 & 0.2252 \\
\hline \multirow{6}{*}{ June 03 / 04} & 13 & $1212+010$ & & $1217+1786$ & 51 & $06 \cdot \cap 010 \cdot 00$ & 090932 & 221605 \\
\hline & 14 & $1212+9.49$ & & $1215+22.73$ & 58.87 & $06: 00-10: 00$ & 0.90944 & $\frac{2.21090}{1.71578}$ \\
\hline & 15 & $1212+9.49$ & vs. & $1216+0.04$ & 64.12 & $06: 00-10: 00$ & 0.88826 & 1.78949 \\
\hline & 16 & $1212+9.49$ & & $1216+5.62$ & 69.7 & $06: 00-10: 00$ & 0.90383 & 1.8966 \\
\hline & 17 & $1212+9.49$ & & $1216+10.23$ & 74.31 & $06: 00-10: 00$ & 0.92441 & 1.29134 \\
\hline & 18 & $1212+9.49$ & & $1217+21.85$ & 84.7 & $07: 30-08: 45$ & 0.77865 & 0.52714 \\
\hline
\end{tabular}


PSP CORRELATION COEFFICIENT SUMMARY (2005 ORF Data Loggers) - continued

\begin{tabular}{|c|c|c|c|c|c|c|c|c|}
\hline Date & $\begin{array}{l}\text { Correlation } \\
\text { Identifier }\end{array}$ & $\begin{array}{l}\text { Reference } \\
\text { Site }\end{array}$ & vs. & $\begin{array}{l}\text { Recording } \\
\text { Site }\end{array}$ & $\begin{array}{c}\text { Distance } \\
\text { Between } \\
\text { Testposts } \\
\text { (km) }\end{array}$ & $\begin{array}{l}\text { Duration } \\
\text { (UT) }\end{array}$ & $\begin{array}{l}\text { Correlation } \\
\text { Coefficient }\end{array}$ & $\begin{array}{l}\text { Slope } \\
\text { Ratio }\end{array}$ \\
\hline \multirow{6}{*}{ June 06 / 07} & 19 & $1212+00$ & & $1212+9.49$ & 9.49 & $02: 00-08: 00$ & 0.91588 & 1.90761 \\
\hline & 20 & $1212+00$ & & $1215+11.09$ & 11.39 & $02: 00-08: 00$ & 0.90212 & 2.6348 \\
\hline & 21 & $1212+00$ & vs. & $1215+14.32$ & 14.57 & $02: 00-08: 00$ & 0.89664 & 3.68299 \\
\hline & 22 & $1212+00$ & & $1217+17.86$ & 63.49 & $02: 00-08: 00$ & 0.90182 & 3.33966 \\
\hline & 23 & $1212+00$ & & $1215+20.93$ & 66.56 & $02: 00-08: 00$ & 0.90024 & 3.18093 \\
\hline & 24 & $1212+00$ & & $1215+22.73$ & 68.36 & $02: 00-08: 00$ & 0.87822 & 2.48518 \\
\hline \multirow{4}{*}{ June $07 / 08$} & 25 & $1213+25$ & & $1213+29.07$ & 4.2 & $00: 00-05: 00$ & 0.97306 & 1.25208 \\
\hline & 26 & $1213+25$ & vs. & $1215+5.81$ & 10.64 & $00: 00-05: 00$ & 0.97065 & 1.35632 \\
\hline & 27 & $1213+25$ & & $1215+9.57$ & 14.4 & $00: 00-05: 00$ & 0.97005 & 1.24249 \\
\hline & 28 & $1213+25$ & & $1217+17.86$ & 22.25 & $00: 00-05: 00$ & 0.9585 & 1.32749 \\
\hline \multirow{6}{*}{ June $08 / 09$} & 29 & $1212+00$ & & $1213+16.48$ & 32.41 & $00: 00-04: 00$ & 0.81781 & 3.0174 \\
\hline & 30 & $1212+00$ & & $1213+19.52$ & 35.45 & $00: 00-04: 00$ & 0.83613 & 2.92809 \\
\hline & 31 & $1212+00$ & vs. & $1213+24.87$ & 40.67 & $00: 00-04: 00$ & 0.83738 & 2.56387 \\
\hline & 32 & $1212+00$ & & $1213+29.07$ & 45 & $00: 00-04: 00$ & 0.81518 & 3.03379 \\
\hline & 33 & $1212+00$ & & $1215+5.81$ & 51.44 & $00: 00-04: 00$ & 0.81984 & 3.25379 \\
\hline & 34 & $1212+00$ & & $1216+8.64$ & 82.91 & $00: 00-04: 00$ & 0.42236 & 1.40514 \\
\hline \multirow{5}{*}{ June $09 / 10$} & 35 & $1212+00$ & & $1212+2.54$ & 2.54 & $01: 00-05: 00$ & 0.87558 & 1.52938 \\
\hline & 36 & $1212+00$ & & $1212+6.10$ & 6.1 & $01: 00-05: 00$ & 0.81389 & 0.55974 \\
\hline & 37 & $1212+00$ & vs. & $1212+9.49$ & 9.49 & $01: 00-05: 00$ & 0.84112 & 1.71444 \\
\hline & 38 & $1212+00$ & & $1212+14.57$ & 11.39 & $01: 00-05: 00$ & 0.82729 & 2.59045 \\
\hline & 39 & $1212+00$ & & $1213+12.62$ & 28.55 & $01: 00-05: 00$ & 0.55488 & 1.3723 \\
\hline
\end{tabular}


PSP CORRELATION COEFFICIENT SUMMARY (2005 ORF Data Loggers) - continued

\begin{tabular}{|c|c|c|c|c|c|c|c|c|}
\hline Date & $\begin{array}{l}\text { Correlation } \\
\text { Identifier }\end{array}$ & $\begin{array}{l}\text { Reference } \\
\text { Site }\end{array}$ & vs. & $\begin{array}{l}\text { Recording } \\
\text { Site }\end{array}$ & $\begin{array}{c}\text { Distance } \\
\text { Between } \\
\text { Testposts } \\
\text { (km) }\end{array}$ & $\begin{array}{l}\text { Duration } \\
\text { (UT) }\end{array}$ & $\begin{array}{l}\text { Correlation } \\
\text { Coefficient }\end{array}$ & $\begin{array}{l}\text { Slope } \\
\text { Ratio }\end{array}$ \\
\hline \multirow{6}{*}{ June $10 / 11$} & 40 & $1212+00$ & & $1211+00$ & 21.14 & $00: 00-04: 00$ & 0.73119 & 0.29917 \\
\hline & 41 & $1212+00$ & & $1211+6.48$ & 14.96 & $00: 00-04: 00$ & 0.84974 & 0.629 \\
\hline & 42 & $1212+00$ & vs. & $1211+10.00$ & 11.44 & $00: 00-04: 00$ & 0.89051 & 0.87912 \\
\hline & 43 & $1212+00$ & & $1211+13.92$ & 7.52 & $00: 00-04: 00$ & 0.83428 & 1.31506 \\
\hline & 44 & $1212+00$ & & $1211+19.00$ & 2.44 & $00: 00-04: 00$ & 0.90068 & 1.36774 \\
\hline & 45 & $1212+00$ & & $1212+00$ & 0 & $00: 00-04: 00$ & 1 & 1 \\
\hline
\end{tabular}

Note: underlined (e.g. $\underline{0.55488}$ ) indicates correlation coefficient $\leq 0.7$ 


\begin{tabular}{|c|c|c|c|c|c|}
\hline \multicolumn{6}{|c|}{ GEOGRAPHIC COORDINATES OF DATA LOGGER TEST POSTS, 2006 ORX } \\
\hline $\mathbf{N}$ & $\begin{array}{l}\text { Test/post } \\
\text { location }\end{array}$ & $\begin{array}{l}\text { Coordinate, } \\
\mathbf{N}\end{array}$ & $\begin{array}{l}\text { Coordinate, } \\
W\end{array}$ & $\begin{array}{l}\text { Recording } \\
\text { days }\end{array}$ & Comments \\
\hline 1 & $1209+17.70$ & $45.89866^{\circ}$ & $77.30938^{\circ}$ & 20 May & $\begin{array}{l}\text { military camp } \\
\text { on } \# 55\end{array}$ \\
\hline 2 & $1210+0.07$ & $45.88^{\circ}$ & $77.29^{\circ}$ & 20,21 May & Murphy Rd. \\
\hline 3 & $1210+2.76$ & $45.86839^{\circ}$ & $77.16545^{\circ}$ & 21 May & Doreen Rd \\
\hline 4 & $1210+4.83$ & $45.85^{\circ}$ & $77.29^{\circ}$ & 20,21 & Airport Rd \\
\hline 5 & $1210+7.26$ & $45.84106^{\circ}$ & $77.22844^{\circ}$ & 20 & Achroy Rd. \\
\hline 6 & $1210+8.193$ & $45.83659^{\circ}$ & $77.22078^{\circ}$ & No records & $\begin{array}{l}\text { Biggs Rd, } t / p \text { of } \\
\text { different } \\
\text { system }\end{array}$ \\
\hline 7 & $1210+9.74$ & $45.82749^{\circ}$ & $77.20657^{\circ}$ & 20,21 & Forest Lea Rd \\
\hline 8 & $1210+14.25$ & $45.79648^{\circ}$ & $77.17553^{\circ}$ & 19 & $\begin{array}{l}\text { Round Lake } \\
\text { Rd }\end{array}$ \\
\hline 9 & $1210+15.60$ & $45.78792^{\circ}$ & $77.16545^{\circ}$ & 21 & B-line Rd \\
\hline 10 & $1210+16.622$ & $45.78226^{\circ}$ & $77.15572^{\circ}$ & $19,20,21$ & $\begin{array}{l}\text { Sandy Beach } \\
\text { R. }\end{array}$ \\
\hline 11 & $1210+20.43$ & $45.75687^{\circ}$ & $77.12587^{\circ}$ & 19 & Walford Rd. \\
\hline 12 & $1210+21.06$ & $45^{\circ} 45.153^{\prime}$ & $77^{\circ} 07.176^{\prime}$ & $18,19,20,21$ & Witt Rd. \\
\hline 13 & $1211+0.71$ & $45^{\circ} 44.453^{\prime}$ & $77^{\circ} 06.006^{\prime}$ & 18 & White Water R. \\
\hline 14 & $1211+6.48$ & $45^{\circ} 41.998$ & $77^{\circ} 03.494^{\prime}$ & 18,19 & Code Rd \\
\hline 15 & $1211+8.27$ & $45.68607^{\circ}$ & $77.04491^{\circ}$ & 18,19 & Ross Rd \\
\hline 16 & $1211+10.295$ & $45^{\circ} 40.481^{\prime}$ & $77^{\circ} 01.668^{\prime}$ & 18,19 & Mountain Rd. \\
\hline 17 & $1211+11.034$ & $45.66888^{\circ}$ & $77.02088^{\circ}$ & 18 & Sojka Rd \\
\hline 18 & $1211+13.922$ & $45.64923^{\circ}$ & $76.99715^{\circ}$ & 22 & $\begin{array}{l}\text { Bromley- } \\
\text { Connaught R. }\end{array}$ \\
\hline 19 & $1211+16.647$ & $45.63031^{\circ}$ & $76.99715^{\circ}$ & 22 & Micksburg Rd. \\
\hline 20 & 1212 & $45^{\circ} 35.973^{\circ}$ & $76^{\circ} 55.984^{\prime}$ & 13-23 May & $\begin{array}{l}\text { Ref Site } 1 \\
\text { Cobden Rd }\end{array}$ \\
\hline 21 & $1212+2.57$ & $45^{\circ} 35.794$ & $76^{\circ} 54.164^{\prime}$ & 17,22 & Patterson Rd. \\
\hline 22 & $1212+6.10$ & $45^{\circ} 35.089^{\prime}$ & $76^{\circ} 51.789^{\prime}$ & 17,22 & Rox Siding Rd. \\
\hline 23 & $1212+9.49$ & $45^{\circ} 34.672^{\prime}$ & $76^{\circ} 49.740^{\prime}$ & 17,22 & Utronki Rd. \\
\hline 24 & $1212+14.57$ & $45^{\circ} 33.334^{\prime}$ & $76^{\circ} 46.452^{\prime}$ & 17,22 & Haley Station \\
\hline 25 & $1213+1.02$ & $45^{\circ} 32.919^{\prime}$ & $76^{\circ} 44.829^{\prime}$ & 16,17 & Orin Rd. \\
\hline 26 & $1213+3.97$ & $45^{\circ} 53.503^{\prime}$ & $76^{\circ} 71.745^{\prime}$ & 16,17 & Garden-o-Eden \\
\hline 27 & $1213+5.54$ & $45^{\circ} 32.351^{\prime}$ & $76^{\circ} 41.970^{\prime}$ & 16,17 & Benett Lafont \\
\hline 28 & $1213+6.845$ & $45^{\circ} 54.013^{\prime}$ & $76^{\circ} 50.024^{\prime}$ & 16 & Storyland \\
\hline 29 & $1213+24.87$ & $45^{\circ} 25.529^{\prime}$ & $76^{\circ} 55.984^{\prime}$ & 13-25 May & $\begin{array}{l}\text { Ref Site2 } \\
\text { Calabogie Rd }\end{array}$ \\
\hline
\end{tabular}




\begin{tabular}{|c|c|c|c|c|c|}
\hline \multicolumn{6}{|c|}{$\begin{array}{l}\text { GEOGRAPHIC COORDINATES OF DATA LOGGER TEST POSTS, } 2006 \text { ORX } \\
\text { - continued }\end{array}$} \\
\hline $\mathbf{N}$ & $\begin{array}{l}\text { Testpost } \\
\text { location }\end{array}$ & $\begin{array}{l}\text { Coordinate, } \\
\mathbf{N}\end{array}$ & $\begin{array}{l}\text { Coordinate, } \\
\text { W }\end{array}$ & $\begin{array}{l}\text { Recording } \\
\text { days }\end{array}$ & Comments \\
\hline 30 & $1213+28.09$ & $45.41298^{\circ}$ & $76.50024^{\circ}$ & 16 & Stewartsville $R$ \\
\hline 31 & $1213+29.02$ & $45^{\circ} 24.571^{\prime}$ & $76^{\circ} 29.499^{\prime}$ & 16 & Flat Rapids R. \\
\hline 32 & $1215+5.8$ & $45^{\circ} 22.262^{\prime}$ & $76^{\circ} 26.599^{\prime}$ & 15,16 & White Lake R. \\
\hline 33 & $1215+9.572$ & $45^{\circ} 21.586^{\prime}$ & $76^{\circ} 24.312^{\prime}$ & 15 & 8 Concession \\
\hline 34 & $1215+11.41$ & $45^{\circ} 21.565^{\prime}$ & $76^{\circ} 22.885^{\prime}$ & 15,23 & 9 Concession \\
\hline 35 & $1215+12.94$ & $45.35322^{\circ}$ & $76.36440^{\circ}$ & $14,15,23$ & 2Waba Rd \\
\hline 36 & $1215+14.78$ & $45^{\circ} 20.844^{\prime}$ & $76^{\circ} 20.620^{\prime}$ & 14 & 10 Concess. \\
\hline 37 & $1215+16.703$ & $45.34862^{\circ}$ & $76.31965^{\circ}$ & 15 & 1Waba Rd \\
\hline 38 & $1215+17.86$ & $45^{\circ} 21.059^{\prime}$ & $76^{\circ} 20.620^{\prime}$ & $14,16,23,24$ & \#29\&Downey \\
\hline 39 & $1215+21.03$ & $45.34265^{\circ}$ & $76.26776^{\circ}$ & $14,23,24$ & Kinburn Rd \\
\hline 40 & $1215+22.73$ & $45^{\circ} 20.039^{\prime}$ & $76^{\circ} 15.277^{\prime}$ & 14.24 & Timmings $\mathrm{Rd}$ \\
\hline 41 & $1216+0.04$ & $45^{\circ} 18.269^{\prime}$ & $76^{\circ} 12.511 \prime$ & $14,23,24,25$ & Panmure Rd \\
\hline 42 & $1216+8.64$ & $45^{\circ} 18.624^{\prime}$ & $76^{\circ} 07.944^{\prime}$ & 23 & $\begin{array}{l}\text { Marshwood } \\
\text { (twinning) }\end{array}$ \\
\hline 43 & $1216+14.012$ & $45^{\circ} 18.389^{\prime}$ & $76^{\circ} 03.994^{\prime}$ & 23 & $\begin{array}{l}\text { March Rd } \\
\text { (twinning) }\end{array}$ \\
\hline 44 & $1216+20.620$ & $45.27281^{\circ}$ & $76.00359^{\circ}$ & 25 & Richardson Rd. \\
\hline 45 & $1216+27.73$ & $45.23275^{\circ}$ & $75.93667^{\circ}$ & 25 & Fernbank \\
\hline 46 & $1217+0.87$ & $45.21386^{\circ}$ & $75.91143^{\circ}$ & 25 & Fallowfield \\
\hline 47 & $1217+2.15$ & $45.20456^{\circ}$ & $75.90059^{\circ}$ & 25 & Mansfield \\
\hline 48 & $1217+6.35$ & $45.17622^{\circ}$ & $75.86671^{\circ}$ & 25 & Franktown \\
\hline 49 & $1217+11.36$ & $45.16069^{\circ}$ & $75.81330^{\circ}$ & 25 & Bowrin \\
\hline 50 & $1217+18.45$ & $45.11427^{\circ}$ & $75.75176^{\circ}$ & 25 & Roger Stevens \\
\hline 51 & $1217+21.85$ & $45^{\circ} 05.742 ’$ & $75^{\circ} 43.213^{\prime}$ & $13,14,15,25$ & McKey Rd. \\
\hline
\end{tabular}




\begin{tabular}{|c|c|c|}
\hline \multicolumn{3}{|c|}{$\begin{array}{c}\text { UTM COORDINATES, } \\
\text { MT SITES, } \\
\text { 2006 0RX SURVEY }\end{array}$} \\
\hline Site & Northing & Easting \\
\hline ORX210 & 4999984 & 435685 \\
\hline ORX213 & 5013260 & 416458 \\
\hline ORX215 & 5017662 & 407113 \\
\hline ORX220 & 5021888 & 403141 \\
\hline ORX220 & 5021888 & 403141 \\
\hline ORX225 & 5023508 & 396860 \\
\hline ORX227 & 5025715 & 390587 \\
\hline ORX230 & 5026443 & 386367 \\
\hline ORX245 & 5043888 & 363615 \\
\hline ORX245 & 5043890 & 363625 \\
\hline ORX255 & 5059370 & 339380 \\
\hline ORX260 & 5066054 & 335531 \\
\hline ORX265 & 5070470 & 329486 \\
\hline ORX270 & 5074942 & 326961 \\
\hline ORX275 & 5079015 & 323353 \\
\hline ORX280 & 5083757 & 320600 \\
\hline ORX2145 & 5024036 & 393010 \\
\hline ORX2005 & 5048790 & 359376 \\
\hline ORX2004 & 5030046 & 377296 \\
\hline
\end{tabular}

UTM Universal Transverse Mercator (Zone 18, NAD-83) 


\begin{tabular}{|c|c|c|c|c|c|}
\hline \multicolumn{6}{|c|}{ GEOGRAPHIC COORDINATES OF DATA LOGGER TEST POSTS, 2009 ORS } \\
\hline $\mathbf{N}$ & $\begin{array}{l}\text { Testpost } \\
\text { location }\end{array}$ & $\begin{array}{l}\text { Coordinate, } \\
\mathbf{N}\end{array}$ & $\begin{array}{l}\text { Coordinate, } \\
\text { W }\end{array}$ & $\begin{array}{l}\text { Recording } \\
\text { days }\end{array}$ & Comments \\
\hline 1 & $1210+7.26$ & $45.84106^{\circ}$ & $77.22844^{\circ}$ & 26-27 April & Achray Rd. \\
\hline 2 & $1213+1.02$ & $45^{\circ} 32.919^{\prime}$ & $76^{\circ} 44.829^{\prime}$ & $\begin{array}{l}\text { 24-25 April } \\
\text { 26-27 April }\end{array}$ & Orin Rd. \\
\hline 3 & $1213+24.87$ & $45^{\circ} 25.529^{\prime}$ & $76^{\circ} 55.984^{\prime}$ & $\begin{array}{l}\text { 24-25 April } \\
\text { 26-27 April }\end{array}$ & $\begin{array}{l}\text { Reference } \\
\text { Site } \\
\text { Calabogie Rd } \\
\end{array}$ \\
\hline 4 & $1215+18.392$ & $\begin{array}{l}45213.74 \\
45.351039\end{array}$ & $\begin{array}{l}761759.17 \\
76.299769\end{array}$ & $\begin{array}{l}\text { 24-25 April } \\
\text { 26-27 April }\end{array}$ & $\begin{array}{l}\text { Hwy \# } 29 \text { \& } \\
\text { Downey }\end{array}$ \\
\hline 5 & $1216+0.04$ & $45^{\circ} 18.269^{\prime}$ & $76^{\circ} 12.511^{\prime}$ & $\begin{array}{l}\text { 24-25 April } \\
\text { 26-27 April }\end{array}$ & Panmure Rd \\
\hline 6 & $1216+8.64$ & $45^{\circ} 18.624^{\prime}$ & $76^{\circ} 07.944^{\prime}$ & 24-25 April & $\begin{array}{l}\text { Marshwood } \\
\text { (pipe now } \\
\text { twinned) }\end{array}$ \\
\hline 7 & $1216+11.674$ & $45^{\circ} 18.920^{\prime}$ & $76^{\circ} 05.581^{\prime}$ & 24-25 April & $\begin{array}{l}\text { Bearhill Rd } \\
\text { (pipe now } \\
\text { twinned) }\end{array}$ \\
\hline 8 & $1216+14.012$ & $45^{\circ} 18.389^{\prime}$ & $76^{\circ} 03.994^{\prime}$ & $\begin{array}{l}\text { 24-25 April } \\
\text { 26-27 April }\end{array}$ & $\begin{array}{l}\text { March Rd } \\
\text { (pipe now } \\
\text { twinned) }\end{array}$ \\
\hline 9 & $1216+27.73$ & $45.23275^{\circ}$ & $75.93667^{\circ}$ & 26-27 April & Fernbank Rd \\
\hline
\end{tabular}




\begin{tabular}{|c|c|c|c|}
\hline \multicolumn{4}{|c|}{$\begin{array}{c}\text { GEOGRAPHIC COORDINATES, } \\
\text { MT SITES, } \\
2009 \text { ORS SURVEY }\end{array}$} \\
\hline Site & Coordinate, $\mathbf{N}$ & Coordinate, $\mathbf{W}$ & Comments \\
\hline ORS315 & $45^{\circ} 18^{\prime} 22.91^{\prime \prime}$ & $76^{\circ} 11^{\prime} 03.56^{\prime \prime}$ & $\begin{array}{l}\text { - west end of Mantil } \\
\text { Side Rd. } \\
\text { - former location of MT } \\
\text { site ORX215 }\end{array}$ \\
\hline ORS345 & $45^{\circ} 31^{\prime} 00.18^{\prime \prime}$ & $76^{\circ} 45^{\prime} 43.66^{\prime \prime}$ & $\begin{array}{l}\text { - Renfrew Golf Club, } \\
\text { undeveloped surplus } \\
\text { lands, sandy hill. }\end{array}$ \\
\hline ORS375 & $45^{\circ} 50^{\prime} 31.42^{\prime \prime}$ & $77^{\circ} 16^{\prime} 29.49^{\prime \prime}$ & $\begin{array}{l}\text { - former location of MT } \\
\text { site ORX275 }\end{array}$ \\
\hline
\end{tabular}

